\title{
IntechOpen
}

\section{Regional Development in Africa}

Edited by Norbert Edomah

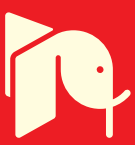





\section{Regional Development in Africa}

Edited by Norbert Edomah 

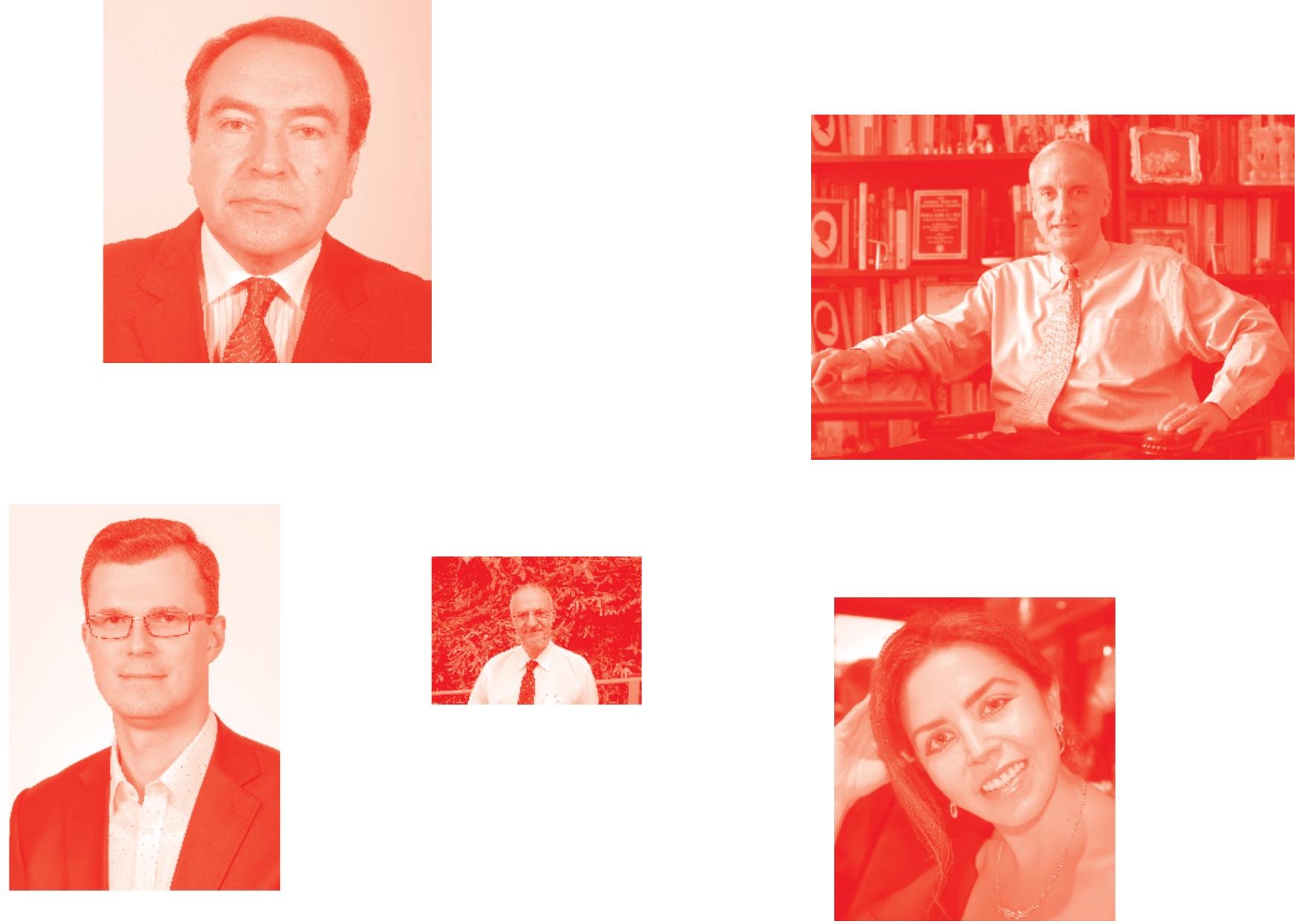

Supporting open minds since 2005
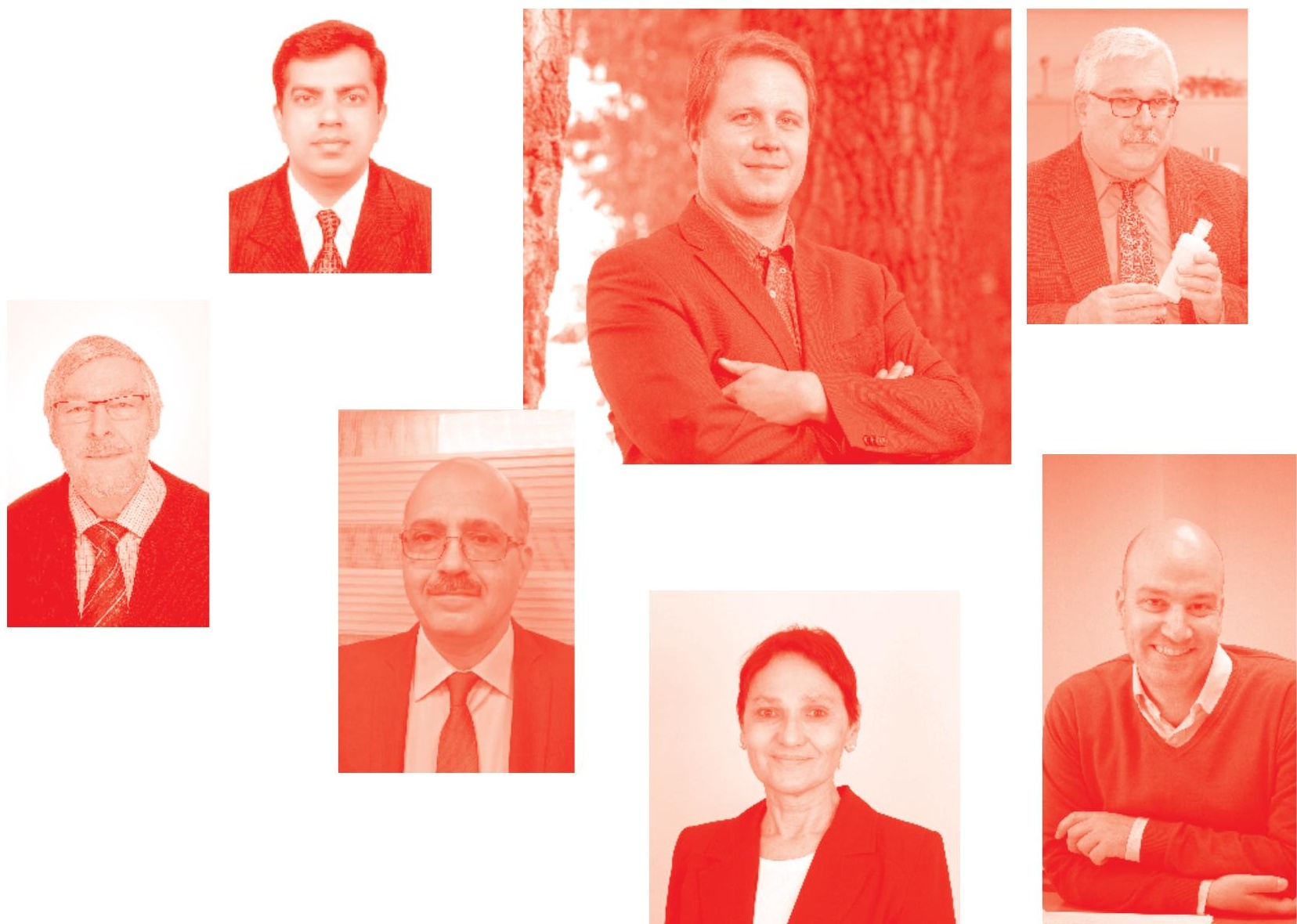
Regional Development in Africa

http : //dx. doi . org/10.5772/intechopen. 78853

Edited by Norbert Edomah

\section{Contributors}

Adetoyese Ade. Adeyemo, Ekuyikeno Silas, Jude Nwachukwu, Emeka Charles Iloh, Michael Nwokedi, Chijioke Francis Onyebukwa, Queeneth Odichi Ekeocha, Kosmas Njanike, Lynnette Widder, Thomas Pacioni, Ousmane Bocoum, Ibrahima Sy, Akrassi Kouakou Evrard Kouame, Linda Godfrey, Mohamed Tawfic Ahmed, Kidane Giday Gebremedhin, Jamidu H. Y. Katima, Oladele Osibanjo, Suzan Oelofse, Ulf Henning Richter, Arsène H. Yonli, Olufemi Julius Olapade, Norbert Edomah, Akpan Ekpo, John Tharakan, Victoria Mabe-Madisa, Johannes Winklmaier, Sissi Adeli Bazan Santos, Tobias Trenkle, Isaac AbekahKoomson, Nwaba Eugene Chinweokwu

(-) The Editor(s) and the Author(s) 2020

The rights of the editor(s) and the author(s) have been asserted in accordance with the Copyright, Designs and Patents Act 1988. All rights to the book as a whole are reserved by INTECHOPEN LIMITED . The book as a whole (compilation) cannot be reproduced, distributed or used for commercial or non-commercial purposes without INTECHOPEN LIMITED's written permission. Enquiries concerning the use of the book should be directed to INTECHOPEN LIMITED rights and permissions department (permissions@intechopen.com).

Violations are liable to prosecution under the governing Copyright Law .

\section{(cc) BY}

Individual chapters of this publication are distributed under the terms of the Creative Commons Attribution 3.0 Unported License which permits commercial use, distribution and reproduction of the individual chapters, provided the original author(s) and source publication are appropriately acknowledged. If so indicated, certain images may not be included under the Creative Commons license. In such cases users will need to obtain permission from the license holder to reproduce the material. More details and guidelines concerning content reuse and adaptation can be found at http : //www . intechopen . com/copyright-policy . html.

\section{Notice}

Statements and opinions expressed in the chapters are these of the individual contributors and not necessarily those of the editors or publisher. No responsibility is accepted for the accuracy of information contained in the published chapters. The publisher assumes no responsibility for any damage or injury to persons or property arising out of the use of any materials, instructions, methods or ideas contained in the book.

First published in London, United Kingdom, 2020 by IntechOpen IntechOpen is the global imprint of INTECHOPEN LIMITED, registered in England and Wales, registration number: 11086078 , 7th floor, 10 Lower Thames Street, London, EC3R 6AF, United Kingdom

Printed in Croatia

British Library Cataloguing-in-Publication Data

A catalogue record for this book is available from the British Library

Additional hard and PDF copies can be obtained from orders@intechopen.com

Regional Development in Africa

Edited by Norbert Edomah

p. cm.

Print ISBN 978-1-78985-237-0

Online ISBN 978-1-78985-238-7

eBook (PDF) ISBN 978-1-83880-@63-5 


\section{We are IntechOpen, \\ the world's leading publisher of Open Access books}

\section{Built by scientists, for scientists}

\section{$4,900+$}

Open access books available

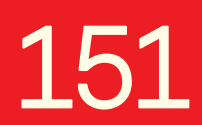

Countries delivered to

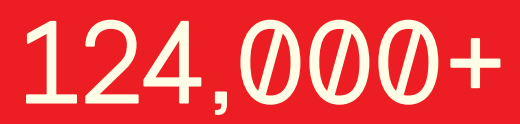

International authors and editors

Our authors are among the

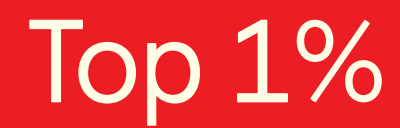

most cited scientists

Contributors from top 500 universities
$140 \mathrm{M}+$

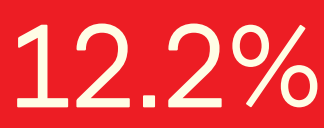

$12.2 \%$

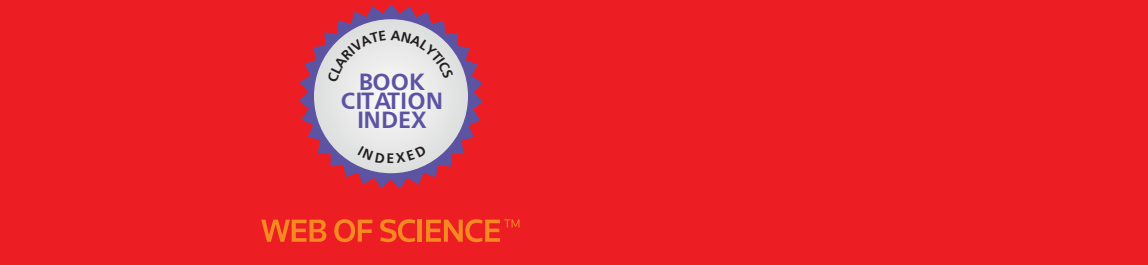

Selection of our books indexed in the Book Citation Index

in Web of Science ${ }^{\mathrm{TM}}$ Core Collection (BKCI)

\section{Interested in publishing with us? \\ Contact book.department@intechopen.com}

Numbers displayed above are based on latest data collected.

For more information visit www.intechopen.com 



\section{Meet the editor}

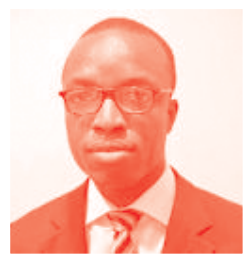

Dr. Norbert Edomah is currently a Senior Lecturer at the Pan-Atlantic University, Lagos, Nigeria. He holds a doctorate degree in Energy and Environmental Sustainability from the Global Sustainability Institute, Anglia Ruskin University, Cambridge, UK. Prior to joining the Pan-Atlantic University, he worked for over 10 years in the manufacturing and engineering services sectors. His experience spans through plant operations and maintenance to sales, marketing and business development of engineering products and solutions with leading Original Equipment Manufacturers (OEMs) such as Schneider Electric and TetraPak. He is the author of several academic peer-reviewed journal articles on various aspects of energy and sustainability. He has collaborative research experience with notable international agencies such as UNIDO, REN21 and Heinrich Boll Stiftung (HBS). 



\section{Contents}

Preface

Section 1

Introduction

Chapter 1

Regional Development in Africa: An Overview

by Norbert Edomah

Section 2

Industry, Trade and Investment in Africa

Chapter 2

Trade and Investment in South Africa

by Garebangwe Victoria Mabe-Madisa

Chapter 3

China-Africa Investments and Economic Growth in Africa

by Isaac Abekah-Koomson and Nwaba Eugene Chinweokwu

Chapter 4

Sustainably Growing Guinea's Bauxite-Aluminum Industry

by Lynnette Widder, Thomas D. Pacioni and Ousmane Bocoum

Chapter 5

The Songhai Agroecological Sustainable Development Model:

Synergy, Symbiosis, Collaboration, and Complementarity

by John Tharakan

Chapter 6

Economic Integration in West Africa: A Reconsideration of the Evidence by Akpan H. Ekpo

Section 3

Agricultural Services and the Water-Energy-Food Nexus in Africa

Chapter 7

Economic Development of Rural Communities in Sub-Saharan Africa through Decentralized Energy-Water-Food Systems

by Johannes Winklmaier, Sissi Adeli Bazan Santos and Tobias Trenkle 
World Trade Organization's Trade Liberalization Policy on Agriculture and Food Security in West Africa

by Emeka C. Iloh, Michael Nwokedi, Chijioke Francis Onyebukwa

and Queeneth Ekeocha

Chapter 9

Agricultural Production Amid Conflict: Implications for Africa's Regional

Development

by Jude Uwaoma Nwachukwu

Chapter 10

The Role of International Donors in Aquaculture Development in Africa by Olufemi Julius Olapade

\section{Section 4}

Environmental and Cultural Dimensions to Africa's Regional Development

Chapter 11

The Role of Culture in Achieving Sustainable Agriculture in South Africa: Examining Zulu Cultural Views and Management Practices of Livestock and Its Productivity

by Adetoyese Ade. Adeyemo and Ekuyikeno Silas

Chapter 12

A Gender Analysis of the Determinants of Youth Unemployment in Côte d'Ivoire

by Ibrahima Sy and Akrassi Kouakou Evrard Kouame

\section{Chapter 13}

The Factors Influencing SMEs Growth in Africa: A Case of SMEs in Zimbabwe

by Kosmas Njanike

Chapter 14

Solid Waste Management in Africa: Governance Failure or Development Opportunity?

by Linda Godfrey, Mohamed Tawfic Ahmed, Kidane Giday Gebremedhin, Jamidu H.Y. Katima, Suzan Oelofse, Oladele Osibanjo, Ulf Henning Richter and Arsène H. Yonli 


\section{Preface}

It is generally believed that the conditions that have limited Africa's economic growth and development are partly due to structural failures and organizational weaknesses. Arguably, it is also believed that colonization, political instability, foreign interests, dependency and neo-liberalism are other factors that have impacted the slow pace of Africa's regional development. Indeed, the slow pace of growth is also revealing a new set of developmental challenges in the region such as migration, brain drain, environmental degradation, regional conflicts, and peace and security issues, among others. The poor state of infrastructure services such as water, energy, food, housing, transportation and healthcare also adds to the growing complexity. Regional Development in Africa provides readers with a better understanding of the contemporary issues and challenges facing the African continent as a result of economic and social changes. It also provides insights on what needs to be done in order to put Africa back on the right development track.

The book starts with an introductory chapter (Section 1), which highlights some important reasons why we should care about Africa's regional development (Chapter 1) and why regional development really matters. It addresses the issues of: energy and development; urbanization and development; food production, consumption and resource constraints; and intra-African migration, trade and economic development as the main issues plaguing Africa's development trajectory.

In section 2, industry, trade and investment dynamics in Africa is presented and discussed. This section starts off by highlighting (in chapter 2) the dynamics of trade and investment in South Africa and the link between Africa's growth and the China-Africa investments (in chapter 3). Some specific cases on industrial practices and how they function on-the-ground are presented in chapters 4 and 5 . This section closes (in chapter 6 ) by highlighting the need to reconsider the evidence for economic integration in West Africa.

Section 3 delves into some salient issues around agricultural services and the water-energy-food nexus in Africa. In Chapter 7, the need for a decentralized waterenergy-food system to support development of local communities is presented and discussed. In Chapter 8, we discuss how the Word Trade Organization's liberalization policy impacts on food security in West Africa. Chapter 9 highlights how conflicts, owing to resource scarcity in food production, impact Africa's development, while Chapter 10 points out the role of international donors in aquaculture development in Africa.

Section 4 provides some environmental and cultural dimensions to Africa's regional development. In Chapter 11, the Zulu's cultural views and practices on livestock productivity management are explored. Chapter 12 provides a gender analysis of youth unemployment in Cote d'Ivoire while some factors influencing entrepreneurship growth in Zimbabwe are presented in Chapter 13. This section concludes in Chapter 14 where development opportunities for Africa's solid waste are presented. 
I express my sincere gratitude to all contributing authors for their high quality contributions. I also express my thanks to many more people who have assisted in various ways in making this book a reality. I also thank the commissioning editor, Romina Skomersic for the time and attention during the entire editorial process and for inviting me to be the editor for this book.

Dr. Norbert Edomah

Pan-Atlantic University,

Lagos, Nigeria 
Section 1

\section{Introduction}





\title{
Chapter 1
}

\section{Regional Development in Africa: An Overview}

\author{
Norbert Edomah
}

\begin{abstract}
This chapter introduces the various dimensions to regional development in Africa. It starts off by highlighting why regional development matters and the important components of the development process. It further highlights the regional dimension of Africa's development in some important sectors, particularly the role of energy, urbanization, consumption, intra-African migration, and trade in Africa's development process. The adverse effect of conflicts, protests, riots, and demonstrations in Africa's development process resulting from issues of resource constraints and scarcity (of food, fuel, and water) was also addressed. It concludes by pointing out the challenges to development and the need for citizen participation in the development process.
\end{abstract}

Keywords: Africa, development, development policy, intra-regional trade, regional policies

\section{Introduction: why regional development matters}

Regional economic prosperity depends upon realizing the full economic potential of all sub-regions. The territorial approach to the issue of development needs to be a part of the strategic thinking of national and regional bodies. However, how do we make the regions more competitive while at the same time prevent further socio-economic discrepancies in countries and regions? Certainly, place-based development is crucial in accelerating regional growth which focuses on the people, their assets, opportunities and challenges. Indeed, understanding the process of development and how development is to occur is crucial in mapping out strategies to reach and attain set goals.

Arguably, the idea of development applies equally to all nations and regions. Some development indicators such as access to energy, healthcare, education and other social amenities are crucial to accelerate the development process. The Challenge Network argues that there are three dominant high-level elements that play a vital role in development of nations. These are [1]:

1. Assets and liabilities possessed by a society

2. Goals and values that society sets for itself

3. Internal rules by which a society operates. 
Assets and liabilities possessed by a society is the first of the elements underpinning the development process. Society's assets such as: natural resources, its people, productive capital, security, etc., has to be properly balanced with its corresponding liabilities such as: resource limits, local and foreign debts, dependent people, etc. The African region is endowed with a lot of natural assets that are yet to be fully harnessed. The natural and human assets of the African region far outweigh its liabilities.

Goals and values that society sets for itself is a crucial element in the development process. Setting clear goals that is well articulated, understood, accepted and actively pursued with clear actions and backed by a general consensus is important. Setting unclear goals makes a society run the risk of either drifting towards the direction where market forces press it to go, or achieving those unclear set goals by accident. Setting unrealistic goals may often lead to a less happy end for that society. This is prevalent within the African region.

The third element underpinning the development of nations is the internal rules by which a society is governed. Development entails learning and managing increasing amounts of complexity that manifests itself in the forms of interconnections, options, information and resources. The internal rules of nations and regions guide its socio-economic and political growth. Indeed, societies which organize themselves for political and socio-economic growth develops, and those who are unable to do this do not.

With respect to the speed of development, institutions play a vital role implicitly through parliaments and embodied laws or explicitly through rules of everyday conduct and social engagement. Indeed, the sum of these structures is what is referred to as the 'social capital' of a society. It is difficult to change tacit institutions in predictable ways. However, policy instruments can be used to alter formal institutions to achieve development outcomes.

Regional development policies should be mainly about integration of several sectoral policies that are often designed in a way that is not coherent. It is also about tailoring policies to the specific needs of different places. Indeed, focusing on increasing productivity will yield increased competitiveness which leads to growth that improves quality of life. The following sections now delve into some African sectoral dynamics and their role in accelerating regional development in Africa.

\section{Energy and development in Africa}

Access to modern energy is vital to ending poverty. Africa is at the epicenter of global energy poverty, specifically sub-Sahara Africa. The International Energy Agency (IEA) argues that about 650 million Africans do not have access to electricity, which amounts to about two-thirds of the continent population [2]. Over 750 million people in Africa still do not have access to clean cooking fuels, leading to a huge number of premature deaths each year resulting from emissions [3]. The energy sector in sub-Sahara Africa is not yet able to meet the needs and aspirations of its citizens [4].

The primary purpose of our energy systems is to enable economic growth and to improve better quality of life [5]. Energy poverty is one of Africa's obstacles to progress, growth and economic development [6]. However, to accelerate regional development, three major factors are revolutionizing Africa's electricity sector; increased consumer demand for energy, technological innovation and new business models to improve energy access. Consumers are demanding renewables and other alternative forms of energy to cater for their basic energy needs. New technologies, such as solar photovoltaic (solar PV) technologies, are changing ways of generating 
power in Africa, and new business models are attracting and bringing public, private and donor investments into the energy sector.

In general, African countries are endowed with abundant renewable energy resources that can be increasingly harnessed [7]. The IEA argues that by 2040, renewables are expected to account for nearly $45 \%$ of all power generation capacity in the region, varying in scale from large to small hydropower dams, to mini and off-grid solutions in more remote areas [2].

Increasing access to electricity can turbocharge economic growth in the region, enabling a major push towards a more self-sustaining model of economic growth [8]. Indeed, this requires high-level political commitment to energy sector reforms with emphasis on building human capacity within the energy sector and strengthening policy/regulatory frameworks that leads to the emergence of more functioning energy markets.

\section{Urbanization and development in Africa}

Urbanization, beyond the cities and infrastructure, is more about the people. The United Nations argues that more than half of the global population now lives in urban areas, with a projected increase of $75 \%$ by 2050 [9]. Urban population in Africa hovers close to 500 million people and it is expected to double by 2040 [10]. Urbanization is vital to fighting poverty in the developing world. Africa has the opportunity to get urbanization right and to avoid mistakes made by other regions through effecting the right urbanization policies and growth strategies.

A challenge we find in Africa is that cities are developing while manufacturing is declining which poses a challenge on job availability. Another challenge we find in Africa is that cities are growing but population are sprawling, with population spread over kilometers which makes concentration, an important value of cities, not so effective. We have the opportunity in Africa to ensure that growth of cities is compact and efficient.

A lack of infrastructure density is another important factor affecting urbanization in Africa. There are lots of opportunities for future infrastructure investments that would make cities work more effectively in small, medium-sized and large (mega) cities. Indeed, every dollar of investment counts so as to ensure that cities are more efficient, that they grow in a more compact manner.

With respect to pattern of urbanization and city development, it is observed that in most African cities, commercial and industrial land are not necessarily concentrated in city centers or in certain parts of the cities. The jobs are very dispersed around the cities. This presents an opportunity for cities to become more efficient with respect to the urban pattern of the cities. With respect to share of commercial land, most African cities have a much lower percentage of commercial and industrial lands, with most having less than $7 \%$ of commercial and industrial land compared to other regions of the world [10]. Indeed, urbanization for most African cities would mean; developing cities with jobs, good housing policies and good transportation linkages that connect the housing and the jobs so that people are able to reach a large number of available jobs within a reasonable time.

\section{Food production, consumption, and resource constraints in Africa}

Food security in Africa is a vital part of development that needs to be addressed using a short, medium and long term approach. Sustainable agriculture and food security needs to be an important part of the policy dialog to secure a sustainable 
growth path for Africa. Rising population and a rich diet that takes a lot more resources to produce than they used to are driving increased demand for food. Increasing food production is becoming increasingly difficult because rising food demand is happening simultaneously with increased energy bills. Rising food demand coupled with climate change issues are making food difficult to produce.

Science and technology can play a vital role in food production, particularly the development of technologies that will help farmers reach their full potential with respect to the amount of food they produce. Having improved quality seeds, fertilizers and better equipment designed for the African climate, soil, cultures and communities can help improve food production. Indeed, the need to develop locally appropriate solutions to local challenges is important to improving food production.

Food distribution is another challenge plaguing Africa. A large proportion of food produced either end up in the bins of are used as animal feeds. In Africa, we need not only to improve our food production but we need to stop wasting food. Globally, 25-35\% of our food gets wasted in different ways. Food wastage is indeed an issue impacting on food scarcity which worsens the poverty challenge that leads to possible conflicts.

Figure 1 is a global chaos map which shows the number of deaths linked to food, fuel and water crises in 2008. The African continent was the most affected in that year. In Mali and Cote d'Ivoire, one death each was recorded as a result of unrest linked to water, fuel and food. In the same year, 60 and 51 deaths were recorded in Cameroon and Sudan as a result of riots and conflict linked to resource constraints. Egypt, Somalia and Tanzania also recorded 15, 5 and 8 deaths owing to riots, protests and conflicts linked to resource constraints (around food, fuel and water) in 2008.

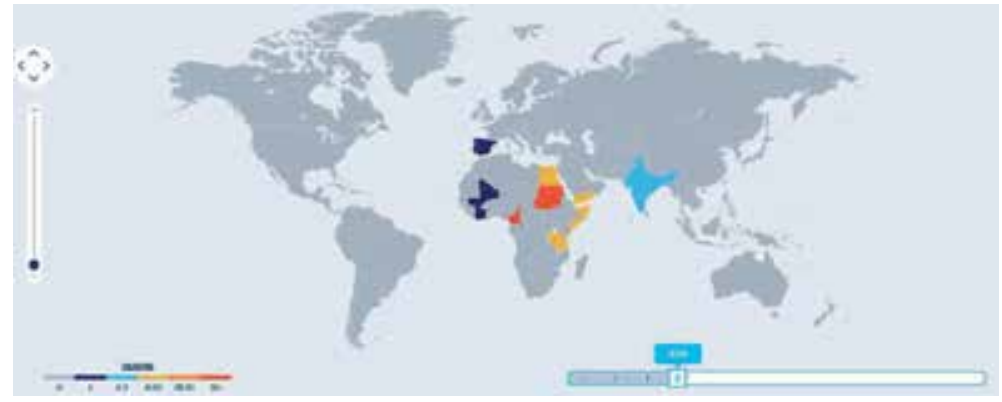

Figure 1.

Global Chaos Map showing number of deaths linked to resource constraints arising from food, fuel and water crises in 2008.

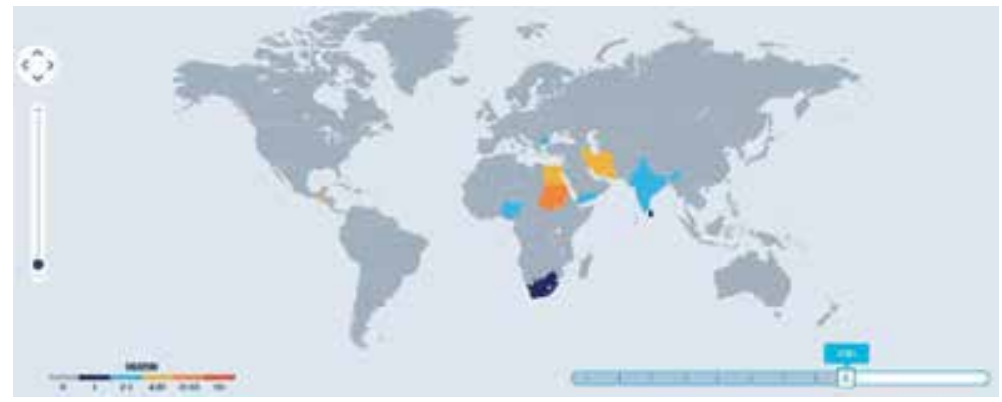

Figure 2.

Global Chaos Map showing number of deaths linked to resource constraints arising from food, fuel and water crises in 2013. 
As with 2008 where most resource crises were experienced on the African continent, the case was no different in 2013 as shown in Figure 2. In 2013, Nigeria and South Africa recorded 2 and 1 death respectively linked to looting and protests. In Sudan, 30 related deaths resulting from demonstrations and protests were recorded that were linked to resource constraints. Egypt in the same year recorded 7 deaths owing to demonstrations linked to resource constraints related to food, fuel and water.

\section{Intra-African migration, trade, and economic development}

The United Nations argues that intra-African migration has grown in recent years, from 15 million in 2000 to 25 million in 2017 [11]. Migration generates significant economic benefits for countries. Specific sector demands in destination countries create economic opportunities for men and women. Intra-African migration stimulates productivity in agriculture, construction, information technology and services sectors. This has contributed to destination countries' GDP, particularly countries such as Cote d'Ivoire, Ghana and South Africa.

Countries of origin benefit from increased intra-African trade. Migrants demand food products from their home countries, stimulating food export. Migrants' remittances and other contributions from Africa's diaspora also boost economic development in countries of origin. In 2016, total remittances accounted for $51 \%$ of private capital flow to Africa [11]. Indeed, women contribute as much as men with respect to remittances.

Ethiopian international migrants' remittances are largely used for productive investments rather than consumption. About $40 \%$ of remittances are used for productive enterprise while about 33\% are used for everyday consumption [11]. If better managed, intra-African migration could yield further benefits for migrants and countries since there is a huge potential contribution of migration to GDP per capita in Africa.

To better harness the opportunities that migration provides within the African continent, it is important for African governments to align migration, trade and investment policies to development objectives. It is also crucial to leverage remittances and harness diaspora for productive investments in countries of origin. It is also important to adopt flexible labor policies to ease migrants' mobility and integrate migrants to the labor markets while also allocating resources to address structural determinants of Africa's socio-economic development.

\section{Concluding thoughts}

Development is often linked with economic prosperity. However, development is a much broader concept incorporating many aspects such as economics, resource distribution, culture, health, politics and questions of poverty, inequality and the way in which the world is structured. Prosperity is important but the question of who gets the prosperity and who has the potential for it is also vital.

A salient issue with regards development is the gender dimension. Historically, women have not participated in the process, design and management of development in many regions. Women have not been involved, or rather permitted to participate, in designing policies for increasing literacy, economic resources and providing social services. The cost of major shifts in development policies have been borne by women, with women constituting a vast majority of the poor. 
Some important aspects to living better lives are better health policies, education and food which simply highlight the need for better incomes. Many global issues impede development. Weak and corrupt governments that are incapable of delivering the kind of services needed for development constitute a major challenge. Many countries have suffered, or are suffering, from internal wars and conflicts which constitute immerse problems for development because people's livelihoods are interrupted and government cannot provide essential services to aid development. Indeed, development can go badly if it is done the corrupt way and some development have very bad environmental consequences.

The most pressing development concerns are situations where decisions are made by small elite, fostering development that is not democratic. This yields a development that is for the people, but not by the people. This calls for a need for citizen participation in the development process.

\section{Author details}

Norbert Edomah

Pan-Atlantic University, Lagos, Nigeria

*Address all correspondence to: nedomah@pau.edu.ng

\section{IntechOpen}

(C) 2020 The Author(s). Licensee IntechOpen. This chapter is distributed under the terms of the Creative Commons Attribution License (http://creativecommons.org/licenses/ by/3.0), which permits unrestricted use, distribution, and reproduction in any medium, provided the original work is properly cited. (cc) BY 


\section{References}

[1] The Challenge Network. On the process of development [Online]. Available from: http://www.chforum. org/library/devt1.shtml [Accessed: 18 October 2019]

[2] IEA. Africa Energy Outlook. A Focus on Energy Prospects in Sub-Sahara Africa. Paris, France: International Energy Agency; 2014

[3] Mitchell EJS et al. Pollutant emissions from improved cookstoves of the type used in sub-Saharan Africa. Combustion Science and Technology. 2019. DOI: 10.1080/00102202.2019.1614922

[4] Iwayemi A. Energy Sector Development in Africa. Abidjan, Côte d'Ivoire: African Development Bank; 1998

[5] Ahlborg H, Boräng F, Jagers SC, Söderholm P. Provision of electricity to African households: The importance of democracy and institutional quality. In: Energy Policy. Vol. 87. Elsevier; 2015. pp. 125-135

[6] OECD/IEA. Energy Poverty: How to Make Modern Energy Access Universal? Paris, France: International Energy Agency; 2010

[7] Edomah N. Economics of energy supply. In: Earth Systems and Environmental Sciences. Elsevier; 2018. pp. 1-16

[8] Edomah N. Deindustrialization and effects of poorly implemented energy policies on sustainable industrial growth. In: Yülek M, editor. Industrial Policy and Sustainable Growth. Singapore: Springer Nature Singapore; 2018. pp. 311-322

[9] Awumbila M. Drivers of migration and urbanization in Africa: Key trends and issues. In: United Nations Expert Group Meeting on Sustainable Cities,
Human Mobility and International Migration. 2017

[10] Saghir J, Santoro J. Urbanization in Sub-Saharan Africa. Meeting Challenges by Bridging Stakeholders. Washington, DC, USA: Center for Strategic \& International Studies; 2018

[11] United Nations. Economic Development in Africa Report 2018: Migration for Structural Transsformation. New York: United Nations; 2018 

Section 2

\section{Industry, Trade and Investment in Africa}





\title{
Chapter 2
}

\section{Trade and Investment in South Africa}

\author{
Garebangwe Victoria Mabe-Madisa
}

\begin{abstract}
A strong and sustained economic growth emanating from trade and investment is needed to confront the challenges of unemployment and poverty. The mining sector is not performing as well as it used to, in South Africa. Reliance on minerals for production has its challenges, for example, being interrupted by strikes, resulting in nonproduction. To fill this gap, using a vector error correction approach, the influence of oil and exchange rate on foreign direct investment (FDI) using quarterly data from January 2008 to January 2017 is investigated. The results for the Johansen approach show that the variables are cointegrated and that there is one cointegrating equation. The long-run cointegration equation shows that oil price and exchange rate have a negative long-run relationship with FDI. The country should continue to focus on policies aimed at strengthening its exchange rate and stabilizing oil prices.
\end{abstract}

Keywords: trade, investment, exchange rate, oil price, foreign trade investments

\section{Introduction}

Trade involves the transfer of goods or services from one person or entity to another, in exchange for money. A system or network that allows trade is called a market. There are two types of trade, namely, retail trade and wholesale trade. Retail trade involves the sale of goods from a very fixed location such as a store, in small or lots, to a purchaser, while wholesale trade is defined as traffic in goods that are sold as merchandise to industrial, commercial, institutional or to other wholesalers.

Investment is defined as the current commitment of resources in order to achieve later benefits. If resources and benefits take the form of money, investment is the present commitment of money for the purpose of receiving money later. In some cases, such as the purchase of a bank certificate of deposit, the amount of money to be obtained later is known. However, in most situations, the amount of money to be obtained later is uncertain [1].

In a report which was recently released by Statistics South Africa [2], under the "Environmental Economic Accounts Compendium", it was estimated that the country has 239 years of platinum-group metals (PGMs) reserves, while coal has 118 years of reserves available, and that there are only 38 years with regard to the amount of gold resources remaining [3]. The report also indicated that in the mining industry, gold was once the biggest employer; however, this all changed in the year 2006 when PGMs took the lead [4]. 
PGMs are made up of six essential metals, namely, platinum, palladium, osmium, ruthenium and iridium. These are considered to be the important raw materials. PGMs play a significant role in the manufacturing process as they are used in commercial applications and the production of different technologies such as computer hard drives, monitors and medical tools and are also used in industrial processes. PGMs are said to also play a huge role in the automotive sector [5].

PGMs contribute greatly to South Africa's mining production. It has been seen over the years that the performance of PGMs has either a positive or negative effect on the performance of other minerals and mining production as a whole. A decline in the production of PGMs has led to the increase in the production of other commodities and vice versa.

It is evident that in South Africa, there is a tendency of over-reliance on certain minerals, such as PGMs, and as a result, this leads to other minerals not performing as well as they should. The mining in South Africa is not performing as well as it used to many years ago; however, it is still considered to be the country's most important employer. It was reported that in the year 2007, the mining sector employed 493,000 workers [6]. In South Africa, the well-known minerals that are mined include platinum, gold, coal and iron ore. South Africa is commonly known for its commodities. However, according to a recent mining report, the PGM industry has the largest number of employees, and this is followed by the gold and coal industries [2]. It is evident that gold production is not performing as well as it used to when mining practices began.

Disruptions or unforeseen situations such as industrial actions or strikes negatively impact industries such as the mining industries. An example of this was in the year 2014 when the South African mining production decreased, and this was caused by strikes which occurred in the sector. According to Stats SA [3], the decline in mining production was mainly caused by the decline in PGMs as a result of strike. The industrial action lasted slightly 5 months during that year.

Since over-reliance on PGMs has adverse results from instability, investigation of the determinants of foreign direct investment (FDI) in growing the economy is important. Investigating the drivers of FDIs will help the country or investors in monetary gain by making informed decisions.

FDI can be explained as when an organization or individual in a particular country is interested in another country's business, either building up business operations or procuring business resources in another country, for example, proprietorship or controlling enthusiasm for an outside organization. FDI includes capital streams starting from one country to another, conceding broad proprietorship stakes in local organizations and resources. Foreign investment signifies that foreigners have a significant role in the administration of a certain country as part of their investment. In simple terms, it can be said that foreign direct investment is a major form of international capital transfer.

Over the previous decade, developing countries around the globe encountered generous development in their economies, with considerably faster development in global exchanges, particularly in the type of FDI. The net offer FDI of world gross domestic product (GDP) has developed more than five times in both the 1990s and the early twenty-first century, making the results and causes of FDI and monetary development a subject of regularly developing intrigue [7].

According to [8] gold, oil and the exchange rate have received much attention recently from investors, traders, policymakers and producers, partly because of the recent flare up in their prices, increases in their economic uses and synchronization of their movements. Their relationships have even attracted the attention of lay persons. 
Policymakers have frequently discussed the link between oil prices and exchange rates in recent years, particularly the idea that an appreciation of the US dollar triggers a dip in oil prices [9]. Empirical research is not so clear on the direction of causation, as there is evidence for bidirectional causality. For example, some studies find that an increase in the real oil price actually results in a real appreciation of the US dollar, while others show that a nominal appreciation of the US dollar triggers decreases in the oil price.

The reverse relationship between the value of US dollar and that of gold is one of the most discussed about relationships in currency markets, and most of the international transactions take place in dollar equivalent. The major reason behind the relationship of gold and USD/INR exchange rate is that gold is used as a hedge against the adverse exchange value of dollar. As the dollar's exchange value decreases, it takes more dollars to buy gold, which increases the value of gold. The value of dollar can be at a potential risk of fluctuation through various factors like shifts in monetary policy, international trade, etc., but the value of yellow metal is largely determined by supply and demand, without interference from shifts in monetary and corporate policies. Therefore, there is a need to investigate the influence of exchange rate and oil on attracting FDI.

The previously mentioned information demonstrates that in supreme terms, South Africa's appeal has improved; however, in contrast with other developing countries, South Africa has not been attracting FDI. The question at hand then is "what method can South Africa use to draw more FDI?" This is a very important question, in light of the fact that FDI can play a major role in the continent's development. FDI can fortify household speculation, encourage innovation exchange, make business, advance fares and, most importantly, produce financial growth. The part of FDI as a wellspring of wealth is especially critical in South Africa, in a setting where net official development assistance (ODA) to the country declines.

To fill the gap identified, this chapter seeks to understand the nature of the relationship between FDI, oil price and exchange rate in order to investigate the determinants of FDI for South Africa. It investigates the drivers of FDI using the vector error correction model (VECM) approach. There is a need for knowledge dissemination and culture change to enable innovation and collective problemsolving, only then will the investment flow with the creation of sustainable employment and economic growth.

This chapter is organized as follows: Section 2 discusses related works. Section 3 discusses the research methodology, while Section 4 discusses the analysis and results. The conclusion and recommendations are discussed in Section 5.

\section{Related works}

\subsection{Mining production and sales}

The South African mining sector has contributed positively to the country's economy, specifically impacting the increase in employment and GDP through trade. The mining industry has played an important role in the contribution to civilization and human existence [10]. Mining is considered to be the second earliest human endeavour, while agriculture is considered the first. To date, these two industries have continued to play an important role in the economy since the beginning of civilization [10]. Mining is not and has not always been the only major contributor to the economy as the manufacturing industry was considered to be the 
largest in the year 1980, making the mining industry the second largest industry, followed by agriculture [3].

Mining practices in South Africa began about 165 years ago. It started with the discovery of diamond followed by that of gold a few years later. These two discoveries played a significant role in the growth of the South African economy.

According to [2], the 1970s are best remembered as the decade in which the South African mining sector greatly influenced the economy and employment. The contribution to the economic production reached its peak in the year 1980, and in 1987 the mining industry employed more than 760,000 individuals [2].

\subsection{Retail sales}

Retail sales are sales of finished goods and services sold to either consumers or businesses. Fluctuations in retail sales are a matter of concern for businessmen and businesswomen, investors and policymakers [11].

According to [12], aggregate retail sales are a summative measure of sales of retail goods over a stated period of time, typically grounded on a data sampling that is extrapolated to model the entire retail sales of a country. Evaluating consumer demands for finished goods, aggregate retail sales help measure the pulse of an economy and its estimated path towards growth [12]. Similarly, to other various economic time series, South Africa's aggregate retail sales have a strong trend and seasonal patterns. Modelling and forecasting these patterns have been a longstanding issue in time series.

According to [13], several years ago, worldwide, participants (buyers and sellers) were individual retail investors and institutions such as banks, insurance companies and hedge funds and also publicly traded corporations trading in their own shares. Investors such as wealthy businessmen were market participants. Previously, markets became more "institutionalized". Buyers and sellers were institutions such as insurance companies, mutual funds, index funds, investor groups, banks and various other financial institutions.

Presently, participants in the stock market array from small individual stock investors to large hedge fund trader. Their orders regularly end up with a professional at the stock exchange, who completes the order. Most stocks are traded at the exchanges, for example, the Johannesburg Stock Exchange (JSE), which are places where participants decide on a price. The key objective of a stock exchange is to simplify the exchange of securities between participants, thus providing a marketplace.

\subsection{Food and beverage sales}

The food and beverage sector is a critical sector of the South African economy, as indicated by [14]. It represents $18 \%$ of assembling deals (sustenance (13.5\%) and drinks (4.4\%)) and $17 \%$ of gross esteem including the assembling segment and utilizes around 230,000 workers in 2009 [3]. The area is a piece of the nourishment business esteem chain, which comprises of cultivating and the generation of crude farming produce; preparing of crude horticultural wares; fabricating, changing the crude and handled delivery into completed or prepared wares; wholesalers and retailers of the completed items; and buyers.

The South African food and beverage sector concentrates on the third connection in the chain beneath and changes through mechanical procedures and agrarian wares into semi-handled or completely prepared nourishment fixings or items. In spite of the fact that there are up- and downstream interdependencies, the nourishment and drinks fabricating part contrasts from the essential horticulture segment through its unpredictability, utilization of capital-concentrated innovation 
and forms and the substantial number of providers, merchants and directs engaged with taking the items to business sectors.

As indicated by the arrangement of monetary exercises in South Africa, the food and beverage sector incorporates the assembling of sustenance items and refreshments, be that as it may, as opposed to the training in most different nations, it prohibits the tobacco-producing area, which is incorporated in the rural division. As indicated by [15], the food and beverage sector is critical in South Africa on account of its high level of forward and in reverse linkages with different enterprises, which enables it to assume an imperative part in quickening monetary action. The food and beverages sector is suited to South Africa's creating nation qualities because handling plants are not generally scale-reliant and little operations might be as monetarily productive as bigger plants, subsequently promising the cooperation of small, medium and microenterprises (SMMEs) in specialty markets [16].

\subsection{The banks' stock prices}

Stock prices are share prices of several numbers of saleable stock of a company. Stock prices are sold and bought to improve the credibility of a company so that investors can come into the company and invest. In addition, selling stock helps the company grow. An empirical study that was done by [17] says that the stock price index is an indicator for reference issued by the financial service institutions that show change in the stock market. The researcher continues to say that it mainly denotes the general trend of stock price and the change range for the market so that it provides investors with real-time movement of the stock market.

\subsection{Foreign direct investments}

In 1970 (the first year for which FDI information was accessible), the aggregate sum of FDI inflows in Africa was $\$ 1.26$ billion, and it rose to $\$ 55.04$ billion in 40 years. This means that from 1970 to 2010, FDI inflows expanded by $4.268 \%$ which is a commendable achievement. Nonetheless, for a decent appraisal of the circumstance, it is smarter to put Africa's achievement into a relative point of view. The picture painted here is extraordinary. In 1970, Africa's offer in the worldwide FDI inflows was $9.5 \%$ dropping to $4.4 \% 40$ years later. Similarly, the offer of Africa in building up the nation's FDI inflows was 32.8\% in 1970, dropping to 9.6\% 40 years later. As per information from the [18] World Bank's 2014 World Development Indicators, Africa's normal net official development assistance as a level of gross national salary decreased from $5.3 \%$ in 2005 to $4.2 \% 3$ years later and later decayed to $3.3 \%$ in 2012. Africa and other developing regions are probably going to keep accepting less ODA, because of monetary challenges, which restrain numerous Western benefactor nations to give improvement help to developing nations. Africa gets less ODA, while its requirement for advancement financings stays very large. In reality, it has been evaluated that about $\$ 186$ billion will be required every year to back Africa's post-2015 advancement motivation [19]. Accordingly, Africa needs to discover elective assets for financing its improvement, and FDI is an essential alternative. The uplifting news for Africa is that, over the previous years, the continent has been one of the quickest developing regions on the planet, which makes it one of the potential outskirt markets. This builds financial specialists' interests in Africa. On the other hand, FDI streams will not consequently appear, and efforts should be made to change the potential into real FDI streams to Africa. [20] emphasize that literature suggests the emergence of policy and non-policy factors as determinants of FDI. The non-policy factors in determining the determinants of FDI would include market size, distance factor proportions and political 
and monetary dependability. The policy factors in determining the determinants of FDI would include openness to trade, product market regulation, labour market arrangements, corporate tax rates and infrastructural developments [20].

\section{Materials and methods}

The data employs quarterly data in all the variables and was sourced from the South African Reserve Bank (SARB). The variables studied are foreign direct investment, exchange rate (EXRATE) and crude oil price (OIL). FDI was used as a dependent variable, while EXRATE and OIL were used as independent variables. Monthly data on these commodities'spot prices cover a 5-year period, from January 2008 to January 2017. E-Views 8 software was used to run the specified models. The table below shows the descriptive statistics of the data (Table 1).

The augmented Dickey-Fuller (ADF) test was used to test for a unit root (nonstationary) in the series and to determine the order of integration in the variables. The optimal lag length which removes serial correlation in the residuals as well as determines the deterministic trend for the vector autoregression (VAR) model was determined in order to apply the Johansen test for cointegration analysis. The Johansen test has two likelihood ratio tests of significance, trace test and maximum eigenvalue test. For choosing the lag order for the VAR, the lag selection criteria approach was applied. The vector error correction model approach was used to evaluate the short-term properties of the time series. Adequacy of the model was tested by performing diagnostic and stability tests.

The coefficients obtained from the estimation of the VAR model may not be proper to interpret directly. Hence, both impulse response functions and the variance decomposition were used. Impulse response functions are used to trace out the dynamic interaction among variables. It shows the dynamic response of all the variables in the system to a shock or innovation in each variable. In other words, it focuses more on the increase or decrease in trend rather than the actual value of the variable. On the other hand, variance decomposition is used to detect the causal relationships among the variables. It shows the extent to which a variable is explained by the innovations or shocks in all the variables in the system.

\begin{tabular}{lccc}
\hline & EXRATE & FDI & OIL \\
\hline Mean & 745.3667 & $783,438.3$ & 50.76139 \\
\hline Median & 713.8900 & 611585.0 & 38.3200 \\
\hline Maximum & 1542.240 & $2,069,790$ & 132.1500 \\
\hline Minimum & 304.7764 & $36,334.00$ & 10.27000 \\
\hline Std. dev & 289.8703 & $651,751.2$ & 34.90964 \\
\hline Skewness & 0.737866 & 0.592239 & 0.713470 \\
\hline Kurtosis & 3.301539 & 2.085011 & 2.173178 \\
\hline Jarque-Bera & 9.169366 & 9.054111 & 10.99249 \\
\hline Probability & 0.010207 & 0.010812 & 0.004102 \\
\hline Sum & $72,300.57$ & $75,993,515$ & 4923.855 \\
\hline Sum sq. dev & $8,066,380$ & $4.08 \mathrm{E}+13$ & 116993.6 \\
\hline Observations & 97 & 97 & 97 \\
\hline
\end{tabular}

Table 1.

Descriptive statistics. 


\subsection{Model specification}

The model below will be generated by FDI being the dependent variable and oil and exchange rate being independent variables.

This can be written as follows:

$$
F D I_{Q}=f\left(E X R A T E_{Q}, O I L_{Q}\right)
$$

where

$F D I_{Q}=$ foreign direct investment in quarter $Q$

EXRATE $E_{Q}=$ exchange rate in quarter $Q$

$O I L_{Q}=$ oil price in quarter $Q$

\section{Analysis and findings}

\subsection{Results}

A stationery time series is defined as a series with constant mean, constant variance and constant auto-variance for each lag. A unit root test examines whether the time series variables are nonstationary. If there are unit roots (nonstationary) in the series, a series of successive differences can change it into a stationary one.

Figures 1 and 2 depict the exchange rate processes. This is to show how nonstationary and stationary processes look like.

After differencing, there exists a stationary linear combination of nonstationary random variables; the variables combined are said to be cointegrated. When two or more variables move together for a long period of time, we say they are cointegrated. The ADF test was used to investigate the order of integration. This test is important in determining whether cointegration methods can be applied to study the long-run relationship between the variables. The variables in this study are integrated to the same order. In order to examine the impact of oil price and the exchange rate on FDI, the VAR model was used. A selection is done using a maximum of four lags.

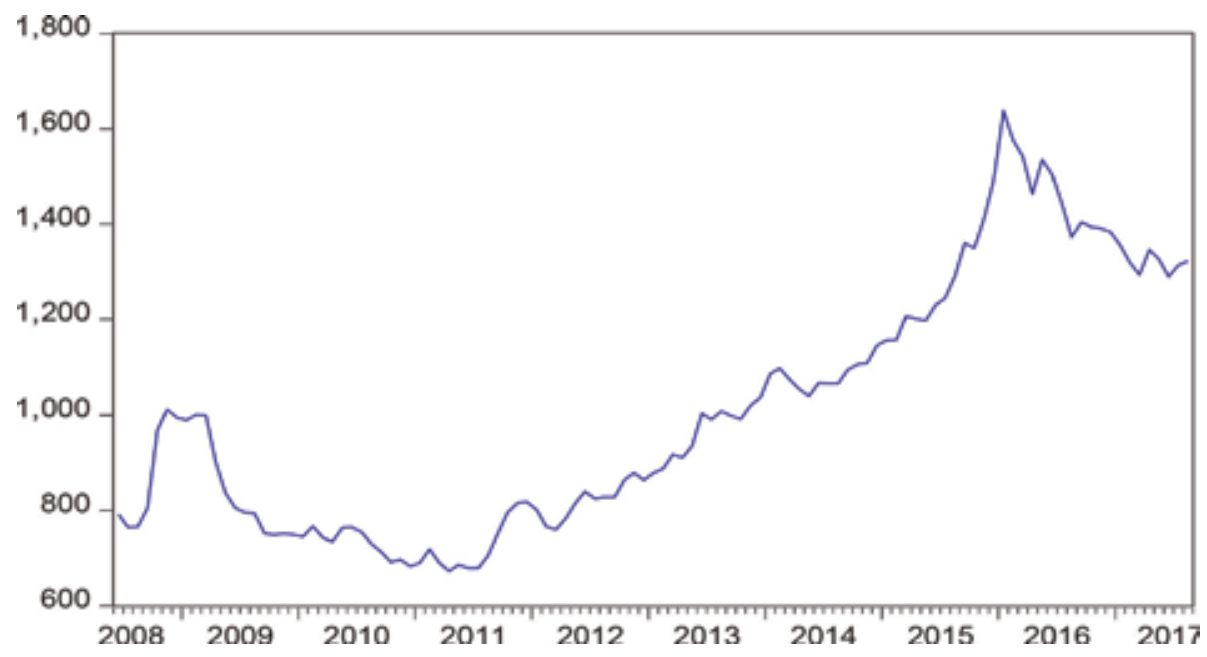

Figure 1.

Exchange rate. 


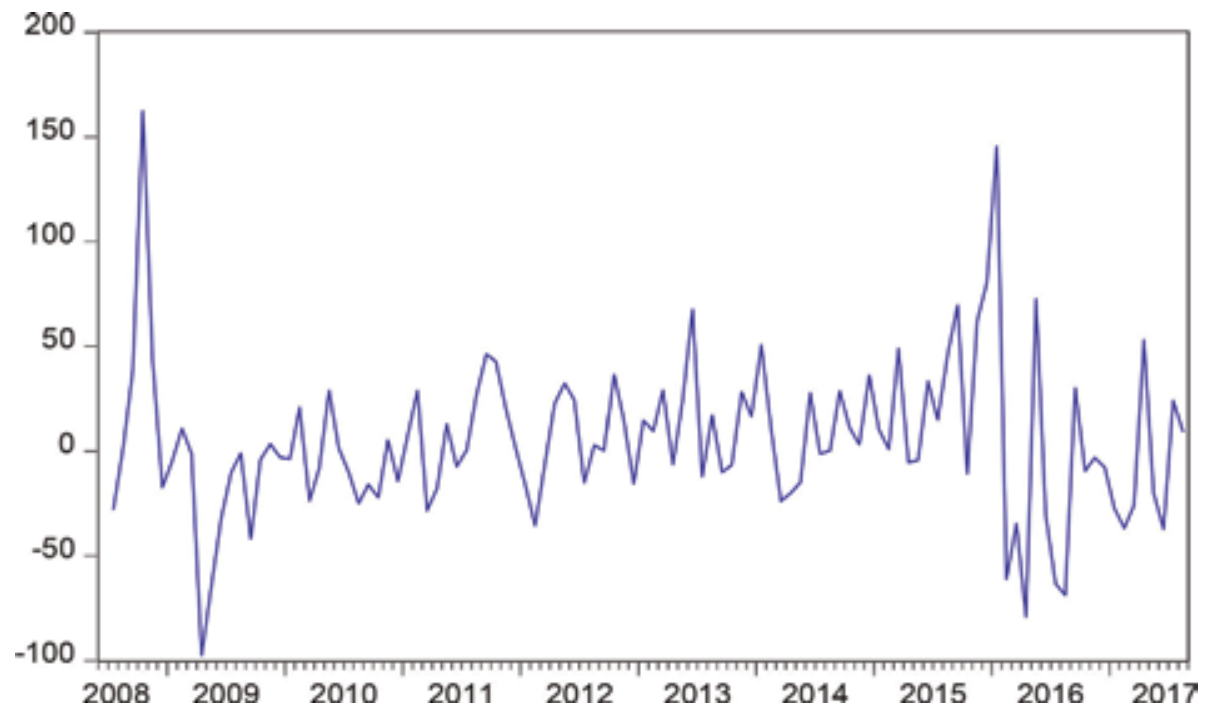

Figure 2.

Differenced exchange rate.

\begin{tabular}{lccc}
\hline & FDI & EXRATE & OIL \\
\hline FDI & 1 & 0.808648 & 0.718984 \\
\hline EXRATE & 0.808648 & 1 & 0.378294 \\
\hline OIL & 0.718984 & 0.378294 & 1 \\
\hline
\end{tabular}

Table 2.

Pair-wise correlation results.

Correlation in statistics is defined as the relationship between variables. It is explained by numbers ranging between -1 and 1 , called correlation coefficients. The pare-wise correlation is shown in Table 2, which shows that FDI was correlated with all the variables and that there was no specific variable that was correlated with all the variables. With this information, we can conclude that there is a less chance of multicollinearity being a problem.

According to the trace and maximum eigenvalue test for cointegration, the null hypothesis for at least one cointegration equation was accepted, concluding that there is one cointegration vector and that there is one significant long-run relationship between variables. From both the Johansen's trace and maximum eigenvalue tests, the results showed that the variables (EXRATE, OIL and FDI) could either have a short- or long-run relationship.

If the variables are cointegrated, the residuals from estimated regression can be used to estimate error correction model so that the short- and long-run effects of the variables can be analysed; VECM was used to analyse these results. Tables $\mathbf{3}$ and $\mathbf{4}$ depict these analyses.

The long-run relationship is shown in the equation below:

$$
F D I=888851.1-1491.34 E X R A T E-10923.00 O I L \ldots
$$

The equation above shows that EXRATE and OIL have a negative long-run relationship with FDI, which can be interpreted by saying that a unit increase in EXRATE and OIL results in a decrease in FDI. 


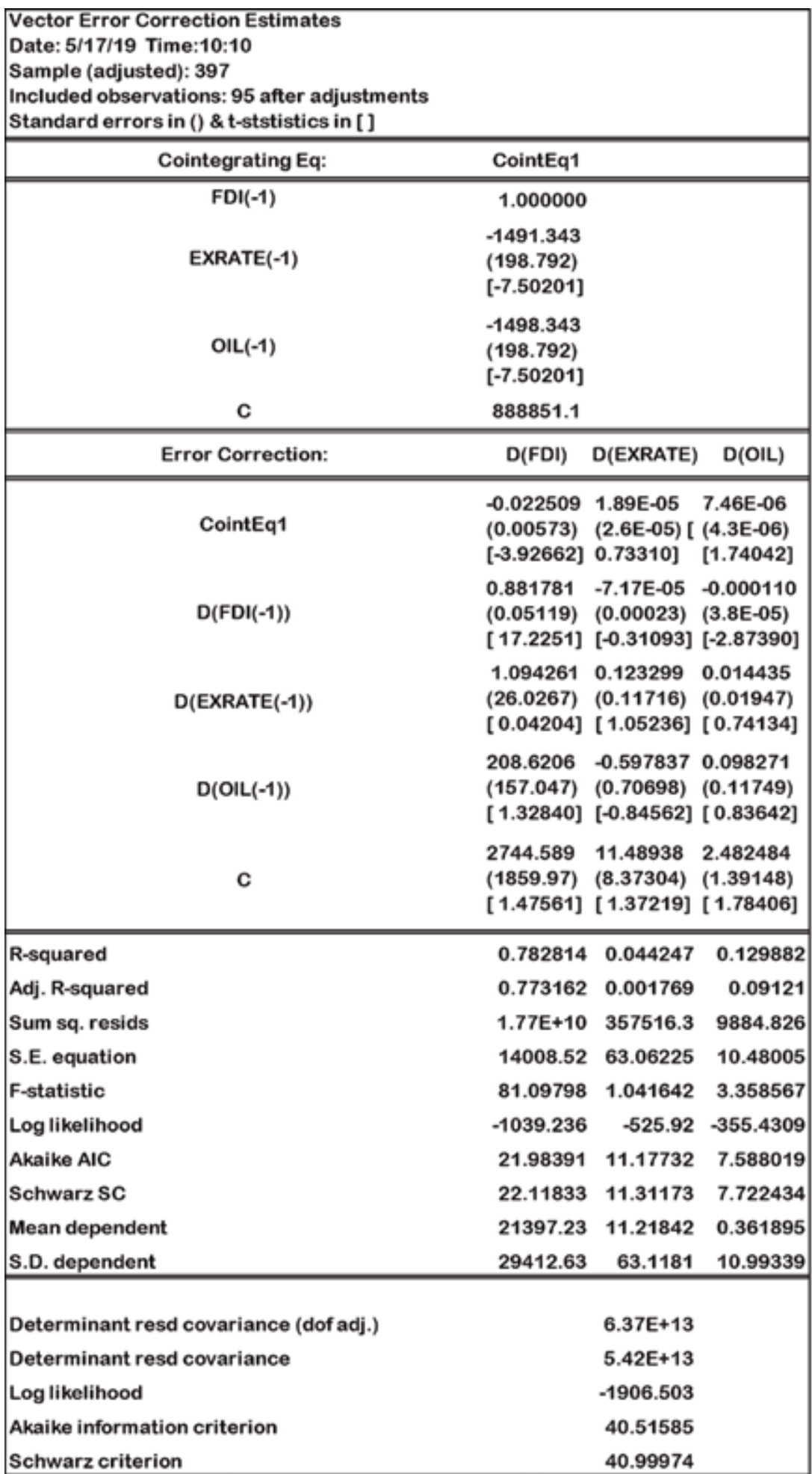

Table 3.

Vector error correction estimates. 


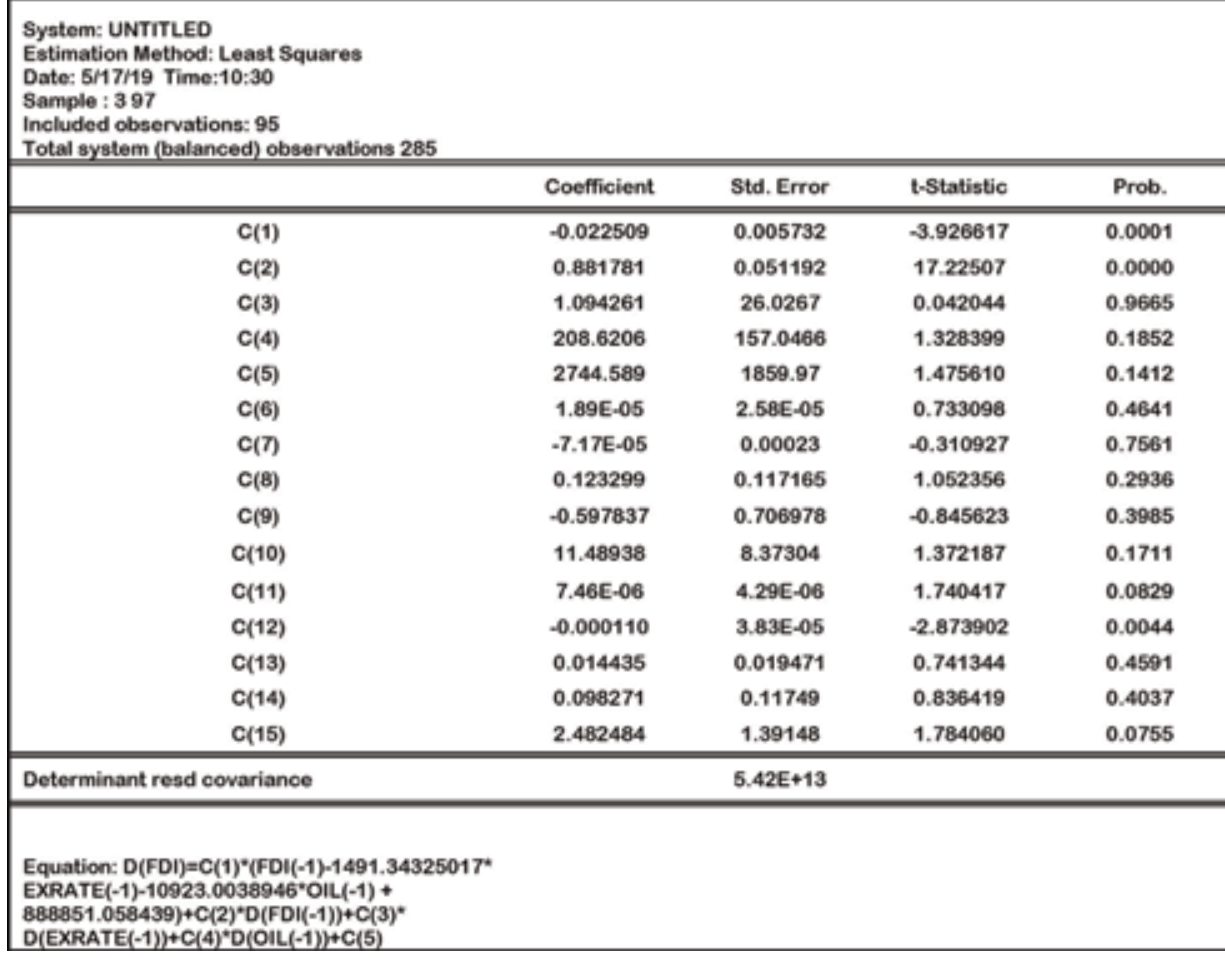

Table 4.

Vector error correction model coefficients.

The vector error correction equation is given as

$$
\begin{aligned}
\Delta F D I= & -0.0225 \times\left(F D I_{t-1}-1491.3433 \times E X R A T E_{t-1}-10923.0039 \times O I L_{t-1}\right. \\
& +888851.0584)+0.8878 \times \Delta F D I_{t-1}+1.0943 \times \Delta E X R A T E_{t-1} \\
& +208.6206 \times \Delta O I L_{t-1}+2744.589
\end{aligned}
$$

where $\left(F D I_{t-1}-1491.3433 \times\right.$ EXRATE $_{t-1}-10923.0039 \times O I L_{t-1}+$ $888851.0584)$ is the error correction term.

\subsection{Summary}

To reiterate, South Africa's appeal has improved; however, in contrast with other developing countries, South Africa has not been attracting FDI. The question at hand was "what method can South Africa use to draw more FDI?" This is a very important question, in light of the fact that FDI can play a major role in the continent's development. FDI can fortify household speculation, encourage innovation exchange, make business, advance fares and, most importantly, produce financial growth. The part of FDI as a wellspring of wealth is especially critical in South Africa, in a setting where net official development assistance to the country declines.

This section analysed FDI and its determinants. The descriptive statistics showed that the mean values of the variables are all positive, ranging from 50.762 to $783,438.3$, with oil price being the lowest and FDI being the highest. This can be interpreted by saying that South Africa has experienced more FDI inflows over the years understudy. 
For stationarity tests, the ADF and PP test were used. The PP test showed that variables used are I(1). The pair-wise correlation showed that FDI was correlated with all the variables and that there were no specific variables that were correlated with all the variables, concluding that there is less chance of multicollinearity. The vector error correction estimates showed that the variables (EXRATE and OIL) have a negative long-run relationship with FDI. All explanatory variables were statistically significant in explaining FDI since they have absolute $t$-values above 2 .

According to the trace and maximum eigenvalue test for cointegration, the null hypothesis for at least one cointegration equation was accepted, concluding that there is one cointegration vector and that there is one significant long-run relationship between variables.

The long-run relationship is shown in the Eq. (2).

The equation above shows that EXCHANGE and OIL have a negative long-run relationship with FDI, which can be interpreted by saying that a unit increase in EXRATE and OIL results in a decrease in FDI.

\section{Conclusion and recommendations}

The results show that exchange rate is an important variable in determining FDI inflows into South Africa as it was highly correlated with FDI. Among other things, this suggests that South Africa needs to reduce inflation rates because if inflation is lower than competing countries, South Africa's goods will become attractive and the demand will rise. Also, the country needs to increase interest rates as this would attract hot money flow, which occurs when banks and financial institutions move money to other countries to get a better rate of return on savings. The empirical results also suggested that oil is another important factor in determining FDI inflows as it was also highly correlated with FDI. The study showed that the country should continue focusing on policies aimed at strengthening its exchange rate and stabilizing oil prices.

What is pertinent to the picture painted above is that economic growth in the country will continue to be stifled if the urgent need to enhance economic growth is not taken into consideration. We have to come up with the methods on how to save our economy.

\section{Author details}

Garebangwe Victoria Mabe-Madisa

Department of Decision Sciences, University of South Africa, Pretoria, South Africa

*Address all correspondence to: mabemgv@unisa.ac.za

\section{IntechOpen}

(C) 2019 The Author(s). Licensee IntechOpen. This chapter is distributed under the terms of the Creative Commons Attribution License (http://creativecommons.org/licenses/ by/3.0), which permits unrestricted use, distribution, and reproduction in any medium, provided the original work is properly cited. (c) BY 


\section{References}

[1] Luenberger DG. Investment Science. New York: Oxford University Press, Inc; 2009

[2] Statistics South Africa. Mining: A Brief Summary. 2015. Available from: http://www.statssa.gov.za/

[3] Statistics South Africa. Statistics South Africa Home. 2016. Available from: http://www.statssa.gov.za/

[4] Statistics South Africa. Mining Industry. 2017. Available from: http:// www.statssa.gov.za/ [Accessed: 29 March 2017]

[5] PGM Market Review. 2017. Available from: http://www.platinum.matthey.c om/documents/new-item/pgm\%20ma rket\%20reports/pgm_market_report_ may_2017.pdf

[6] Mathews C. South Africa: Mining Investment Shows Recovery. Business day; 2007

[7] World Investment Report (WIR). Global Investment Trends: United Nations Conference on Trade and Development, Geneva; 2011

[8] Thai-Ha Le S, Chang Y. 2011. Available from: https://mpra.ub.unimuenchen.de/31795/1/Oil_and_Gold_ Correlation_or_causation_2011_yh_th. pdf

[9] Beckmann J, Berger T, Czudaj R. Gold Price Forecasts in a Dynamic Model Averaging Framework-Have the Determinants Changed Over Time? Ruhr Economic Papers 506, RWI 147; 2017. pp. $11-40$

[10] Madigan R. Australian Institute of Mining and Metallurgy; 1981

[11] Paul I, Sankaranarayanan K, Mekoth N. Customer satisfaction in retail stores: Theory and implications. International
Journal of Consumer Studies. 2016; 40(6):635-642

[12] Gomez M. Customer satisfaction and retail sales performance: An empirical investigation. Journal of Retailing. 2004;80(4):265-278

[13] De Cesari A, Espenlaub S, Khurshed A, Simkovic M. The effects of ownership and stock liquidity on the timing of repurchase transactions. Journal of Corporate Finance. 2012; 18(5):1023-1050

[14] Free State Provincial Government. Free State Growth Development Strategy, 2004-2014. 2005. Available from: www.fs.gov.za//FS\%20Prov\% 20Growth\%20Strt/FSGDS\%20Exec\% 20Summary\%20combine\%20foreword. doc Bloemfontein

[15] FoodBev SETA Council. Sector skills plan for the food and beverages manufacturing sector; 2011

[16] Bureau for Economic Research (BER). The macroeconomic impact of HIV/Aids under alternative intervention scenarios (with specific reference to ART) on the South African economy. South Africa: University of Stellenbosch; 2006

[17] Zhang D, Zhang X. Study on forecasting the stock market trend based on stochastic analysis method. International Journal of Business Management. 2009;4(6):163-170

[18] World Bank. Global financial development report 2014: Financial inclusion (English). Global financial development report. Washington, DC: World Bank Group; 2014. Available from: http://documents.worldbank.org/ curated/en/225251468330270218/Globa l-financial-development-report-2014-f inancial-inclusion 
Trade and Investment in South Africa

DOI: http://dx.doi.org/10.5772/intechopen.87186

[19] Seyoum B, Manyak TG. The impact of public and private sector transparency on foreign direct investment in developing countries. Critical Perspectives on International Business. 2009;5(3):187-206. DOI: 10.1108/17422040910974686

[20] Borenztein E, Gregorio J, Lee J. How does foreign direct investment affect economic growth? Journal of International Economics. 1998;45:

115-135 



\title{
China-Africa Investments and Economic Growth in Africa
}

\author{
Isaac Abekah-Koomson and Nwaba Eugene Chinweokwu
}

\begin{abstract}
China-Africa's economic cooperation has existed for decades. In this chapter, we observed the significance of China's FDI on economic growth, using two decades of FDI data. In the last decades, the economic growth of Africa has been impressive despite recurrent structural and technical issues. China's FDI stock relative to other economies has been growing, rapidly. How does it affect the performance of key macroeconomic indicators, particularly unemployment and export? Using the Pesaran Autoregressive Distributive lag (ARDL) model, there was a negative growth link between China's FDI to Africa and growth. However, the impacts of US FDI to Africa, China Export, and Imports from Africa were insignificant. The long-run effect of World FDI inflow to Africa reported a positive effect on growth. There was no evidence of Okun's law as unemployment increases with growth. For the Granger causality test, all macroeconomic indicators reported a uni-directional link with economic growth, except human capital and unemployment. It is recommended to shift FDI resources toward promoting labor-intensive programs because it has high employability compared to capital intensive programs. Pursuing the Pull Growth Model (PGM) technique will pull enough funds to support the growth of infrastructures and technical capacity development in the region.
\end{abstract}

Keywords: China, Africa, foreign direct investment (FDI), economic growth, macro-economic policy

\section{Introduction}

As the global economy expands, market activities grow and become more complex leading to product heterogeneity. Product heterogeneity increases the pace of competition which then leads to scarcity of resources. Partnerships become an official platform where economies cooperate mutually to boost trade and facilitate the flow of economic resources under less stringent rules. Non-partners are exempted from the rules and are made to go through all the complexities in trade and resource transfer.

Therefore, cooperations are developed to favor partners within a group. Strong economies help the weaker ones with favorable economic packages to sustain the partnership. China is a key player in partnership agreements. It has several economic engagements with both developed and less developed economies. It connects with Africa through what is known as the Forum on China-Africa Cooperation (FOCAC). FOCAC was established in 2000. Since it developments, several economic packages and investment programs have been developed to boost trade and infrastructural development in the region. 
FOCAC was not the first economic cooperation China has had with Africa. The long-standing friendship between China and Africa can be traced 600 years ago via the legendary expeditions of Chinese navigator Zheng He, whose fleet reached the East African shores four times. In the 1960s, China developed the TAZARA Railway line between Tanzania and Zambia, which served as a monument of what the two regions can achieve together. The cooperation did not progress further until the mid-1900s [1]. FOCAC is the most successful cooperation China has ever had with Africa.

The FOCAC has supported many growth initiatives in Africa, the latest project being "China One Belt Road or Maritime silk road initiatives," connecting Africa with railway and shipping link to major markets in the Middle East and Central Asia. Despite other interests, it is believed that China is much focused on developing infrastructural systems in Africa through the provision of loans and financial investment, hence a preferred partner for most African economies. Currently, China's investments are found in at least 46 countries in the region under different investment portfolios [2]. At least 2200 Chinese enterprises, both private and state-owned, are operating in Africa [3]. China's social program launched in 2013 has developed hundreds of educational projects, medical institutions, anti-malarial centers, and agricultural technologies [4]. China's banks, notably the People's Bank of China, the China Development Bank, and the Export-Import Bank of China (Exim Bank of China), have financed large-scale investment projects in Africa.

In addition to financing projects in Africa, China is also interested in sustaining its industrial program in the mainland. It has a strong manufacturing sector and a wider market share (both domestic and international), which requires constant resource and commodity supplies to sustain activities and supply its partners. With such a wider market share, China is scared of losing its activities because of the resource or commodity gap. It cannot have a sustainable operation without partnering with other resource-rich economies, hence cooperating with Africa. On the one hand, China's domestic resource and commodity capacities are currently under pressure because of higher demands. Africa, on the other hand, has vast resource and commodity potentials yet in a less industrialized zone. It has an emerging industrial sector facing infrastructural, technical, and funding challenges. The economy of China, however, is stronger in that sector, hence a good reason for a mutual partnership. China's technical competencies and industrial experiences can help Africa to build an effective industrial economy, while African resources and commodity potential can help sustain China's manufacturing sectors.

At this moment, China is well positioned to grow favorably. It has a large domestic and international market (due to growing population), efficient human capital, and a low-wage economy, which gives it a competitive edge over other industrialized economies. As a result of this, China attracts more industries and companies into its space. This reallocation has further raised the inflow of FDI into the economy and widened its position as a global leader in manufacturing activities, overtaking the US. It is now in high demand for resource and commodity supplies to feed anthropogenic activities. Through economic cooperation, China is partnering with resource-rich economies to boost supplies and to close the resource gap in the domestic economy [5].

China imports a significant part of its economic resources and commodity from Africa. It also has private companies operating in the agricultural and mining sectors. The resources and commodities produced are transferred to China to feed industries. Private businesses in Africa import processed and technical goods from China to feed and support domestic activities. Financial investment via loans supports infrastructural projects in Africa, hence reducing the financial burdens on the budget. China is Africa's major trading partner; it buys one-quarter of Africa's trade. 
China's energy demand has doubled in the last decades [6]. It buys at least one-third of African oil supplies, particularly from Egypt, Libya, and Tunisia, and Nigeria.

It also imports non-oil products from various parts of Africa (coal is imported from South Africa, ore from Gabon, timber from Equatorial Guinea, and copper from Zambia). Some local exporters export primary resources to China and in return import consumables such as textiles, pharmaceuticals, technological systems, and telecommunication to boost the small- and medium-scale sectors [7]. FOCAC is the key facilitator in all these activities. In 2012, Africa's total export ( $\$ 3.1$ billion) to China was one-third of China's total export to Africa ( $\$ 9.4$ billion). In 2011, it was four times the size of China's total export to Africa [8].

China imports more from Africa than what Africa imports from China. According to Figure 1, from 1995 to 2012, China's import by Africans was three times the size of China's export by Africans on average. In the same period, China's FDI inflow to Africa grew by 800 -fold. It was significantly high in 2008 , where it grew by 2000 -fold but dropped significantly in 500-fold in 2009. This was induced by the cascading effect of the global financial bubble. It later picked up massively in 2011 to 1200 -fold. On aggregate, China has invested about $\$ 40$ billion of FDI stocks in major African economies. About $\$ 13.8$ billion of the stock is capital injection, which went into infrastructural development. The inflows of African FDI to China from 1995 to 2000 grew about two-folds [9].

Foreign direct investment (FDI) is a key indicator of economic development. It stimulates the performance of the factor of production to boost economic growth [10]. It is a reliable source of technical resources and financial capital [11]. As a result of these, policies and programs are formulated to facilitate its movement across sectors [12]. FDI also promotes efficient output performance of the human capital [13]. It is considered the cheapest source of technical and financial capital to support growth [14]. In a broader spectrum, FDI's negotiations deepen group commitment, as investors prefer working with a group rather than a single economy [14].

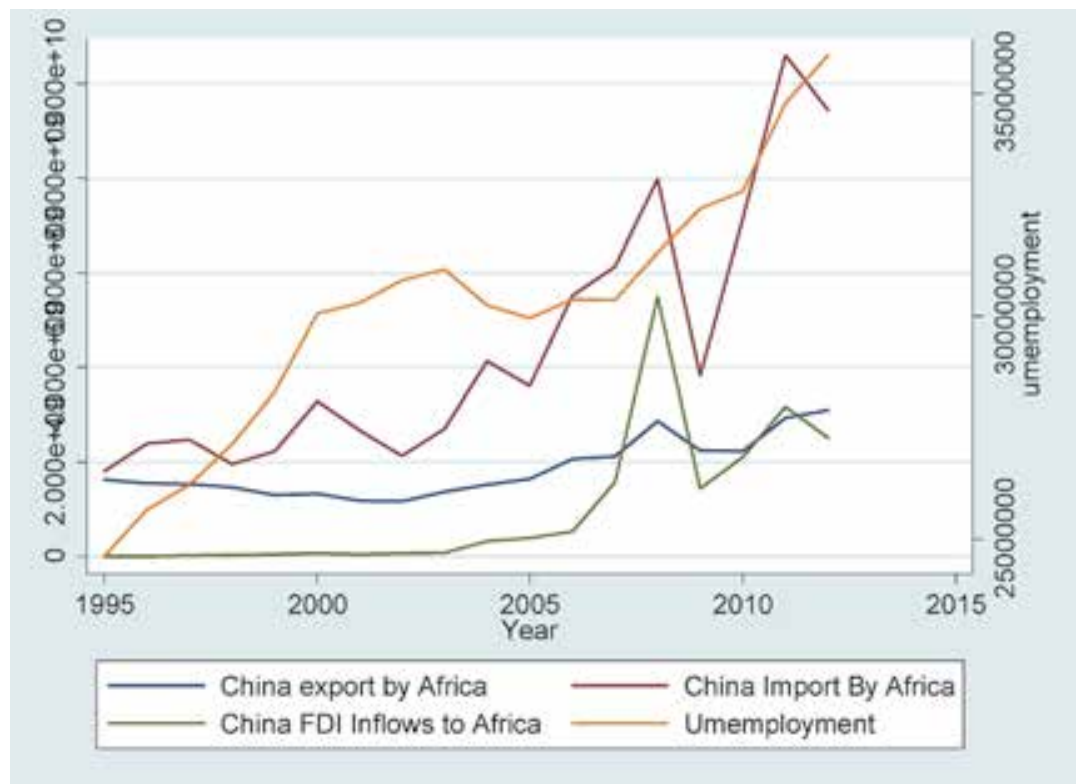

Figure 1.

Shows the pattern of China's export by Africans, China's import by Africans, China's FDI inflows to Africa, and unemployment. Sources: China Statistical Year Book 2012, and World Development Indicator (WDI). 
Developing economies receive FDIs from various regions but they gain less from it because of institutional and infrastructural challenges. An economy with an established institutions and proper infrastructural systems is able to coordinate effectively with the flow of FDI [15-17]. In such economies, FDIs are properly allocated without compromising activities of local investors. FDIs are directed into areas of the economy where local investors have limited capacities to operate, thus widening the economic scope $[18,19]$. Investors' confidence is high in such economies because of low operational cost and high investment returns.

A dysfunctional institution creates unhealthy competition between foreign and local investors [20]. Unhealthy competition freezes the activities of local investors causing them to exit the market (because of capital and skills disadvantage), creating a foreign-dominated market. An effective institution properly coordinates FDI inflows across all sectors. According to the World Investment Report (WIR) (2012), about $60 \%$ of FDI inflows in Africa go to capital intensive activities such as mining and oil and gas activities [21]. Capital intensive requires high capitalization which the local investors have no capacity to operate.

A review of growth literature highlights some studies on FDI. They examined the key determinants of FDI at the national level. Similar to what we highlighted in the foregone paragraph, institutions and infrastructure are the main prerequisite for affective FDI programs. For instance, Adewuni [1] examined Nigeria-China economic cooperation. The findings revealed a less than expected growth between FDI and economic growth, citing institutions and infrastructural and human capital as the main challenges. Kamara [21] in broader studies examined several Sub-Sahara African (SSA) economies. Busse and Groizard [15] also examined a national economy. Despite finding a positive growth relationship between FDI and economic growth, the finding also cited low human capital and weak infrastructural systems as the main drawbacks. However, AbuAl-Foul [22] found mixed outcomes in a dicountry study between Morocco and Tunisia. The economy of Morocco experienced a resilient growth link between FDI and growth while the economy of Tunisia experienced otherwise. All the studies gave insights in understanding FDI-growth relation, particularly at the national level [22]. However, there remains a gap at the regional level that needs to be filled.

This chapter is examining Africa regional economy, looking at the impact of key macroeconomic indicators particularly China's FDI on regional economic growth using at least two decades of data. The remaining macroeconomic indicators include export, import, unemployment, and trade openness. Furthermore, the chapter is examining the impact of World and US FDI inflow on African economic growth using Granger causality test and autoregressive distributed lag (ARDL) model. The ARDL model will help test the short- and long-run effects of FDI on economic growth. Granger causality technique will help examine the causal relationship between economic growth and all the macroeconomic indicators. Finally, the chapter will look at whether Okun's law exists between unemployment and economic growth.

The outcome of this chapter has a two-fold effect; (1) inform policy regulators about the actual empirical behavior of China's FDI on economic growth in Sub-Sahara Africa, (2) Policy regulators will be able to make effective allocation of FDI resources to areas of greater impact in the economy. The recommendation session will offer some practical guidelines or policies that will boost the benefits of FDIs in creating jobs and reducing inequalities.

The rest of the chapter is organized as follows. Section two explains the methods (i.e. Autoregressive Distributed Lag (ARDL) and Granger Causality) Section three 
explains materials and methods for the analysis. Section four explains results and analysis. Section five offers conclusion and policy recommendations.

\section{Model}

\subsection{Bound testing technique}

The vector auto-regression (VAR) of order $\mathrm{p}$, denoted VAR (p), is expressed as the following [23]:

$$
\mathrm{Y}_{\mathrm{t}}=\mathrm{a}+\sum_{\mathrm{i}=1}^{\rho} \varnothing_{\mathrm{i}} \mathrm{Y}_{\mathrm{t}-\mathrm{i}}+\sum_{\mathrm{i}=1}^{\rho} \theta_{1} \mathrm{X}_{\mathrm{t}}+\varepsilon_{\mathrm{t}}
$$

where $y_{t}$ is the dependent variable presented by economic growth (RGDP), $x_{t}$ is a vector matrix representing explanatory variables, i.e., trade openness (OPENN), China's FDI inflow to Africa (CFDIITA), US FDI inflow to Africa (USFDIITA), China's export by Africa (CEBA), China's import by Africa (CIBA), $t$ is trend variable, and others. According to bound model, $y_{t}$ must be an $I(1)$ variable, but the independent variable $x_{t}$ must be stationary at either $I(0)$ or $I(1)$.

The vector error correction model (VECM) is expressed as follows:

$$
\Delta \mathrm{Y}_{\mathrm{t}}=\mathrm{a}_{\mathrm{t}}+\delta_{\mathrm{t}}+\lambda \mathrm{Y}_{\mathrm{t}-1}+\sum_{\mathrm{i}=1}^{\rho} \varnothing_{1} \Delta \mathrm{Y}_{\mathrm{t}-\mathrm{i}}+\sum_{\mathrm{i}=1}^{\rho-1} \theta_{1} \Delta \mathrm{X}_{\mathrm{t}-1}+\varepsilon_{\mathrm{t}}
$$

where $\Delta$ is the first-difference order and $\lambda$ represents the long-run multiplier matrix as follows:

$$
\lambda=\left|\begin{array}{cc}
\lambda_{\mathrm{yy}} & \lambda_{\mathrm{yx}} \\
\lambda_{\mathrm{xy}} & \lambda_{\mathrm{xx}}
\end{array}\right|
$$

The diagonal elements of Eq. (4) are unrestricted, so the selected series can be either $\mathrm{I}(0)$ or I(1). If, then $\mathrm{Y}$ is I(1). In contrast, if, then $\mathrm{Y}$ is $\mathrm{I}(0)$.

Eq. 2 is expanded to include all the regressors for the study, as shown below for later bound testing after estimation.

$$
\begin{aligned}
& \Delta \ln \mathrm{RGDP}_{\mathrm{t}}=\mathrm{a}_{\mathrm{t}}+\sum_{\mathrm{i}=1}^{\mathrm{p}} \varnothing_{\mathrm{i}} \Delta \ln \operatorname{RGDP}_{\mathrm{t}-\mathrm{i}}+\sum_{\mathrm{i}=0}^{\mathrm{p}} \theta_{\mathrm{i}} \Delta \ln \mathrm{OPENN}_{\mathrm{t}-\mathrm{i}}+\sum_{\mathrm{i}=0}^{\mathrm{p}} \gamma_{\mathrm{i}} \Delta \ln \operatorname{lnSE}_{\mathrm{t}-\mathrm{i}} \\
& +\sum_{\mathrm{i}=0}^{\mathrm{p}} \varphi_{\mathrm{i}} \Delta \ln \mathrm{CEBA}_{\mathrm{t}-\mathrm{i}}+\sum_{\mathrm{i}=0}^{\mathrm{p}} \rho_{\mathrm{i}} \Delta \operatorname{lnCIBA}_{\mathrm{t}-\mathrm{i}}+\sum_{\mathrm{i}=0}^{\mathrm{p}} \delta_{\mathrm{i}} \Delta \ln \text { AFDIOTTW }_{\mathrm{t}-\mathrm{i}} \\
& +\sum_{\mathrm{i}=0}^{\mathrm{p}} \vartheta_{\mathrm{i}} \Delta \ln \mathrm{CFDIITA}_{\mathrm{t}-\mathrm{i}}+\sum_{\mathrm{i}=0}^{\mathrm{p}} \nexists_{\mathrm{i}} \Delta \ln \text { FDIITA }_{\mathrm{t}-\mathrm{i}} \\
& +\sum_{\mathrm{i}=0}^{\mathrm{p}} \in_{\mathrm{i}} \Delta \ln \text { USFDIITA }_{\mathrm{t}-\mathrm{i}}+\pi_{1} \ln \mathrm{RGDP}_{\mathrm{t}}+\pi_{2} \ln \text { OPENN }_{\mathrm{t}} \\
& +\pi_{3} \ln \mathrm{SSE}_{\mathrm{t}}+\pi_{4} \ln \mathrm{CEBA}_{\mathrm{t}}+\pi_{5} \operatorname{lnCIBA}_{\mathrm{t}}+\pi_{6} \ln \mathrm{AFDIOTTW}_{\mathrm{t}} \\
& +\pi_{7} \operatorname{lnCFDIITA} A_{t}+\pi_{8} \ln \text { FDIITA }_{t}+\pi_{g} \ln \text { USFDIITA }_{t}+\varepsilon_{\mathrm{t}}
\end{aligned}
$$


where $\varnothing_{\mathrm{i}}, \theta_{\mathrm{i}}, \gamma, \vartheta_{\mathrm{i}}, \vartheta_{\mathrm{i}}, \nexists_{\mathrm{i}}, \in_{\mathrm{i}}, \rho_{\mathrm{i}}, \delta_{\mathrm{i}}$, and $\varphi_{\mathrm{i}}$ are short-run coefficients for the model and $\pi_{1}, \pi_{2}, \pi_{3}, \pi_{4}, \pi_{5}, \pi_{6}, \pi_{7}, \pi_{8}, \pi_{9}, \pi_{10}$ are long-run coefficients.

Eq. (4) also can be viewed as an ARDL of order (p, q, r). Eq. (4) indicates that economic growth tends to be influenced and explained by its past values. The structural lags are established by using minimum Akaike's information criteria (AIC). After regression of Eq. (4), the Wald test (F-statistic) is used to test the long-run coefficient to check whether it is significant or not.

According to Pesaran et al. [23], the null and alternative hypotheses can be read as follows:

$$
\begin{gathered}
\mathrm{H}_{0}=\pi_{1}=\pi_{2}=\pi_{3}=\pi_{4} \ldots \ldots \ldots \ldots \ldots . \pi_{10}=0 \text { (NO LR Association) } \\
\mathrm{H}_{0} \neq \pi_{1} \neq \pi_{2} \neq \pi_{3} \neq \pi_{4} \ldots \ldots \ldots \ldots \ldots \ldots . \pi_{10} \neq 0 \text { (LR Association) }
\end{gathered}
$$

The computed F-statistic value will be evaluated with the critical values tabulated in Table CI (iii) of Pesaran et al. [23] paper. As explained in Table CI (iii), the lower bound critical values assume the explanatory variables are integrated of order 0 , or I(0), while the upper bound critical values assume the explanatory variables are integrated of order one, or I(1). Therefore, if the computed F-statistic is smaller than the lower bound value, then the null hypothesis is not rejected, which implies that there is no long-run relationship between economic growth and its determinants. However, if the computed F-statistic is greater than the upper bound value, then there is a long-run relationship between economic growth and its determinants. But, if the computed F-statistic falls between the lower and upper bound values, then the results are inconclusive.

\subsection{Granger causality}

Granger causality analysis is an analytical tool for examining whether a one-time series can correctly predict the other [21]. It is built on the premise that the future cannot predict the past because time does not travel backward. Theoretically, lag term of the independent variable is introduced into the model to statistically improve its prediction on the dependent variable as shown below:

$$
\begin{aligned}
& \mathrm{Y}_{\mathrm{t}}=\sum_{\mathrm{n}=1}^{\rho} \varnothing_{\mathrm{n}} \mathrm{Y}_{\mathrm{t}-\rho}+\sum_{\mathrm{n}=1}^{\rho} \delta_{\mathrm{n}} \mathrm{X}_{\mathrm{t}-\rho}+\varepsilon_{\mathrm{t}} \\
& \mathrm{X}_{\mathrm{t}}=\sum_{\mathrm{n}=1}^{\rho} \gamma_{\mathrm{n}} \mathrm{X}_{\mathrm{t}-\rho}+\sum_{\mathrm{n}=1}^{\rho} \varphi_{\mathrm{n}} \mathrm{X}_{\mathrm{t}-\mathrm{i}}+\epsilon_{\mathrm{t}}
\end{aligned}
$$

where $Y_{t}$ and $X_{t}$ represent the two time series at t. $X_{(t-p)}$ and $Y_{(t-p)}$ represent the time series at time $\mathrm{t}-\mathrm{p}$, and $\mathrm{p}$ represents the number of lagged time points (order). $\varnothing_{\mathrm{n}}$ and $\gamma_{\mathrm{n}}$ are signed path coefficients. $\delta_{\mathrm{n}}$ and $\varphi_{\mathrm{n}}$ are autoregression coefficients, while $\varepsilon_{\mathrm{t}}$ and $\epsilon_{\mathrm{t}}$ are residuals.

Peculiar to this study, mathematically, we introduce the lag of each series such as China's FDI inflows to Africa (CFDIITA), China's export to Africa (CEBA), China's import to Africa (CIBA), US FDI inflows to Africa (USFDIITA), openness (OPEN), and secondary enrolment (SSE) into equations for better prediction. Our model is thus expressed as follows: 


$$
\begin{aligned}
& \ln \operatorname{RGDP}_{\mathrm{t}}=\mathrm{a}+\sum_{\mathrm{i}=1}^{\mathrm{p}} \varnothing_{\mathrm{i}} \operatorname{lnRGDP} \mathrm{t}_{\mathrm{t}-\mathrm{i}}+\sum_{\mathrm{i}=0}^{\mathrm{p}} \theta_{\mathrm{i}} \ln \operatorname{OPENN}_{\mathrm{t}-\mathrm{i}}+\varepsilon_{\mathrm{t}} \\
& \ln \text { OPENN }_{\mathrm{t}}=\mathrm{a}+\sum_{\mathrm{i}=1}^{\mathrm{p}} \varnothing_{\mathrm{i}} \operatorname{lnRGDP} \mathrm{t-i}+\sum_{\mathrm{i}=0}^{\mathrm{p}} \theta_{\mathrm{i}} \ln \mathrm{OPENN}_{\mathrm{t}-\mathrm{i}}+\varepsilon_{\mathrm{t}} \\
& \operatorname{lnlnSSE} E_{t}=\mathrm{a}+\sum_{\mathrm{i}=1}^{\mathrm{p}} \varnothing_{\mathrm{i}} \operatorname{lnRGDP} \mathrm{P}_{\mathrm{t}-\mathrm{i}}+\sum_{\mathrm{i}=0}^{\mathrm{p}} \gamma_{\mathrm{i}} \operatorname{lnSSE_{\mathrm {t}-\mathrm {i}}}+\varepsilon_{\mathrm{t}} \\
& \ln \mathrm{CEBA}_{\mathrm{t}}=\mathrm{a}+\sum_{\mathrm{i}=1}^{\mathrm{p}} \varnothing_{\mathrm{i}} \ln \operatorname{lnGDP}_{\mathrm{t}-\mathrm{i}}+\sum_{\mathrm{i}=0}^{\mathrm{p}} \varphi_{\mathrm{i}} \ln \mathrm{CEBA}_{\mathrm{t}-\mathrm{i}}+\varepsilon_{\mathrm{t}} \\
& \ln \mathrm{CIBA}_{\mathrm{t}}=\mathrm{a}+\sum_{\mathrm{i}=1}^{\mathrm{p}} \varnothing_{\mathrm{i}} \operatorname{lnRGDP} \mathrm{P}_{\mathrm{t}-\mathrm{i}}+\sum_{\mathrm{i}=0}^{\mathrm{p}} \alpha_{\mathrm{i}} \ln \operatorname{CIBA}_{\mathrm{t}-\mathrm{i}}++\varepsilon_{\mathrm{t}} \\
& \ln \text { AFDIOTTW }_{\mathrm{t}}=\mathrm{a}+\sum_{\mathrm{i}=1}^{\mathrm{p}} \varnothing_{\mathrm{i}} \operatorname{lnRGDP}_{\mathrm{t}-\mathrm{i}}+\sum_{\mathrm{i}=0}^{\mathrm{p}} \delta_{\mathrm{i}} \ln \text { AFDIOTTW }_{\mathrm{t}-\mathrm{i}}+\varepsilon_{\mathrm{t}} \\
& \ln \text { CFDIITA }_{t}=\mathrm{a}+\sum_{\mathrm{i}=1}^{\mathrm{p}} \varnothing_{\mathrm{i}} \ln \operatorname{lnGDP}_{\mathrm{t}-\mathrm{i}}+\sum_{\mathrm{i}=0}^{\mathrm{p}} \vartheta_{\mathrm{i}} \operatorname{lnCFDIITA} \mathrm{t}_{\mathrm{t}-\mathrm{i}}+\varepsilon_{\mathrm{t}} \\
& \ln \text { FDIITA }_{\mathrm{t}}=\mathrm{a}+\sum_{\mathrm{i}=1}^{\mathrm{p}} \varnothing_{\mathrm{i}} \ln \operatorname{RGDP}_{\mathrm{t}-\mathrm{i}}+\sum_{\mathrm{i}=0}^{\mathrm{p}} \nexists_{\mathrm{i}} \ln \text { FDIITA }_{\mathrm{t}-\mathrm{i}}+\varepsilon_{\mathrm{t}} \\
& \ln \text { USFDIITA }_{\mathrm{t}}=\mathrm{a}+\sum_{\mathrm{i}=1}^{\mathrm{p}} \varnothing_{\mathrm{i}} \operatorname{lnRGDP} \mathrm{t}_{-\mathrm{i}}+\sum_{\mathrm{i}=0}^{\mathrm{p}} \in_{\mathrm{i}} \ln \mathrm{USFDIITA}_{\mathrm{t}-\mathrm{i}}+\varepsilon_{\mathrm{t}}
\end{aligned}
$$

\section{Materials and method}

The research considered point annual FDI data but not accumulated stock data. Two models were used for the estimation, GMM and Granger causality method.

\subsection{Data and analysis}

As a policy-based paper, the purpose of this chapter is to find an empirical justification for what has become a popular dialog in the economic environment, "China sudden interest in Africa." Has China's increasing presence in Africa via bilateral trade and investment link during the last two decades impacted significantly on Africa's macroeconomic indicators such as GDP per capita, unemployment, and human capital development. Considering Okun's law, there a link between economic growth and unemployment in the region? These questions arise because of the growing domination of China's investment in Africa vice verse that of the United States. Is the supposedly China's economic motive plan more effective and receptive to African economies than the US in addition to political motive? The latter will be addressed in detail in the next chapter.

However, this Chapter is looking at the impact of FDI on key macroeconomic indicators in Africa using over decades of time series data from 1990 to 2014. The series include China's FDI inflow to Africa, China's Export to Africa, China's import from Africa, Secondary School Enrollment (SSE) (a measure of human capital), openness index, US FDI Inflows to Africa (USFDITA), World FDI inflows to Africa (WFDIITA) and African Investment Outflows to the World (AIOTTW). Annual 


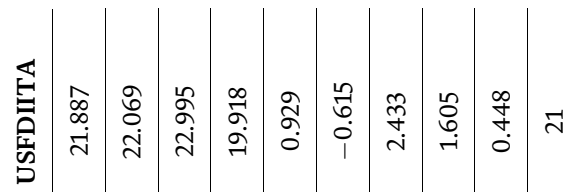

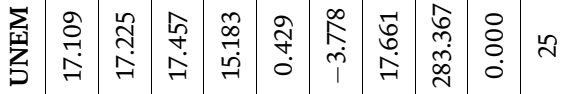

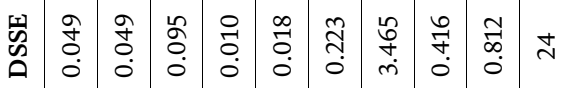

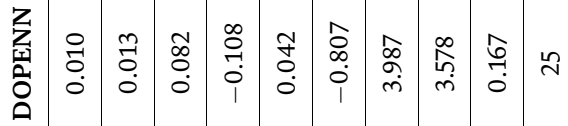

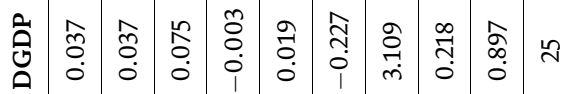



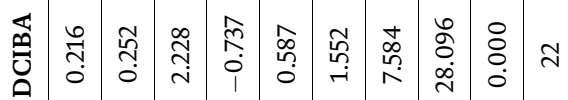

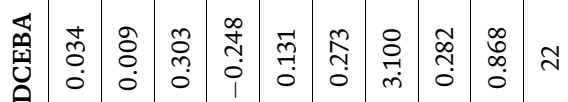

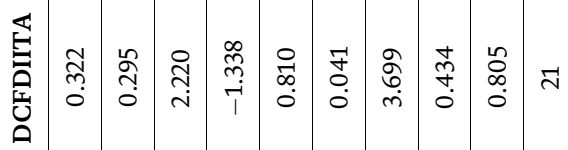

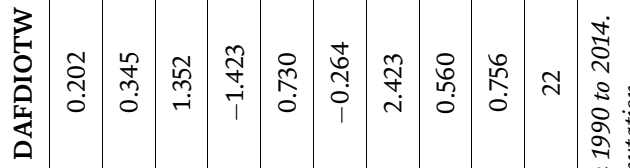

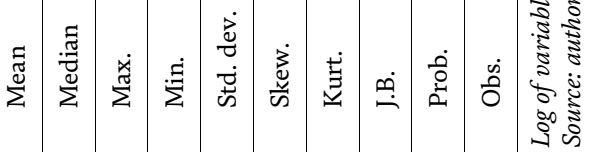

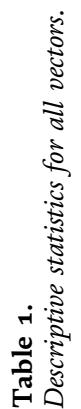




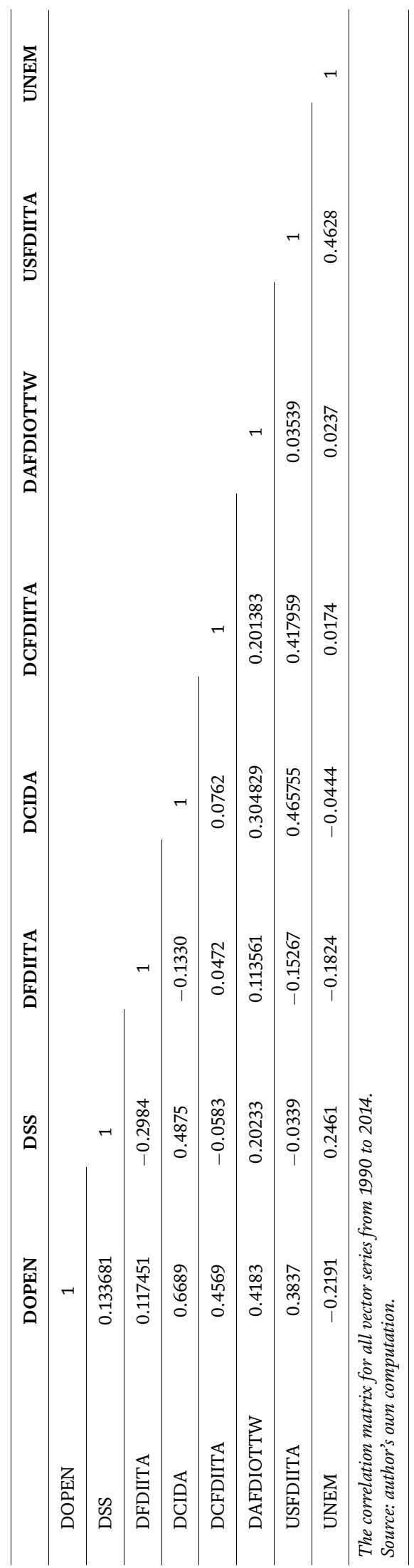



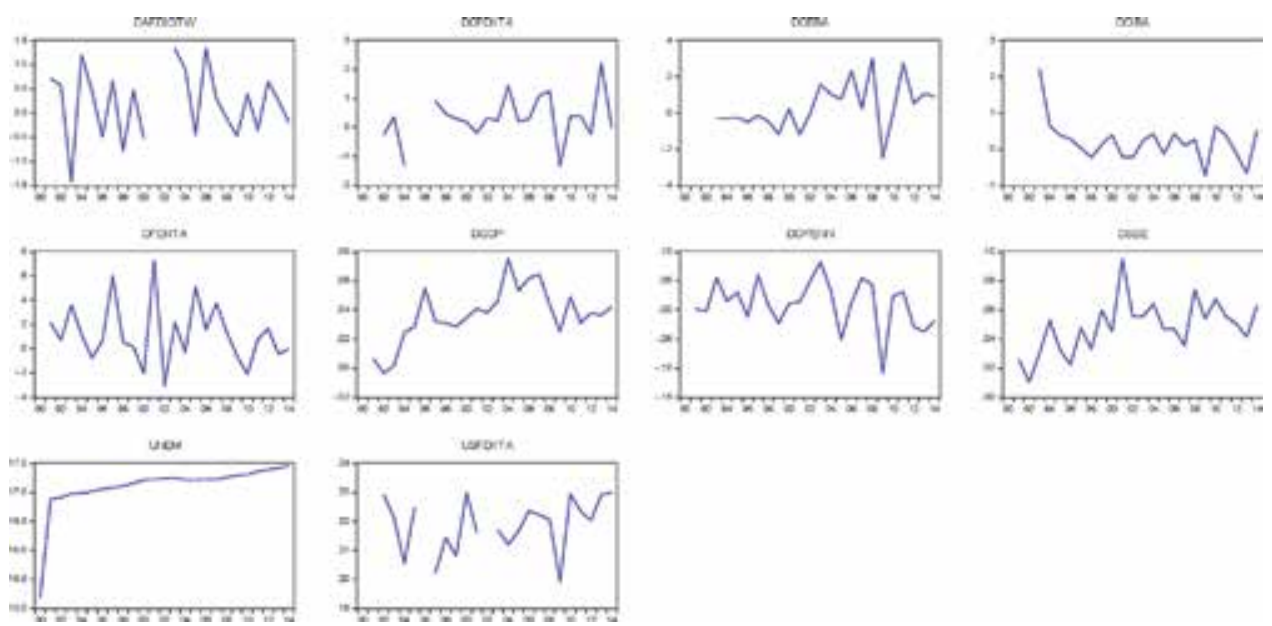

Figure 2.

Shows the unit root testing results for each of the series using the augmented Dickey-Fuller (ADF) technique. The series were stationary at different levels (either at $I(0)$ or $I(I)$ ). The gaps represent missing data.

FDI series (rather than FDI stock ${ }^{1}$ ) is used in the analysis. Real GDP ${ }^{2}$, served as the dependable variable, a measure of economic growth. ${ }^{3}$ Trade openness stimulates economic growth.

Table 1 shows the log description of the vector series. The average mean of real GDP is 0.037 , less than the average mean of all regressors except China's export to Africa (CEBA) and openness (OPEN), which estimated average mean values of 0.034 and 0.010 , respectively. The standard variance of all vectors is relatively a higher mean, suggesting high variation within vector indicators. Except for CIBA and UNEM, other vectors are not normally distributed (look at the Jarque-Bera test, they are not significant at $5 \%$ ). In Table 2 , there is a lower correlation between variables, suggesting a lower chance of perfect multicollinearity (Figure 2).

Figure 1 shows the log stationary for each series for the Africa economy forms the period 1990 to 2010 employing the augmented Dickey-Fuller unit root test. We found a stationary path for all vector series at first difference I(1) except for UNEM and USFDIITA. The break within AFDIOTW, USFDIITA, and CFDIITA stationary paths was due to missing data series. CFDIITA, CIBA, USFDIITA, and CEBA also lost some data at the beginning.

\section{Results analysis}

In this session, the analysis was based on the Pesaran [23] autoregressive distributed lag (ARDL) technique. There are two phases in the model: the long run and the short run [23]. Using real GDP (proxy by economic growth) as a dependent variable, the finding for both phases is presented in Table 3.

Given the principle of ARDL model, each series must be either be stationary at first different I(1) or at the level I(0). According to Dickey-Fuller unit root test in Figure 1, all the series satisfied the ARDL condition, i.e., I(0) or I(1). For instance,

\footnotetext{
${ }^{1}$ It is broader and includes previous reserves and capital invested.

${ }^{2}$ GDP is a domestic-based indicator that measures the monetary value of all the finished goods and services produced within a country's borders in a specific time.

${ }^{3}$ Some use net export.
} 
China-Africa Investments and Economic Growth in Africa

DOI: http://dx.doi.org/10.5772/intechopen.89444

\begin{tabular}{|c|c|c|c|}
\hline Variables & Short-run coefficients & Variables & Long-run coefficients \\
\hline Constant term & $-1100(-6.080)$ & & \\
\hline $\mathrm{D}(\operatorname{RGDP}(-1))$ & $0.989(-0.232)$ & $\mathrm{D}(\mathrm{RGD})$ & $-0.792(-0.193)$ \\
\hline $\mathrm{D}(\mathrm{CEBA}(-1))$ & $-8.513(-3.502)$ & $\mathrm{D}(\mathrm{CEBA})$ & $49.783(-13.383)$ \\
\hline $\mathrm{D}(\mathrm{CFDITA}(-1))$ & $-4.518(0.712)^{*}$ & $\mathrm{D}$ (CFDITA) & $-8.865(1.579)^{*}$ \\
\hline $\mathrm{D}(\mathrm{OPEN}(-1))$ & $-8.908(-8.597)$ & $\mathrm{D}(\mathrm{OPEN})$ & $-8.975(-8.500)$ \\
\hline $\mathrm{D}(\operatorname{UNEMP}(-1))$ & $59.566(-12.056)$ & D(UNEMP) & $942.98(182.909)^{*}$ \\
\hline D(USFDIITA $(-1))$ & $0.658(-0.518)$ & D(USFDIITA) & $0.026(-0.770)$ \\
\hline $\mathrm{D}(\operatorname{SSE}(-1))$ & $-1026.498(-420.350)$ & $\mathrm{D}(\mathrm{SSE})$ & $170.536(363.717)^{*}$ \\
\hline $\mathrm{D}(\operatorname{FDIITA}(-1))$ & $1.783(0.3554)^{*}$ & D(FDIITA) & $-0.0124(-0.660)$ \\
\hline $\mathrm{D}(\mathrm{CIBA}(-1))$ & $0.687(-2.641)$ & $\mathrm{D}(\mathrm{CIBA})$ & $-13.413(-3.304)$ \\
\hline D(AFDIOTTW $(-1))$ & $-0.654(-1.272)$ & D(AFDIOTTW $)$ & $5.798(-2.563)$ \\
\hline R-squared & 0.896 & R-squared & OBS: 23 \\
\hline F-computed & 2.959 & & F-computed:18.94 \\
\hline \multicolumn{4}{|c|}{$\begin{array}{l}\text { Real GDP as dependent variable (Model } 1) . \\
\text { Absolute lower } I(0) \text { and upper bound value I(1) of } 2.86 \text { and } 5.03 . \text { The standard errors are reported in brackets. } \\
\text { Significance levels: }{ }^{* * *} \text { if } p<1 \%,{ }^{* *} \text { if } p<5 \% . \text { and }{ }^{*} \text { if } p<10 \%[22] . \\
\text { Source: author's computation. }\end{array}$} \\
\hline
\end{tabular}

Table 3.

Dynamic ARDL Model Result.

unemployment (UNEM) and US FDI inflow to Africa (USFDIITA) were stationary at the level I(0), while RGDP, China's export to Africa (CEBA), China's FDI to Africa (CFDIITA), openness (OPENN), secondary school enrollment (SSE), China's import from Africa (CIBA), Africa FDI outflow to the World (AFDIOTTW), and FDI inflow to Africa (FDIITA) were stationary at I(1). Furthermore, all the models satisfied the conditions for multicollinearity, i.e., there is no serial correlation.

In Pesaran (2001), there are predefined critical values for making a statistical decision for the ARDL short- and long-run parameters [25]. There are different critical values for different significant levels depending on the structure of the model. Essential to this analysis is the critical values highlighted in Pesaran (2001), Table CII (iii) of page 303. It has an unrestricted intercept and no trend condition. At a 5\% critical value, using ten (10) parameters point, Pesaran (2001) predefined the critical values in Table CII (iii). According to Table 3, critical values of 2.86 and 5.03 are decision results for an absolute lower $\mathrm{I}(0)$ and upper bound value $\mathrm{I}(1)$. 
In Table 3, the dynamic model presented a computed F-value of 2.9595 for the short run. Based on the decision rule, it falls on the indecisive region, suggesting that China-Africa economic cooperation over the decades (in the short run) has not shown a significant effect on economic growth, i.e., indeterminate. Therefore, a lot is expected to be done for Africa's economic growth to experience the significance of China's FDI to Africa, China's export and import to Africa, US FDI to Africa, and Africa openness policies in the short run.

However, some selective series reported a decisive outcome. For example, Fcomputed value (22.47) for China's FDI inflows to Africa (CFDIITA) and FDI to Africa (FDIITA) critical value fell above the upper bound limit (5.03), suggesting a significant effect on regional economic growth. This is consistent with the theory that states that FDI stimulates growth [22]. This analysis has shown the significance of China's FDI on African growth.

In Table 3, in the long run, the F-computed value (18.94) fell above the upper limit of Pesaran [23] critical value (5.03), (i.e., it is in the acceptance region). The result suggests that overall change in all the series has a significant effect on economic growth. The estimated F-value (14.677) of unemployment, secondary school enrollment, and China's FDI to Africa is above the upper limit of the critical value, hence has a significant effect on economic growth. On this account, a change in China's FDI to Africa (CFDIITA) in the long-run will generally boost regional economic growth.

An individual analysis of each series or indicator reported different outcomes. In Table 3, all the series except China's FDI Inflows to Africa (CFDIITA) and Unemployment (UNEMP) in the long-run experienced an insignificant relationship with regional economic growth (at 5\%). The impact of UNEMP on economic growth was positive at $5 \%$. Highlighting the significance of education in economic development. A change in the quality of human capital will further boost regional economic growth.

Concerning China's FDI to Africa (CFDITA) series, in the long-run, a change leads to a fall in economic growth. A similar outcome was estimated in the shortrun. These outcomes give policy regulators a fair notion about the behavior of Chinese investments in Africa. If the evidence is considered enough, African economies must question the credibility of the investment. A contrary outcome was assumed before the analysis because of Chinese investment domination vice versa other developed economies. On this caveat, policy regulators in the region must review Chinese economic potentials and effectively attract investments from areas they have a comparative advantage or greater efficiencies that will benefit African economies. When successfully achieved, African economies will gain favorably from Chinese growing investments in the region. In the immediate term, governments across Africa can push most of China's FDI into developing labor-intensive programs or value addition industrial activities.

In model 1, a change in unemployment leads to a decline in economic growth in the long run. On the contrary, economic growth widens the unemployment gap in the region. This shows the lack of consistency between the flow of FDI and how it is applied in reducing unemployment. Mis allocation of investment harms development and widens the gap in inequalities and unemployment. Unemployment is a leakage in development and can affect economic growth negatively if loosely handled. Currently, at least $20 \%$ of the regional population remains unemployed. This paints a glooming picture for the region's future development if practical steps are not proposed today to boost job creation.

In Table 4, the impact of World FDI inflow in Africa (FDIIITA) on economic growth was positive. African FDI outflow to the World (AFDIOTTW) was found to have a positive effect on economic growth. On the contrary, the US FDI Inflows to 
China-Africa Investments and Economic Growth in Africa

DOI: http://dx.doi.org/10.5772/intechopen.89444

\begin{tabular}{|c|c|}
\hline & Static model 2 \\
\hline Variables & OLS regression \\
\hline \multirow[t]{2}{*}{ Constant term } & $22 . .900$ \\
\hline & $(350.941)^{* *}$ \\
\hline \multirow[t]{2}{*}{$\mathrm{D}(\mathrm{CEBA})$} & -14.446 \\
\hline & $(-8.226)$ \\
\hline \multirow[t]{2}{*}{$\mathrm{D}$ (CFDITA) } & -0.262 \\
\hline & $(-0.966)$ \\
\hline \multirow[t]{2}{*}{$\mathrm{D}(\mathrm{OPEN})$} & -9.240 \\
\hline & $(7.734)$ \\
\hline \multirow[t]{2}{*}{ D(UNEMP) } & -397.358 \\
\hline & -815.034 \\
\hline \multirow[t]{2}{*}{ D(USFDIITA) } & 0.884 \\
\hline & -0.948 \\
\hline \multirow[t]{2}{*}{$\mathrm{D}$ (SSE) } & 175.769 \\
\hline & $(99.78)^{* *}$ \\
\hline \multirow[t]{2}{*}{ D(FDIITA) } & 2.217 \\
\hline & $(0.523)^{* *}$ \\
\hline \multirow[t]{2}{*}{$\mathrm{D}(\mathrm{CIBA})$} & 2.453 \\
\hline & -2.591 \\
\hline \multirow[t]{2}{*}{ D(AFDIOTTW) } & 3.567 \\
\hline & $(1.438)^{*}$ \\
\hline R-SQUARED: & 23 \\
\hline $\begin{array}{l}\text { he standard errors re } \\
\text { ource: author's comp }\end{array}$ & $p<5 \%$, and ${ }^{*}$ if $p<10 \%$. \\
\hline
\end{tabular}

Table 4 .

Static Model-Real GDP as Dependent Variable.

Africa (USFDIITA), China's Export to Africa (CEBA), and China's Import to Africa (CIBA) reported an insignificant effect on economic growth. The effect of openness (OPENN) was also insignificant. The latter does not imply African economies are closed or are not fully integrated into the global economy but rather suggests that less is gained from external participation. The majority of the exporting activities are primary-based. Primary-based activities have lower economic returns compared to capital or processed activities. In the last decade, the net wealth of African global trade inclusiveness was less than $10 \%$. This figure is small compared to the combined volume of China and the United States, about $18 \%$ of world trade. Meanwhile, Africa is a significant player in the commodity and resource activities (led by Equatorial Guinea, Nigeria, Liberia, Kenya, Botswana, and Tunisia; mining: Ghana, South Africa, and others).

The US FDI inflow to Africa was found to be insignificant on African economic growth. This is due to the US losing interest in the African economy. The US FDI stock is by far the highest in African compared to China. But lately, it is declining while that of China is rising because of increasing China's interest in Africa. It is argued that the model of operation in Africa by China businesses is very much liked by the national governments because it is mainly economic. The US model, on the 
other hand, has a strong element of political interference which is not very much liked by the national governments. But research shows that a stable environment promotes an effective growth [24].

\subsection{Granger causality test}

Granger causality test is used for forecasting between two series in an analysis. When two series are co-integrated then, there is likelihood of causality in at least one of the directions [25]. For instance, FDI and GDP are co-related, which implies that a change in one can cause the other to change, vice versa. To observe empirically the causality test for all the series in this study, Granger causality technique was employed. The results are presented in Table 5. Conclusively, there are situations of a unidirectional effect for some of the series.

Table 5 summarizes the results for each series. According to Table 5 , there is a uni-directional causality link between China's Export by Africa (CEBA), openness (OPEN), Africa's FDI Outflow Around the World (AFDIOTW), China's Import from Africa (CIBA), and China's FDI inflow to Africa (CFDIITA) on economic growth (GDP). This suggests that a change in any of the determinants or indicators will influence regional economic growth (but the reserve is not certain). As a result of this, proper allocation of FDI inflow from various sources including those from China and the US will directly boost regional economic growth. This certainly shows that Chinese investment in Africa is adding more to development. The ARDL findings in Table 3 confirm this situation.

\begin{tabular}{|c|c|c|c|}
\hline Variable & & F-stats & Prob. \\
\hline OPEN does not Granger cause RGDP & 24 & 8.19958 & 0.0093 \\
\hline RGDP does not Granger cause OPENN & & 0.01898 & 0.8917 \\
\hline CIBA does not Granger cause RGDP & 24 & 0.44314 & 0.5129 \\
\hline RGDP does not Granger cause CIBA & & 15.4376 & 0.0008 \\
\hline AFDIOTTW does not Granger cause RGDP & 24 & 2.47903 & 0.1303 \\
\hline RGDP does not Granger cause AFDIOTTW & & 8.51158 & 0.0082 \\
\hline CEBA does not Granger cause RGDP & 24 & 0.12593 & 0.7262 \\
\hline RGDP does not Granger cause CEBA & & 7.86194 & 0.0106 \\
\hline CFDIITA does not Granger cause RGDP & 24 & 0.90823 & 0.3514 \\
\hline RGDP does not Granger cause CFDIITA & & 5.13697 & 0.0341 \\
\hline UNEM does not Granger cause RGDP & 24 & 3.47945 & 0.0762 \\
\hline RGDP does not Granger cause UNEM & & 51.5813 & 0.074 \\
\hline UNFDIITA does not Granger cause $\mathrm{H}$ & 24 & 0.24272 & 0.6274 \\
\hline $\mathrm{H}$ does not Granger cause UNFDIITA & & 5.25532 & 0.0323 \\
\hline SSE does not Granger cause RGDP & 24 & 2.04574 & 0.1673 \\
\hline RGDP does not Granger cause SSE & & 0.44133 & 0.5137 \\
\hline FDIITA does not Granger cause RGDP & 24 & 1.21995 & 0.2819 \\
\hline RGDP does not Granger cause FDIITA & & 5.95881 & 0.0236 \\
\hline
\end{tabular}

Table 5 .

Granger causality test results. 
On the contrary, there was no causality link between unemployment and economic growth. There was also no granger causality link between secondary enrollment (i.e., human capital) and economic growth. In theory, unemployment is a leakage in development when found to directly influence economic growth. Unemployment imposes a heavy burden on development via social intervention programs. As a result of that, minimizing the unemployment gap is a major aim for every economy. An increase in secondary school enrollment closes the literacy gap and increases the quality of human capital.

\section{Conclusions and policy implications}

\subsection{Conclusion}

The FOCAC cooperation has benefited China's economies more than it did for African because of growth hindering factors. In the form of foreign direct and portfolio investment, Chinese activities have grown in the region and are seen everywhere. China knows exactly what it wants from Africa while Africa is yet to wakeup. Africa is still assuming it will gain from China engagement.

Is African economic performance growing as a result of China's economic cooperation or is yet to happen? This Chapter examined this question from the preview of FDI and growth analysis using at least two decades of FDI data. The chapter also examined the effect of US and the World FDI on growth using Autoregressive Distributive Lags (ARDL) and Granger Causality models. According to the ARDL model, there was a positive growth relationship between China's FDI and African economic growth in the long term but not the short term. It was positive for the World FDI inflow to African. However, the effect of US FDI inflows to Africa was insignificant.

Change in human capital positively influences regional economic growth. There was no evidence of Okums Law as economic growth increases with unemployment, suggesting a lack of growth in the job market. Activities prevailing activities in the government and non-government sectors are not enough to bridge the gap in unemployment. The impact of openness i.e. economic inclusiveness was unexpectedly negative with economic growth in all models. This does not suggest, the region is a closed economy.

\subsection{Policy recommendation}

The African community will gain significantly from China's investment engagements if the following recommendations are factored in the region growth plans.

In the African economy, resolving growth issues are necessary, if gaining the most from FDI is the ultimate objective. Lingering growth problems will continue to hinder effective investment allocations. Without specifically outlining the core issues (facing development in the region) and actually resolving them is a recipe for underdevelopment. For example, Oil-producing nations need to go beyond crude oil activities which has a lower market price to processing activities which has a higher market price. Continuing with temporarily fixed and front-loaded deals with China will not resolve the region's major problems. China in particular knows that it wants from Africa and as a result deals with African in that regard. In the same vein, African economies need to know what they want to influence investment programs with China. They will be able to attract investments that will resolve their growth issues other than going for anything at all which has a long-run effect of collapsing 
the domestic activities and the exporting sectors. Diversification programs will have a greater impact as a result while the non-oil sectors will be well developed.

The African community can leverage China's economic interest to attract investment resources to bridge the infrastructural gaps facing development in the region. As the majority of countries experiencing heavy financial depts from doner organizations (the IMF and World Bank and) thereby losing their creditworthiness. The most viable approach to continue expanding infrastructural development in the region is to adopt and implement the Mutual or Pooled Growth Model (MGM/ PGM) investment plan with China. This strategy as the name implies requires China and African economies to initiate a "susu" plan together. Depending on the agreement, both countries (i.e. China and any other country in African or all ) can pull a fixed amount of funds together to be invested in a viable structural program or project in a partner country (say an African country) for at least two years and later pull another for the remaining country (say China) for a similar or different project/ s. Both countries after the two years will account for the funds to avoid missappropriateness. This type of financing or investment is unique because unlike the IMF funding system, it has no interest commitment hence reducing the debt to GDP ratio for partner economies.

Africa's manufacturing sector remains underdeveloped, yet China is an industrial hub. Africa is an endowed region with diverse resource potential, hence a suitable place to site processing and manufacturing industries. The lack of effective technical competencies is delaying industrial programs in the region. China-Africa cooperation is a forum that can help Africa close the technical gap and boost industrial development. The cooperation can be used to transfer technical resources to support the sector. Through government policies, young entrepreneurial visions can be supported by given special incentives such as tax holidays for at least one year, technical and skills training, and others to sustain activities. The government through its machinery can also protect young vision from competitions. This will allow them to grow into huge exporting industries and create more jobs to reduce unemployment.

Lastly, Africa needs to reform its investment policies with China. Observing China's past partnership engagements with the ASEAN community and other rising economies will help gain wisdom and help shape future engagement with China. In the future, Africa community will be able to develop proper economic deals with China via trade and investment. Again, the US has had long-standing trade and investment history with China. Most of such engagements have had a couple of successes and as well as failures to learn from. 


\section{Author details}

Isaac Abekah-Koomson ${ }^{1,2 *}$ and Nwaba Eugene Chinweokwu ${ }^{2}$

1 School of Business Economics (SBE), University of Brunei Darussalam (UBD), Gadong, Brunei Darussalam

2 W2POINTS Limited, China

*Address all correspondence to: isabkoworld@gmail.com

\section{IntechOpen}

(C) 2020 The Author(s). Licensee IntechOpen. This chapter is distributed under the terms of the Creative Commons Attribution License (http://creativecommons.org/licenses/ by/3.0), which permits unrestricted use, distribution, and reproduction in any medium, provided the original work is properly cited. (c) BY 


\section{References}

[1] Adewumi S, Hacker S, Dzansi J. The Impact of FDI on Growth in Developing Countries: An African Experience. Jonkoping International Business School; 2006

[2] Osakwe P, Nkurunziza J, Bolaky B. Economic development in Africa report 2013. In: Intra-African Trade: Unlocking Private Sector Dynamism.

[3] $\mathrm{Gu}$ J. China's private enterprises in Africa and the implications for African development. The European Journal of Development Research. 2009;21(4): 570-587

[4] Oladipo OS. Foreign direct investment (FDI): Determinants and growth effects in a small open economy. The International Journal of Business and Finance Research. 2010;4(4):75-88

[5] Pigato M, Tang W. China and Africa: Expanding economic ties in an evolving global context. In: Investing in Africa Forum. World Bank Working Paper. 2015. p. 95161

[6] Crompton P, Wu Y. Energy consumption in China: Past trends and future directions. Energy Economics. 2005;27(1):195-208

[7] Baah AY, Jauch H. Chinese investments in Africa: A labour perspective. African Labour Research Network; 2009

[8] China Statistics Bureau. China Statistical Yearbook. China Statistics Bureau: Beijing, China; 2012

[9] Shen L, Zhou J. Examining the effectiveness of indicators for guiding sustainable urbanization in China. Habitat International. 2014;44:111-120

[10] Ndikumana L, Verick S. The linkages between FDI and domestic investment: Unravelling the developmental impact of foreign investment in sub-Saharan Africa. Development and Policy Review. 2008; 26(6):713-726

[11] Ozturk I. Foreign direct investmentgrowth nexus: A review of the recent literature. International Journal of Applied Econometrics and Quantitative Studies. 2007;4(2)

[12] Adams S. Can foreign direct investment (FDI) help to promote growth in Africa? African Journal of Business Management. 2009;3(May): 178-183. DOI: 10.5897/AJBM09.001

[13] Abekah-Koomson I, Loon PW, Premaratne G, Yean TS. Total factor productivity growth: Evidence from West African economies. Global Business Review. 2019;4. DOI: 0972150919856194

[14] Jenkins R. Globalization, FDI and employment in Viet Nam. Transnational Corporations. 2006;15(1):115

[15] Busse M, Groizard JL. Foreign Direct Investment, Regulations, and Growth. The World Bank; 2006

[16] Te Velde DW, Bezemer D. Regional integration and foreign direct investment in developing countries. Transnational Corporations. 2006;15(2):41-70

[17] Alfaro L, Chanda A, Kalemli-Ozcan S, Sayek S. How does foreign direct investment promote economic growth? Exploring the effects of financial markets on linkages. National Bureau of Economic Research. 21 September 2006

[18] Kamara YU. Foreign direct investment and growth in sub-Saharan Africa what are the channels. Lions on the Move II: Realizing the Potential of Africa's Economies. University of Kansas: McKinsey Global Institute; 2016. pp. 1-148 
[19] McKinsey Global Institute. Lions on the Move II: Realizing the Potential of Africa's Economies. Mckinsey Global Institute; 2016. pp. 1-148

[20] Borensztein E, De Gregorio J, Lee JW. How does a foreign direct investment affect economic growth? Journal of International Economics. 1998;45(1):115-135

[21] De Gregorio J, Guidotti PE. Financial development and economic growth. World Development. 1995; 23(3):433-448

[22] AbuAl-Foul B. The causal relation between savings and economic growth: Some evidence from MENA countries. Topics in Middle Eastern and North African Economies. 2010;12

[23] Pesaran MH, Shin Y, Smith RJ. Bounds testing approaches to the analysis of level relationships. Journal of Applied Econometrics. 2001;16(3): 289-326

[24] Granger CWJ. Investigating causal relations by econometric models and cross-spectral methods. Econometrica. 2015;37(3):424-438

[25] Nunnenkamp P, Spatz J. FDI and economic growth in developing economies: How relevant are hosteconomy and industry characteristics. Transnational Corporations. 2004;13(3): 53-86 



\title{
Sustainably Growing Guinea’s Bauxite-Aluminum Industry
}

\author{
Lynnette Widder, Thomas D. Pacioni and Ousmane Bocoum
}

\begin{abstract}
Guinea's bauxite-aluminum industry is undergoing significant expansion of investment, concession agreements, and in-country mining and refining operations. In 2018, UNDP-Guinea and Columbia University developed a framework that would evaluate this development against metrics for social and environmental sustainability, such as energy access and diversification, water quality, land use, biodiversity restoration, waste management, and community engagement. Current environmental impacts measured in GHGs, a metric both economic and environmental, were compared to potential impacts anticipated as a consequence of expansion. These anticipated impacts include enormous increases in countrywide GHG emissions and significant regional shortfalls in access to electrical energy. Case studies from the international bauxite-aluminum industry were then used to illustrate best practices for climate mitigation and adaptation and to describe opportunities for regional collaboration on shared-use energy and infrastructure development (e.g., hydropower used across West Africa, rail transportation) while achieving measurable benefits to communities, NGOs, regulators, and mining companies.
\end{abstract}

Keywords: Guinea, bauxite, aluminum, alumina refining, greenhouse gas emissions, GHG, sustainable mining, climate mitigation, climate adaptation, industrialization, regional investment, infrastructure, cumulative impacts, environment

\section{Introduction}

The Republic of Guinea is rich in natural resources yet, since its independence in 1958, has struggled to transform that advantage into durable economic and social development. The small country has over a quarter of the world's proven bauxite reserves, approximately 7.4 billion metric tonnes $(t)[1,2]$, more than any other nation. Bauxite is the primary ore used to produce aluminum; aluminum alloys are used to manufacture countless items around the globe. Still, Guinea's bauxite mining industry did not grow substantially between the 1960s and 2015 [3]. Thus, Guinea's government [4], along with the World Bank [5], African Development Bank [4, 6], and others [7], has identified Guinea's mining sector with economic growth, infrastructure development, poverty reduction, and social well-being. Recently, foreign direct investment (FDI) has fueled dramatic increases in Guinea's bauxite-aluminum industry (Figure 1). This growth presents new challenges as governments and industries worldwide have focused more and more on (GHG) 


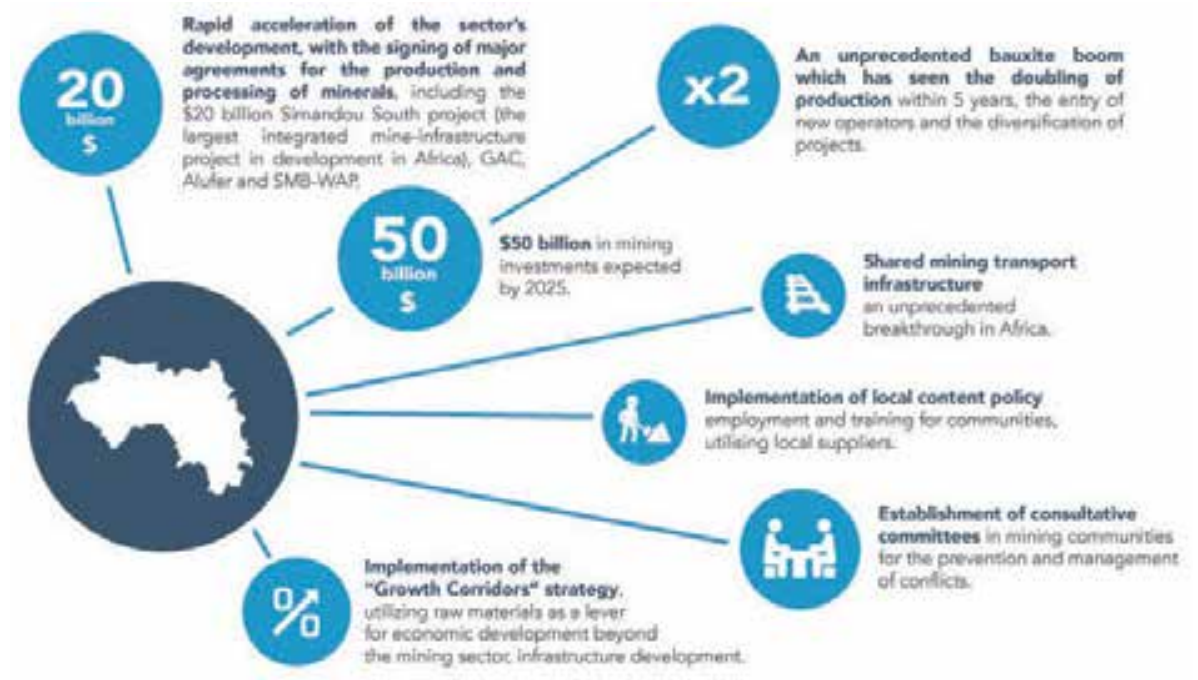

Figure 1.

Rise of Guinea's mining sector.

emissions and climate adaptation strategies. Notably, Guinea formalized a commitment to the United Nations Framework Convention on Climate Change (UNFCCC) by publishing its intended national development goals (INDCs) and sustainable development strategy priorities [4] in 2015.

Like most developing countries, Guinea lacks capacity to meet its INDCs alone. Recognizing this widespread need, UNFCCC created the Green Climate Fund (GCF) as a mechanism to encourage climate change adaptation and mitigation by matching private sector investment funds. The GCF's eligibility requirements are quite strict, and programmatic assistance is often needed to qualify. Hence, in 2016 Guinea requested and received a GCF Readiness Programme grant to help build its capacity. The UNDP, an accredited partner of the GCF [8], led Guinea's Readiness Programme and, as part of capacity building, sought out Columbia University to develop tools to engage Guinea's private sector in sustainable mining practices. This chapter summarizes that project's conceptualization, methods, and results, including generalized insights into public-private collaborations. The Readiness Programme wrapped up in December 2018 with Guinea's National Designated Authority established and prepared to articulate initiatives, mobilize private sector engagement, and develop a robust GCF Country Programme plan. Thus, Guinea is now fully equipped to access the GCF funding.

\subsection{Conspicuous sustainability resources}

The UN's Sustainable Development Goals (SDGs) 8, 9, 11, and 17 integrate responsible resource extraction regimes into sustainable development. At present, a confluence of factors-new mining concessions, presidential agenda, civil society organization activity in the mining regions, and not least of all the GCF matching funding - has created opportunities to solidify sustainable mining practices. UNDPGuinea's decision to ask Columbia University for support with this acutely relevant work underpins the notion that student-based research can be an effective impetus to useful and compelling outcomes when it is backed by in-depth involvement of seasoned researchers like Widder and Pacioni, on-site face-to-face interactions, and a commitment to collaboration. This project fostered genuine engagement from stakeholders in industry, government, and local NGOs by uncovering pathways to 
influence local technical approaches, regional development, and national policy. Because the project was objective and academic, leveraging resources not typically available (e.g., Columbia University's degree programs in sustainability), its approach offers a unique methodological reference.

\subsection{Economic, environmental, and social context}

The seemingly dissonant condition of abundant natural resources coupled with highly limited economic and social development is not uncommon in West Africa [6]. The challenge of remedying that deeply rooted condition is daunting because economic development, social development, and environmental protection are overlapping and often conflicting components in a highly complex system (i.e., sustainable development). To help determine needs, the UNDP calculates a Human Development Index (HDI) based on inputs including life expectancy, education, and per capita income. Of UN's 189 member nations, Guinea's HDI ranks 175 [9]. In fact, all West African nations are ranked in the lowest quartile. To vitalize sustainable development in Guinea, UNDP-Guinea focuses specifically on poverty reduction, climate change risk, and peace building and governance [10].

With a population of $12.7 \mathrm{M}$ [11], Guinea ranks among the world's least developed in infrastructure [12] and, until very recently, FDI [13]. However, in a remarkable change from decades of economic stagnation, gross domestic product (GDP) rose 10+\% in both 2016 and 2017, largely due to mining sector expansion $[13,14]$. In accordance with its strategic plan [4], Guinea's Ministry of Mines and Geology actively developed new concessions and promulgated a special economic zone (SEZ) for the Boké Region in 2017, underscoring its importance to the bauxitealuminum industry. Of particular note, the bauxite-aluminum industry's current boom is borne largely of FDI from China [15], the UAE [16], Russia [17], and, to a lesser extent, Iran [18], France [19], the USA [20], the UK, Australia, India, and the Netherlands in joint ventures with federal ownership. Moreover, a consortium of mining companies funded a new trade organization, Guinea's Chamber of Mines, to communicate and represent private mining sector interests.

As the World Bank describes in its report on Guinea's mining sector, the bauxite industry's need for infrastructure offers crucial potential for industrialization and service sector development [14]. For example, recent investment in rail transport from Guinea's mining hub in the Boké Region to its commercial port originated in the private sector working through the Chamber of Mines. Potentials for the transportation and service sectors to provide local employment exceed that of the largely automated mining industry, especially if that development is part of a regional network linking nearby landlocked economies to Guinea's port. In fact, Guinea's abundant waterways and other freshwater assets have high regional importance and must be part of any sustainable development plan. Nonetheless, difficulties remain in defining and enacting mechanisms to distribute the mining sector's benefits and to enact good governance, community enhancement, and environmental mitigation.

\subsection{Regulatory and policy context}

A lack of transparency about mining concessions and practices, poor communication with communities impacted, inadequate or poorly timed remuneration for agricultural land, and the tendency among foreign mining companies to import everything from power plants and fuel to workers from their home countries have led to civil unrest, especially in the Boké Region [21]. Riots, destruction of property, 
and disruption of electrical and transportation infrastructure hobble extraction and threaten its continued build-out.

Although regulations requiring environmental impact reports are in place, Guinea's Ministry of Environment is underfunded and underequipped to monitor and enforce industry commitments [22]. A recent Human Rights Watch report [22] illustrates impacts of poorly enforced regulation on farmers' livelihoods, civil society, and citizen confidence. Reports of waterway degradation from dust released during open-pit mining suggest that the current boom is adversely impacting fisheries, mostly practiced at artisanal scale, which is the country's other primary employment sector [23]. Because Guinea encompasses the source and/or course of nearly all major West African rivers, any water quality or flow degradation will have considerable regional ramifications. Further, these impacts will have a compounding negative effect on region-wide ecosystems as underscored by independent climate change models predicting increased desertification in West Africa [14], especially in the transition zone between the Sahara Desert and the southern savanna (i.e., Sahel).

\subsection{Current funding mechanisms}

After clarifying Guinea's willingness to meet its responsibilities under the UNFCCC's Paris Accord, UNDP-Guinea turned its attention to the bauxitealuminum industry because it has overwhelming bearing on Guinea's sustainable development and because it is among the few industries with the capacities to cofinance GCF projects. Currently mining companies are required to pay a small proportion of their profits as a "royalty" intended for use in federal remediation projects. Although mining companies may see the benefits of addressing the cumulative impacts of their activities, this mining royalty modality, the primary modality for participation, is not sufficiently robust. Existing mechanisms designed to ensure effective application of legal and regulatory instruments for mining development are very weak and constitute a hindrance for crowding in private sector investment.

However, one might find opportunity rather than conflict where mining investment and civil society participation intersect. This study landed on the concept of "shared use" to describe these synergies (described below). Accordingly, and as a direct result of the collaborative activities described, UNDP-Guinea is developing a work scope for integrated management of the coastal region that has been impacted by mining activities and erosion, with co-financing of USD $11 \mathrm{M}$ from the GCF and the Chamber of Mines. This demonstrates how the GCF created opportunity to couple Guinea's rapid industrialization to its INDCs.

\section{Project design}

\subsection{Objectives}

The overarching project objective was to engage Guinea's private-sector mining companies in productive dialog regarding sustainable mining practices, both current and future. Specific goals included the following: (a) identify public-sector stakeholders that could champion sustainability-based initiatives and private-sector stakeholders with expertise in sustainable mining practices; (b) determine the industry's current direct GHG emissions and potential impacts from near-term industry growth; (c) in light of enormous pressure to expand, identify perceived and actual barriers to sector growth and perceived barriers to more sustainable practices; (d) describe proven best practices for sustainability in mining that are applicable and appropriate in Guinea; (e) assist in positioning the mining sector to help meet Guinea's INDCs 
and to access new forms of capital (e.g., GCF); and (f) provide UNDP-Guinea a model for implementing such initiatives in the future.

Columbia's conceptual approach was threefold: (1) establish credibility with private- and public-sector stakeholders; (2) develop an unbiased overview of the industry's likely or typical operations, challenges, risks, and opportunities relative to environmental and social conditions; and (3) share pragmatic approaches to sustainable mining in a face-to-face forum to (i) enhance Guinea's knowledge base, (ii) elicit industry feedback on specific tactics used currently and challenges foreseen, and (iii) leverage dialog to form a collaborative effort among stakeholders to share knowledge and to focus on achievable sustainability goals.

\subsection{Scope and methods}

In spring 2018, Dr. Lynnette Widder, a Columbia University professor of sustainable development and urbanism, assembled a team that included technical advisor Thomas D. Pacioni whose decades-long experience in extractives and advanced degrees in geology and sustainability management equipped him to guide research and analysis and four graduate students recruited based on academic performance from Columbia's Master's Degree programs in Sustainability Management and in Public Administration and Development [24]. UNDP-Guinea committed to monitor progress and facilitate communication with Guinean organizations, and their operational support and strategic input proved invaluable. The work scope was modeled on the GCF's 2015 Readiness Proposal for Guinea [25] and was completed in two distinct phases. Columbia's research team initially completed:

- Literature reviews on (a) Guinea's current and planned capacity expansion of bauxite-aluminum operations; (b) inputs, outputs, throughput volumes, and potential sustainability impacts from operations; (c) typical GHG emission factors correlated to production; (d) standards and guidelines used elsewhere that could be adapted to Guinea; and (e) successful implementation of sustainability practices in bauxite mining under environmental and social conditions similar to Guinea's.

- Interviews with mining industry insiders with expertise in environmental, social, and governance (ESG) practices, financing capital projects in international extractives, and Guinea's regulators, including: a representative of the International Council on Mining and Metals (ICMM), a biodiversity consultant working in Guinea's mining sector, International Finance Corporation (IFC), Power Africa (a USAID program), an independent consultant, Columbia's Center for Sustainable Investment (CCSI), Guinea's Ministry of Energy and Water Resources, and Electricité de Guinée.

- GHG emissions were estimated for (a) current actual bauxite volumes reported; and (b) near-term future conditions based on conservative estimates of published expansion plans.

- Case studies were selected that (a) apply directly to Guinea's bauxite mining conditions; (b) mitigate effectively and realistically a spectrum of sustainability risks; (c) cross-reference industry standards; (d) incentivize action on environmental and social performance; and (e) could facilitate knowledge sharing and initiate a dialog with Guinea's mining companies, leading to future collaborative data gathering and discussion of best practices. 
Subsequent to Phase 1, and with facilitation support from UNDP-Guinea's Ousmane Bocoum, Widder and Pacioni expanded work on qualitative and quantitative drivers that included (a) field-based research in Guinea to isolate data gaps and to verify and/or update Phase 1 data; (b) interviewing executives from Guinea's Chamber of Mines and UNDP-Guinea's local ESG programs, in part to gain insight into the relationships among mining's actual (i.e., on-the-ground) environmental and social drivers; (c) beginning to explore methodologies for developing shared infrastructure in transportation and energy that can benefit communities and private-sector stakeholders durably; (d) developing an advocacy strategy to prove how sustainabilitybased best practices will reduce intense social pressures by expressing a longer-term growth approach that includes generational community needs, not only annual revenues; (e) leveraging a recently created consortium of bauxite mining companies in the Boké Region dedicated to cross-border biodiversity to disseminate and access critical data; and (f) leading a workshop to share sustainable findings and support collaboration and/or friendly competition among bauxite mining companies in Guinea.

\subsection{Limitations}

The study was not comprehensive in scope but instead was limited to readily available data. Although financing mechanisms were discussed, neither a detailed financial analysis nor a review of potential capitalization strategies was completed. Rather, the results of a non-funded academic exercise were expanded in the hope that tangible progress in private-sector engagement could further the UNDP/GCF's Readiness Programme.

\section{Academia's POV: benefits and value}

Although the benefits of university research to policy makers are well established, less attention has been given to the role that academic coursework can play. For this project, UNDP-Guinea prioritized academic objectivity. This relationship allowed the team of students and faculty to retain full academic freedom, to conceptualize the project's scope, and to reframe questions as warranted by iterative research results.

The team's independent position translated into access to subject-matter experts who might otherwise have treated their knowledge as proprietary, including international trade organizations, industry representatives, independent finance and science consultants, development aid organizations, and researchers from other academic institutions. Because the workshop format of the research project led to broad-based action items, Guinea's bauxite-aluminum industry representatives and regulators could consider its outcomes without concerns about conflicting agendas.

\section{Production processes}

Bauxite, a sedimentary rock, is the primary ore used to produce aluminum. In turn, aluminum alloys are widely used [26] to manufacture all types of vehicles, mobile phones and electronics, machinery, building construction materials, and household items. Transforming bauxite into aluminum is a three-step industrial process (Figure 2), each step having social and environmental impacts (e.g., GHG emissions). Based on typical worldwide production data, approximately $5.54 \mathrm{t}$ of extracted bauxite will produce $2.25 \mathrm{t}$ of alumina which, in turn, will produce $1 \mathrm{t}$ of aluminum [27]. 


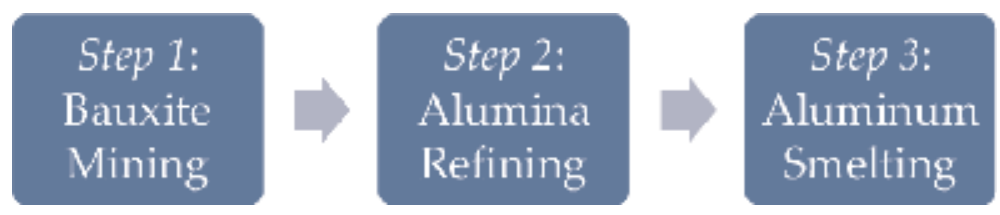

Figure 2.

Bauxite-aluminum process steps.

\subsection{Bauxite-aluminum production}

Bauxite mining - In Guinea, bauxite is mined from open pits, crushed, and washed on site with water to reduce dust and remove some impurities. The material is then screened and dried, producing beneficiated bauxite and wastewater, and then transported to an alumina refinery. At most bauxite mines around the world, wastewater is retained in settling ponds for reuse [28]. This is likely true in Guinea; however, specific company practices are not publicly available. Most of Guinea's beneficiated bauxite is shipped abroad for refining.

Alumina refining - Beneficiated bauxite is then refined into alumina (i.e., aluminum oxide, $\mathrm{Al}_{2} \mathrm{O}_{3}$ ) using the Bayer process, wherein hot caustic soda is added to dissolve the aluminum compounds. Insoluble residue (i.e., red mud) is then filtered out, and alumina is precipitated. The red mud is washed to recover as much caustic as practical and then disposed.

Aluminum smelting-Smelting (anode paste production, electrolysis, and ingot casting) is the process by which alumina is dissolved in sodium aluminum hexafluoride (cryolite) at $1,000^{\circ} \mathrm{C}$ and then placed in a cell with carbon (typically graphite) cathodes and anodes. Electrolysis oxidizes the anode's carbon to carbon dioxide $\left(\mathrm{CO}_{2}\right)$, and aluminum ions are reduced to aluminum metal at the cathode.

\subsection{Resource use and impacts}

Potential environmental impacts of bauxite-aluminum production include topsoil destruction, dust generation, overuse of freshwater supplies, wastewater releases, and GHG emissions. Resource inputs and non-GHG waste based on typical production data are summarized in Table 1, and qualitative summaries are provided below.

Bauxite mining-Mechanical mining causes dusty conditions, and airborne particulates are both a direct respiratory risk and the primary source of reddish deposits in the areas around. Energy inputs at this phase are mostly diesel used in bulldozers, excavators, and haul trucks. While Guinea's mining wastewater may be recovered as a general practice, there are reports of surface water impacts [22]. This means wastewater management may not be adequate to protect Guinea's allimportant waterways.

Alumina refining-Refining requires substantially more water and electricity than mining. Disposed red mud is high in $\mathrm{pH}$ and salinity. In addition, metals and natural background radioactivity from its parent bauxite are often concentrated in red mud. Although there are potential uses for red mud, the international rate of reuse is only $2-3 \%$ [32]. Other by-products of alumina refining include hydrocarbons, suspended solids in water, and air emissions of nitrogen dioxide, sulfur dioxide, and mercury $[28,30]$. Thus, risks to human health and surrounding ecosystems from alumina refining [33] dramatically eclipses.

Aluminum smelting-Smelting requires yet another order of magnitude increase in energy input. Water requirements are also significantly greater than 


\begin{tabular}{|c|c|c|c|}
\hline & $\begin{array}{l}\text { Bauxite mining (per } t \text { of } \\
\text { bauxite ore extracted) }\end{array}$ & $\begin{array}{l}\text { Alumina refining (per } t \\
\text { of alumina refined) }\end{array}$ & $\begin{array}{l}\text { Aluminum smelting (per } t \text { of } \\
\text { primary aluminum smelted) }\end{array}$ \\
\hline Fuel input & $1.5 \mathrm{~kg}[29]$ & $100 \mathrm{~kg}[30]$ & Not available \\
\hline $\begin{array}{l}\text { Electricity } \\
\text { input }\end{array}$ & $5 \mathrm{kWh}[29]$ & 150 kWh [29] & $14,000 \mathrm{kWh}[31]$ \\
\hline $\begin{array}{l}\text { Water } \\
\text { input }\end{array}$ & $0.6 \mathrm{~m}^{3}$ & $8 \mathrm{~m}^{3}[31]$ & $\sim 20 \mathrm{~m}^{3}$ \\
\hline \multirow{2}{*}{$\begin{array}{l}\text { Waste } \\
\text { output }\end{array}$} & $0.00095 \mathrm{t}$ dust & $1-1.5 \mathrm{t}$ & $0.05 \mathrm{t}$ \\
\hline & $\begin{array}{c}\text { Bauxite mining (per } t \text { of } \\
\text { aluminum) }\end{array}$ & $\begin{array}{l}\text { Alumina refining (per } t \\
\text { of aluminum) }\end{array}$ & $\begin{array}{l}\text { Aluminum smelting (per t of } \\
\text { aluminum) }\end{array}$ \\
\hline Fuel input & $8.3 \mathrm{~kg}$ & $225 \mathrm{~kg}$ & Not available \\
\hline $\begin{array}{l}\text { Electricity } \\
\text { input }\end{array}$ & $27.7 \mathrm{kWh}$ & $337.5 \mathrm{kWh}$ & $14,000 \mathrm{kWh}$ \\
\hline $\begin{array}{l}\text { Water } \\
\text { input }\end{array}$ & $3.3 \mathrm{~m}^{3}$ & $18 \mathrm{~m}^{3}$ & $\sim 20 \mathrm{~m}^{3}$ \\
\hline $\begin{array}{l}\text { Waste } \\
\text { output }\end{array}$ & Negligible & $3.4 \mathrm{t}$ & $0.05 \mathrm{t}$ \\
\hline
\end{tabular}

Table 1.

Inputs for bauxite-aluminum production.

mining or alumina refining. Smelting also produces air emissions of fluorides and hydrocarbons [28].

\section{Guinea's bauxite-aluminum industry}

Figure 3 shows the location and number of concessions, or permits to operate, for bauxite mining and alumina refining. Mining is largely centered in northwestern Guinea in the Boké Region's SEZ. The majority of concessions are held in whole or in part by foreign mining organizations that have incorporated Guinean operating companies in conjunction with the Republic of Guinea's government. Through 2015, Compagnie des Bauxites de Guinée (CBG, a.k.a. Guinea Bauxite Company) accounted for $>75 \%$ of extracted bauxite. Guinea's government holds a $49 \%$ interest in CBG, with the balance held by an international consortium. The remaining 20$25 \%$ of Guinea's bauxite industry prior to 2016 was controlled by Russia's RUSAL, operating three wholly owned subsidiaries. Large-scale growth began in 2015 (primarily) by expanding existing concessions and granting new concessions, with new mining operations coming on line in 2016. Guinea's government controls $10-15 \%$ of most of the new concessions.

\subsection{Current bauxite-aluminum production}

Bauxite production for 2008-2018 (estimated) is provided in Table 2, and a summary of mining companies operating in Guinea is provided in Appendix A. Despite more than a half-century of bauxite mining, only one alumina refinery has been established in Guinea and its operation has been sporadic and largely inconsequential. No smelters have yet been constructed. 


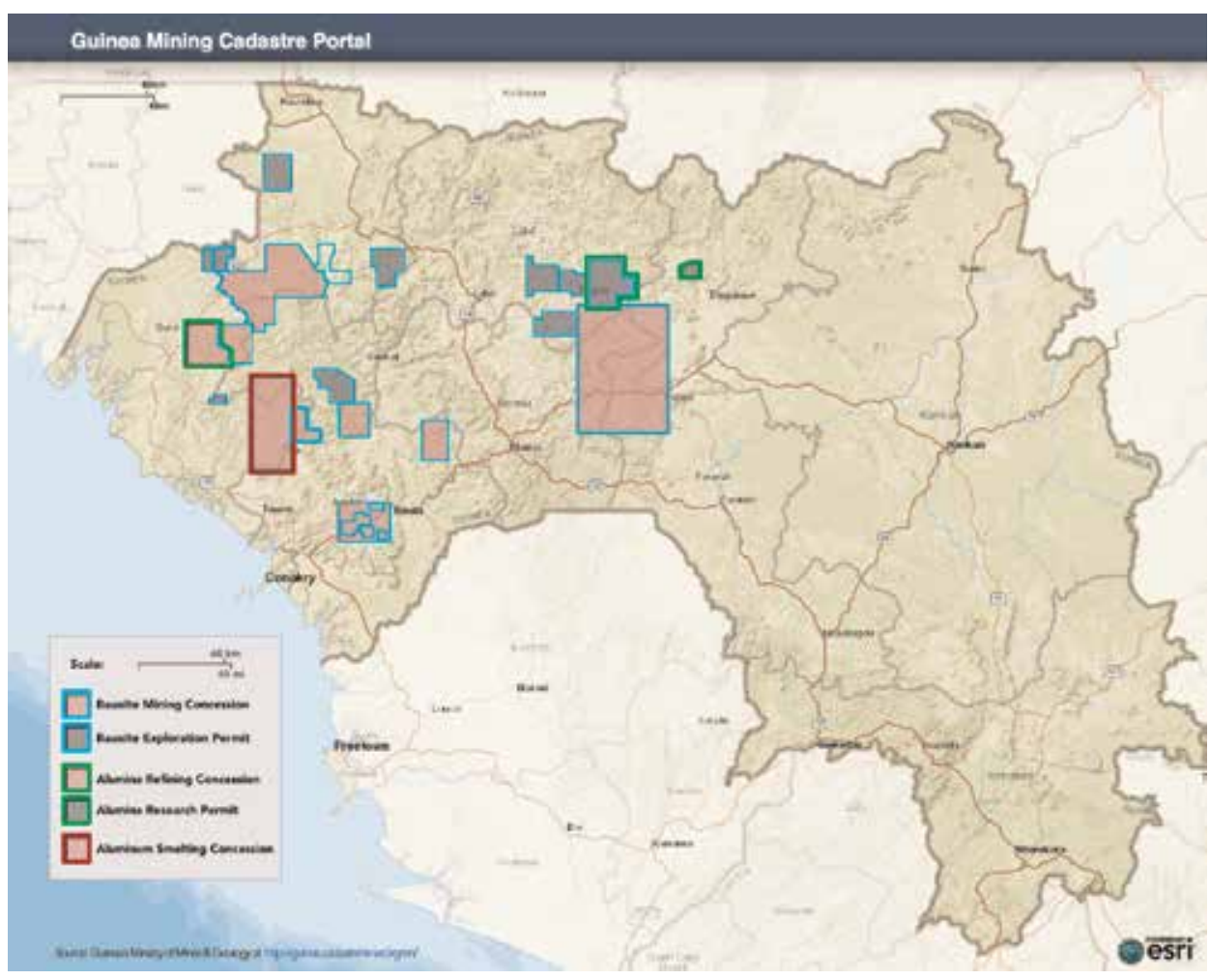

Figure 3 .

Location of Guinea's bauxite-aluminum concessions.

\begin{tabular}{ccc}
\hline Year & Bauxite production (Mt) [3] & GHG emissions $\left(\mathbf{M t C O}_{2} \mathbf{e}\right)$ \\
\hline 2008 & 18.5 & 0.33 \\
\hline 2009 & 15.6 & 0.28 \\
\hline 2010 & 17.4 & 0.31 \\
\hline 2011 & 17.6 & 0.32 \\
\hline 2012 & 17.8 & 0.32 \\
\hline 2013 & 18.8 & 0.34 \\
\hline 2014 & 17.3 & 0.31 \\
\hline 2015 & 18.1 & 0.33 \\
\hline 2016 & 31.5 & 0.57 \\
\hline 2017 & 46.2 & 0.83 \\
\hline $2018{ }^{*}$ & 50.0 & 0.90 \\
\hline${ }^{*}$ Estimated. & & \\
\hline
\end{tabular}

Table 2.

Bauxite production and GHG emissions, 2008-2018.

\subsection{GHG emissions}

Although it does not integrate water pollution, soil pollution, or other types of air pollution relevant to the funding opportunities offered by the GCF, GHG emissions is the primary metric used to determine climate mitigation and adaptation 
needs. For the purpose of calculating conservative GHG estimates, the proportion of hydroelectric power in the industry's overall energy mix was assumed to be consistent with regional averages in Africa (i.e., 43\% [34]), compared to Guinea's actual proportion of hydroelectric power, approximately 56\% [35]. This GHG analysis only considered the industry's current direct emissions, and not secondary emissions from transportation between facilities or to end users. GHG emissions are expressed throughout this chapter as t of $\mathrm{CO}_{2}$ equivalents or $\mathrm{tCO}_{2}$ e. Table 2 and Figure 4 summarize annual bauxite-aluminum production and GHG emissions for 2008-2018. Emission factors (EFs) used to calculate GHG emissions for each step in the aluminum production process are summarized in Table 3. EFs are provided per $t$ of material produced in each step and per $t$ of aluminum produced across each step. To determine EFs, the relative proportions of material required to produce $1 \mathrm{t}$ of aluminum (described in Section 4) were assumed.

Consistent with Guinea's strategic plan, bauxite production has increased rapidly since 2016. Guinea's alumina refinery had not been operating, so recent GHG emissions were negligible, though refining resumed in early 2018.

\subsection{Expansion plans and future GHG emissions}

Since 2015 Guinea's government has consistently signaled strong interest in expanding bauxite mining, as well as in-country alumina refining and aluminum smelting. Specifically, all new mining concessions have included rights for alumina refineries, most notably a USD 2.8 B investment from the Chinese company

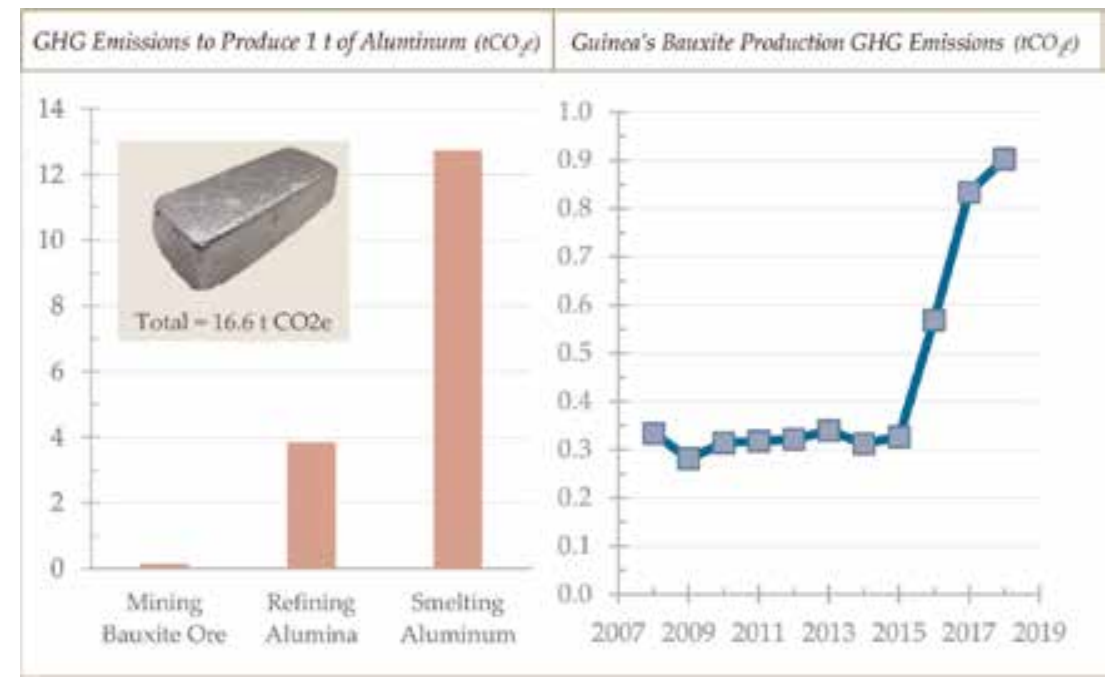

Figure 4.

Current GHG emissions.

\begin{tabular}{lcc}
\hline Process stage & \multicolumn{1}{c}{ GHG EF } & GHG EF normalized to $1 \mathrm{t}$ aluminum \\
\hline Bauxite mining & $0.02 \mathrm{tCO}_{2} \mathrm{e} / \mathrm{t}$ of bauxite & $<0.1 \mathrm{tCO}_{2} \mathrm{e} / \mathrm{t}$ of aluminum \\
\hline Alumina refining & $1.69 \mathrm{tCO}_{2} \mathrm{e} / \mathrm{t}$ of alumina & $3.8 \mathrm{tCO}_{2} \mathrm{e} / \mathrm{t}$ of aluminum \\
\hline Aluminum ${ }^{*}$ production & $12.7 \mathrm{tCO}_{2} \mathrm{e} / \mathrm{t}$ of aluminum & $12.7 \mathrm{tCO}_{2} \mathrm{e} / \mathrm{t}$ of aluminum \\
\hline \multicolumn{2}{l}{ Total to produce $1 \mathrm{t}$ aluminum } & $16.5 \mathrm{tCO}_{2} \mathrm{e} / \mathrm{t}$ of aluminum \\
\hline${ }^{*}$ Includes anode paste $\left(0.6 t \mathrm{tCO}_{2} \mathrm{e}\right)+$ electrolysis $\left(11.9 t \mathrm{tCO}_{2} \mathrm{e}\right)+$ ingot casting $\left(0.2 t \mathrm{tCO}_{2} \mathrm{e}\right)$. \\
\hline
\end{tabular}

Table 3.

Average GHG EFs by process [34]. 


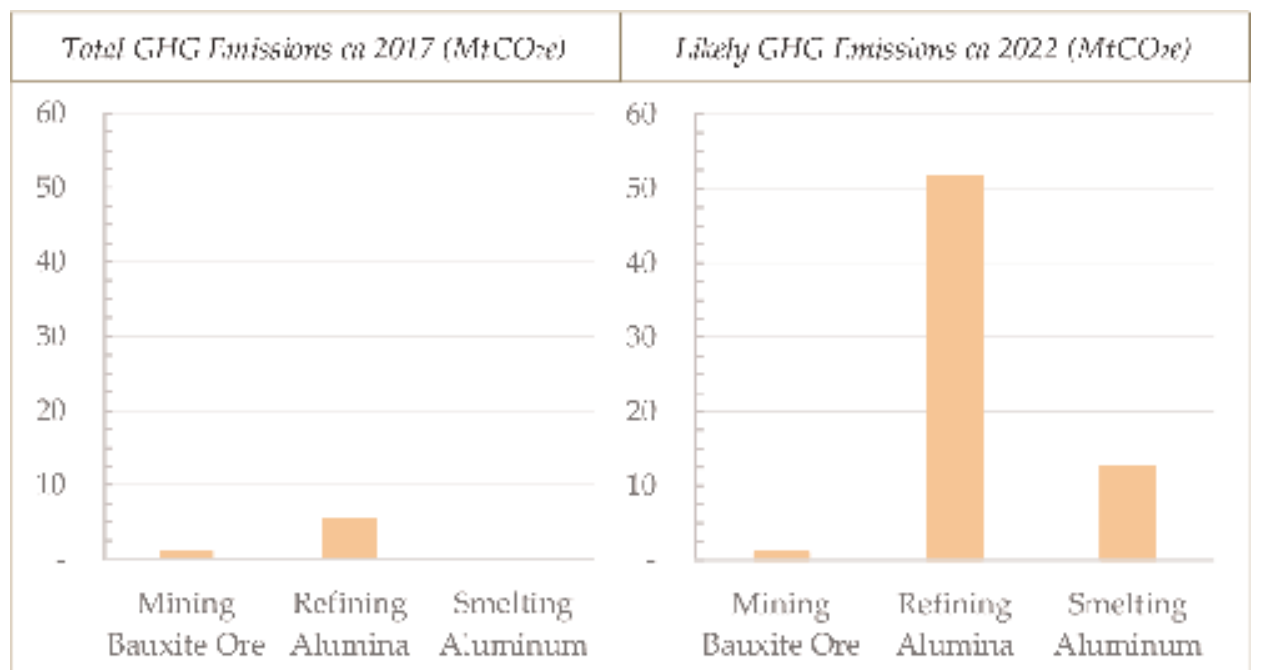

Figure 5 .

Future GHG emissions.

TBEA [36]. TBEA plans to bring its alumina refinery online by June 2021 and to start smelter construction by 2025. (Because TBEA's concession is not yet available, it is not included in Appendix A). In addition to private-sector funds, the World Bank's [37] investment matching program has facilitated the mining industry's rapid expansion. Guinea's stated goal is to grow extraction refining from 0.6 to $>1 \mathrm{Mt}$ by 2024 [38], thereby boosting GDP and generating considerable demand for local employment, though it is not clear that local workers will benefit from these new concessions. More concerning than the lack of transparency about staffing plans in these new concessions is the extraordinary increase in GHG emissions that will accompany alumina and aluminum productions (Figure 4). The likely impact on near-term GHG emissions is shown in Figure 5.

\subsection{Regulations and standards}

International, sectorial, and industry standards can ensure that mining companies follow best practices, especially if mutual monitoring by competing bauxite companies of one another's compliance was embedded in compliance plans. The Guinea Sustainable Bauxite Mining Consortium, founded as a vehicle for GCF support, is one such opportunity. Additional standards are published by the IFC, the ICMM, the Aluminum Stewardship Initiative (ASI), and the Business and Biodiversity Offsets Programme (BBOP). However, because few of the companies operating in Guinea are publicly traded and therefore less likely to feel pressure from shareholders regarding accurate and timely environmental reporting, consensual oversight among peer companies is particularly important. Guinea's laws and industry guidelines include provisions and methods for rehabilitating exhausted mines with local collaboration [39]. However, this has had limited success in the Boké Region [22].

\section{A shared values approach to solutions}

Given limitations on Guinea's capacity to enforce its regulatory requirements and to create transparency around the environmental impact assessments required by law, it was prudent to look to other, less conventional pathways to help prioritize mining and refining processes that will decrease the magnitude of environmental 


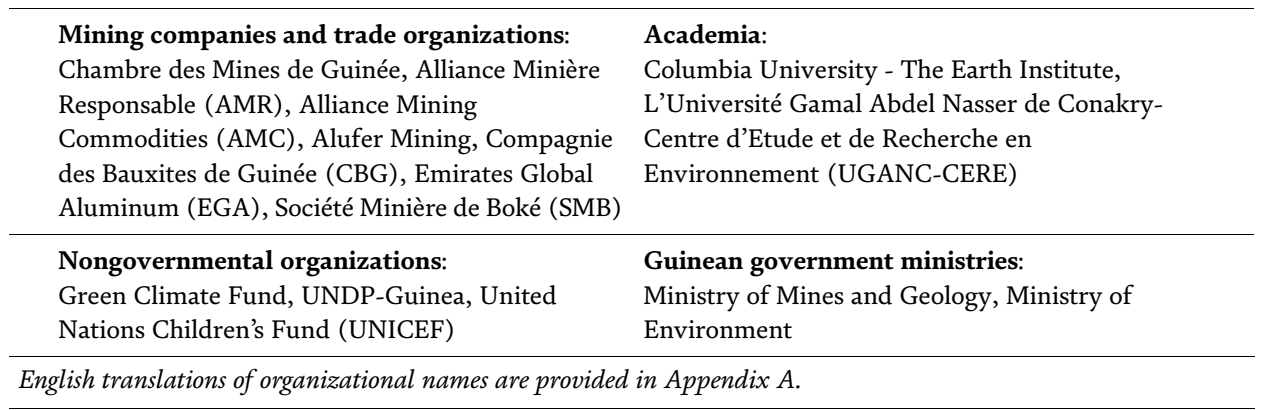

\section{Table 4 .}

Workshop participants.

and community damage. Conflict around competing resource needs is inevitable unless synergies and compromise are integrated. This points to consideration of shared values, an approach that has already realized rail and port improvement co-funded by mining companies.

With collaboration, Guinea's hydropower potential may be used to leapfrog GHG impacts while also benefiting underserved rural communities. Guinea is the source of at least a dozen major West African rivers and a similar number of regional rivers, and could potentially generate 19,300-26,000 GWh of hydropower annually $[35,40]$. The present installed capacity, subject to considerable seasonal fluctuation, is $0.5-0.6 \mathrm{GW}$ [41]. Still, rural electrification is less than half the national average (11 vs. $26 \%$ ). System build-out in which the bauxite industry can serve as an anchor client coupled with careful planning and monitoring to ensure biodiversity and waterway health could provide enormous national and regional benefit in perpetuity.

\subsection{From shared use to shared solutions: a successful workshop}

On June 29, 2018, the results from both phases of this study were presented in a workshop chaired by the Chamber of Mines with extensive participation from mining companies and organizations (Table 4). Stakeholders applauded UNDP-Guinea and Columbia University and described the workshop to Mr. Ousmane Bocoum (UNDPGuinea, June 29, 2018) as "solutions served on a plate". Debate on best practices inspired mining companies to discuss remediation strategies they are already practicing, making public efforts already underway (because they privately held, mining companies in Guinea have neither shareholder reporting nor robust corporate social responsibility reports). The workshop culminated in discussions on the benefits that mining companies would gain by more extensive knowledge sharing among companies, and how that knowledge sharing would help reach sustainability goals.

\subsection{Case studies}

Case study no. 1: Land Rehabilitation for Bauxite Mining

Objective: Enhance biodiversity by landscaping closed areas with native plants

Solution: Nucleation method at bauxite mine in Brazil's Amazon region

Methods/technical approach:

- Integrate solutions for closing tapped-out areas, enhancing biodiversity, and develop local economy
Standards/regulatory drivers:

- IFC 6: Biodiversity, IFC 4: Community, IFC 1: Assessment and Management of Environmental and Social Risks and Impacts 
- Use land-use offsets to drive toward footprint-neutral goal

- Hire locals to collect and plant seeds for indigenous vegetation

- Leverage natural processes to build microenvironments that reduce landscape fragmentation

- Create topsoil from vegetation and rainwater

- Reduce runoff by contouring land surface

- Create wildlife shelters

- Underwrite local biodiversity conservation program
- ICMM 6, 7, 9 (10, reporting)

- ASI Principle 8 biodiversity, 9.7 local communities

- BBOP principles and mitigation hierarchy

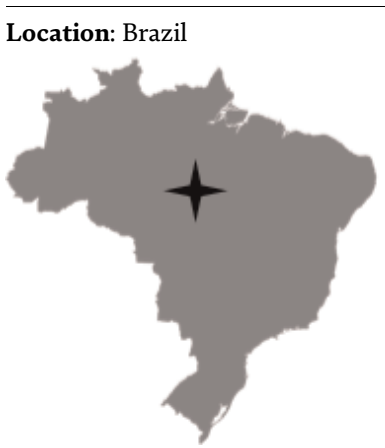

- Area population: 35,000

- High population growth

- Very high poverty rate

\section{Benefits/business value:}

- Reduce closure/restoration cost by $40 \%$

- Reduce long-term liability from biodiversity loss beyond fence line

- Bolster reputation by spending restoration expenses locally

- Help achieve strategic goal of footprint-neutral mining

Case study no. 2: Community Engagement for Bauxite Mining

Objective: Improve transparency and stakeholder dialog to reduce social unrest Solution: Dialog and support for local communities around bauxite mine, Brazil

\section{Methods/technical approach:}

- Host annual intersectoral forum with an international education foundation to include 60 civil society organizations and local authorities

- Use itinerant dialogue process to bring company reps into communities for regular meetings

- Offer access to monitor local water quality during extreme weather events and support local, recovery efforts and services

- Involve local NGOs as third-party observers in community-related actions

- Use open-house initiative to provide scheduled facility tours for local residents

\section{Standards/regulatory drivers:}

- IFC 4: Community, IFC 7: Indigenous Peoples, IFC 1: Assessment and Management of Environmental and Social Risks and Impacts

- ICMM 1, 4, 10

- ASI Principle 9.7 local communities, 3.4 stakeholder complaints, grievances, and requests for information

\section{Location: Brazil}

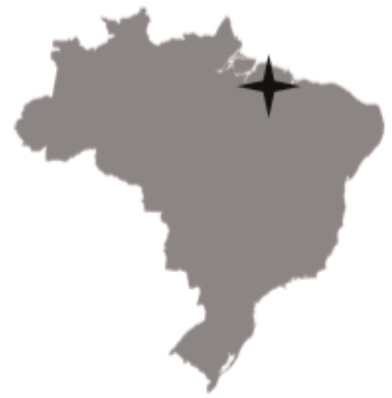

- Three small communities within an area with population of 88,000

- Subject to flooding, deforestation

- Low employment, high poverty 


\section{Benefits/business value:}

- Corporate Sustainability Report supports listing on Dow Jones Sustainability Index

- Better informed local communities see company as reliable partner and resource for information

- Third-party verification allows limited incidents of less popular actions (remove illegal dwellings)

- Investment in community infrastructure and climate change (i.e., weather related) resilience facilitates production continuity during and after extreme events

- Improved local economic conditions reduces dependency on future mining support

Case study no. 3: Water Management for Alumina Refining

Objective: Optimize water usage and wastewater treatment

Solution: Water treatment and systems at alumina and aluminum refineries

\section{Methods/technical approach:}

- Use on-site wastewater treatment to eliminate fuel use from waste transportation, and reuse treated water on site to reduce discharge into local waterways

- Reduce freshwater drawdown

- Improve recovery process to capture and reuse of caustic soda for beneficiation process

- Create and use a water risk management tool that covers use and discharge

- Limit accidental discharge by reinforcing mine tailing lagoons and using topography for waste

\section{Standards/regulatory drivers:}

- IFC 3: Resource Efficiency, IFC 1: Assessment and Management of Environmental and Social Risks and Impacts

- ICMM 6, (10, reporting), Water Commitments 1-3

- ASI Principle 7 water stewardship

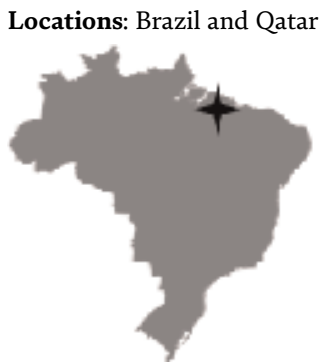

- Qatar: water-poor region

- Qatar: energy-rich location

- Brazil: susceptible to flooding

- Brazil: sensitive local hydrology

\section{Benefits/business value:}

- Improve control over input sourcing reduces need for freshwater

- Reduce cost for water resources and treatment

- Reduce cost for caustic soda (ca. $15 \%$ of total cash costs in refining process

- Proactive water risk management contains ecosystem threats during extreme events

- Proactive water risk management and on-site treatment minimize infrastructure disruption

- Water husbandry co-benefits local communities

Case study no. 4: Red Mud Management for Alumina Refining

Objective: Improve options for red mud storage and sequestration

Solution: Dry stacking method for storing bauxite-alumina refining residue

\section{Methods/technical approach:}

- New filter press technique reduces moisture content in red mud to $22 \%$ (standard moisture content for drum filter is $36 \%$ )

- Caustic soda, alumina, water recovery/reuse

- Denser red mud residue requires significantly smaller areas for storage and sequestration

- Storage dams are drained from the bottom for further caustic soda and alumina recovery

- Storage dams may be reforested after 5 years deposition

\section{Standards/regulatory drivers:}

- IFC 3: Resource Efficiency, IFC 1: Assessment and Management of Environmental and Social Risks and Impacts)

- ICMM 6, (10, reporting)

- ASI Principle 6 emissions, effluents, waste 


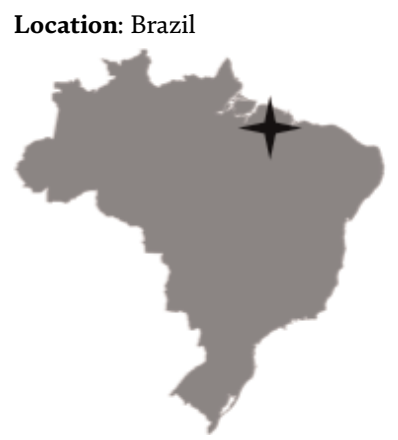

- Three small communities within an area with population of 88,000

- Subject to flooding, deforestation

- Low employment, high poverty

\section{Benefits/business value:}

- Reduce operating costs by recovering additional water, caustic soda, and alumina

- Use dry stacking to reduce environmental risk from extreme weather, flooding, or leakage

- Smaller storage areas reduce need for new dams, footprint expansion, and logistical effort

- Reforestation efforts can be used or monetized for carbon offsets

Case study no. 5: Cost-Effective Clean Energy for Aluminum Smelting

Objective: Long-term fixed price clean energy supply for smelting

Solution: Purchase Agreement (PPA) for hydroelectric power

\section{Methods/technical approach:}

- Preliminary financial agreement between company as anchor customer and governmental agencies permits project development and financing

- Shared investment and concessions: publicly funded energy infrastructure in exchange for company-funded smelter, job creation guarantee, financial support for national park to offset lands lost to hydroelectric plant

- Multi-year energy supply contract guarantees offtake to amortize public investment and 40-year commitment for reduced energy pricing for smelting company

\section{Standards/regulatory drivers:}

- IFC 3: Resource Efficiency, IFC 1: Assessment and Management of Environmental and Social Risks and Impacts

- ICMM 6, (10, reporting)

- ASI Principle 5 greenhouse gas emissions

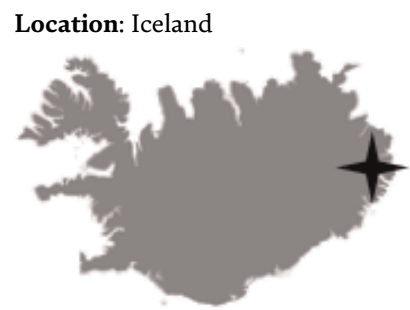

- Area population of 5000

- High environmental sensitivity

- Highly educated community

\section{Benefits/business value:}

- Use of long-term pricing agreement will produce $30 \%$ energy cost savings over other smelting operations

- Guaranteed uninterrupted power supply to smelter, accounting for $1 / 3$ of hydroplant's output

- Three-year window between signing of agreement and start of operations

- Co-financing through banks and lenders looking to expand their green finance portfolio

- National parklands constructed under agreement create carbon sequestration, environmental benefit, community recreation, and national good will 


\subsection{Strategy and benefits}

UNDP-Guinea is now working with the Chamber of Mines on operationalizing their intention to adopt specific sustainable mining practices. This strategic momentum is timely because a landmark 2019 US Supreme Court decision in Jam v. IFC exposes the World Bank's liability when financing negligent projects and promises to add pressure from civilian advocates. As an example, a suit has already been brought by 13 Guinean communities against the IFC for its support of mining projects, thus highlighting the immediate effect of the court's decision. Coincidently, only days later, three major French banks announced their financing for the largest bauxite mining operation on the planet in Guinea [42]. As pressures to address increasingly empowered stakeholders grow, new pathways for investing in environmental and community sustainability gain much-needed traction.

\subsection{Developments toward sustainable mining since project completion}

Coastal mangrove rice growing has been impacted by bauxite dust released during mining. As a first step in providing opportunities for mining companies to engage in meaningful climate adaptation activities, the GCF recently approved a proposal for "Enhancing the Resilience of Guinea's Coastal Rural Communities to Coastal Erosion Due to Climate Change" (see Section 4). This proposal, submitted by UNDP-Guinea and the Chamber of Mines, represents a milestone achievement in advancing Guinea's SDG agenda beyond mandated royalties. Specifically, the Chamber of Mines pledged mining company investment to implement a paradigmshifting adaptation solution based on (a) design and adoption of an integrated coastal zone management plan; (b) a tailored combination of ecosystem-based adaptation activities, including mangrove restoration and infrastructure for coastal protection; and (c) promotion of climate-resilient livelihoods among rural communities as a buffer against climate change risk and as incentive to preserve the mangrove ecosystem.

\section{Conclusions}

The experience of this 6-month engagement offers replicable values:

- Academia has a valuable role to play by virtue of expertise (Widder and Pacioni), objectivity, ability to ask questions that others cannot due to expectations in their deliverables, and access to talented labor (i.e., graduate students).

- Best practices can be shared and adapted-the companies operating in Guinea should share best practices and adapt others from comparable situations to conserve resources, engage community, and support the environment.

- Research is a shared value-measuring environmental health, resources, flows, and community well-being is an opportunity for collaboration between universities and industry and will facilitate standards compliance.

- Standards for sustainability—consensus around international standards ensures social license to operate, improved process efficiencies, resource savings, and funding opportunities for projects with multiple beneficiaries. 


\section{Acknowledgements}

- Cecilia Coates, Dolores De La Cruz, and Ellen Griesemer (Columbia University, Sustainability Management MS, 2018) and Micah Cruz (Columbia University, Sustainable Development MPA, 2018)

- Sophie Dejonckheere (Senter for Internasjonal Klimaforskning), Claudia Ortiz (UNDP), and Lionel Laurens (UNDP-Guinea Country Director)

- Luc Dejonckheere (Azimuth Advisory Services), Perrine Toledano (CCSI), Olga Puntus (IFC), Chris McCombe (ICMM), Dr. Rockfeler Herisse (USAID), Benoit Limoges (Réseau Environnement Bauxite), Charles Balamou (Electricité de Guinée), Chaïkou Yaya Diallo (Chambre des Mines de Guinée), and Mr. Barry (CBG)

- Professor Kandey Bangoura (Scientific Research Center of Conakry Rogbane, CERESCOR) and Elias Ayu (UN University)

\section{Conflict of interest}

An evaluation of potential conflicts of interest that could influence the scientific work described herein, including but not limited to financial, personal, and/or commercial conflicts of interest, was completed for each author and co-author of this manuscript. No conflicts of interest were identified.

\section{A. Appendices: Guinea's bauxite mining operations}

\begin{tabular}{|c|c|c|c|c|c|}
\hline & Company name & Controlling interest & $\begin{array}{l}\text { Guinea } \\
\text { interest (\%) }\end{array}$ & Location & $\begin{array}{l}\text { Concession } \\
\text { type }\end{array}$ \\
\hline \multirow[t]{5}{*}{ CBG } & Compagnie des & \multirow{5}{*}{$\begin{array}{l}\text { USA, Australia, UK ( } 51 \% \\
\text { Halco: Alcoa, Rio Tinto-Alcan, } \\
\text {-Dadco) }\end{array}$} & \multirow[t]{5}{*}{49} & \multirow[t]{5}{*}{ Boké Rgn } & \multirow{4}{*}{$\begin{array}{l}\text { Bauxite, } \\
\text { alumina }\end{array}$} \\
\hline & Bauxites de Guinée & & & & \\
\hline & a.k.a. Guinea Bauxite & & & & \\
\hline & Company & & & & \\
\hline & $\begin{array}{l}\text { also party to CBG/ } \\
\text { GAC joint agreement }\end{array}$ & & & & $\begin{array}{l}\text { Bauxite, } \\
\text { alumina }\end{array}$ \\
\hline \multirow[t]{3}{*}{ Fria } & $\begin{array}{l}\text { RUSAL (using three } \\
\text { separate operating } \\
\text { cos) }\end{array}$ & \multirow[t]{3}{*}{$\begin{array}{l}\text { Russia }(48.1 \% \text { of RUSAL is } \\
\text { owned by En }+ \text { Group }\end{array}$} & \multirow[t]{3}{*}{0} & & \\
\hline & d.b.a. Alumina & & & Fria Prf, & Bauxite, \\
\hline & Company of Guinea & & & Boké Rgn & alumina \\
\hline \multirow[t]{4}{*}{ CBK } & d.b.a. Compagnie des & & & \multirow{4}{*}{$\begin{array}{l}\text { Kindia } \\
\text { Prf/Rgn }\end{array}$} & \multirow{4}{*}{$\begin{array}{l}\text { Bauxite, } \\
\text { Alumina }\end{array}$} \\
\hline & Bauxites de Kindia & & & & \\
\hline & a.k.a. Kindia Bauxite & & & & \\
\hline & Company & & & & \\
\hline \multirow[t]{5}{*}{ COBAD } & d.b.a. Compagnie de & & & \multirow[t]{5}{*}{ Boké Rgn } & \multirow{5}{*}{$\begin{array}{l}\text { Bauxite, } \\
\text { alumina }\end{array}$} \\
\hline & Bauxiteet d'Aluminie & & & & \\
\hline & & & & & \\
\hline & a.k.a. Dian Bauxite & & & & \\
\hline & Company & & & & \\
\hline
\end{tabular}


Regional Development in Africa

\begin{tabular}{|c|c|c|c|c|c|}
\hline & Company name & Controlling interest & $\begin{array}{l}\text { Guinea } \\
\text { interest (\%) }\end{array}$ & Location & $\begin{array}{l}\text { Concession } \\
\text { type }\end{array}$ \\
\hline EGA & $\begin{array}{l}\text { Emirates Global } \\
\text { Aluminum }\end{array}$ & \multirow[t]{3}{*}{ UAE } & \multirow[t]{3}{*}{0} & \multirow[t]{3}{*}{ Boké Rgn } & \multirow{3}{*}{$\begin{array}{l}\text { Bauxite, } \\
\text { alumina, } \\
\text { aluminum }\end{array}$} \\
\hline \multirow[t]{2}{*}{ GAC } & $\begin{array}{l}\text { d.b.a. Guinea Alumina } \\
\text { Corp }\end{array}$ & & & & \\
\hline & $\begin{array}{l}\text { f.k.a. Global Alumina } \\
\text { Corp }\end{array}$ & & & & \\
\hline $\mathrm{CDM}$ & $\begin{array}{l}\text { China Henan } \\
\text { International Mining } \\
\text { Development Group }\end{array}$ & $\begin{array}{l}\text { China ( } 41 \% \text { Chico, } 51 \% \\
\text { Y'ngc'g C'1 Elec, } 8 \% \text { Henan) }\end{array}$ & 0 & $\begin{array}{l}\text { Boffa Prf, } \\
\text { Boké Rgn }\end{array}$ & $\begin{array}{l}\text { Bauxite, } \\
\text { aluminum }\end{array}$ \\
\hline \multirow[t]{2}{*}{ CPI } & $\begin{array}{l}\text { China Power } \\
\text { Investment } \\
\text { Corporation }\end{array}$ & China & 0 & $\begin{array}{l}\text { Boffa Prf, } \\
\text { Boké Rgn }\end{array}$ & $\begin{array}{l}\text { Bauxite, } \\
\text { alumina }\end{array}$ \\
\hline & $\begin{array}{l}\text { a.k.a. CPI Boffa } \\
\text { Alumina }\end{array}$ & & & & \\
\hline \multirow[t]{3}{*}{ CHALCO } & $\begin{array}{l}\text { Aluminum } \\
\text { Corporation of China } \\
\text { Ltd. }\end{array}$ & China & 0 & $\begin{array}{l}\text { Boffa Prf, } \\
\text { Boké Rgn }\end{array}$ & Bauxite \\
\hline & $\begin{array}{l}\text { d.b.a. Chalco Guinea } \\
\text { Company }\end{array}$ & & & & \\
\hline & $\begin{array}{l}\text { a.k.a. Chalco Hong } \\
\text { Kong Ltd. }\end{array}$ & & & & \\
\hline \multirow[t]{3}{*}{ SBG } & $\begin{array}{l}\text { Metalcorp Group B.V. } \\
\text { d.b.a. Société des } \\
\text { Bauxites de Guinée }\end{array}$ & $\begin{array}{l}\text { The Netherlands }(76.1 \% \\
\text { Metalcorp) }\end{array}$ & 23.9 & $\begin{array}{l}\text { Kindia } \\
\text { Rgn }\end{array}$ & $\begin{array}{l}\text { Bauxite, } \\
\text { alumina }\end{array}$ \\
\hline & $\begin{array}{l}\text { a.k.a. SBG Bauxite and } \\
\text { Alumina NV }\end{array}$ & & & & \\
\hline & $\begin{array}{l}\text { a.k.a. Guinea Bauxite } \\
\text { Corporation }\end{array}$ & & & & \\
\hline $\begin{array}{l}\text { SMB- } \\
\text { WAP }\end{array}$ & $\begin{array}{l}\text { Société Minière de } \\
\text { Boké-Wining Port } \\
\text { Afrique } \\
\text { a.k.a. Boké Mining } \\
\text { Company }\end{array}$ & $\begin{array}{l}\text { China, Singapore, France } \\
\text { (Shandong Weiqiao Al Pwr, } \\
\text { Winning Ship'g, UMS) }\end{array}$ & 10 & Boké Rgn & Bauxite \\
\hline SBDT & $\begin{array}{l}\text { Societe des Bauxites de } \\
\text { Dabola-Tougue }\end{array}$ & Iran $(51 \%$ SBDT) & 49 & $\begin{array}{l}\text { Dabola } \\
\text { and } \\
\text { Tougué } \\
\text { Prfs }\end{array}$ & $\begin{array}{l}\text { Bauxite, } \\
\text { alumina }\end{array}$ \\
\hline \multirow[t]{4}{*}{ AMC } & $\begin{array}{l}\text { Société Alliance } \\
\text { Mining Commodities } \\
\text { Guinée } \\
\text { a.k.a. Alliance Mining } \\
\text { Commodities Ltd. }\end{array}$ & Australia (90\% AMC) & 10 & $\begin{array}{l}\text { Gaoaul } \\
\text { Prf, Boké } \\
\text { Rgn }\end{array}$ & Bauxite \\
\hline & Pella Ventures Limited & \multirow[t]{3}{*}{ UK (85\% Pella Ventures) } & \multirow[t]{3}{*}{15} & \multirow{3}{*}{$\begin{array}{l}\text { Boffa Prf, } \\
\text { Boké Rgn }\end{array}$} & \multirow[t]{3}{*}{ Bauxite } \\
\hline & d.b.a. Alufer Mining & & & & \\
\hline & a.k.a. Bel Air Mining & & & & \\
\hline \multirow[t]{2}{*}{ AMR } & $\begin{array}{l}\text { Alliance Minière } \\
\text { Responsible }\end{array}$ & \multirow[t]{2}{*}{ France } & & \multirow[t]{2}{*}{ Boké Rgn } & \multirow[t]{2}{*}{ Bauxite } \\
\hline & $\begin{array}{l}\text { a.k.a. Responsible } \\
\text { Mining Alliance }\end{array}$ & & & & \\
\hline
\end{tabular}


Sustainably Growing Guinea's Bauxite-Aluminum Industry

DOI: http://dx.doi.org/10.5772/intechopen.86471

\begin{tabular}{|c|c|c|c|c|c|}
\hline & Company name & Controlling interest & $\begin{array}{l}\text { Guinea } \\
\text { interest (\%) }\end{array}$ & Location & $\begin{array}{l}\text { Concession } \\
\text { type }\end{array}$ \\
\hline & Jaguar Overseas & India (50\% Dynamic Mining) & 50 & Boké Rgn & Bauxite \\
\hline & d.b.a. Dynamic Mining & & & & \\
\hline & $\begin{array}{l}\text { a.k.a. International } \\
\text { Gulf ZFC }\end{array}$ & & & & \\
\hline \multirow[t]{2}{*}{ IMD } & $\begin{array}{l}\text { International Mining } \\
\text { Development }\end{array}$ & Ireland & & $\begin{array}{l}\text { Fria Prf, } \\
\text { Boké Rgn }\end{array}$ & $\begin{array}{l}\text { Bauxite, } \\
\text { alumina }\end{array}$ \\
\hline & a.k.a. Lissa Mining & & & & \\
\hline
\end{tabular}

\section{Author details}

Lynnette Widder ${ }^{1 *}$, Thomas D. Pacioni ${ }^{2}$ and Ousmane Bocoum ${ }^{3}$

1 Columbia University, New York, NY, USA

2 Columbia University SUMA Prgm, New York, NY, USA

3 United Nations Development Programme, Conakry, Guinea

*Address all correspondence to: lw268@columbia.edu

\section{IntechOpen}

(C) 2019 The Author(s). Licensee IntechOpen. This chapter is distributed under the terms of the Creative Commons Attribution License (http://creativecommons.org/licenses/ by/3.0), which permits unrestricted use, distribution, and reproduction in any medium, provided the original work is properly cited. (cc)BY 


\section{References}

[1] Renaud KM. The Mineral Industry of Guinea. In: US Geological Survey Minerals Yearbook 2016. 2018. Washington, DC: U.S. Geological Survey; p. 20.1. [Accessed: 02 April 2019]

[2] Bray EL. Bauxite and Alumina: US Geological Survey Mineral Commodity Summaries 2019. U.S. Geological Survey. 2019. p. 31. [Accessed: 01 April 2019]

[3] Statista. Production of Bauxite: Largest producers of bauxite worldwide from 2010 to 2017, by mine production volume (in 1,000 metric tons). 2019. [Accessed: 09 May 2019]

[4] Republic of Guinea. 2016-2020 National Economic and Social Development Plan. IMF Country Report No. 17/388. November 2017. [Accessed: 15 April 2019]

[5] Word Bank. World Bank Report 114539-GN. 29 June 2018. [Accessed: 15 April 2019]

[6] Africa Development Bank. West Africa Economic Outlook 2018. [Accessed: 02 April 2019]

[7] International Monetary Fund. Guinea: First Review of the Arrangement Under the Three-Year Extended Credit Facility. July 2018. [Accessed: 26 March 2019]

[8] UNDP. UNDP among first partners selected by Green Climate Fund. 31 May 2015. [Accessed: 02 April 2019]

[9] UNDP. UNDP Human Development Indices and Indicators: 2018 Statistical Update. 2018. [Accessed: 15 April 2019]

[10] UNDP-Guinea. UNDP-Guinea Priorities. Conakry, Guinea: United Nations Development Programme - Guinée; 2019. [Accessed: 02 April 2019]
[11] World Bank. World Bank Country Data for Guinea. 2019. [Accessed: 02 April 2019]

[12] World Bank. World Bank Logistics Performance Index: Global Rankings 2018. 2018. [Accessed: 27 March 2019]

[13] UNDP. UNDP Human Development Data, 1990-2017. New York: United Nations Development Programme; 2019. [Accessed: 26 March 2019]

[14] World Bank. The World Bank in Guinea. 16 November 2018. [Accessed: 30 March 2019]

[15] The Economist. Guinea's bauxite boom is helping China but failing locals. 03 November 2018. [Accessed: 02 April 2019]

[16] Gleeson D, International Mining. Emirates global aluminium achieves milestone at Guinea bauxite project. 23 January 2019. [Accessed: 02 April 2019]

[17] Aluminum Insider. Rusal plans first bauxite production at Guinea's Dian Dian Mine by Month's End. 16 April 2019. [Accessed: 02 April 2019]

[18] Financial Tribune. Explorations Boost Bauxite Reserves By 14m tons. 12 August 2017. [Accessed: 01 April 2019]

[19] Benton D. Global Mining. Alliance Minière responsable begins production at Guinea bauxite mine, targets 6-10 million tonnes. Conakry: United Nations Development Programme; 13 December 2017. [Accessed: 01 April 2019]

[20] Reuters. Guinea bauxite miner CBG plans $\$ 1$ bln expansion to meet demand. 29 May 2015. [Accessed: 30 March 2019]

[21] Reuters. Guinea bauxite mining back to normal after week of riots. 25 September 2017. [Accessed: 30 March 2019] 
[22] Wormington J. Human Rights Watch. "What Do We Get Out of It?". 2018. [Accessed: 30 March 2019]

[23] Japan International Cooperation Agency. Signing of Grant Agreement with Guinea: Contributing to the supply of quality marine products and improving the livelihoods of fishing communities through artisanal fishing port facility infrastructure. New York: United Nations Development Programme; 14 August 2017. [Accessed: 20 March 2019]

[24] Columbia's student team: Cecilia Coates, Dolores De La Cruz, and Ellen Griesemer (MS in sustainability management, 2018); Micah Cruz (MPA in sustainable development, 2018)

[25] Green Climate Fund. Readiness proposal for Guinea, activity 2, strategic framework for engagement with the fund. 16 December 2015. [Accessed: 20 March 2019]

[26] Davis JR. Aluminum and Aluminum Alloys. Materials Park, OH, USA: ASM International; 1993. pp. 13-17. ISBN 978-0-87170-496-2

[27] World Aluminium. Life cycle inventory data and environmental metrics for the primary aluminium industry: 2015 data. June 2017.

[Accessed: 20 March 2019]

[28] PE Americas. Life cycle assessment of aluminum beverage cans. o.b.o. Aluminum Association, Inc; 21 May 2010. [Accessed: 20 February 2019]

[29] International Aluminium Institute. Aluminum for future generations, mining and refining, energy efficiency. 2018. [Accessed: 07 May 2018]

[30] OECD Environment Directorate. Sustainable materials management, materials case study 2: Aluminum. Global Forum on Environment; 27 October 2010. [Accessed: 20 April 2018]
[31] Kvande H, Drabløs PA. “The aluminum smelting process and innovative alternative technologies." Journal of Occupational and Environmental Medicine. 2014;56(5S): S23-S32

[32] US EPA. TENORM: Bauxite and alumina production wastes. Overviews and Factsheets; US EPA, Office of Air and Radiation; 22 April 2015

[33] US EPA. Final report:

Environmentally responsible treatment of and useful products from aluminum extraction waste materials. EPA Grant SU835324, Michigan Technological University; 2013. [Accessed: 07 May 2018]

[34] Nunez P, Jones S. "Cradle to gate: Life cycle impact of primary aluminium production". The International Journal of Life Cycle Assessment. November 2016; 21(11):1594-1604. [First online: 21 December 2015, Accessed: 04 May 2018]

[35] UNEP. Energy profile: Guinea. 2013. [Accessed: 07 May 2018]

[36] Aluminum Insider. Chinese Firm To Invest US $\$ 2.8$ Billion In Guinean bauxite operation. 17 December 2017.

[Accessed: 08 May 2018]

[37] World Bank, Guinee, Projet D’appui A la Gouvernance Dans Secteur Minier (PAGSEM): Plan de passation. 2016.

[Accessed: 05 May 2018]

[38] Reuters. Sanctions-hit rusal restarts alumina refinery in Guinea. 20 June 2018. [Accessed: 20 March 2019]

[39] Donoghue AM, Frisch N, Olney D. "Bauxite mining and alumina refining: Process description and occupational health risks." Journal of Occupational and Environmental Medicine. May 2014;56:S12-S17. [Accessed: 20 March 2018]

[40] Renewable Energy and Energy Efficiency Partnership. Guinea (2012). 
11 October 2013. [Accessed: 15 March 2018]

[41] Power Africa. Power Africa in Guinea. September 2016. [Accessed: 07 May 2018]

[42] Meyer JM. Business \& Human Rights Resource Center. Guinea: Local communities filed a complaint against the World Bank for financing destructive bauxite mine. 04 April 2019. [Accessed: 12 April 2018] 


\title{
The Songhai Agroecological Sustainable Development Model: Synergy, Symbiosis, Collaboration, and Complementarity
}

\author{
John Tharakan
}

\begin{abstract}
The development across Africa has been piecemeal and uneven, sometimes actually leading to impoverishment and "underdevelopment." Former colonizers and multilateral development agencies have often been the agents of these postcolonial development practices, which focused on facilitation of extraction of wealth, either as material resources or raw agricultural product and export, usually to former colonial era companies. The processing of those natural resources produced immense value-added wealth; however, not much wealth returned to Africa. These development models have been piecemeal, with symptomatic solutions that are Band-Aids, resulting in minimal progress in terms of actual improvement in the quality of life and well-being of citizens. To counter this, it is necessary to shift from linear, mechanistic worldviews to holistic, complex visualizations that are integrated and systemic. This transformation, in understanding and conceptualization through system lenses, makes clear that the unit of development must be ecosystems centered and represent organizational patterns that encompass the whole environment, including human, social, cultural, technological, and economic facets. This new understanding requires comprehensive ecological literacy transitioning from homo-arrogance to biomimicry. Such transformation enables comprehensive solutions that account for interaction among natural, physical, and social phenomena. This chapter describes a development approach, embodied in the Songhai model and conceptualized, developed, and successfully implemented by Godfrey Nzamujo. It captures the essence and reflects a new paradigm, whose core foundational ideas are synergy, symbiosis, collaboration, and complementarity. This new paradigm, as demonstrated by Nzamujo and Songhai, is described as a potentially transformative development model, ensuring sustainability for the future of Africa.
\end{abstract}

Keywords: symbiosis, synergy, collaboration, complementarity, supplementarity, sustainable, development, biomimicry

\section{Introduction}

The African continent has been endowed with immense natural and human resources. In addition, she has a huge inherent capital in terms of cultural, 
economic, ecological, and natural diversity. Nevertheless, conditions of progress and development across Africa remain weak, with a current poverty rate of $43 \%$ and with 27 of the 28 poorest countries in the world in sub-Saharan Africa. In fact, poverty rates in many countries have fallen dramatically, but the story is the reverse in many African countries [1]. That this obtains despite more than six decades of development interventions by multilateral institutions like the World Bank (WB), International Monetary Fund (IMF), United Nations Development Program (UNDP), national and international development agencies such as the United States Agency for International Development (US AID), the German Development Agency (GIZ), and the United Kingdom's Department for International Development (DFID), as well as regional agencies and institutions like the African Development Bank (ADB) and the African Union (AU), speaks to the ineffectiveness and inadequacy of current development models and practices and calls for a radical rethinking of the approach.

Most African countries began to emerge from their colonial pasts, beginning in the 1950s and 1960s. At the time of independence, there was a great deal of hope and expectation for rapid improvements in the quality and condition of life in these former colonies, colonies that had been plundered and looted for material resources, natural wealth, and human capital for over three centuries. Yet, after over half a century of development assistance and intervention, the social, development, and public health indicators across Africa are lacking. Millions of African citizens, from Gambia in the west to Somalia in the east, from Tunisia in the north to South Africa in the south, remain mired in poverty and underdevelopment, with no or limited access to clean water, electricity, safe and affordable food, accessible and available healthcare, and broadband or even limited Internet connectivity, not to mention a critical shortfall in infrastructure for education, healthcare, transportation, communication, and finance. This challenging reality on the ground was the driver for the first Millennium Development Goals (MDGs), which were eight development goals set following the Millennium UN Summit of 2000 [2]. By 2015, most of these goals remained unmet, at least to the level and degree to have real impact. The MDGs later transmogrified into the United Nations sustainable development goals (SDGs). The SDGs outline and articulate what is needed across the various sectors, such as water, sanitation, and health, in terms of the development that is critical to achieve some measure of equity, justice, and sustainability across countries and the planet. The SDGs are a universal call to action to end poverty and ensure that all people enjoy a life of peace and prosperity, while protecting the planet and preserving its capacity to continue to support future generations of humanity.

The SDGs are comprehensive and encompass all aspects of what are needed for our species to be considered peaceful, prosperous, and flourishing. Although the SDGs are numbered, there is no particular ranking, and all are considered critically important. Specifically, the SDGs call for an end to poverty and hunger and good health and high well-being for all. This includes quality education, gender equality, clean water, sanitation, affordable and clean energy, and decent work accompanied by economic growth. These are goals that can be concretely measured in terms of achievement, such as what percentage of a population has access to clean water, sanitary sewer systems, and electricity, for example. Additional SDGs are broader and more aspirational, such as building capacity in industry, innovation and infrastructure, reduction of inequalities, transformations to sustainable cities and communities, responsible production and consumption, and climate action to mitigate climate change impacts. The last four SDGs are even broader as well as much more general, speaking more to policy development perspectives, such as addressing life below water, life on land, building peace, expanding justice, and building strong institutions. The final SDG focused on building the partnerships that will 
be critically necessary for our civilization and species to meet all these SDGs, especially given how far removed we are, from a global and planetary perspective, from actually addressing and meeting all the SDGs. Given the current state of global geopolitical dysfunction, with the rise of authoritarian governments and regimes that promote privatization, deregulation, and unrestricted access to capital's exploitation of natural resources, as well as the already much degraded condition of our geography and geophysical environment, whether the SDGs are even close to being attainable remains a serious and substantive question.

The fact that there is a continuing need for articulation of these basic development goals close to the dawn of the third decade of the twenty-first century speaks volumes about the failure of conventional development models. These models, implemented by multilateral institutions and Global North national development agencies since the end of the colonial era and the dawn of independence in Africa, Latin America, Asia, and other former island colonies, have failed to deliver. If we take 1960 as an arbitrary baseline, since many former colonies saw their independence around that time (plus or minus around 10 - 15 years) and we track development as measured by various indices forward through time, we will see that most indicators have risen slowly, some not at all, while others have changed dramatically. Clear measures of this "progress," after more than half a century of development actions and interventions, would be the percentages of the population that live below the poverty line, have access to clean water, have access to improved and sewer-based sanitation, and have access to electricity. We can pick a country from any of the colonized continents-Asia, Africa, and Latin America-and track the change in these indicators, using that as a prima facie measure of the success of development and growth policies from independence forward, under the intervention of traditional aid and development agencies.

An alternate approach could be to focus on well-being, referencing development to baseline conditions necessary for societal flourishing as posited by Verharen et al. $[3,4]$ in their survival ethics model. This model articulates the critical utilities, services, and infrastructure that are essential and necessary, from moral and ethical to biogeochemical and physical perspectives, to support a society to actually flourish. At the basic physical level, we need air, water, shelter, food, and clothing. To be meaningfully sustainable, this would have to be clean air; clean and safe water; available, accessible, and safe food; temperature-controlled shelter; and sustainably renewable energy. One would have imagined, given the scale and overabundance of resources available in the Global North, that 50 years of interventionist development, under the direction of multilateral agencies such as the World Bank, the United Nations Development Program (UNDP), and the United States Agency for International Development (US AID), would have ensured that these minimum requirements for a healthy life would, by now, have easily been met across the planet. After all, none of these services require advanced technologies, and practically the entire population in the developed world has access to all. The story in the Global South is quite different. In the Global South, by 2015, there still are close to a billion humans - 844 million-who do not have access to an improved drinking water source $[5,6]$. Although the world apparently made "tremendous progress" in meeting the millennial development goal (MDG) of halving the number of people without sustainable access to safe drinking water by 2015, 5 years "ahead of schedule" in 2010, many of the "improved" drinking water sources do not consistently, reliably, and reproducibly provide safe and potable water, resulting in as many as 2 billion people not having really reliable access to clean potable water.

The situation with sanitation, the other end of the clean water spectrum, is even worse. Over two and a half billion people, practically every third person on this planet, do not have access to improved sanitation $[5,6]$. Needless to say, it is 
most likely that those without access to an improved water source are likely also to lack access to improved sanitation. The consequences of the unavailability of these two critical needs are evinced in numerous diverse negative ways: an estimated 801,000 children younger than 5 years of age perish from diarrhea each year, mostly in developing countries, or about 2200 children are dying everyday as a result of (preventable) diarrheal diseases [7]; worldwide, millions of people are infected with neglected tropical diseases (NTDs), many of which are water- and/or hygienerelated, such as Guinea worm disease, Buruli ulcer, trachoma, and schistosomiasis, and are found in places with unsafe drinking water and poor sanitation [8]. Clearly, the impact of clean water technologies on public health has a high rate of return, reducing morbidity from diarrhea and other water-borne diseases $[9,10]$.

In terms of food, close to 800 million people do not have sufficient food to lead a healthy, active life, while over a third of produced and processed food is wasted! Needless to say, the vast majority of the hungry live in developing countries, where as many as one in eight people are undernourished and hence unable to flourish. Two thirds of these are from Asia, and, while the percentage in southern Asia has reduced, an increase has also seen in recent years in western Asia, due to conflict and war. The negative impact of lack of food is profound: nearly half of deaths in children under 5 , almost 3.1 million a year, are a direct result of poor nutrition. More than 100 million children in developing countries are underweight, and one in four of the world's children are stunted [11].

Over 1.6 billion people, almost one out of every four, on this planet lack adequate housing and shelter as estimated by Habitat for Humanity, while there are over 150 million people in the world who are completely homeless. India has the most homeless people in the world with almost 70 million homeless, while another 170 million are "almost homeless." The tenuous and shaky, literally, nature of the housing of those with inadequate shelter puts these individuals and families at high risk of being added to the roll of homeless, potentially dramatically increasing the level of homelessness on our planet [12].

Nearly 1.1 billion people had no access to electricity in 2014, and more than 3 billion had no access to clean fuels and clean fuel cookstove technologies, despite the fact that these technologies have been widely researched, developed, and promulgated with numerous alternative designs developed and implemented in terms of cookstove design and fuel type being promoted by numerous development agencies and NGOs. The United Nations Sustainable Development Goal 7 recognizes that extending access to electricity and other forms of energy is fundamental to improving people's lives and communities. As recently as 2016, only $10 \%$ of the energy consumed on the planet was coming from renewable and sustainable sources such as wind and solar energy [13].

Now, in the globalized world of the twenty-first century, access to the Internet and the World Wide Web of information and communication has become a basic need that is critically necessary to build community capacity. However, only about half of the world's population is online. There are about 4.4 billion people with access to the Internet and World Wide Web, bringing the percentage of people with Internet access above the 50\% mark. And as in the areas of water, sanitation, shelter, and energy, there are enormous discrepancies in terms of access, speed of connection, bandwidth, and quality of access. In the developed world, over $80 \%$ of people have broadband Internet access, while in the developing world, it is closer to half or just over $50 \%$ of people with Internet access. This does not drill down into the speed and bandwidth available. In the most connected country on earth with the highest number of Internet users, China with over 750 million users still has more than $40 \%$ of the population unconnected. In India, with almost 700 million Internet users, almost half of the population has no Internet connection [14]. 
For now, focusing on the very basic needs of water and sanitation, it is evident that, after 50 years of conventional interventionist development, a billion people are still left without access to reliable clean potable water, whether by way of decentralized or centralized water collection, treatment, and distribution piping systems. Even more telling, two and a half billion people are still without access to sanitation and the sanitary removal and disposal of human waste. The fact that these numbers across Africa are even lower speaks to the need for a different approach, one that will engage and empower communities and result in tangible community-centered development, capacitation, and urgent addressing of all these basic needs.

\section{The Songhai approach}

This is where the Songhai Center and the agroecological approach $[15,16]$ provide a radical rethinking of the conventional top-down, external agency-supported development practices of the twentieth century. The Songhai approach involves integrated and community-based sustainable technology research, development, implementation, transfer, and dispersion. This model forms the structural and existential fabric of the Songhai approach to development. This is where the three Rs of the twentieth century, limited to reduce, reuse, and recycle, have effectively, holistically, and successfully been expanded to a true twenty-first century model of multiple Rs, incorporating respect for the environment, radical rethinking of our approach, and an ethos of recovery where waste is reconceptualized as resource and a true circular economy becomes possible.

What we will here call the Songhai approach is self-defined and identified as a rural growth initiative than that is an alternative sustainable development model that promulgated by multilateral aid and development agencies which tend to be a top-down interventionist and have, at best, simply failed at achieving development targets and, at worst, resulted in actual underdevelopment and increased dependency [17]. The development focus and attention in decolonizing Africa were on the maintenance and expansion of the infrastructure that would enable newly independent African nations to grow, harvest, and transport fresh agricultural produce or extract, transport, and export raw mineral resources, the processing and value addition to both (agricultural produce and mineral resources) of which would occur in the industrialized Global North. The development that took place in the former colonies, as well as the infrastructure that was put in place, ensured that this export of raw materials and agricultural produce would be maintained and expanded. The long-term result of that focus has been the impoverishment of many African nations, brought about by the depletion of resources, the transformation to monoculture cash crops, and the wanton, unrestricted, and unregulated exploitation and extraction of resources, enabled through the corrupt and undemocratic regimes that enriched themselves at the cost of national development through these regime collusions with former colonial governments and their multinational corporate partners.

Multilateral and international aid agencies tend to view poverty as a symptom that can be treated through some directed intervention, whether that intervention is focused on providing clean water through the installation of a pump or the establishment of a rural health clinic and expecting these directed and very often uncoordinated interventions to result in fundamental change that has at its core the empowerment of communities through the integrated development of the community's capacities and capabilities. The Songhai analysis sees the succumbing of Africa to the logic of poverty and underdevelopment caused by the loss of internal, some would argue organic, capacity “...to build the appropriate institutions 
and structure that will enable us to consistently unleash the appropriate creative and organizational forces to produce the social values, goods and services that correspond to our needs and desires" [15]. The loss of this capacity breeds passive consumerism and the adoption of piecemeal solutions, other people's experiences, systems of production, as well as values as the cheaper, quicker substitute, instead of doing the hard work necessary to have indigenously and endogenously developed relevant solutions that are authentic, holistic, and sustainable.

Having correctly identified the multiple crises that face development in Africa, including food security, poverty, demographic transitions, youth unemployment, and environmental challenges, and recognizing that these are all connected and interdependent, the Songhai vision has been underscored by understanding the problem as systemic, requiring an integrated and holistic approach. The integration and holistic conceptualization was hypothesized to result in and enable synergy and sustainability. In the African rural context, where agriculture is the main and core human activity, this agroecological initiative and approach should reverse the logic of poverty in a sustainable manner.

Undergirding the Songhai approach is the development of the human capacity for authentic, holistic, and thus sustainable development. The program for human capacity development must be well-designed and coherent, integrating authentic technologies as well as enabling environments, which together would be required to guarantee sustainable, broad-based, and inclusive growth and development on the African continent. The human resource development program is designed to grow and maintain a new human resource base with a fundamentally new culture and capacities that are aligned with the socioeconomic realities of today and tomorrow. The Songhai Center's human development program is aimed at developing socioeconomic leaders who can implement and operate sustainable rural growth programs throughout Africa $[15,16]$. Leading sustainable rural development programs requires an awareness of the integrated nature of rural environments involving crosscutting and interrelated dynamics among a diverse resource base, engaging polyvalent personnel and interdependent structures and organizations. Thus, the business model that is employed is essentially a call for dynamics and orientations that go broader and deeper than previous attempts at development, which means a radical shift that combines environmental, scientific, technical, social, and economic orientations. This combination must be both latitudinal, across areas of emphasis, but also longitudinal, from production to consumption; the continuum begins with resource extraction or cultivation followed by processing and transformation into value-added products and services. Given the agricultural context, the approach has to be systemic and multifunctional, which will insure food and nutrition security and health, but also increase household income, all in a sustainable manner.

Implemented in this framework, integrated agroecological rural development can become, as it were, a weapon of mass construction. Providing the relevant ecological literacy to the youth of a community can empower and capacitate them to develop and deploy appropriate technologies that are aligned with this new vision. The vision has to have a core, enabling institutional framework to foster skill development, as well as the generation and sharing of technologies that are relevant to the rural communities the youth inhabit.

In the Songhai model $[17,18]$, agriculture is holistically conceptualized to promote the biological processes in which investments can focus the development of environmental and biological capitals that facilitate agricultural systems to operate effectively and efficiently in a systemic and synergistic manner. At the fundamental (biomass and bioenergy) level, Songhai processes effectively manage the flows of energy and biomass within the whole system to create new and better 
biological capitals. Hence, agriculture is multidimensional and multifunctional and enhances production cycles and pathways by producing food in sufficient quantities to promote health, enhancing the environment in terms of soil quality. This provides a framework for green rural communities and builds sustainability and biodiversity. The system also concurrently provides raw materials for agro-industry and feedstocks for renewables, and in so doing, the system creates employment for youth and builds household income.

\section{Integrated production system: symbiosis and synergy}

The holistic approach provides the rational for an integrated production system, where crop production, livestock production, and aquaculture-based production are all centered around and connected through the bioenergy that all three areas of production require as well as produce. This regenerative approach enables the creation of new biological capitals while breaking the cycle of poverty stemming from the scarcity that can lead to socioeconomic conflicts, through the effective recycling and management of bioenergy and biomass, now integrated into a virtuous cycle of biological capital regeneration.

This integrated production system is holistic, so that it also is embedded in the rural and peri-urban communities, linking primary production to marketing services, and the small and medium enterprises based in the community, all of which are connected through the centrality of innovative and sustainable technology contributing to all stakeholder's in the environment. Primary production includes crops, livestock, aquaculture-based fisheries, as well as specialty items that pertain to specific geographic locales and environments. Marketing and services include retail, restaurants, and food exports. Small and medium enterprises are focused on value-added processing, which could include food processing or materials processing for small-scale manufacture and construction.

At the Songhai Centers, this approach necessitated the redesign of production and development systems based on this new understanding of the integrated and interdependent nature of agriculture-engaging a broad and holistic appreciation of cyclic biomass and bioenergy flows with human ecosystems. The Center also focuses on increasing the entrepreneurial and production capacity of youth through functional training coupled with the appropriation and deployment of authentic and sustainable technologies. The Center assists youth in the incubation, seeding, and support of the development and launching of commercially viable enterprises. Across all this, the amelioration of environmental degradation and the preservation of environmental quality to ensure future generations inherit a healthier and less compromised environment than currently extant is the undergirding thematic $[15,16]$.

\section{Organization of the Songhai Center: complementarity and supplementarity}

The Songhai business model has articulated five components to deliver its mission. The model builds on a foundation of symbiosis and synergy in the ecosystem and articulates a framework based on complementarity and supplementarity. First and foremost, it is a cultural reorientation and training center where ecological literacy is foundational, and the emerging world view, concepts, and principles from modern science, combined with the implications for economic and social organizations, is inculcated into youth from the community. Second, the Center serves as a technology park, where new technologies and organizational structures 
and patterns that are aligned with the new world view are elaborated, and these are developed and contextualized in collaboration with research institutions and universities. Third, the Center is an industrial park and production center, where the ideas, techniques, and organizational tools developed as part of the education and research in progress are turned into small enterprises and launched in an integrated and systemic manner $[15,16]$.

Fourth, it is also an incubation and training center for human resource development. Here new competencies are developed, while new visions are harnessed and new techniques and methods are developed and deployed within the technology parks. The target is the establishment of productive, effective, and efficient enterprises. The community, participating in the study, design, development, and production activities, always facilitated by mentor-practitioners, builds capacity and enhances technical, organizational, and managerial competencies, resulting in the creation of a functional entrepreneurial workforce able to add value. Since their inception, large numbers of youth have sought enrollment in the various Songhai Centers, a sign that youth are excited and attracted to new innovative agricultural initiatives that they see as bringing income and value into their and their family's lives. Fifth and finally, the Songhai Centers are also service centers, where graduates from the various training and capacity building programs are leveraged with critical services such as marketing, input procurement, hospitality services, networking, financial and loan services, as well as advisory and advocacy services and programs that create the synergies which enable the program's graduates to create synergies through initiative and cooperation.

\section{Songhai rural growth initiative: sustainable development}

The Songhai rural growth initiative is centered in the "mother" enterprise that is an ecosystem based in the community that functions as an enterprise development, incubation, and extension space, incorporating agribusinesses, an industrial park, and a technology park with innovation and research and development spaces. Based in the community, it draws on families and the community production zone and builds capacity in terms of youth entrepreneurial zones, bringing the two together. Programs leverage the five components of the center to serve as a networking and extension space for farmers who can constantly improve and update their knowledge and skills to key into regional markets, capture export opportunities, and harness the reinvestment in agriculture while safeguarding national autonomy in development.

\section{Core theories supporting Songhai}

The rationale and justification for the Songhai approach center around three strategic core theories. The first strategic core theory postulates that a new human resource base is the key to addressing the development and growth challenges of the present day. The second strategic core theory, in the current post-modern science era, argues a paradigm shift toward producing more and better with less through an agroecological framework that efficiently and productively harnesses biological capital of living systems. The third strategic core theory is that the entire world has to move toward true sustainable development $[17,18]$.

The justification for the first strategic core theory is embedded in what has transpired in Africa in the past 50 years since many countries became independent of their former colonial masters. The world has progressed from where the socioeconomic health and well-being of a nation do not depend fundamentally or 
principally on its natural resources or geographical position. The foundations of national well-being, economic prosperity, energy sufficiency, industrial capacity, public health, security, and environmental quality are all now knowledge based. Thus, knowledge and technical capacity are the principal social and capital resources in the world; nevertheless, these forms of capital are extremely unevenly distributed across the world. Sub-Saharan Africa especially suffers from a lack of access as well as availability of primary and secondary education, resulting in populations and workforces that are insufficiently capacitated in terms of education. The Songhai programs are predicated on the received understanding and wisdom that people with more knowledge and more access to knowledge and technical competence have more opportunity and are more successful than people with less knowledge and technological competence. Given this understanding, it is clear that any significant improvement on the efforts of African youth and their productivity will depend critically on the level and quality of investment in human capital development.

The Songhai metric for the performance of any of these human capital development programs is grounded in the functional value of the knowledge, skill, creativity, and humanity that is engendered through investment in such programs. This type of investment is what will provide engaged, constructive citizens of tomorrow who will be the future innovators and entrepreneurs bringing value to their communities.

The justification for the second strategic core theory locates us in a shifting paradigm where we have to produce better and more with less through an agroecological approach that efficiently harnesses and grows biological capital of living systems. Understanding the interconnected ecosystem that we inhabit is a major step in this new direction, where we will need to determine how to go about building the appropriate institutional framework and cultivate and grow the human resource base that will be empowered and capacitated to harness new opportunities that will be revealed as the new paradigm dawns on us. Framed another way, the challenge that a Songhai Center faces is how to align with the emerging world view and create an enabling institutional framework that will underpin the production of a critical mass of new human resources equipped with the right vision, values, and operational capacities to help African communities and nations navigate through this difficult and challenging period.

The paradigm shift requires that we have to change our present-day attitudes and logic. What is required is the development of new mental and operational frameworks based on what we know about how the world works. Bringing all this together, the new paradigm that is emerging has a completely new technological, organizational, and socioeconomic orientation, challenging us to learn from the basic principles of the working of our planet and human history. The new paradigm must be appropriated and deployed by a critical mass of people before we begin to see the design, creation, and invention of new organizations, industries, and economic activities that will contribute to solving our present-day problems [15].

Ultimately, the new paradigm calls for increasing the production capacity of Africans through the leapfrogging approach, which is to create innovation that jumps over older technologies and deploy and implement new and appropriate technologies that result in sustainability. That points to the third core foundational theory of the Songhai Center, which is sustainable development.

It has long been recognized that the present-day modern agro-industrial approach to food production characterized by the intensive use of fertilizers and pesticides, as well as the indiscriminate use of water, is not sustainable. It is true that this approach has resulted in tremendous grain and food surpluses in many regions, resulting in increases in per capita food consumption. This, however, has come about with severe and unsustainable costs: the depletion of soil fertility over time 
and the increase in greenhouse gas emissions as well as increased water and soil pollution. More importantly, the current agro-industrial approach has not significantly reduced the numbers of chronically hungry, which is estimated at over 850 million.

Thus, what is needed is a new approach, one that the Songhai Centers have been developing and improving over the past 30 years, since the first Songhai site was established on 1 hectare of poor agricultural land in Benin. The approach must be predicated upon the holistic appreciation of the ecosystem we inhabit and take an agroecological stance that appropriately values biological and environmental capitals. This new developmental trajectory is centered around harnessing environmental capitals to produce more and better quality food with less inputs for a growing population and to do this not only for protecting, but enhancing, environmental quality and capital. This Songhai approach of regenerative agriculture promotes the real "greening" of agriculture because it is an ecosystem's approach that draws upon nature's contributions to crop and animal growth in all its multifaceted and interlinked mechanisms, including soil organic matter, soil microorganisms, rainfall, pollination, biocontrol, integrated pest management, and eco-services including water, shade, and landscape. Hence, the space-time can be filled up quicker and more efficiently if we harness life cycles of different sizes that occupy different space-times, which in essence means we must mimic the biodiverse ecosystems in nature and be able to build into our interconnected efforts the reciprocal, the symbiotic, the complementarity, and the supplementarity that will result in the required synergies to go forward.

\section{Implementing sustainable development}

The resulting synergy is what will result in the enhancement of all, and this is what will make innovative technologies and sustainable development possible. The biggest technological and commercial opportunities in the future will have these as their underlying theme and raison d'etre, and they will all emanate from these efforts. Sustainable development technologies will enable the African agricultural sectors to produce more and better with less and with less adverse environmental impact. Integration of these principles and values into our technology design and development thinking will enable the creation of products and services that dramatically increase productivity, nutritional value, and quality while eliminating waste and pollution [17].

The Songhai initiative seeks to harness these principles to imagine and construct new and appropriate technological and developmental models and trajectories. It is an integrated development system that organically creates both forward and backward linkages and synergy between agriculture, industry, and services and within reach for each subset as well. Thus, Songhai develops and promotes processes that strive to harness the regenerative forces and elements in nature to develop agriculture that is multidimensional and multifunctional and also enhances the benevolent cycles and pathways within an ecosystem.

Hence, the underlying core themes and efforts are production of sufficient food in terms of quantity and quality to promote healthy living, aging, and disease prevention, enhancement of the environment in terms of soil quality, building of sustainability and biodiversity, provision of raw materials for agro-industry, provision of feed stocks for renewable energy, and creation of employment opportunities, especially for youth and women.

The merits of such a development approach and strategy, grounded firmly in an agroecological model of sustainable agriculture, are safe, affordable, of high yield and high quality, and sustainable; at the same time, this approach also addresses problems of degraded environments and unemployment, in both rural and urban areas, and builds a strong base for a broad and inclusive economy [19]. 
The Songhai Agroecological Sustainable Development Model: Synergy, Symbiosis, Collaboration... DOI: http://dx.doi.org/10.5772/intechopen.87929

\section{Conclusion}

The core of the design approach is reciprocity, symbiosis, complementarity, and supplementarity, all focused on elucidating and exploiting the synergies that abound in a "designed" natural and integrated farming system based on low-cost inputs through recycling by-products, reclaiming "wastes" as resources through the deployment of new biotechnologies based on microorganisms. These synergies and amplifications have been ignored by conventional industrial agriculture and have resulted in the degradation of soil environments to such a degree that without intensive inputs of fertilizers and pesticides, agro-industry cannot deliver. Hence, an added and critical advantage of the synergistic agroecological approach to development is the creation of a probiotic environment that empowers the regenerative agents of nature. It should be clear that this agriculture will not be a chemical intensive and interventionist process, like conventional agriculture. Instead, it will harness fundamental biological and microbiological processes, where the full range of biological and environmental capitals is completely engaged and harnessed. This will require the (re)learning of the processes whereby our environmental capital can be harnessed, providing the impetus and undergirding the transformation of the rural economy to become productive, efficient, and remunerative. The effects of this broad-based approach should result in the creation of diverse and meaningful employment that should eventually support a reversal of the exodus from the villages to the cities and provide a pathway to a diverse, viable, and inclusive economy that will provide the strong and stable foundation for sustainable development.

\section{Acknowledgements}

The author wishes to acknowledge the tremendous input and support of Rev. Fr. Godfrey Nzamujo, Director of the Songhai Center in Porto-Novo, Benin, and the organizer of the 8th International Conference on Appropriate Technology, held at the Songhai Center in November 2018.

\section{Conflict of interest}

The author has no conflict of interest, is not employed by the Songhai Center, and has no financial or monetary interest in its promotion.

\section{Notes/thanks/other declarations}

The author wishes to thank his colleagues at Howard University including Prof. Charles Verharen, Department of Philosophy, and Prof. George Middendorf, Department of Biology, for their invaluable contribution to the discussions leading to the development of this chapter. 


\section{Author details}

John Tharakan

Department of Chemical Engineering, Howard University, Washington, DC, USA

*Address all correspondence to: jtharakan@howard.edu

\section{IntechOpen}

(C) 2019 The Author(s). Licensee IntechOpen. This chapter is distributed under the terms of the Creative Commons Attribution License (http://creativecommons.org/licenses/ by/3.0), which permits unrestricted use, distribution, and reproduction in any medium, provided the original work is properly cited. (cc) BY 
The Songhai Agroecological Sustainable Development Model: Synergy, Symbiosis, Collaboration... DOI: http://dx.doi.org/10.5772/intechopen.87929

\section{References}

[1] Jolliffe DM, Prydz EB. Estimating International Poverty Lines from Comparable National Thresholds, Policy Research Working Paper WPS 7606. Washington, DC: World Bank Group; 2016

[2] UN. Millennium Development Goals. 2000. Available from: https://www. un.org/millenniumgoals/ [Accessed: 20 April 2019]

[3] Verharen C, Tharakan J, Middendorf G, Kadoda G, Castro M. Introducing survival ethics into engineering education and practice. Science and Engineering Ethics. 2013;19(2):599-623. DOI: 10.1007/ s11948-011-9332-9

[4] Verharen C, Tharakan J, Middendorf G, Kadoda G, Fortunak J, Bugarin F. Survival ethics in the real world-The research university and sustainable development. Science and Engineering Ethics. 2014;20:135-154

[5] World Health Organization (WHO) and UNICEF. Progress on Drinking Water and Sanitation: 2012 Update. United States: WHO/UNICEF Joint Monitoring Programme for Water Supply and Sanitation; 2012

[6] WHO Library Cataloguing and Publication Data: Progress on Sanitation and Drinking Water - Update and MDG Assessment. 2015. pp. 90. ISBN: 9789241509145

[7] Liu L, Johnson HL, Cousens S, Perin J, Scott S, Lawn JE, et al. Child Health Epidemiology Reference Group of WHO and UNICEF. Global, regional, and national causes of child mortality: An updated systematic analysis for 2010 with time trends since 2000. Lancet. 2012;379(9832):2151-2161

[8] Hotez PJ, Molyneux DH, Fenwick A, Ottesen E, Ehrlich Sachs S, Sachs JD.
Incorporating a rapid-impact package for neglected tropical diseases with programs for HIV/AIDS, tuberculosis, malaria. PLoS Medicine. 2006;3(5):e102

[9] Hutton G, Haller L, Bartram J. Global cost-benefit analysis of water supply and sanitation interventions. Journal of Water and Health. 2007;5(4):481-502

[10] Prüss-Üstün A, Bos R, Gore F, Bartram J. Safer Water, Better Health: Costs, Benefits and Sustainability of Interventions to Protect and Promote Health. Geneva: World Health Organization; 2008. p. 60

[11] UNICEF. Report Card on Nutrition: Progress for Children. 2006. Available from: https://www.unicef.org/ progressforchildren/2006n4/index howmany.html?q=printme [Accessed: 29 April 2019]

[12] UN. With Millions Lacking Food, Education, Shelter, Targeted Approaches Needed to Meet Needs of Most Vulnerable, Mandate-Holders Tell Third Committee. 2017. Available from: https:// www.un.org/press/en/2017/gashc4209. doc.htm [Accessed: 29 April 2019]

[13] Lindeman T. 1.3 Billion are living in the dark. The Washington Post. 2012. Available from: https://www. washingtonpost.com/graphics/world/ world-without-power/ [Accessed: 30 April 2019]

[14] Kemp S. The global state of the Internet in 2017. The Next Web. 2017. Available from: https:/thenextweb.com/ contributors/2017/04/11/current-globalstate-internet/ [Accessed: 29 April 2019]

[15] Nzamujo G. Songhai Quand L'Afrique Releve la Tete. Cerf, Histoire a Vif. 2002. EAN13: 9782204069175

[16] Nzamujo GF. The African University of the Future: A Knowledge Enterprise 
for Articulating and Incubating Radical Solutions to the Formidable Challenges on the Continent. Porto-Novo, Republic of Benin: Songhai Press; 2018. Available from: http://www.songhai.org/index. php/en/home-en

[17] Nzamujo G. TEDx talk. Green Rural Cities 2019. 2017. Available from: https://afrolegends.com/2018/02/09/ godfrey-nzamujo-at-tedx-green-ruralcities/

[18] Agossu G, Gbehounou G, Nzamujo G, Poisot A-S, Locontu A, Battelo C. Songhai model of integrated production in Benin. In: Food and Agricultural Organization (FAO), editor. Innovative Markets for Sustainable Development. New York, USA: FAO-UN Press; 2014

[19] Agbarakwe UH, Anowor OF.

Government intervention and economic development: Lessons from Songhai development initiative farm in River State, Nigeria. International Journal of Economics and Financial Research. 2018;4(1):13-21 


\title{
Economic Integration in West Africa: A Reconsideration of the Evidence
}

\author{
Akpan H. Ekpo
}

\begin{abstract}
There is no doubt that economic integration in the sub-region would be beneficial to member countries. However, the conditions precedent suggest the need to consider other factors outside the convergence criteria for the West African Monetary Zone (WAMZ) region and the link between the Franco-phone countries with France. Using stylized facts and preliminary panel results, there are still unsettled important issues as the region moves towards economic integration. These issues include but not limited to political will, huge infrastructure deficit and fiscal imperatives. $^{1}$
\end{abstract}

Keywords: economic integration, ECOWAS, unsettled issues

JEL classification: F02, 01

\section{Introduction}

The Economic Community of West Africa States (ECOWAS) was established in 1975 with the aim of achieving a monetary union for the sub-region. ECOWAS consists of 15 countries that were colonized by the British, French and Portugal. The process towards economic integration has not been smooth. After 43 years of existence, with some marginal gains, enormous challenges face the bloc.

There is no doubt that there are benefits associated with a monetary union, for example, large market as well as a regional bloc for negotiating with other groups globally. The Institution has set several deadlines for eventual integration, but each deadline has not been met. Recently, the Heads of state and Governments have insisted on the year 2020 for eventual monetary union. The technocrats and policymakers seem to be working hard to meet the new deadline of 2020 .

It must be noted that the Franco-phone economies are integrated (West African Economic and Monetary Union) with one Currency (CFA), one central bank and several approved protocols.

In 2000, in order to fast-track integration, another monetary zone known as the West African Monetary Zone (WAMZ) was established to work towards the

\footnotetext{
${ }^{1}$ Paper was presented at the American Economic Association (AEA), African Finances Economic Association (AFEA) and the National Economic Association (NEA), Atlanta, Georgia, January 1-4, 2018. I thank the participants at the conference whose comments have enriched the paper.
} 
convergence of the currencies of the economies of WAMZ with the aim of aligning with the CFA to have a single currency for the region.

The WAMZ consists of The Gambia, Ghana, Liberia, Nigeria and Sierra Leone. An agency called the West African Monetary Institute (WAMI) was created to drive the process. WAMI was to ensure the convergence of the currencies of the six countries-the goal post for achieving a common currency has been shifted several times. The last deadline was the year 2020. The attempt to shift the 2020 deadline was resisted by the Heads of States and Governments.

Presently, the ECOWAS Commission has provided a single-track approach to a monetary union. The requirements for the fast-track approach are not too different from the convergence criteria set by the WAMZ. However, whether the proposed year of 2020 for the establishment of the monetary union is feasible is a matter of debate.

While the Heads of State and Governments appear to be optimistic at one hand, the technocrats on the other hand are pessimistic insisting that the primary criteria must be met by all the countries for integration to take place. Can the political consideration be ignored? After over 40 years of the creation of ECOWAS, the road towards a monetary union remains bumpy.

The objective of this paper is to re-examine the issues and possible challenges facing the West African sub-region as it 'progresses' towards economic integration.

The paper is organized as follows: following the introduction, Section 2 briefly examines the performance of the ECOWAS economy, while Section 3 provides the review of literature. Section 4 analyses the evidence using both stylized facts and regression approach. Section 5 provides the conclusion and recommendation. It is expected that the inherent discussion would provide further insights into the economic integration conundrum confronting the sub-region.

\section{Performance of the ECOWAS economy}

The tables below briefly explain the performance of the West African economies for the period of 2011-2017. The growth in real GDP which stood at 6.2 percent in 2011 declined sharply to 2.8 percent in 2015. By 2016, all the economies in the West African Monetary Zone (WAMZ) were in a recession partly due to the collapse of commodity prices. The economic analysis of the fundamentals in the sub-region is the story of export in primary commodities whether agriculture and/or minerals. The fluctuations and volatility of commodity and mineral prices affect all other macroeconomic fundamentals either directly or indirectly (Tables 1-3).

The rate of inflation which was 11.2 percent in 2011 averaged single digit during the period, while the growth of money supply contracted at 19.5 percent in 2016 from a positive growth of almost 12 percent in 2011. Tax revenue as a percent of GDP remained very low during the period when compared to the African average. To meet the deficit/GDP criteria in spite of huge infrastructural deficit, this ratio remained within the benchmark with or without grants. It is necessary to note that if the deficit/GDP ratio is slightly violated in favor of capital projects (hard and soft infrastructures), there would be multiplier effects on the economies of the subregion.

Throughout the period under review, growth of GDP in WAMZ was below that of the entire ECOWAS. However, in 2016 most of the economies in WAMZ were in recession; growth in GDP was very marginal for the entire ECOWAS. The sharp drop in export commodities as well as structural problems contributed to the recession in 2016. The recession in a large economy like Nigeria has impact on other countries in the region. 


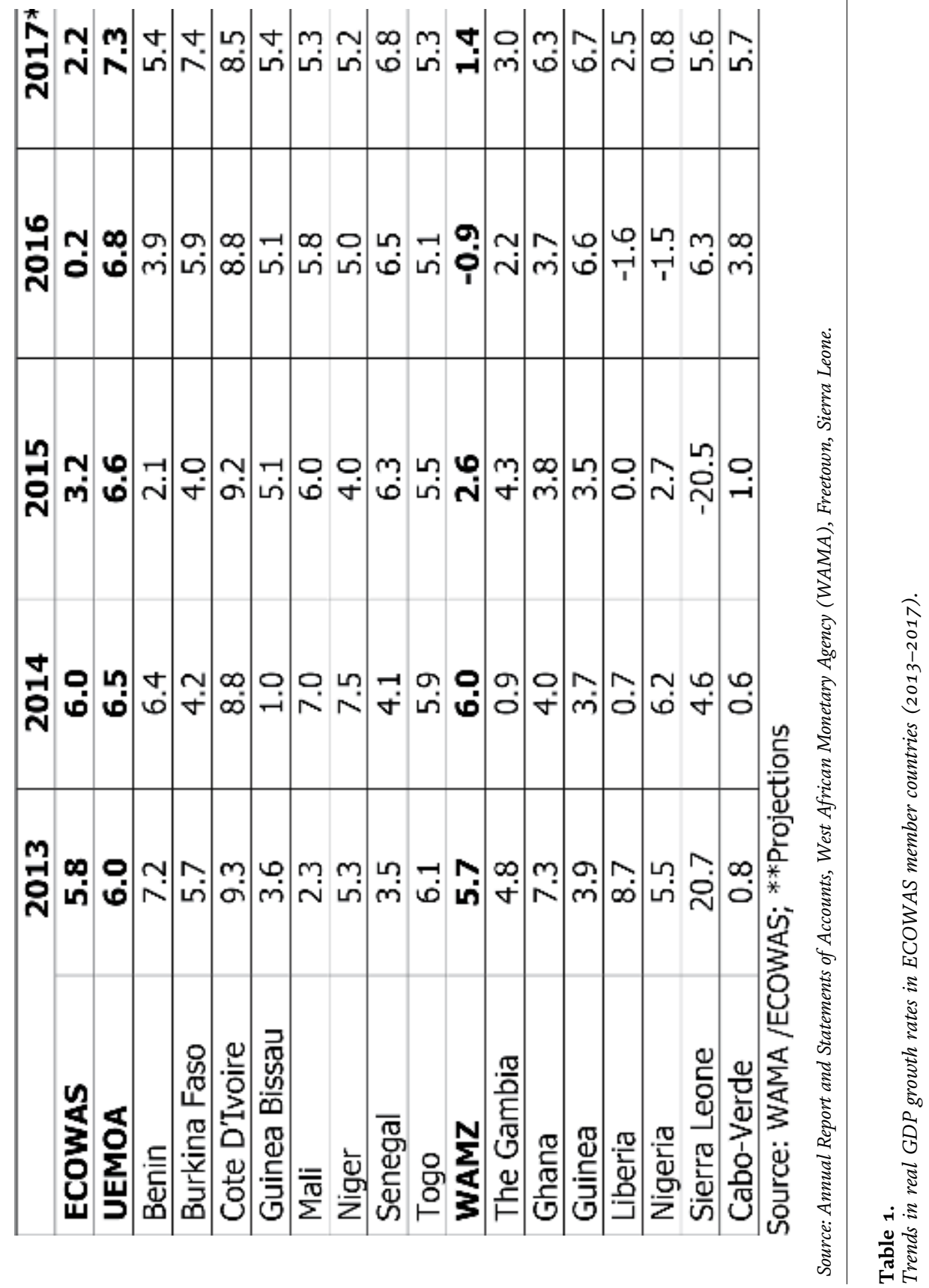


It should be noted that the growth rate of 2.2 percent in 2017 is less than the growth rate of population which is about 3 percent. The growth rate must average about 10 percent and sustainable for 10-15 years to have a dent on poverty reduction.

\begin{tabular}{|l|c|c|c|}
\hline & $\mathbf{2 0 1 5}$ & $\mathbf{2 0 1 6}$ & $\mathbf{2 0 1 7}$ \\
\hline ECOWAS & $\mathbf{8 . 9}$ & $\mathbf{1 5 . 5}$ & $\mathbf{1 3 . 6}$ \\
\hline UEMOA & $\mathbf{1 . 3}$ & $\mathbf{0 . 3}$ & $\mathbf{0 . 9}$ \\
WAMZ & $\mathbf{1 0 . 2}$ & $\mathbf{1 6 . 5}$ & $\mathbf{1 5 . 7}$ \\
\hline The Gambia & 6.7 & 7.1 & 8.4 \\
\hline Ghana & 17.7 & 15.4 & 12.1 \\
\hline Guinea & 7.3 & 8.7 & 8.7 \\
\hline Liberia & 8.0 & 12.5 & 10.8 \\
\hline Nigeria & 9.6 & 18.6 & 16.1 \\
\hline Sierra Leone & 8.9 & 9.5 & 19.1 \\
\hline Cape-Verde & -0.2 & -1.8 & 1.7 \\
\hline
\end{tabular}

Source: WAMZ: 2017 Report

Table 2.

Inflation in ECOWAS and WAMZ (2015-2017) (\%).

\begin{tabular}{lcccc}
\hline & 2014 & 2015 & 2016 & 2017 \\
\hline ECOWAS & -2.2 & -2.8 & -3.5 & -3.6 \\
\hline UEMOA & -5.9 & -6.5 & -6.4 & -7.3 \\
\hline WAMZ & -1.6 & -1.2 & -3.0 & -3.0 \\
\hline Cape Verde & -9.1 & -6.4 & -4.8 & -4.8 \\
\hline Nigeria & -0.9 & -1.7 & -2.2 & -2.7 \\
\hline Ghana & -7.1 & -6.6 & -11.0 & -5.3 \\
\hline Cote d'Ivoire & -4.0 & -4.3 & -5.0 & -5.7 \\
\hline Senegal & -8.5 & -7.7 & -7.0 & -6.3 \\
\hline
\end{tabular}

Source: Annual Report and Statement of Accounts, West African Monetary Institute (WAMI), Accra (various issues).

Table 3.

Budget deficit (excluding grants) as \% of GDP in ECOWAS.And selected countries.

\begin{tabular}{lcccc}
\hline Year & West Africa & SSA & Africa & Oil-importing countries \\
\hline $2009-2019$ & $-2.9(1.6)$ & $-2.8(-1.9)$ & $-3.4(-1.2)$ & $-4.3(-5.9)$ \\
\hline 2014 & $-2.8(-1.6)$ & $-3.6(-4.4)$ & $-5.7(-4.9)$ & $-4.5(-7.5)$ \\
\hline 2015 & $-3.7(-4.2)$ & $-4.3(-6.2)$ & $-7.1(-6.8)$ & $-4.8(-6.7)$ \\
\hline 2016 & $-5.0(-1.8)$ & $-4.6(-4.6)$ & $-7.0(-5.9)$ & $-4.7(-6.3)$ \\
\hline 2017 & $-4.8(-1.0)$ & $-4.5(-3.4)$ & $-5.7(-4.2)$ & $-4.5(-5.5)$ \\
\hline $2018^{*}$ & $-4.4(-1.4)$ & $-4.1(-3.6)$ & $-4.7(-3.5)$ & $-4.3(-5.7)$ \\
\hline $2019^{* *}$ & $1-4.0(-1.1)$ & $-3.8(-3.5)$ & $-4.3(-3.2)$ & $-3.9(-5.7)$ \\
\hline Source: see Table 3. & & &
\end{tabular}

Table 4.

Fiscal balance and external current account (including grants) in Africa 2009-2019 (\% of GDP). 
Another disturbing trend in the region is the presence of twin deficits. The economies of West Africa experienced twin deficits throughout the period 20092017. Instability in the external sector is not healthy for the economy of the subregion. In other to restore fiscal balance especially in the external sector, the countries might resort to borrowing with implications for the wider economy of the region (see Table 4). When the performance of the macroeconomic indices is juxtaposed with the rising misery index, it becomes certain that performance has not been satisfactory.

\section{Review of Literature and Theoretical Underpinnings}

The literature on regional economic development efforts in Africa is vast, and we make no attempt to review them in this paper. There are about five stages towards a complete regional economic integration, that is, a monetary union. These stages include free trade area, customs union, common market, economic union and monetary union. Each stage has several requirements theoretically and in practice. In the West African sub-region, some successes have been achieved at various stages, but there exist overlaps between the stages (WAMI, 2018).

A monetary union is the highest form of economic integration which is often characterized by the establishment of fixed exchange rates between the currencies of Member States and the harmonization of monetary and fiscal policies. Furthermore, there must be an authority such as the central bank to administer the accepted common currency [1].

An optimum currency area (OCA) which is a currency area that affords the most efficient adjustment process in response to both internal and external disturbances is not only crucial but ideal. However, factors that influence the size of an OCA include the degree of the mobility of the factors of production and the degree of capital mobility especially financial capital. Other features are price and wage flexibility, economic openness, diversification in production and consumption, similarity in inflation rates, fiscal integration and political integration.

Another set of theoretical considerations centre around issues of convergence and vulnerability. Consequently, countries eager to be part of a monetary union are required to meet the following primary criteria to ensure currency convergence: (1) fiscal deficit plus grants of not more than 3.0 percent of GDP; (2) yearly inflation rate of less than 10 percent; (3) a central bank deficit financing of not more than 10 percent of the previous year's tax revenues; and (4) gross external reserves not less than 3 months of import cover.

In some regional efforts, there may be secondary requirements such as in the WAMZ region-members are required to meet additional two secondary criteria, namely, exchange rate stability with nominal exchange rate depreciation/depreciation of not exceeding 10 percent and a public debt-to-GDP ratio not exceeding 70 percent to complement the primary criteria.

As would be shown later, the economies of the sub-region have challenges in meeting both the primary and secondary criteria for convergence due to the vulnerability of their economies to various economic shocks particularly those related to commodity prices. Most the shocks are outside the control of the economies in the WAMZ [2].

A recent study [3] confirmed the vulnerability of the economies of the WAMZ to external shocks. The components of the economic vulnerability indices (EVI), having trade openness, export concentration and dependence on strategic imports as its elements, clearly showed that the reliance of the economies of the sub-region on commodity exports, reliance on one or two commodities as well as the reliance 
on strategic imports such as capital cement its inability to meet the various convergence criteria [4].

It is, therefore, crucial that while not dismissing the importance of currency convergence, it is paramount to think outside the box and optimize other benefits of economic integration by being practical and functional. Even with the economic space for progressing towards a monetary union, there remain several unsettled issues.

Several studies conducted by African scholars have highlighted the benefits and challenges of regional economic integration. These studies also suggested the way forward if the objectives of integration are to be achieved [5-7].

We next utilize stylized facts and regression approach to reconsider the issues and challenges facing economic integration in the West African sub-region after examining the convergence matter.

Notwithstanding the paucity of data, we will attempt to estimate the following relationship:

$$
Y g=f(M 2, g c f ; X)
$$

where Yg = growth in GDP; M2 = broad money supply; gcf = gross capital formation; and $\mathrm{X}=$ control variables.

\subsection{Convergence dilemma?}

Tables 5-7 and Tables A1-A5 in the Appendix provide a summary of the status of the convergence criteria required for progress towards currency convergence necessary for economic integration during the period of 2001-2016. The data for earlier period is in the Appendix.

From 2001 to 2015, The Gambia only met the inflation and import cover requirements, while Ghana met only one requirement, that is, import cover. Liberia satisfies four requirements, while Nigeria satisfied three criteria. Sierra Leone and Guinea both met three requirements. As a zone, all the countries struggled to meet the requirements during the period of 2001-2015. The number of primary criteria met by each country is summarized in Table 5 .

Performance score is calculated as the sum of numbers of countries satisfying each criterion expressed as a percentage of total expected score on all four criteria. Six countries were assessed, giving a total expected score of 24 .

\begin{tabular}{lcccc}
\hline Indicator & $\begin{array}{c}\text { Inflation } \\
(<\mathbf{1 0} \%)\end{array}$ & $\begin{array}{c}\text { Fiscal deficit } \\
(<\mathbf{4} \%)\end{array}$ & $\begin{array}{c}\text { Central bank deficit } \\
\text { financing }(<\mathbf{1 0})\end{array}$ & $\begin{array}{c}\text { Gross external reserve } \\
(\geq \mathbf{3} \text { months of imports })\end{array}$ \\
\hline The Gambia & 6.8 & 4.4 & 20.5 & 5.3 \\
\hline Ghana & 14.5 & 4.9 & 10.0 & 3.6 \\
\hline Guinea & 15.6 & 3.3 & 10.3 & 2.3 \\
\hline Liberia & 9.0 & -0.6 & 0.0 & 2.8 \\
\hline Nigeria & 11.9 & 3.2 & 2.4 & 3.2 \\
\hline Sierra Leone & 10.4 & 7.5 & 11.8 & 4.7 \\
\hline WAMZ & 11.4 & 3.8 & 11.0 & 2.7 \\
\hline
\end{tabular}

Source: WAMI Annual Report (various issues).

Table 5 .

Average primary convergence criteria (2001-2015). 


\begin{tabular}{|l|rrrrrr|}
\hline & 2011 & 2012 & 2013 & 2014 & $\mathbf{2 0 1 5}$ & $\mathbf{2 0 1 6}$ \\
\hline Dec & Dec & Dec & Dec & Dec & Dec \\
Ghana & 3 & 3 & 2 & 2 & 1 & 1 \\
Guinea & 3 & 3 & 2 & 1 & 2 & 1 \\
Liberia & 2 & 2 & 2 & 2 & 1 & 3 \\
Nigeria & 3 & 3 & 3 & 3 & 3 & 3 \\
Sierra Leone & 3 & 3 & 4 & 4 & 4 & 3 \\
\hline
\end{tabular}

Source: WAMI Annual Report (various issues).

Table 6.

Number of primary criteria satisfied by Member States.

\begin{tabular}{|l|rrrrrr|}
\hline Year & 2011 & 2012 & 2013 & 2014 & 2015 & 2016 \\
\hline Inflation & 2 & 3 & 4 & 5 & 5 & 2 \\
\hline Fiscal Deficit & 4 & 2 & 2 & 2 & 2 & 3 \\
Central Bank Financing & 6 & 6 & 4 & 4 & 4 & 4 \\
External Reserves & 5 & 5 & 5 & 5 & 3 & 4 \\
Performance Score (\%) & 70.83 & 66.67 & 62.50 & 66.67 & 58.33 & 54.17 \\
\hline
\end{tabular}

Source: WAMI, Accra, Ghana.

Performance score is calculated as the sum of numbers.

Table 7.

Primary criteria-performance score.

Examining the performance scores, meeting the primary criteria declined from almost 71 percent in 2011 to 54.2 percent in 2016. Though there are always reasons for poor performance, the underlying question is whether the convergence criteria should be both the necessary and sufficient conditions for economic integration. It is surprising why and how the economies in the zone try to meet the deficit/GDP when there is huge infrastructural deficit.

It seems desirable to invest in capital projects to foster integration. If that is the case, then there is nothing absolutely wrong in borrowing to fill the gap provided the amount borrowed is utilized in capital projects that would pay its way. While fiscal discipline is crucial, infrastructure is necessary for increased trade which is important for economic integration.

Another element affecting convergence is the matter of vulnerability of the zone to external shocks. WAMI [3] identified the following implications of vulnerability of Member States on the convergence process:

- Persistence of economic and social divergence. Different growth paths of member countries may create migration from countries with high growth to those of low growth, and this may result in social disequilibrium.

- Incomplete union. This a case of budgetary control in practice. This involves budgetary unification in order to smoothen consumption among member countries. However, it is a tall order as the fiscal operations of countries in the zone are far from being harmonized. 
- Risk of exchange rate crisis. How stable would the accepted and unified currency be? There are issues of convertibility to global currencies such as the US dollar and the British pound, among others.

- Likelihood of banking crisis. 'In the event of adverse shock from the external environment, which affect output and hence the tax base of the issuing country, the incentives to default could be high. Under this scenario, investors would want to pull out from the domestic bond market, a development that would elicit increase in interest rate on government bonds. Since domestic banks are the main investors in the domestic sovereign bond market, the banks could be caught up in a funding problem' ([3], p. 35).

- Loss of potency of instrument of automatic stabilizer. With the high vulnerability of Member States to shocks, it becomes doubtful whether the budget could serve as an instrument of automatic stabilizer especially in a recessionary phase of the economies in the zone.

- Risk of debt overhang and sovereign debt crisis. A sharp decline in commodity exports as a result of a shock may result in sharp decline in revenue resulting in current account imbalances and potential domestic fiscal deficits. The resultant twin deficits would be unhealthy for the zone.

The inconsistency in meeting the primary and secondary criteria for convergence overtime suggests the need to stress other economic variables. It would be extremely difficult if not impossible for all the member countries to meet the criteria at the same time. The evidence from 2001 to 2016 confirms this position. Consequently, it may desirable to consider point convergence and/or convergence by two big economies in the zone in addition to other factors in order to push ahead the integration process.

\section{A reconsideration of the evidence: unsettled issues}

We have argued elsewhere that there still exist unsettled matters concerning progress towards economic integration in the sub-region via WAMZ [7]. These include the following:

- Increased intra-WAMZ trade. Trade among member countries increased very marginally between 2015 and 2016. Intra-WAMZ trade improved to US $\$ 2.8$ billion ( 0.71 percent of GDP), from US $\$ 1.6$ billion ( 0.30 percent of GDP), reflecting increases in The Gambia, Nigeria and Sierra Leone. The degree of intra-WAMZ trade relative to the rest of the world rose to 2.6 percent, from 1.2 percent in the previous year. While The Gambia, Nigeria and Sierra Leone recorded improvements in intra-WAMZ trade, Ghana, Guinea and Liberia posted declines. WAMZ Member States trade with the rest of ECOWAS declined to US $\$ 3.09$ billion ( 0.80 percent of GDP) in the review period, from US $\$ 5.95$ billion (1.10 percent of GDP) in 2015 .

- There are still challenges when it comes to free movement of goods and services. This is more pronounced during road transport. Traders and nontraders go through 'hell' when traveling by road in the sub-region. It seems the customs and immigration officers do not know of existing protocols. Several unnecessary road blocks hinder free flow of goods and services. 
- There is a huge infrastructural deficit in the zone. The absence of good roads, railways and good air connection coupled with poor electricity supply cannot foster economic integration.

- Economic diversification. The high vulnerability of the economies of the subregion compels the need for economic diversification implying that economies in the region must earn revenue from other sources other than the export of primary commodities whether agricultural or minerals. We have shown elsewhere through panel regression analysis that private sector investment, GDP per capita growth, infrastructures, trade openness and public investment enhance economic diversification. The economies in the sub-region export similar goods; hence it is difficult to trade among themselves. Consequently, diversification implies the urgency of industrializing the zone.

- Fiscal consolidation and coordination. It is important to begin to address the fiscal imperatives of integration. This goes beyond meeting the deficit-to-GDP ratio. Are the economies ready to have a unified budget? Has each economy passed and implemented its fiscal responsibility? Arising from the European Union experience, the fiscal aspect of regional integration is key to the process of consolidating a monetary union. In addition, it is necessary to harmonize the indirect taxes in the zone. For example, VAT in Nigeria is 5 percent, while it is 15 percent in Sierra Leone and Ghana.

- The citizens in the zone have integrated as evidenced by their ability to move between the countries notwithstanding the challenges. In fact, they trade to some extent with the currencies of the member countries. The Ghanaian cedi is accepted in the Balogun Market in Nigeria, while the Nigerian currency, the naira, is accepted in most markets in member countries. The informal sector is waiting for the policymakers and bureaucrats to formalize the process of currency convertibility within the zone. In this regard, the East African experience is a case in point. The Kenyan shilling is quoted in Tanzanian banks and vice versa.

- Political commitment. Without this variable, there would be no economic integration. The economics though crucial cannot be 100 percent. Once the politicians take the decision after considering the economics to some extent, other economic variables would adjust. The road to economic integration no matter the theorizing cannot and is never linear. It has bumps, but once there is political commitment, the challenges would be addressed as the process continues.

- Growth trajectory versus misery index. The growth of GDP in the sub-region averaged about 3 percent which is almost the same growth rate of population. However, a bigger question would be to investigate the misery index in the various countries. For example, in Nigeria which is the largest economy, the misery index has shown an upward trend during the period under review.

- The 'conflict' between the Anglophone and Franco-phone countries. The issue to address is whether the Franco-countries would delink with France given the strong historical ties. The CFA has a fixed parity with the Euro, and the reserves of the Franco-phone countries are domiciled in Paris with certain conditions. If the Franco-phone countries delink with France, then certain macroeconomic fundamentals such as inflation rate would definitely exceed the benchmark set by the ECOWAS Commission. 


\begin{tabular}{lccc}
\hline Variables & Coefficient & Standard error & t \\
\hline$\frac{m_{2}}{Y}$ & -0.0929 & 0.0439 & $2.11^{*}$ \\
\hline Gcf & 0.1551 & 0.0565 & $2.75^{*}$ \\
\hline Inf & -0.0552 & 0.0152 & $3.63^{*}$ \\
\hline Infant mortality & -0.0585 & 0.0488 & $1.20^{* *}$ \\
\hline Openness & 2.8981 & 0.9353 & $3.10^{*}$ \\
\hline Cag & 0.1325 & 0.0463 & $2.86^{*}$ \\
\hline Constant & -14.3780 & 6.0257 & $2.39^{*}$ \\
\hline
\end{tabular}

Significant at $5 \%$.

Significant at $10 \%$.

Table 8.

Regression results. Dependable variables: $Y_{g}$ Number of observations: 304 Method: Least squares (panel)Period: 1980-2017Fixed effects

- The financial system in the sub-region is yet to be integrated. A recent study [8] clearly discusses the implications of non-integration of the financial system.

- Ratification of protocols. Several protocols agreed upon by member countries are yet to be ratified by their respective parliaments.

Furthermore, we examined the relationship between economic growth and relevant economic variables for the period of 1980-2017. After almost 43 years at economic integration effort, what has been the precise link between capital expenditures, openness, broad money supply, private investment and inflation to growth? The results are presented in Table 8.

$$
R^{2} \cdot 0.14 ; F(7,290)=3.25
$$

$\mathrm{Y}_{\mathrm{g}}=$ growth of GDP; $\frac{m_{2}}{Y}=$ broad money supply; gcf = gross capital formation (private investment); Infant mort = infant mortality rate; Inf = inflation; Openness $=$ openness; Cag = capital expenditure (public investment).

The regression results indicate that broad money supply, inflation and infant mortality (a proxy for capturing development) are negatively related to growth and are statistically significant at 5 percent and 10 percent, respectively. Openness, gross capital formation and capital expenditures are positively related and statistically significant. The properly signed openness variable indicates the importance of trade in the sub-region. The explanatory power is weak; hence the results need to be interpreted with caution.

It should be noted that some of the variables, for example, delinking with France, discussed above cannot be captured in the regression due to lack of data.

\section{Conclusion and recommendation}

We examined the integration efforts of ECOWAS which was established in 1975 and argued that the stylized facts suggest that there are still fundamental challenges if the union has to be a reality. The convergence criteria set by the WAMZ component of ECOWAS as well as the link between the Franco-phone countries and 
France pose significant matters to be addressed. The political dimension vis-à-vis the work of the technocrats needs to be reconciled as the sub-region moves towards economic integration.

The preliminary panel regression provides mixed results regarding the relationship between economic growth, inflation and private investment, among others, from 1980 to 2017. Both the economics and politics of economic integration must be considered as the movement towards a monetary union progresses.

Based on the issues examined above, economic integration is not a smooth journey. The experience of Europe is worth emulating. The Heads of State and Government must strive to address the unsettled issues discussed above. Within that context, point convergence as well as two or three big economies in the region may jump start the integration process for other economies to join later.

\section{A. Appendix}

\begin{tabular}{llllllllllllllll}
\hline Countries & 2001 & 2002 & 2003 & 2004 & 2005 & 2006 & 2007 & 2008 & 2009 & 2010 & 2011 & 2012 & 2013 & 2014 & 2015 \\
\hline $\begin{array}{l}\text { The } \\
\text { Gambia }\end{array}$ & 2 & 1 & 1 & 3 & 3 & 4 & 4 & 4 & 4 & 4 & 3 & 3 & 2 & 2 & 1 \\
\hline Ghana & 1 & 0 & 2 & 1 & 3 & 2 & 2 & 0 & 2 & 3 & 3 & 3 & 2 & 1 & 2 \\
\hline Guinea & 3 & 2 & 0 & 0 & 2 & 1 & 2 & 1 & 1 & 0 & 2 & 2 & 2 & 2 & 1 \\
\hline Liberia & NA & NA & NA & NA & NA & NA & 1 & 2 & 4 & 3 & 3 & 3 & 3 & 3 & 3 \\
\hline Nigeria & 3 & 3 & 2 & 3 & 3 & 4 & 4 & 3 & 3 & 2 & 3 & 3 & 4 & 4 & 4 \\
\hline $\begin{array}{l}\text { Sierra } \\
\text { Leone }\end{array}$ & 2 & 2 & 0 & 2 & 2 & 2 & 2 & 2 & 1 & 1 & 1 & 2 & 4 & 3 & 3 \\
\hline Source: WAMI, Annual Report and Statement of Accounts (various issues). & & & & & & & & & & & & & & & \\
\hline
\end{tabular}

Table A1.

Number of primary convergence criteria met by Member States (2001-2015).

\begin{tabular}{|l|rrrrrr|}
\hline Year & 2011 & 2012 & 2013 & 2014 & 2015 & 2016 \\
\hline Country & \multicolumn{7}{|c}{. } & & & & & \\
\hline The Gambia & -5.5 & -5 & -4.3 & -3 & -3.2 & -2.0 \\
Ghana & -1.3 & -1.1 & 3.6 & 7.1 & 7.8 & 5.5 \\
Guinea & 9.1 & 2.9 & 0.6 & -0.9 & -2.6 & -1.2 \\
Liberia & 1.6 & -2.2 & -1.4 & -2.2 & -1.9 & 2.6 \\
Nigeria & 0.4 & 2.1 & -1.9 & -1.9 & -0.3 & 8.7 \\
Sierra Leone & 7 & 1.5 & -1.7 & -2 & -1.0 & 7.5 \\
\hline Mean Deviation & 1.9 & -0.3 & -0.9 & -0.5 & -0.2 & 3.5 \\
\hline
\end{tabular}

Source: WAMI, Annual Report and Statement of Accounts.

The inflation threshold used for computing the deviation is 9.9 percent. A negative value means a country is within the threshold, while a positive value implies a country is above the threshold.

Table A2.

Member States' deviation from inflation threshold. 


\begin{tabular}{|c|c|c|c|c|c|c|}
\hline Year & 2011 & 2012 & 2013 & 2014 & 2015 & 2016 \\
\hline \multicolumn{7}{|l|}{ Country } \\
\hline The Gambia & 1.2 & 1.6 & 5.7 & 6.1 & 3.6 & 6.5 \\
\hline Ghana & -2.1 & 2.7 & 4.6 & 3.4 & 1.5 & 7.4 \\
\hline Guinea & -1.8 & -1.8 & -0.1 & 0.9 & 5.9 & -2.8 \\
\hline Liberia & -2.5 & -7.3 & -5.1 & -3.2 & -4.6 & -5.2 \\
\hline Nigeria & -1.9 & -4.4 & -4.4 & -3.9 & -1.4 & -0.8 \\
\hline Sierra Leone & 1.3 & 2.1 & -1.5 & 0.4 & 1.1 & 4.7 \\
\hline Mean Deviation & -1.0 & -1.2 & -0.1 & 0.6 & 1.0 & 1.6 \\
\hline
\end{tabular}

Source: WAMI, Annual Report and Statement of Accounts (various issues).

The fiscal deficit/GDP threshold used is 3.0 percent. A negative value indicates a country is within the threshold, while a positive value implies a country is above the threshold.

Table A3.

Member States' deviation from fiscal deficit threshold.

\begin{tabular}{|l|rrrrrr|}
\hline Year & 2011 & 2012 & 2013 & 2014 & 2015 & 2016 \\
\hline Country & & & & & & \\
\hline The Gambia & -10.0 & -10.0 & 38.3 & 23.3 & 31.5 & 23.1 \\
\hline Ghana & 18.3 & -0.6 & -0.8 & 0.9 & -10.0 & 0.0 \\
Guinea & -10.0 & -10.0 & -10.0 & -10.0 & 15.0 & -8.1 \\
\hline Liberia & -10.0 & -10.0 & -10.0 & -10.0 & -10.0 & -10.0 \\
Nigeria & -10.0 & -10.0 & -10.0 & -10.0 & -10.0 & -10.0 \\
Sierra Leone & -8.9 & -10.0 & -8.3 & -19 & -10.0 & 23.1 \\
Mean Deviation & -5.1 & -8.4 & -0.1 & -1.3 & 1.1 & 3.0 \\
\hline
\end{tabular}

Source: WAMI, Annual Report and Statement of Accounts (various issues).

The central bank financing threshold used is 10.0 percent. A negative value indicates a country is below the threshold, while a positive value implies a country is above the threshold.

Table A4.

Deviation from central bank financing threshold.

\begin{tabular}{|l|rrrrrr|}
\hline Year & 2011 & 2012 & 2013 & 2014 & 2015 & 2016 \\
Country & & & & & & \\
\hline The Gambia & 3.1 & 1.8 & 1.6 & 0.7 & -0.5 & -0.6 \\
Ghana & 0.9 & 0.4 & 0.6 & 1.2 & 0.6 & 1.2 \\
Guinca & 1.3 & 0.0 & 0.5 & 0.2 & -0.7 & -1.6 \\
Liberia & 0.3 & -0.2 & -0.4 & -0.3 & -0.3 & 0.3 \\
Nigeria & 3.3 & 5.5 & 5.9 & 3.0 & 2.8 & 5.2 \\
Sierra Leone & -0.5 & 0.4 & 0.2 & 0.6 & 1.8 & 2.3 \\
Mean Deviation & 1.4 & 1.3 & 1.4 & 0.9 & 0.6 & 1.1 \\
\hline
\end{tabular}

Source: WAMI, Annual Report and Statement of Accounts (various issues).

The GRMI threshold used is 3.0. A positive value implies a country is above the threshold (favorable development), while a negative value indicates a country is below the threshold (unfavorable development).

Table A5.

Deviation from external reserves (in months of import cover) threshold. 


\section{Author details}

Akpan H. Ekpo ${ }^{1,2}$

1 Department of Economics, University of Uyo, Uyo, Nigeria

2 Foundation for Economic Research and Training (FERT), Uyo and Lagos, Nigeria

*Address all correspondence to: ahekpo@gmail.com

\section{IntechOpen}

(C) 2020 The Author(s). Licensee IntechOpen. This chapter is distributed under the terms of the Creative Commons Attribution License (http://creativecommons.org/licenses/ by/3.0), which permits unrestricted use, distribution, and reproduction in any medium, provided the original work is properly cited. (c) BY 


\section{References}

[1] Velde DW. Regional integration, growth and convergence. Journal of Economic Integration. 2011;26(1):1-28

[2] Guillaumont P. On the Economic Vulnerability of Low Income Countries, CERDI. 2000. Available from: http:// cerdi.org/uploads/ed/2000/2000.16.pdf

[3] WAMI. Vulnerability of WAMZ Member Countries to External Shocks and Implications on the Convergence Process. Ghana: Accra; 2017

[4] Briguglio L. A Vulnerability and Resilience Framework for Small States. 2014. Available from: https://www.um. edu.mt/_data/assets/pdf_file/0007/ 215692/Briguglio_The_Vulnerability_ Resilience_Framework,_23_Mar_2014. pdf

[5] Ekpo AH, Udo E. Policy coordination framework for the proposed monetary union in ECOWAS. In: Seck D, editor. Regional Economic Integration in West Africa. New York: Springer; 2014

[6] Ekpo AH. public investment and competitiveness in ECOWAS: An empirical investigation. In: Seck D, editor. Investment and Competitiveness in Africa. Switzerland: Springer; 2017

[7] Ekpo AH. Growth without development in West Africa: Is it a paradox? In: Seck D, editor. Accelerated Economic Growth in West Africa. Springer; 2016

[8] Ekpo AH, Chuku C. Regional Financial Integration and Economic Activity in Africa. Journal of African Economies. 2017;26:ii40-ii75 
Section 3

Agricultural Services and the Water-Energy-Food Nexus in Africa 



\title{
Economic Development of Rural Communities in Sub-Saharan Africa through Decentralized Energy-Water-Food Systems
}

\author{
Johannes Winklmaier, Sissi Adeli Bazan Santos \\ and Tobias Trenkle
}

\begin{abstract}
Access to electricity is essential for humanity to develop. Nowadays, 600 million people in sub-Saharan Africa (SSA) have no access to energy services, most of them living in rural areas. However, this region has an outstanding solar potential that could unlock cheap power generation through solar power systems. This raises the question of how rural communities in Africa could avail the benefits of renewable energy systems to gain access to electricity and develop sustainable and productive activities around while facing low purchase power, high interest rates, and high investment costs. The concept of decentralized energy-water-food system proposes a solution: it enables renewable energy access with biomass and solar energy for the private power of the local community, provides secure water supply and yearround irrigation, and increases their livelihood through the profitability of farming and generation of jobs. The concept is applied to a case study in rural Ghana and the least-cost design is obtained. An economic feasibility analysis is carried out on the evaluation of profitability and the total financial value generated for the main stakeholders. The results portrait the economic advantages of the proposed concept design - a hybrid solar-biogas system - to deliver affordable electricity, water, and food supply.
\end{abstract}

Keywords: rural electrification, economic model, hybrid energy system, sustainable development, least-cost optimization, agricultural productivity, water-food-energy nexus

\section{Introduction}

In 2017, internal migration was estimated at 1 billion people in developing countries. Rural to urban migration is at the core of this displacement [1]. Rural migration is "one of the main coping and survival mechanisms that is available to those affected by environmental degradation and climate change" [2], an important component of rural livelihoods' strategies to couple with poverty, food insecurity, lack of employment and income-generating opportunities, and inequality, among the root causes [3]. In sub-Saharan Africa (SSA) rural migration counts at least for 
$75 \%$ of all internal movements [4]. Not without reason, migration is particularly important in this rural-dominated society. Most of rural communities driven to migration in SSA have still traditional rain-fed farming as the main source for income and food security, and their livelihood is characterized by inadequate infrastructure-including the reliable provision of mobility and services such as electricity and water access $[3,5]$. These factors, added to exposure to climatic change on farming, push rural dwellers to escape low-productive and climate-vulnerable agriculture, searching the opportunity to raise their level of income. Indeed, according to the last report of rural migrants' profiles of the FAO, around $60 \%$ of rural household members in SSA earn less than 1 USD per day and increase their earning to 2 USD per day per rural migrant from the change of main economic activity and access to basic infrastructure [5]. The search for better incomegenerating activities to cover basic human needs as food, water, and energy supply is hence a crucial motivation.

Decentralized energy-water-food systems (EWFS) propose a sustainable mechanism to improve living conditions in rural communities with the supply of electricity, water, and food using renewable resources and catalyze community welfare by investing in infrastructure for agricultural productivity. This concept was presented in $[6,7]$, which introduced the theory of techno-economic linear modeling and least-cost design of EWFS. Based on two case studies on rural Zimbabwe and Ghana, both contributions showed the positive effects of sector coupling models on the total system costs.

\subsection{Contribution}

On the basis of this preliminary work, this chapter formalizes the concept model framework of decentralized energy-water-food systems and presents an analysis of their economic feasibility based on least-cost optimization and scenario analysis, the latter based on the variability of interest rate and energy system design. The aim is to analyze the capability of EWFS to provide economic-feasible solutions for rural electrification in contrast with existing state-of-the-art solutions and assess its financial attractiveness for major stakeholders.

The next section addresses the root motivation of this work, the role of electricity access for sustainable economic development, and presents the challenges met by the public and private sector in providing it to the rural communities. Section 3 deals with the EWFS' concept and the modeling of its least-cost design. Lastly, Section 4 evaluates the economic feasibility of EWFS based on the variability of the weighted average costs of capital and on the change in system design. The scenario development will show that fully fledged EWFS is the most superior system design to achieve long-term economic sustainable development by enabling the access to electricity and water and increasing agricultural productivity with the lowest annual system costs.

\section{The energy access paradigm on rural economic development in sub-Saharan Africa}

"Access to affordable, reliable, and sustainable energy for all" is the seventh United Nations Sustainable Development Goal and a key enabler of economic growth and human development [8]. The clear correlation of higher poverty level with lower electricity access is estimated to catalyze the private and public investment of 6 billion USD per year over the 2017-2030 period towards electrification in SSA $[9,10]$. While progress is being made, there are still around 600 million people 
in sub-Saharan Africa without access to electricity, over $80 \%$ of them living in rural areas [9]. Meanwhile, rapid population growth is estimated to offset the electrification efforts in the period up to 2030: more people in SSA would lack access to electricity than today; $90 \%$ of them would be living in rural areas [9].

Targeting electrification in rural areas is a resulting policy strategy to outperform the forecasts and enable the economic development that electricity access could potentially provide to these areas. One dominant strategy is the expansion of national power grid, which has accounted for $97 \%$ of new electricity connections since the year 2000; however, it is focused until now in urban areas [9]. Solar-based off-grid systems are the second strategy as SSA receives some of the highest levels of solar irradiation worldwide, with outstanding values of up to 2500 $\mathrm{kWh} / \mathrm{m}^{2}$ annually [5]. These systems, ranging to a power capacity of $5 \mathrm{MWel}$, offer a cost-effective solution due to the rapidly declining costs of solar photovoltaic systems (PV) and the improvement of their efficiency in energy conversion $[11,12]$. However, there are still obstacles in both strategies for the allocation of investment by the public and private sector. Low and dispersed population, low per capita electrical demand, high costs, and efficiency losses of high-voltage transmission lines and distribution networks make rural areas an expensive strategy in the centralized electrification process and rarely economically attractive for electric utilities [13]. In addition, developing countries deal with the lack of sufficient generation capacity, poorly maintained network infrastructure, and the limited ability of rural households to afford the connection charges [10]. Shifting the paradigm towards off-grid solar-based solutions has not yet made a significant contribution on tackling energy poverty in rural areas either [14]. Solar home systems and other solutions tailored to the low payment capacity of the rural population offer the most basic private power, usually for lighting. This access does not enable economic development [15]. As shown in Figure 1, $1000 \mathrm{kWh}$ per person are need for a medium human development, which is not achieved by the provision of light alone. Conversely, off-grid renewable solutions tailored for agriculture and other productive uses, which could potentially create jobs and increase the income level of the community, require a high upfront investment. This, coupled with interest rates of $15 \%$ and higher, depicts an unattractive high-risk investment for the private sector and an unattainable barrier for rural households, which are constrained by their low purchase power [17].

These challenges require electrification strategies of holistic nature, one that "plans to meet the targets for household electrification taking into account other

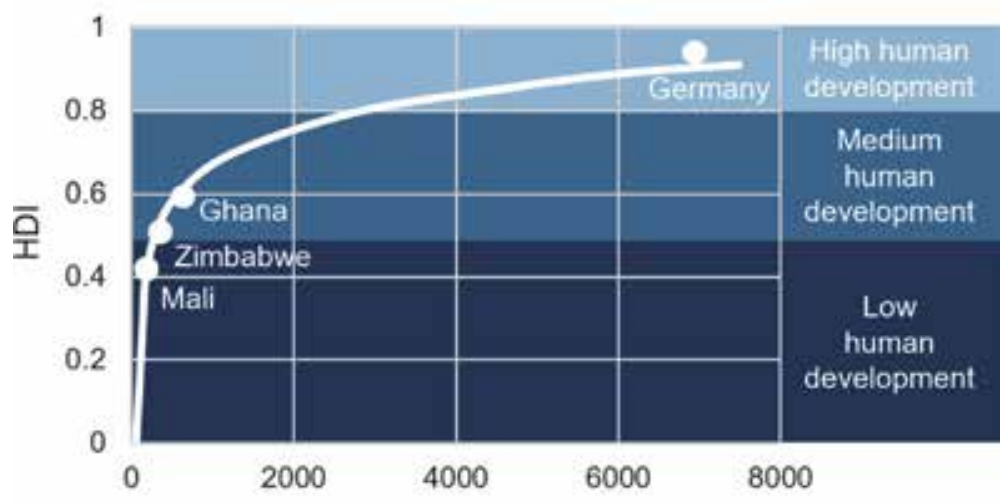

Annual electricity consumption per capita [kWh]

Figure 1.

Macro-level correlation between electricity and human development [16]. 
development goals and opportunities to use energy access to stimulate economic activity" [9]. In the absence thereof, rural electrification may not bring the economic development it promises.

\section{Decentralized energy-water-food systems}

Decentralized energy-water-food systems are the proposed solution for rural farmers in SSA to provide the necessary amount of electricity that fosters a higher level of human development. It addresses the low purchase power of the local community, gives renewable-based power access as pillar for human development, and increases the income of local community through agricultural productivity. It is based on the water-energy-food nexus, a conceptual framework for integrated resource management, which took particular prominence in 2011 as a wake-up call reacting to the forecast of a worldwide increasing resource demand, climate change, and the awareness of the unsustainable stress on scarce resources (energy, water, and food) [18]. As a result, it supports the coordination and management of the three sectors and the decision-making process under the consideration of synergies and trade-offs between the three resources when dealing with human development challenges [19]. This system thinking has from henceforth had an impact on the new policy frameworks, business assessment methods, and modeling tools, specially addressing challenges in the urban context and the multi-sectoral use of energy [20]. However, the application of this approach in the context of rural development of farming communities is limited. Due to the transformational effect of the nexus thinking [21], it deserves the formalization of a concept framework that is suited for rural farming communities and for sustainable economic development.

The model scheme for a decentralized energy-water-food system with their major inputs and outputs is depicted in Figure 2. Key system characteristics are:

1. Hybrid power system

\section{Electric water pumps}

3. Yield optimizing and sustainable agriculture

\section{Biogas generation through agricultural waste}

The combination of the photovoltaic battery and biogas system provides electricity to meet the private demands of a community. Because the deployment of diesel generators in off-grid villages is widespread [22], it is considered in this concept as well (1). Private power is provided free of charge in a first step and priced to cover potential system losses if needed. The hybrid power system generates enough power to operate electric groundwater pumps (2), powered mainly with cheap solar energy enabled by the strong global irradiation in SSA and by the flexible load management of water pumps. These pumps supply the community with domestic water demand. In this concept, up to 50 liters per day and capita are provided free of charge to meet the drinking and sanitation water right standards [23]. The pumps supply also all-year irrigation under the consideration of arable land and groundwater use constraints. Community farmers are able to grow crops independent of the rainfall pattern. This allows multiple harvests per year for selling to the domestic or external market participants (3). The resulting higher agricultural productivity leads also to an increase in biomass waste, which is fermented 


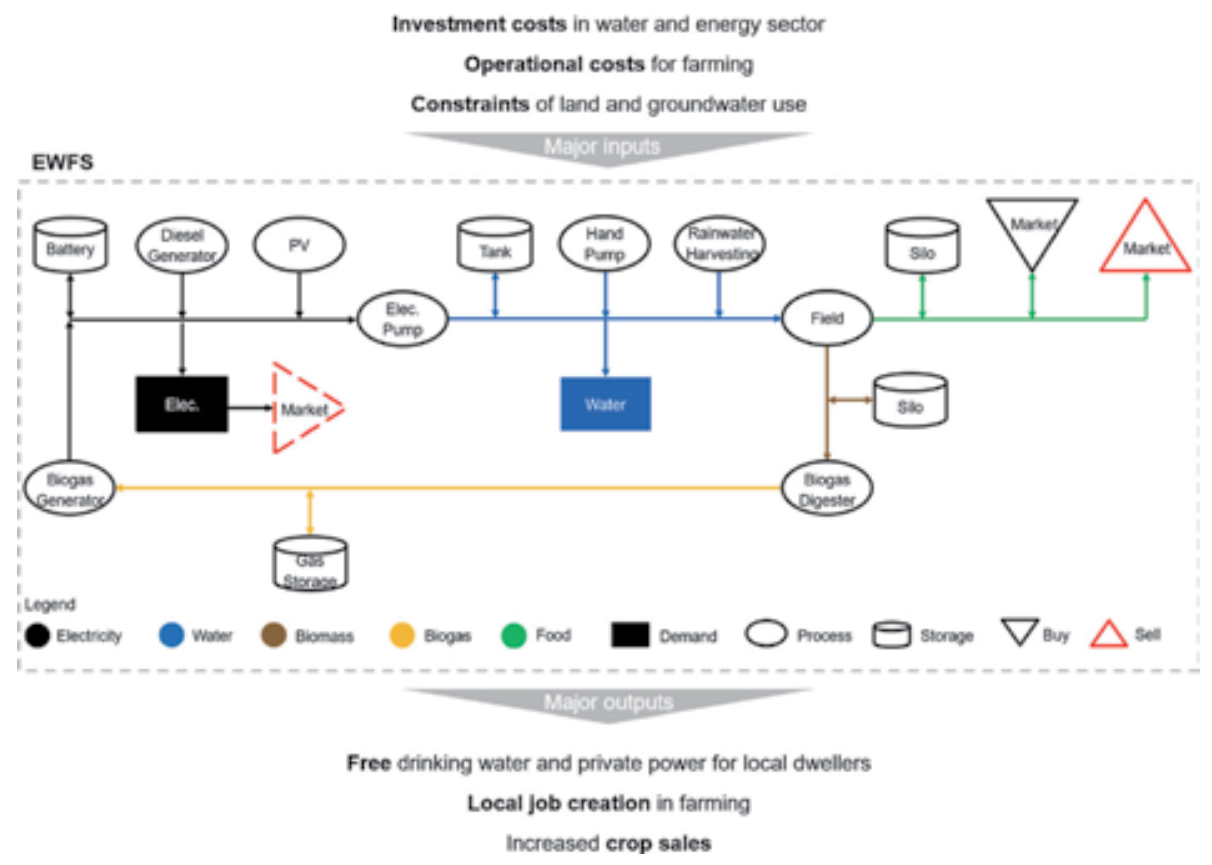

Figure 2.

Business model scheme of decentralized energy-water-food systems. Major inputs and outputs as well as system boundaries, technological components, and commodity flows are depicted. Modified from [6, 7].

into biogas and later converted into electricity (4). As a by-product, the biogas digestion process produces fertilizer that is used for agricultural purposes.

As a result, the rural community not only has gained access to electricity and domestic water supply but also secures the year-round supply of water for productive uses and food. In the medium to long term, the improved agriculture has the potential to create fair-paid jobs, increase the community's purchasing power, lead to a higher standard of living, and provide economic opportunities [12]. This concept also suggests that the high, so far unaffordable, investment costs for infrastructure development can be repaid by the local population through their revenues in agriculture as crops yield increase by up to $300 \%$ with regular irrigation [24]. After paying the system investment and operational costs, profits are distributed to the local community. Besides this socioeconomic benefits, preliminary studies of this concept in $[6,7]$ showed that due to the high resource potential of solar and biomass, the cheapest power generation is based to over $90 \%$ on renewable energies.

\subsection{Least-cost design of decentralized energy-water-food systems}

Decentralized EWFS have potential to deliver social, environmental, and economic returns. The sector coupling causes an unavoidable complexity in designing EWFS, specially when the lowest cost and technical feasibility are to be guaranteed. Optimization models facilitate the engineering effort to provide basic dimensions for the system implementation. These models are the state of the art for rural electrification as they enable stakeholders to understand, evaluate, and ultimately make decisions about the system setup $[25,26]$. To date, there are only a limited number of models accessible to researchers that address all three resources of an EWF system together, and most tools cannot be customized to the specific environmental and economic characteristics of the respective project location [27]. The 


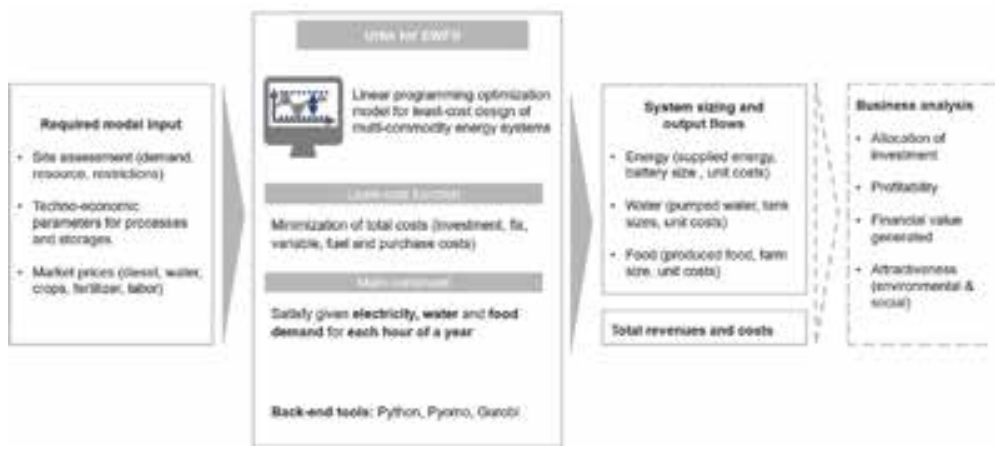

Figure 3.

Work flow to obtain least-cost design of decentralized energy-water-food systems with programming tool urbs. A business analysis is derived from the output results.

contribution [6,7] addressed the adaption of urbs, an economic model, which was originally designed by the Chair of Renewable and Sustainable Energy Systems of the Technical University of Munich (ENS) for distributed energy systems. Urbs has a well-documented mathematical description; it is open-source and can be used for cross-sectoral models in any spatial and temporal resolution [28]. Hence, it is used to conduct the economic feasibility analysis aimed in this work.

urbs is a linear optimization tool programmed in Python and identifies the optimal system configuration based on the minimization of the total system costs resulting from the techno-economic modeling of each process and storage technologies in the system. Figure 3 gives an overview of the urbs model for decentralized EWFS.

It requires three kinds of input data. Site data is defined by the demand, solar and rainfall time series, techno-economic parameters of the processes and storages as depicted in the EWFS model schema (Figure 2), and lastly the market prices of the commodities that can be bought or sold between the system boundaries. This data is read by urbs, which already has an implemented script adapted to model EWFS with a linear approach [7], and the total system costs are optimized. The output data includes the installed capacities related to the three sectors, the commodity flows, total revenues, and costs. A pre-feasibility analysis can be conducted on the basis of these results to evaluate the business attractiveness and ensure a sustainable project operation.

\section{Economic feasibility of decentralized energy-water-food systems: case study Kpori}

The northern region of Ghana is selected as case study. Although Ghana has a relatively high national electrification rate of $82.5 \%$ (2016), there is a drastic regional contrast between urban and rural areas within the country [29]. While the urban Greater Accra area has the highest regional electrification rate of $85 \%$, the three northernmost, sparsely populated regions have an average electrification rate of only 30\% [30]. These rural areas are the most expensive regions to be connected to the main grid and therefore particularly suitable for off-grid energy solutions. Since rural northern Ghana is characterized by high solar radiation and high agricultural activity, the use of solar photovoltaics and the coupling of the energy sector to the water and food sectors promise great productivity potential.

Kpori is a village of about 300 inhabitants in the West Gonja District in the north of Ghana. It is an off-grid village with no access to the national energy network, 
water infrastructure, or telecommunications network. Although agriculture is their main economic activity and livelihood, farming in Kpori is $100 \%$ rainfall dependent. At the same time, domestic water supply relies on rainwater harvesting and hand pumps. As a result of a significant drop in rainfall and an increase in temperature over the last century, the already climatically stressed region is dependent on drought-resistant plants such as maize and sorghum. According to on-ground questionnaire, Kpori's inhabitants have an annual income per capita below the lower poverty line of $208 \mathrm{USD} /$ year [31].

\subsection{Model input}

As depicted in Figure 3, urbs already includes the EWFS model and optimization script. The input data needed about Kpori are the following:

- Demand time series: Residential electricity, domestic water, food

- Supply time series: Solar irradiation, rainfall

- Technical parameters: Efficiency, capacity, and lifetime of machinery and storage units

- Economic parameters: Weighted average cost of capital (WACC), investment cost, fixed cost, variable cost, purchase cost, and fuel cost of machinery and storage units

The community demand for residential electricity and domestic water is determined by the approx. 300 Kpori inhabitants distributed over 70 households with an average household size of 4.4 [32]. The hourly private power demand is obtained by a Monte Carlo simulation based on the hourly utilization probability of residential appliances and their rated power. This data was obtained from an on-site survey on the nearest electrified farming community. The results of Figure 4 show a typical load profile of a farming community with a total annual consumption of $42.5 \mathrm{MWh}$ or $138 \mathrm{kWh}$ per inhabitant.

Domestic water demand is set to 50 liters per day and person based on the drinking and sanitation water right standards [23]. Daily food demand is modeled as $658 \mathrm{~g}$ of maize grain per inhabitant, which covers the minimum dietary calorie intake of $2400 \mathrm{kcal}$ [33]. In Kpori, up to 263 tons of maize grain can be produced annually on the domestic farmland due to the maximum capacity of arable land of

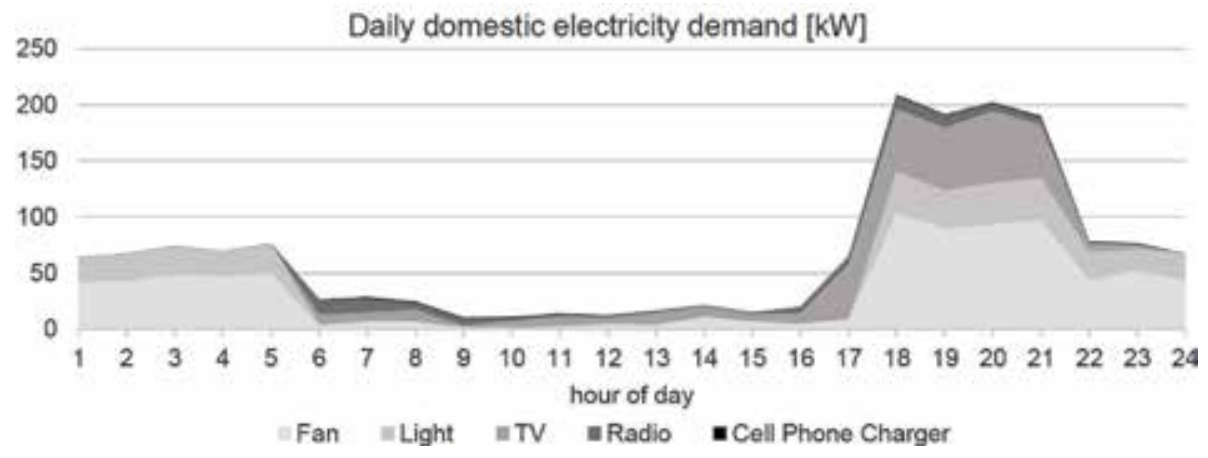

Figure 4.

Time series electricity demand for a Kpori house obtained with Monte Carlo simulation. 
15 ha. Mismatches in food supply and demand can be balanced by selling or purchasing maize grain on external markets for 200 USD per ton. Additionally, maize stover and chicken manure is fermented into biogas. The capacity of the biogas digestion process is limited to $367.5 \mathrm{~kg} /$ day due to the amount of manure available from approx. 3000 chickens in a nearby town. The solar and rainfall time series are obtained by data from geographical information systems (GIS) or online data bases.

The technical and economic parameters for all technologies depicted in Figure 2 are listed in the Appendix. Lastly, the weighted average cost of capital is assumed to be at the market rate of $15 \%$ according to the study [17].

\subsubsection{Scenario development}

The proposed scenario development, summarized in Table 1, evaluates the economic feasibility of a EWFS for sustainable project operation and as an attractive investment for its stakeholders. The base scenario (S1) analyzes these factors for a complete EWFS, as designed in Figure 2, with a cost of capital at the average market rate of $15 \%$, the integration of all power generation technologies (diesel generators, solar photovoltaics, and biogas generators), and the coupling of the three sectors: energy, water, and food. Secondly, the system's sensitivity to changes in the cost of capital is tested through a parameter variation for discrete values between WACC $0 \%$ and WACC 30\% (S2). The WACC variation serves as an appropriate starting point to evaluate the economic attractiveness of a decentralized EWFS in SSA. Indeed, there are highly investment-intensive installations related to an EWFS, and the WACC is therefore of great relevance. The third analysis tests the changes of power-generating technologies in the system design. It compares the fully fledged EWFS, in which electricity is generated from diesel, solar, and biogas, with a system without biogas and a system based exclusively on diesel.

\subsection{Optimization results}

The techno-economic results for all scenarios are listed in the Appendix.

\subsection{Results of base scenario S1}

Starting with a look on the economics of the base scenario depicted in Figure 5, the total system costs (52,562 USD) slightly exceed total revenues (52,560 USD) by 2 USD - the profitability break-even point is almost reached. In this scenario, the maximum field capacity of 15 ha is utilized, covering the entire domestic food demand (70 tons) and selling the remaining 193 tons to external market participants. Maize grain is sold to the domestic community at the market price of 200 USD per ton and accounts for one quarter of total revenues. On the cost site, the biggest contributor is labor costs related to agriculture, which accounts for $37 \%$ of the total costs. The second biggest contributor is investment costs, $30 \%$ of total

\begin{tabular}{lccc}
\hline Scenario title & WACC (\%) & Technologies & Sectors \\
\hline S1: Base scenario & 15 & DG + PV + BG & E + W + F \\
\hline S2: WACC variation & $0-30$ & DG + PV + BG & E + W + F \\
\hline S3: Technology variation & $0,15,30$ & DG,DG + PV & E + W + F \\
\hline
\end{tabular}

Table 1.

Modeled scenarios. 


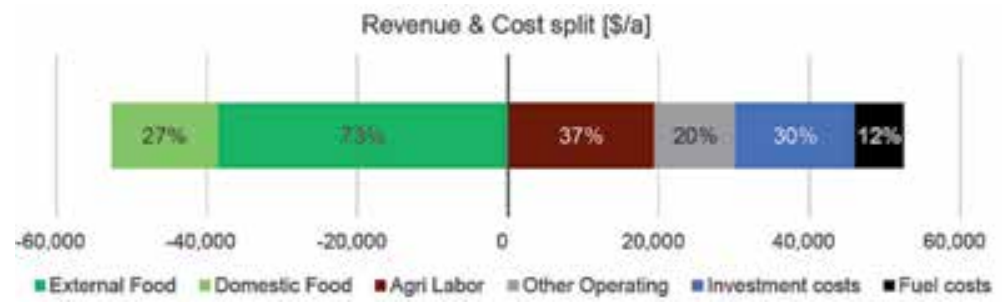

Figure 5.

Costs and revenues for EWFS with WACC $=15 \%$.
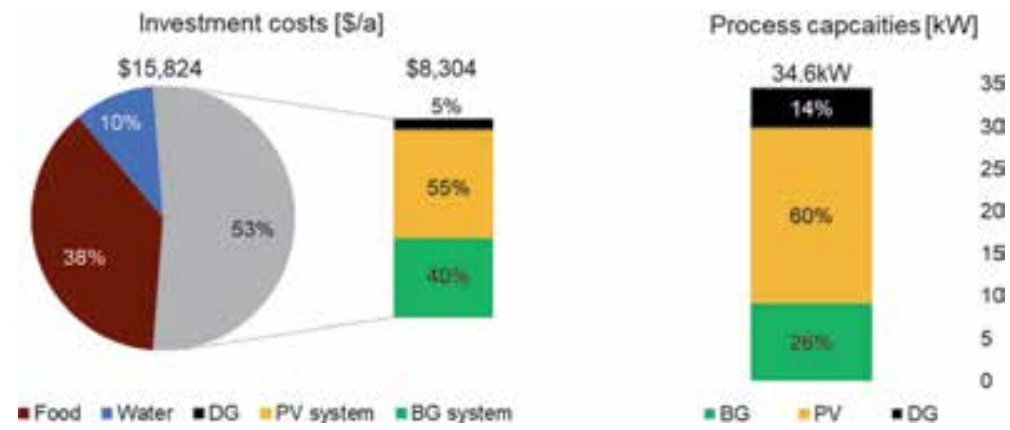

Figure 6.

Investment costs and capacities of power generation technologies.

costs—consisting of depreciation expenses (9\%) and cost of capital (21\%). Diesel expenses (fuel costs) account for $12 \%$ of total costs.

Provided that the domestic community purchases its food from the system and water is provided free of charge, the 2 USD loss must be allocated to the total domestic electricity consumption of $42.5 \mathrm{MWh} /$ year equaling an electricity fee of $0.01 \mathrm{USD} / \mathrm{kWh}$. The total annual costs for energy, water, and food equal $45.52 \mathrm{USD}$ per capita.

Total capital expenditure (CapEx) for long-term assets amount to $98.4 \mathrm{k}$ USD, which is only $30 \%$ of the cumulative investment costs over the respective useful life of the assets. The remaining $70 \%$ of the cumulative investment costs originates from the WACC and is distributed to investors. Analyzing the annual investment costs on a technology level, as depicted in Figure 6, it is observed that the majority of the annual investment costs is invested in electricity-related technologies (53\%), while $38 \%$ is spent on food-related assets and $10 \%$ on water-related assets. Within the costs for energy-related investments, the majority (55\%) is invested in solar photovoltaics and only $5 \%$ in nonrenewable electricity generation technologies (diesel generator). However, the diesel generator accounts for a drastically greater share of total installed capacity (14\%) then of total investment costs (5\%) illustrating the low specific investment costs of this technology. In contrast, the relatively lower ratios of installed capacity to investment costs for photovoltaic and biogas systems reflect the high CapEx intensity of renewable energy technologies.

The unit costs of the respective commodities, as shown in Table 2, depict that the costs related to producing 1 ton of maize grain (164 USD) are below the sales price of 200 USD. The profit generated from this revenue-cost difference is used to provide water free of charge and subsidize electricity prices to the domestic community. The unit cost of electricity (LCOE) is at $0.22 \mathrm{USD} / \mathrm{kWh}$. Due to the relatively high cost of capital as well as the CapEx-intensive photovoltaic and battery system, LCOE from PV (0.18 USD/kWh) is still above values around 


\begin{tabular}{lcc}
\hline Commodity & Unit & Costs \\
\hline Electricity total & USD $/ \mathrm{kWh}$ & 0.22 \\
\hline Electricity from diesel generator & USD $/ \mathrm{kWh}$ & 0.41 \\
\hline Electricity from solar photovoltaics & $\mathrm{USD} / \mathrm{kWh}$ & 0.18 \\
\hline Electricity from biogas generator & $\mathrm{USD} / \mathrm{kWh}$ & 0.14 \\
\hline Water & $\mathrm{USD} / \mathrm{m}^{3}$ & 0.05 \\
\hline Food & $\mathrm{USD} / \mathrm{ton}$ & 164 \\
\hline
\end{tabular}

Table 2.

Unit costs of electricity, water, and food.

\begin{tabular}{lc}
\hline Stakeholder & Financial value generated [USD/year] \\
\hline Labor & 19,425 \\
\hline Community & -2 \\
\hline Return to investors & 10,869 \\
\hline Total financial value generated [USD/year] & 30,293 \\
\hline
\end{tabular}

Table 3.

Total financial value generated.

0.13 USD/kWh, which is the benchmark for small-scale PV systems in Germany [34]. Sufficient profits from maize grain production enable an almost complete subsidization of electricity for the local community and burden households with only 0.03 USD for electricity per year to cover the loss of the system.

The financial attractiveness of the project for all major stakeholders is shown in Table 3. This analysis does not include a financial valuation of the water and electricity that is provided to the domestic community free of charge, nor does it account for social and environmental value added. Some system expenses can be considered as income to the respective shareholders. Consequently, labor expenses of 19,426 USD are income to the domestic community. The system loss of 2 USD is allocated among the entire domestic community. The net cash flow from labor and system losses to the community of $19.4 \mathrm{k}$ USD exceed total community expenses of $14 \mathrm{k}$ USD for food. Annual returns to investors of $10.9 \mathrm{k}$ USD match the market cost of capital (15\%). The total financial value added to the main stakeholders amounts to $30.3 \mathrm{k}$ USD per year.

Altogether, the base scenario presents an economically feasible solution to provide the domestic community of Kpori with electricity and water free of charge as well as to produce enough maize grain to meet the domestic demand and sell crop surpluses on an external market. Total funds of $98.4 \mathrm{k}$ USD must be raised to finance long-term assets. The maximum capacity of farmland and biogas is utilized; $82 \%$ of the consumed electricity is from renewable resources.

\subsection{Results of WACC variation scenario S2}

Profit overview illustrates an almost linear relationship between the cost of capital and the system profitability. Results show that for all scenarios between WACC $0 \%$ and $20 \%$, the cost-minimizing system is designed in a dimension that the maximum farmland capacity of 15 ha is cultivated. Consequently, the annual demand and supply for all three resources energy, water, and food are almost constant at $80 \mathrm{MWh}, 205,000 \mathrm{~m}^{3}$, and 263 tons, respectively. For the WACC 30\% 
scenario, maize grain production is still at 104 tons per year and hence more than sufficient to meet the annual domestic demand of 70 tons. The domestic demand for electricity and water remains constant, but cultivable farm land decreases.

Figure 7 provides an overview of the annual revenues and costs of the respective profit maximizing system design. Revenues move proportionally to the food production, remaining constant all through the WACC 20\% scenario (52.6 k USD), and decrease by $60 \%$ for WACC $30 \%$ to $20.9 \mathrm{k}$ USD per year. Agriculture-related labor costs and other operating costs move in line with revenues, accounting for approx. 37 and $21 \%$, respectively. Investment costs and fuel costs increase with higher WACC as they cover investor returns and an increase in consumed diesel; thus, investment costs and fuel costs are the main drivers of profitability.

Figure 8 shows the EWFS profitability. A fully socially financed system (WACC $0 \%$ ) generates $14.1 \mathrm{k}$ USD in annual profits, equivalent to a profit margin of $27 \%$. In the case of a WACC $10 \%$, which could represent the support of a financial cooperative, costs would increase by $24 \%$, resulting in an annual net profit of $4.8 \mathrm{k} \mathrm{USD}$, equivalent to a $9 \%$ net profit margin. The profit break-even point is reached for a WACC value slightly below the expected market rate of 15\%; for WACC 15\% a net loss of 1.8 USD is generated. Under the premise of free electricity and water, increasing net losses are generated for WACC values greater than $15 \%$, which implies that the business model is no longer economically sustainable. For the scenario of WACC $30 \%$, costs exceed revenues by the factor of 0.5 , resulting in an annual net loss of $10.4 \mathrm{k}$ USD. The profit overview illustrates an almost linear relationship between the cost of capital and the system profitability. An increase in WACC by one percentage point results in a decrease in profits by 880.42 USD.

Regarding the cost analysis, investment costs are the only cost category factored in the cost of capital, as it is assumed that all other expenses can be financed internally going from period to period. Consequently, it is intuitive that with an

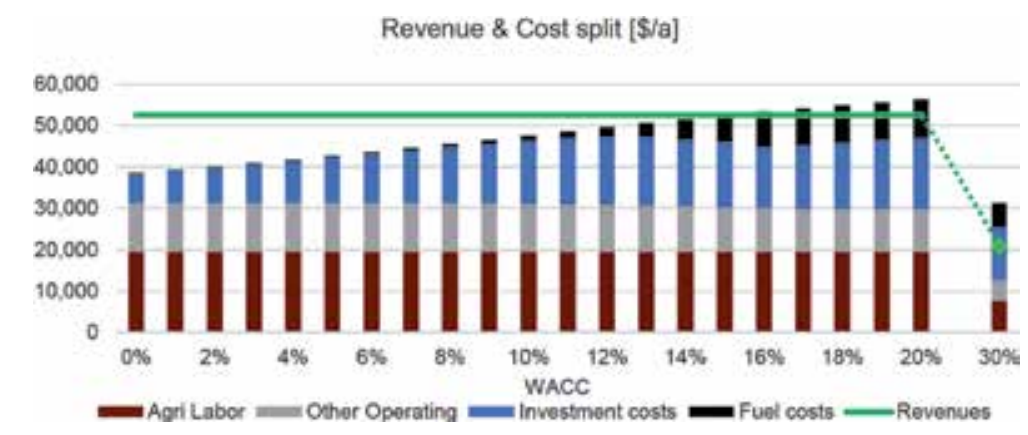

Figure 7.

Costs and revenues for EWFS for WACC variation from o to $30 \%$.

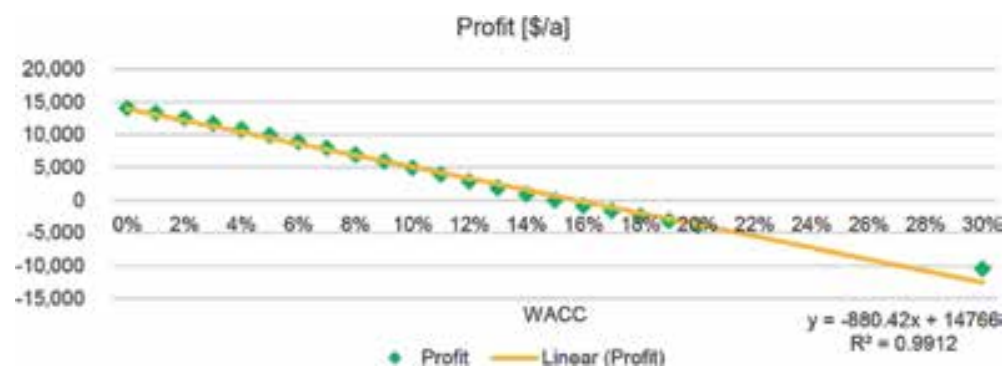

Figure 8.

EWFS profitability for WACC variation from o to $30 \%$. 
increase in cost of capital, the system design shifts towards CapEx-light technologies. Therefore, the share of CapEx in the cumulative investment costs continuously decreases, and the share of investment costs in total costs tendentially increases (Figure 9). This in turn implies that investment costs are generally impacted stronger by the increasing returns to investors than by the reduction in CapEx. Nevertheless, there are some exceptions which explain the dip around WACC 16\% where the increase in cost of capital is overcompensated by a drastic decrease in CapEx of $11 \%$. Highest capital expenditures and thus largest external funding requirements occur in the WACC $0 \%$ scenario, in which $139.0 \mathrm{k}$ USD is invested in long-term assets. With an increase in WACC, the required funding decreases by $70 \%$ to $41.7 \mathrm{k}$ USD in the WACC $30 \%$ scenario. At the WACC market rate of $15 \%$, total required funding amounts to $98.4 \mathrm{k}$ USD and accounts for $30 \%$ of cumulative investment costs. Figure 10 shows the variation of process capacity and electric power generation with the increase of WACC. Since PV is the most CapExintensive power generation technology with $1400 \mathrm{USD} / \mathrm{kW}$ of installed capacity followed by the biogas generator with $675 \mathrm{USD} / \mathrm{kW}$ and diesel generator with 500 $\mathrm{USD} / \mathrm{kW}$ (see Appendix), PV is continuously substituted by diesel generators as the WACC increases. With the decrease in installed capacity of the inflexible but volatile solar power source-and the limited storage capacity due to high investment costs related to the corresponding battery system-diesel-generated electricity increases as biogas is already fully utilized. For low WACC values, diesel power accounts for only a small share of the total electricity, but starting at WACC 13\%, diesel-generated electricity already accounts for a substantial share of $12 \%$ and continues to increase to around one third of total produced electricity for WACC $20 \%$. Biogas capacity and energy remain almost constant at their maximum levels.

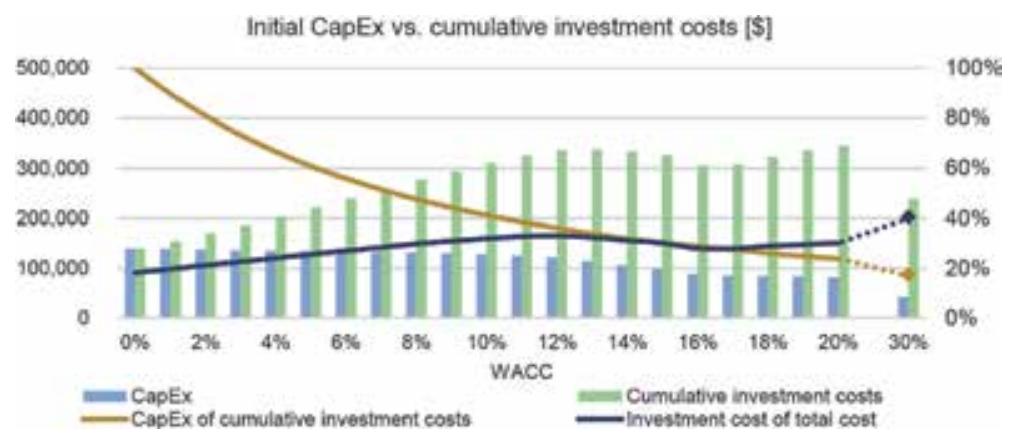

Figure 9.

Capital expenditure and cumulative investment costs for WACC variation from o to $30 \%$.

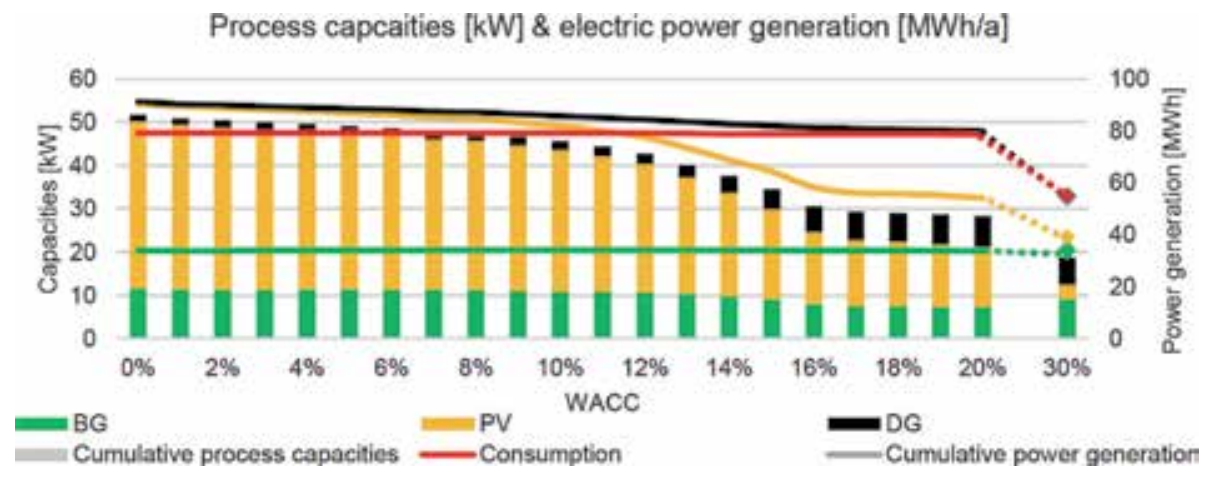

Figure 10.

Process capacities and electric power generation for WACC variation from o to $30 \%$. 
Table 4 outlines the variation of the unit costs of electricity, water, and food with increasing WACC. With an increase in WACC, the weighted average LCOE increases from $0.08 \mathrm{USD} / \mathrm{kWh}$ (WACC $0 \%$ ) to $0.29 \mathrm{USD} / \mathrm{kWh}$ (WACC 30\%). This is not only because the LCOE from PV and LCOE from biogas system (BG) increase by a factor of 3.9 and 2.6, respectively, but predominantly because the electricity mix shifts from the relatively cheaper technologies with high CapEx (PV and BG) to the more expensive but investment light diesel generator (DG). The LCOE from DG slightly decrease from $0.46 \mathrm{USD} / \mathrm{kWh}$ (WACC $0 \%$ ) to $0.41 \mathrm{USD} / \mathrm{kWh}$ for WACC $15 \%$ before again increasing to $0.45 \mathrm{USD} / \mathrm{kWh}$ (WACC $30 \%$ ). This variation in LCOE from DG is related to the opposing impact of an increasing utilization rate and increasing specific investment costs. The development of LCOE is also reflected in the development of the unit costs of water and food as both-the access to water and the production of food-require a substantial amount of electricity.

The total financial value generated, visualized in Figure 11, includes the system costs $19.4 \mathrm{k}$ USD (WACC 0-20\%) of annual labor expenses related to farming that can be paid to domestic workers. Because the WACC 30\% scenario does not utilize the maximum farmland capacity, labor costs are as low as $7.7 \mathrm{k}$ USD. As the WACC represents the relative return to investors, this increases as long as CapEx decreases slower than the increase in cost of capital compensates for. Net profits to the domestic community behave reversely and decrease with an increasing WACC. The maximum total financial value added by the system to the major stakeholders is reached for WACC $0 \%$, where the annual cumulative financial value added to the domestic community and investors adds up to $33.5 \mathrm{k}$ USD and continuously decreases from there on.

\begin{tabular}{lcccc}
\hline Commodity & Unit & \multicolumn{3}{c}{ Costs } \\
\cline { 3 - 5 } & & WACC 0\% & WACC 15\% & WACC 30\% \\
\hline Electricity total & USD/kWh & 0.08 & 0.22 & 0.29 \\
\hline Electricity from diesel generator & USD/kWh & 0.46 & 0.41 & 0.45 \\
\hline Electricity from solar photovoltaics & USD/kWh & 0.08 & 0.18 & 0.31 \\
\hline Electricity from biogas generator & USD/kWh & 0.08 & 0.14 & 0.22 \\
\hline Water & USD/m ${ }^{3}$ & 0.03 & 0.05 & 0.05 \\
\hline Food & USD/ton & 132 & 164 & 178 \\
\hline
\end{tabular}

Table 4 .

Unit costs of electricity, water, and food.

\section{Total financial value generated $[\$ / a]$}

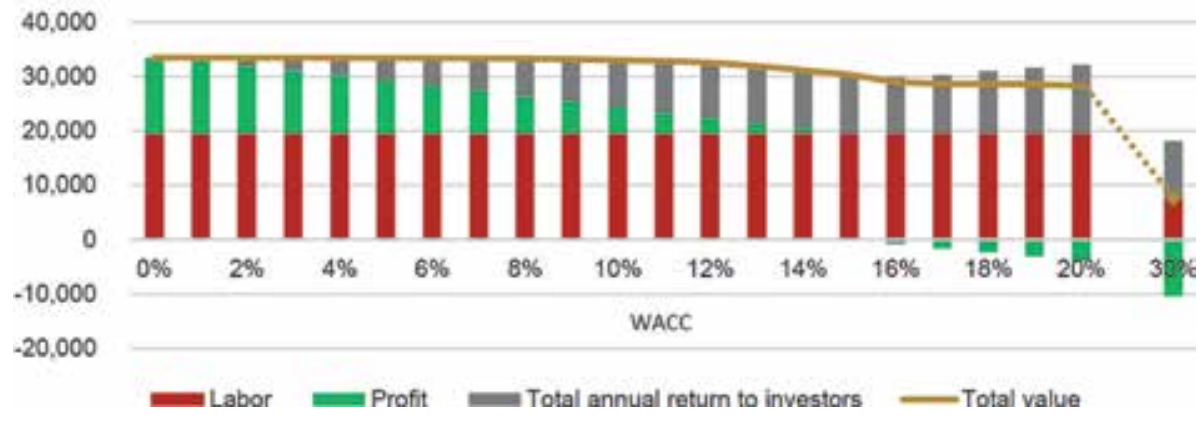

Figure 11.

Total financial value generated for WACC variation from o to $30 \%$. 
For WACC 0\%, the system profits of $14.1 \mathrm{k}$ USD are distributed to the domestic community, corresponding to 45.61 USD per capita-0.10 more than the total expenses required for food. The market-based financing scenario (WACC 15\%) breaks even (net loss of 1.8 USD). A finance system with WACC $30 \%$ generates a loss of $10.4 \mathrm{k}$ USD, which implies an electricity price of $0.25 \mathrm{USD} / \mathrm{kWh}$ or annual costs of 33.84 USD per capita for electricity and total costs of 79.45 USD per capita for energy, water, and food.

Altogether, there is a strong impact of the costs of capital on the financial and technical parameters of the system. The maximum field capacity is utilized up to the WACC $20 \%$ scenario, and even for WACC $30 \%$, the food production of a leastcost system would be sufficient to meet the domestic demand. An increase in the cost of capital by $1 \%$ leads to a decrease in system profits by 880 USD. The required funds to finance long-term assets amount to $139.0 \mathrm{k}$ USD for WACC $0 \%$ and decrease from there on as CapEx-intensive technologies such as PV are increasingly substituted with investment light technologies such as diesel.

\subsection{Results of technology variation scenario S3}

The costs, revenues, and profit for scenario S3 are depicted in Figure 12. For WACC $0 \%$, the cost-minimizing system is designed in a dimension that the maximum farmland capacity is utilized, regardless of the available power generation technologies. Since revenues are directly proportional to the maize grain production, annual revenues are constant at $52.6 \mathrm{k}$ USD. It can be clearly seen that system costs rise with the constraints on combination of power generation technologies. While the total annual costs for the fully fledged system amount to $38.5 \mathrm{k} \mathrm{USD}$, the omission of biogas leads to a cost increase by $29 \%$, while the omission of biogas and photovoltaics leads to an increase by $74 \%$ to $66.8 \mathrm{k}$ USD. Hence, a system in which electricity is exclusively generated from diesel is not even net-profitable in a fully socially financed scenario and thus cannot sustainably provide the domestic community with energy and water free of charge. In order to cover the net losses, 46.4 USD per capita and year or $0.34 \mathrm{USD} / \mathrm{kWh}$ are charged for electricity. As the WACC increases to $15 \%$, only the fully fledged EWF system operates at full food production, while the omission of biogas reduces the agricultural productivity by $16 \%$ and the absence of both renewable energy sources reduces the productivity by $68 \%$ to 70 tons per year, which is just sufficient to feed the domestic community. While the fully fledged EWF system breaks even, the unavailability of biogas prevents the systems from being profitable. Net losses for the DG + PV EWF system of $15.4 \mathrm{k}$ USD and $17.3 \mathrm{k}$ USD for the pure DG EWF system imply annual electricity and water expenses of 50 USD and 56.3 USD per capita, respectively; allocated to power consumption, this equals $0.36 \mathrm{USD} / \mathrm{kWh}$ and $0.41 \mathrm{USD} / \mathrm{kWh}$, respectively.

In the WACC $30 \%$ scenario, none of the EWF systems utilizes the maximum field capacity. While the fully fledged system still produces enough maize grain to provide for the domestic community (104 tons), the DG + PV EWF system and the pure DG EWF system produce just 13 tons and 8 tons, respectively. As the trend of declining profitability with an increase in WACC continues to proceed, even the

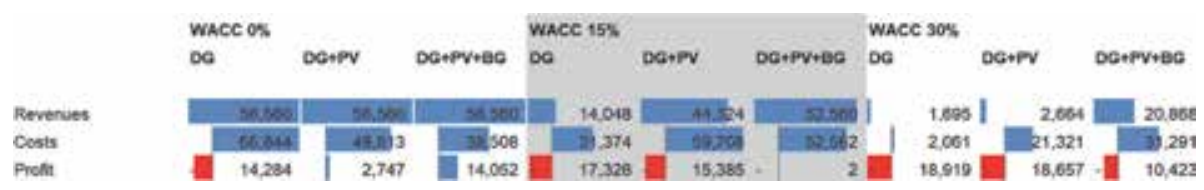

Figure 12.

Costs and revenues variation in power generation technology choice for $W A C C=0,15$, and 30\%. 
fully fledged EWF system generates an annual net loss of $10.4 \mathrm{k}$ USD, while the DG + PV EWF system loses $18.7 \mathrm{k}$ USD and the pure DG EWF system $18.9 \mathrm{k}$ USD. On a per capita level, this means that total annual costs for energy and water for a domestic inhabitant amounts to 33.8 USD (DG + PV + BG), 60.6 USD (DG + PV), and 61.4 USD (DG). In terms of consumed electricity, this implies a price of 0.25 USD/kWh for the fully fledged EWF system, $0.44 \mathrm{USD} / \mathrm{kWh}$ for the DG + PV EWF system, and $0.45 \mathrm{USD} / \mathrm{kWh}$ for the pure DG EWF system.

Out of this analysis, it is clear that a purely diesel-based EWF system is not sufficiently economical to provide the domestic community with free electricity and water on a sustainable basis, regardless of the cost of capital. The extension of this system by photovoltaics is only the first step towards a superior economic solution in which biogas generators are included as well. Especially for higher cost of capital, the positive financial impact of photovoltaics decreases as investor returns increase and the area of application decreases as agricultural activities decline. Regardless of the WACC, from a financial standpoint, the deployment of biogas systems is indispensable.

\section{Conclusions and outlook}

This contribution presents an economic analysis of decentralized energy-waterfood systems and their capability to provide economic-feasible solutions for rural electrification and thus the potential to enable economic development of the rural population in sub-Saharan Africa. Their decentralized design avoids the financial and governmental obstacles coming with electrification through grid extension. Biogas motors as controllable power generators substitute the costly and environmental unfriendly use of diesel generators. Although the deployment of water pumps increases the system investment costs, they lead to two major advantages compared to micro-grids without their utilization. Firstly, they are flexible loads opposite to most private power consumers (e.g., light bulbs). The water pumps are powered by cheap solar power during daytime with little or even without use of costly battery storage. Secondly, water pumps are productive power consumers opposite to private consumption, because their utilization enables year-round agriculture, which increases local productivity. Hence the local population is enabled to pay back the investment costs despite their formerly low purchase power. The leastcost modeling on the case study of the rural community Kpori, a 300-inhabitant farming village in northern Ghana, confirmed this hypothesis. The system integration of biogas generators and water pumps to closed-loop energy-water-food systems reduces the costs significantly compared to current electrification approaches with diesel generators only or diesel generators combined with solar photovoltaics and batteries. The decreased demand of costly batteries and diesel and increased profits from year-round agriculture lead to annual costs of 2 USD for the for electricity and water supply of the community compared to 17,326 USD for power supply just with diesel, assuming WACC of $15 \%$ and that the profits from agricultural sales subsidize the power supply. The cost analysis of these modeling results shows that $37 \%$ of the costs are spent for farming salaries and just $9 \%$ on CAPEX but $21 \%$ on capital costs due to the WACC of $15 \%$. The remaining costs result from costs for fuel and other operation costs such as maintenance. The conducted variation of WACC showed on the one hand that this has a strong impact on the LCOE, which are $0.08 \mathrm{USD} / \mathrm{kWh}$ for WACC of $0 \%, 0.22 \mathrm{USD} / \mathrm{kWh}$ for WACC of $15 \%$, and 0.29 USD/kWh for WACC of 30\%. On the other hand, increasing WACC leads to significant reduction of installed PV capacities and increased share of power from diesel generators. The utilization of biogas is almost independent of the WACC 
because of its low CAPEX and constrained maximum capacity due to shortage of livestock manure as input. Based on this model results, decentralized energy-waterfood systems have shown their potential to enable LCOE below state-of-the-art offgrid systems and local job creation through improved agricultural productivity.

In order to prove the potential of decentralized energy-water-food systems, they must be implemented on-ground including research on the optimal management and ownership structures; professional requirements for its managers, technicians, and farmers; as well as possible investment strategies. Also, the least-cost model shall be improved regarding more detailed modeling of groundwater availability, nutrients in the soil, water consumption of different crops, and biogas digestion of various inputs. After adding these improvements of the model, it shall be disseminated to and used by interested NGOs and social enterprises. Thereby, decentralized energy-water-food systems could prove their potential to improve access to reliable energy, water, and food supply, to create local jobs, and thus to fight extreme poverty of the population in rural sub-Saharan Africa.

\section{Nomenclature}

$\begin{array}{ll}\text { BG } & \text { biogas generator } \\ \text { DG } & \text { diesel generator } \\ \text { EWFS } & \text { energy-water-food system } \\ \text { E }+ \text { W } & \text { energy and water } \\ \text { HH } & \text { household } \\ \text { LCOE } & \text { levelized costs of electricity } \\ \text { OpEx } & \text { operational expenses } \\ \text { PV } & \text { solar photovoltaics } \\ \text { SSA } & \text { sub-Saharan Africa }\end{array}$

\section{Appendix A: model inputs}

\begin{tabular}{lcc}
\hline & Unit & Value \\
\hline Load efficiency & $\%$ & 28 \\
\hline Minimum load & $\%$ & 25 \\
\hline Investment costs & USD/kW & 500 \\
\hline Fixed costs & USD/kW/year & 10 \\
\hline Variable costs & USD/kWh & 0.01 \\
\hline Lifetime & Year & 15 \\
\hline
\end{tabular}

Table A1.

Techno-economic parameters for diesel generator.

\begin{tabular}{lcc}
\hline & Unit & Value \\
\hline Module type & - & Crystalline silicon \\
\hline Tracking system & - & Fixed \\
\hline Investment costs & USD/kW & 1400 \\
\hline
\end{tabular}


Economic Development of Rural Communities in Sub-Saharan Africa through Decentralized... DOI: http://dx.doi.org/10.5772/intechopen.90424

\begin{tabular}{lcc}
\hline & Unit & Value \\
\hline Fixed costs & USD/kW/year & 20 \\
\hline Variable costs & USD/kWh & 0 \\
\hline Lifetime & Year & 25 \\
\hline
\end{tabular}

Table A2.

Techno-economic parameters for solar photovoltaics.

\begin{tabular}{lcc}
\hline & Unit & Value \\
\hline Technology & - & Lead-acid \\
\hline Depth of discharge & - & 60 \\
\hline Energy investment cost capacity & USD/kWh & 350 \\
\hline Power investment costs & USD/kW & 300 \\
\hline Energy fixed costs & USD/kWh/year & 10 \\
\hline Power fixed costs & USD/kW/year & 30 \\
\hline Variable costs & USD/kWh & 0 \\
\hline Round-trip efficiency & $\%$ & 85 \\
\hline Lifetime & Year & 10 \\
\hline
\end{tabular}

Table A3.

Techno-economic parameters for battery.

\begin{tabular}{lcc}
\hline & Unit & Value \\
\hline Load efficiency & $\%$ & 29 \\
\hline Minimum load & $\%$ & 40 \\
\hline Investment costs & USD/kW & 675 \\
\hline Fixed costs & USD/kW/year & 10 \\
\hline Variable costs & USD/kWh & 0.01 \\
\hline Lifetime & Year & 15 \\
\hline
\end{tabular}

Table A4.

Techno-economic parameters for biogas generator.

\begin{tabular}{lcc}
\hline & Unit & Value \\
\hline Maximum installed capacity & ton/h & 0.0153 \\
\hline Investment costs & USD/ton/h & $788.4 \mathrm{k}$ \\
\hline Fixed costs & $\%$ & $3.5 \%$ of investment costs \\
\hline Variable costs & USD/ton & 2.1 \\
\hline Lifetime & Year & 20 \\
\hline
\end{tabular}

Table A5.

Techno-economic parameters for biogas digester.

\begin{tabular}{lcc}
\hline & Unit & Value \\
\hline Material & - & Plastic (PVC) \\
\hline Investment costs & $\mathrm{USD} / \mathrm{m}^{3}$ & 60 \\
\hline
\end{tabular}


Regional Development in Africa

\begin{tabular}{lcc}
\hline & Unit & Value \\
\hline Fixed costs & USD $/ \mathrm{m}^{3} /$ year & 0 \\
\hline Efficiency & $\%$ & 100 \\
\hline Lifetime & Year & 10 \\
\hline
\end{tabular}

Table A6.

Techno-economic parameters for biogas tank.

\begin{tabular}{lcc}
\hline & Unit & Value \\
\hline Technology & - & 3-phase AC submersible pump \\
\hline Total dynamic head & $\mathrm{m}$ & 50 \\
\hline Rated volume & $\mathrm{m}^{3} / \mathrm{kWh}$ & 4.4 \\
\hline Investment costs & $\mathrm{USD} / \mathrm{kW}$ & 900 \\
\hline Fixed costs & USD/kW/year & $10 \%$ of investment costs \\
\hline Variable costs & USD/kWh & 0.01 \\
\hline Lifetime & Year & 15 \\
\hline
\end{tabular}

Table A7.

Techno-economic parameters for water pump.

\begin{tabular}{lcc}
\hline & Unit & Value \\
\hline Material & - & Ferrocement \\
\hline Investment costs & USD $/ \mathrm{m}^{3}$ & 35 \\
\hline Fixed costs & USD $/ \mathrm{m}^{3} /$ year & $1 \%$ of investment costs \\
\hline Efficiency & $\%$ & 100 \\
\hline Lifetime & Year & 25 \\
\hline
\end{tabular}

Table A8.

Techno-economic parameters for water tank.

\begin{tabular}{lcc}
\hline & Unit & Value \\
\hline Arable land & ha & 15 \\
\hline Modeled crop & - & Maize \\
\hline Maize growth time & day & 125 \\
\hline Maize yield & ton/ha & 6 \\
\hline Annual crop evapotranspiration & mm/year & 1330.7 \\
\hline Crop residue to maize grain ratio & - & 1.69 \\
\hline Fertilizer costs & USD/ton & 400 \\
\hline Labor requirement & day/ha & 144 \\
\hline Labor wage & USD/day & 3.08 \\
\hline Drip irrigation investment costs & USD/ha & 2000 \\
\hline Drip irrigation efficiency & $\%$ & 90 \\
\hline Fixed costs & USD/ton/h/year & 20 \\
\hline Lifetime & Year & \\
\hline
\end{tabular}

Table A9.

Techno-economic parameters for maize field. 
Economic Development of Rural Communities in Sub-Saharan Africa through Decentralized... DOI: http://dx.doi.org/10.5772/intechopen.90424

\begin{tabular}{lcc}
\hline & Unit & Value \\
\hline Material & - & Ferrocement \\
\hline Investment costs & USD $/ \mathrm{m}^{3}$ & 35 \\
\hline Fixed costs & $\mathrm{USD} / \mathrm{m}^{3} /$ year & $1 \%$ of investment costs \\
\hline Efficiency & $\%$ & 100 \\
\hline Lifetime & Year & 25 \\
\hline
\end{tabular}

Table A10.

Techno-economic parameters for waste silo.

\begin{tabular}{ccc}
\hline & Unit & Value \\
\hline Diesel fuel & USD/kWh & 0.106 \\
\hline Maize grain & USD/ton & 200 \\
\hline
\end{tabular}

Table A11.

Economic parameters of commodities bought from market.

\begin{tabular}{ccc}
\hline & Unit & Value \\
\hline Maize grain & USD/ton & 200 \\
\hline
\end{tabular}

Table A12.

Economic parameters of commodities sold to market.

\section{Appendix B: model results}

\begin{tabular}{|c|c|c|c|}
\hline Output variable/technology & DG & DG + PV & DG + PV + BG (=EWFS) \\
\hline Food production (ton/year) & 263 & 263 & 263 \\
\hline Total revenues (USD/year) & 56,560 & 56,560 & 56,560 \\
\hline Total costs (USD/year) & 66,844 & 49,813 & 38,508 \\
\hline Profit (USD/year) & $-14,284$ & 2747 & 14,052 \\
\hline Profit per HH (USD/year) & - & 39 & 201 \\
\hline Cost per $\mathrm{HH}$ for $\mathrm{E}+\mathrm{W}$ (USD/year) & 204 & - & - \\
\hline Electricity costs (USD/kWh) & 0.34 & - & - \\
\hline LCOE (USD/kWh) & 0.39 & 0.14 & 0.08 \\
\hline Unit costs of water $\left(\mathrm{USD} / \mathrm{m}^{3}\right)$ & 0.08 & 0.04 & 0.03 \\
\hline Unit costs of food (USD/ton) & 189 & 163 & 132 \\
\hline Investment costs - Electricity (USD/year) & 644 & 8198 & 3959 \\
\hline Investment costs - DG (USD/year) & 644 & 104 & 52 \\
\hline Investment costs - PV (USD/year) & - & 8095 & 2567 \\
\hline Investment costs - BG (USD/year) & - & - & 1341 \\
\hline Total installed power $(\mathrm{kW})$ & 19 & 71 & 52 \\
\hline Installed power - DG $(\mathrm{kW})$ & 19 & 3 & 2 \\
\hline Installed power - PV (kW) & - & 68 & 39 \\
\hline Installed power - BG $(\mathrm{kW})$ & - & - & 12 \\
\hline
\end{tabular}




\begin{tabular}{lccc}
\hline Output variable/technology & DG & DG + PV & DG + PV + BG (=EWFS) \\
\hline Total electricity generated (kWh) & 78,838 & 101,197 & 91,318 \\
\hline Electricity generation - DG (kWh) & 78,838 & 1696 & 853 \\
\hline Electricity generation - PV (kWh) & - & 99,501 & 56,517 \\
\hline Electricity generation - BG (kWh) & - & - & 33,948 \\
\hline
\end{tabular}

Table B1.

Model results for technology variation for $W A C C=0 \%$.

\begin{tabular}{|c|c|c|c|}
\hline Output variable/technology & DG & $\mathrm{DG}+\mathrm{PV}$ & $\mathrm{DG}+\mathrm{PV}+\mathrm{BG}(=\mathrm{EWFS})$ \\
\hline Food production (ton/year) & 70 & 222 & 263 \\
\hline Total revenues (USD/year) & 14,048 & 44,324 & 52,560 \\
\hline Total costs (USD/year) & 31,374 & 59,708 & 52,562 \\
\hline Profit (USD/year) & $-17,326$ & $-15,385$ & -2 \\
\hline Profit per HH (USD/year) & - & - & - \\
\hline Cost per $\mathrm{HH}$ for $\mathrm{E}+\mathrm{W}$ (USD/year) & 284 & 220 & 0 \\
\hline Electricity costs (USD/kWh) & 0.41 & 0.36 & 0.00 \\
\hline LCOE (USD/kWh) & 0.41 & 0.34 & 0.22 \\
\hline Unit costs of water $\left(\mathrm{USD} / \mathrm{m}^{3}\right)$ & 0.06 & 0.07 & 0.05 \\
\hline Unit costs of food (USD/ton) & 193 & 203 & 164 \\
\hline Investment costs_Electricity (USD/year) & 1291 & 5722 & 8304 \\
\hline Investment costs_-DG (USD/year) & 1291 & 1090 & 408 \\
\hline Investment costs-PV (USD/year) & - & 4631 & 4549 \\
\hline Investment costs-BG (USD/year) & - & - & 3347 \\
\hline Total installed power $(\mathrm{kW})$ & 15 & 32 & 35 \\
\hline Installed power-DG (kW) & 15 & 13 & 5 \\
\hline Installed power-PV (kW) & - & 19 & 21 \\
\hline Installed power-BG $(\mathrm{kW})$ & - & - & 9 \\
\hline Total electricity generated $(\mathrm{kWh})$ & 50,349 & 75,290 & 81,967 \\
\hline Electricity generation-DG (kWh) & 50,349 & 46,916 & 17,583 \\
\hline Electricity generation-PV $(\mathrm{kWh})$ & - & 28,374 & 30,292 \\
\hline Electricity generation-BG (kWh) & - & - & 34,092 \\
\hline
\end{tabular}

Table B2.

Model results for technology variation for $W A C C=15 \%$.

\begin{tabular}{lccc}
\hline Output variable/technology & DG & DG + PV & DG + PV + BG (=EWFS) \\
\hline Food production (ton/year) & 8 & 13 & 104 \\
\hline Total revenues (USD/year) & 1695 & 2664 & 20,868 \\
\hline Total costs (USD/year) & 2061 & 21,321 & 31,291 \\
\hline Profit (USD/year) & $-18,919$ & $-18,657$ & $-10,423$ \\
\hline Profit per HH (USD/year) & - & - & 149 \\
\hline Cost per HH for E + W (USD/year) & 270 & 267 & 0.25 \\
\hline Electricity costs (USD/kWh) & 0.45 & 0.44 & - \\
\hline
\end{tabular}


Economic Development of Rural Communities in Sub-Saharan Africa through Decentralized... DOI: http://dx.doi.org/10.5772/intechopen.90424

\begin{tabular}{lccc}
\hline Output variable/technology & DG & DG + PV & DG + PV + BG (=EWFS) \\
\hline LCOE (USD/kWh) & 0.44 & 0.43 & 0.29 \\
\hline Unit costs of water (USD/m $\left.{ }^{3}\right)$ & 0.06 & 0.06 & 0.05 \\
\hline Unit costs of food (USD/ton) & 208 & 207 & 179 \\
\hline Investment costs-Electricity (USD/year) & 2163 & 3228 & 8278 \\
\hline Investment costs-DG (USD/year) & 2163 & 2163 & 974 \\
\hline Investment costs-PV (USD/year) & - & 1065 & 1394 \\
\hline Investment costs-BG (USD/year) & - & - & 5910 \\
\hline Total installed power (kW) & 14 & 17 & 6 \\
\hline Installed power-DG (kW) & 14 & 14 & 3 \\
\hline Installed power-PV (kW) & - & 3 & 9 \\
\hline Installed power-BG (kW) & - & - & 54,781 \\
\hline Total electricity generated (kWh) & 43,853 & 44,324 & 15,851 \\
\hline Electricity generation-DG (kWh) & 43,853 & 40,617 & 4852 \\
\hline Electricity generation-PV (kWh) & - & 3707 & 34,144 \\
\hline Electricity generation—BG (kWh) & - & - & \\
\hline
\end{tabular}

Table B3.

Model results for technology variation for $W A C C=30 \%$. 


\section{Author details}

Johannes Winklmaier ${ }^{* \dagger}$, Sissi Adeli Bazan Santos ${ }^{* \dagger}$ and Tobias Trenkle ${ }^{\dagger}$ Chair of Renewable and Sustainable Energy Systems, Technical University of Munich, Munich, Germany

*Address all correspondence to: johannes.winklmaier@tum.de and adeli.bazan@tum.de

$\uparrow$ These authors contributed equally.

\section{IntechOpen}

(C) 2020 The Author(s). Licensee IntechOpen. This chapter is distributed under the terms of the Creative Commons Attribution License (http://creativecommons.org/licenses/ by/3.0), which permits unrestricted use, distribution, and reproduction in any medium, provided the original work is properly cited. (cc) BY 


\section{References}

[1] Food and Agriculture Organization of the United Nations. FAO Migration Framework: Migration as a Choice and an Opportunity for Rural Development. 2019

[2] Lopez-Ekra S. Workshop on Migration and Climate Change Held. 2017. Available from: https://ghanane wsagency.org/social/workshop-onmigration-and-climate-change-held115501 [Accessed: 10 January 2019]

[3] Food and Agriculture Organization of the United Nations. Migration, Agriculture and Rural Development: Addressing the Root Causes of Migration and Harnessing its Potential for Development. 2016

[4] Food and Agriculture Organization of the United Nations. The State of Food and Agriculture 2018. Migration, Agriculture and Rural Development. 2018

[5] Food and Agriculture Organization of the United Nations. Atlas: Rural Africa in Motion. Dynamics and Drivers of Migration South of the Sahara. 2017

[6] Winklmaier J, Bazan Santos S. Promoting Rural Electrification in SubSaharan Africa: Least-Cost Modelling of Decentralized Energy-Water-Food Systems: Case Study of St. Rupert Mayer, Zimbabwe, Africa-EU Renewable Energy Research and Innovation Symposium. 2018. DOI: 10.1007/978-3-319-93438-9

[7] Bazan S, Winklmaier J, Ramde E, Hamacher T. Towards rural development in Sub-Saharan Africa through least-cost modeling of decentralized Energy-WaterFood systems: Case study Kpori, Ghana. (forthcoming)
[8] United Nations. Transforming Our World: The 2030 Agenda for Sustainable Development. In A New Era in Global Health. 2018. DOI: 10.1891/ 9780826190123.ap02

[9] International Energy Agency. WEO2017 Special Report: Energy Access Outlook. 2017. DOI: $10.1787 / 20725302$

[10] The World Bank. State of Electricity Access Report 2017. 2017. DOI: 10.1596/ 26646

[11] Mandelli S, Barbieri J, Mereu R, Colombo E. Off-grid systems for rural electrification in developing countries: Definitions, classification and a comprehensive literature review. Renewable and Sustainable Energy Reviews. 2016;58:1621-1646. DOI: 10.1016/j.rser.2015.12.338

[12] Holmes J. 2016 Findings and Recommendations from the Smart Villages Initiative 2014-2017. 2017

[13] Brivio C, Mandelli S. Rural electrification in developing countries via autonomous micro-grids. 2014. Available from: http://gdee.eu/index. php/resources.html

[14] Williams N, Jaramillo P, Taneja J, Ustun T. Enabling private sector investment in microgrid-based rural electrification in developing countries: A review. Renewable and Sustainable Energy Reviews. 2015;52:1268-1281. DOI: 10.1016/j.rser.2015.07.153

[15] Stevens L, Gallagher M, Practical Action. The Energy-Water-Food Nexus at Decentralized Scales: Synergies, Trade-Offs, and How to Manage Them. Poor People's Energy Briefing. Vol. 3. 2015

[16] United Nations Development Programme. Human Development 
Reports. 2017. Available from: http:// hdr.undp.org/en/data [Accessed: 10 January 2019]

[17] Labordena M, Patt A, Bazilian M, Howells M, Lilliestam J. Impact of political and economical barriers for concentrating solar power in subSaharan Africa. Energy Policy. 2017;102: 52-72. DOI: 10.1016/j.enpol.2016.12.008

[18] German Federal Ministry for Environment, Nature Conversation and Nuclear Safety (BMU), German Federal Ministry for Economic Cooperation and Development (BMZ). Bonn 2011 Conference: The Water, Energy and Food Security Nexus - Solutions for a Green Economy. 2012

[19] International Renewable Energy Agency. Renewable Energy in the Water, Energy and Food Nexus. 2015

[20] The Water, Energy \& Food Security Resource Platform. Resources. Available from: https://www.water-energy-food. org/resources/recent [Accessed: 11 January 2019]

[21] RES4Africa. WEF Nexus Publication:Applying the WaterEnergy-Food Nexus Approach to Catalyse Transformational Change in Africa. 2019

[22] Kempener R, Lavagne O, Saygin D, Skeer J, Vinci S, Gielen D. Off-Grid Renewable Energy Systems: Status and Methodological Issues. 2015

[23] United Nations Human Rights Council. Safe Drinking Water as a Human Right. 2015. Available from: https://www.un.org/waterforlifedecade/ human_right_to_water.shtml

[24] Energy4Impact. Strategic Advice Helps Solar Irrigation Company Overcome Barriers To Market Scale. Available from: https://www.energ y4impact.org/news/strategic-advicehelps-solar-irrigation-company-overcomebarriers-market-scale [Accessed: 11 January 2019]

[25] Bahramara S, Moghaddam M, Haghifam M. Optimal planning of hybrid renewable energy systems using HOMER: A review. Renewable and Sustainable Energy Reviews. 2016. DOI: 10.1016/j.rser.2016.05.039

[26] Mandelli S, Barbieri J. Off-grid systems for rural electrification in developing countries: Definitions, classification and a comprehensive literature review. Renewable and Sustainable Energy Reviews. 2016;62: 609-620. DOI: 10.1016/j. rser.2015.12.338

[27] Albrecht T, Crootof A, Scott C. The water-energy-food Nexus: A systematic review of methods for nexus assessment. Environmental Research Letters. 2018;13:043002. DOI: 10.1088/ 1748-9326/aaa9c6

[28] Tum-Ens. urbs: A Linear Optimisation Model for Distributed Energy Systems. 1999. Available from: https://urbs.readthedocs.io/en/latest/ [Accessed: 10 January 2019]

[29] Kumi E. The Electricity Situation in Ghana: Challenges and Opportunities. Washington: CGD Policy Paper; 2017

[30] Arandamola M, Quansah D, AgelinChaab M, Paul S. Multipurpose renewable energy resources based hybrid energy system for remote community in northern Ghana. Sustainable Energy Technologies and Assessments. 2017;22:161-170

[31] Ghana Statistical Service. Poverty Map for Ghana. 2015

[32] Ghana Statistical Service. Population and Housing Consensus. 2012 
Economic Development of Rural Communities in Sub-Saharan Africa through Decentralized... DOI: http://dx.doi.org/10.5772/intechopen.90424

[33] Darko A. Cost-minimizing food

budgets in Ghana. Journal of

Development and Agricultural

Economics. 2013;5:135-141. DOI:

10.5897/jdae12.097

[34] Frauenhofer ISE. Levelized Cost of Electricity - Renewable Energy

Technologies. 2018 



\title{
World Trade Organization's Trade Liberalization Policy on Agriculture and Food Security in West Africa
}

\author{
Emeka C. Iloh, Michael Nwokedi, \\ Chijioke Francis Onyebukwa and Queeneth Ekeocha
}

\begin{abstract}
The study explores the link between WTO's trade liberalization policy on agriculture and food security in West Africa. Specifically, it investigates whether the policy undermines food security in the subregion by examining its impacts on food importation and food dumping. The study relied mainly on documentary evidence. Data were scooped from documents and annual publications of the WTO, UNCTAD, FAO, ECOWAS, and World Bank. Data were analysed using content analysis, rooted on logical deductions. The results of data analysis show that the increased dependency on international trade (as being championed by the WTO) by many countries in West Africa has a number of direct and indirect implications on the realization of food security in the subregion. Importation not only exposes producers and consumers to increased vulnerability both to worsening terms of trade and to fluctuations in commodity prices, but also exposes the domestic foodproducing industries to danger of extinction through steep competition. The study also found that relying on international trade for food supply encourages dumping of the excess products on developing countries at relatively cheaper prices. This harms domestic production and reduces the income of domestic farmers and other investors in the food production chain.
\end{abstract}

Keywords: trade liberalization policy, food importation, food dumping, international trade, agriculture

\section{Introduction}

Trade liberalization is a cardinal principle of the World Trade Organization (WTO), though its origin could be traced to the structural adjustment programmes of the international financial institutions (The World Bank and the IMF) in their attempts to incorporate developing countries into the capitalist development paradigm. In order to hasten this process of incorporation, countries, especially from the developing world, were mandated to liberalize their economies, including their trade relations with the rest of the world. Thus, every member country of the world trade body, while acceding to the document that embodies the WTO agreement, undertakes to liberalize its trade, especially trade in agriculture. Developing 
countries in particular are being encouraged to liberalize their agricultural trade in order to maximize abundant food and foreign exchange earnings for their evergrowing population.

Agriculture is a very important sector for West African countries. In addition to being the biggest employer of labour in the ECOWAS region, constituting 60\% of the active labour force, and also representing about 35\% of the gross domestic product (GDP) of the region [1], agricultural exports constitute an important element of West Africa's foreign trade. With the exception of Nigeria that its main trade commodity in the international market is crude oil, agriculture constitutes the major trade commodity between West African countries and the rest of the world. More importantly, it is a vital factor in efforts by the region to combat poverty and food insecurity.

However, the importance of agriculture to West Africa as enumerated above notwithstanding, two major worrying trends have been noticed in West Africa's agricultural trade performance in the international market. First, despite the majority of its population being engaged in agricultural activities, many of the countries in West Africa are food insecure. In other words, there is food security crisis in the subregion. Second, despite the fact that agriculture constitutes its main trade commodity in the international market, West Africa's food imports have been on the increase.

Available evidence suggests that trade liberalization, instead of addressing these issues as promised by the international financial institutions, reinforces them. This is because the policy promotes unfair trade practices such as dumping, which undermines food security in developing countries. The policy also encourages food importation from developed countries, thereby undermining food self-sufficiency strategy of most developing countries, especially in West Africa. In other words, it has made many West African countries to depend on importation in order to meet their food requirements.

The role of international trade in this importation and redistribution of food from food-surplus regions to food-deficit regions cannot be over-emphasised. This is where the WTO, being the only prevailing international organization charged with the regulation of international trade, comes in. Through its Agreement on Agriculture, the WTO, therefore, has an undisputed international legal authority to make certain policies relating to food security, like other food and agriculture-based organizations such as the Food and Agriculture Organization [FAO], the World Food Programme [WFP], and the International Fund for Agricultural Development [IFAD]. Thus, since the WTO was institutionalised in 1995, it has been playing increasing role in global food governance through its Agreement on Agriculture. The trade liberalization policy has been the driving force of this agreement.

In West Africa, there are three major agro-ecological zones-the Sahelian, Sudanese, and Coastal zones-where production and consumption of food staples can be easily classified. In the Sahelian zone (northern Senegal, southern Mauritania, central Mali, northern Burkina Faso, Niger, Cape Verde and extreme north of Nigeria), the main cereal cultivated by most farmers is millet. However, in Cape Verde, rice and maize are mostly cultivated. In Mauritania, maize and sorghum are mostly cultivated. In Senegal, rice production is dominant. The principal alternatives are cassava floor, rice and sorghum. In the Sudanese zone (Southern Chad, Central Nigeria, Benin, Ghana, Togo, Côte d'Ivoire, southern Burkina Faso, Mali, Senegal, Guinea Bissau, Sierra Leone, Liberia) maize and sorghum are the principal cereals consumed by most of the population, followed by rice, cassava, and yam. In the Coastal zone-with two rainy seasons-(Guinea, Cote d'Ivoire, Liberia, Sierra Leone and southern Nigeria) yam and maize are the most important food products, supplemented by cowpea [2]. 
As noted above, West Africa has historically relied on international and regional trade to help assure its food security [3]. In other words, the region has always depended on food importation to provide sustainable supply of food for its population. The questions emanating from this fact are: why is this so since agricultural products remain the major item in West Africa's export basket? Why do West African countries still grapple with food security issues when the majority of its active labour force is engaged in agriculture? These issues make a good case study in West Africa's experience in multilateral trade in agriculture, especially as it affects its food security. Meanwhile, extant literature has mainly attributed food insecurity in West Africa and other subregions in the developing world to issues relating to unfriendly weather conditions, lack of research and development (R\&D) in agriculture, lack of investments in the sector and many other reasons. Thus, the link between WTO's trade liberalization policy on agriculture and food security problems in West African countries is yet to be adequately explored and given systematic treatment in extant literature. Against this background, this study intends to examine the role of WTO's trade liberalization policy on agriculture in undermining food security in West Africa.

The chapter is divided into six sections. Following this introduction is Section 2, which discusses the materials and methods used for the study. Section 3 gives an overview of the WTO's trade liberalization policy while Section 4 explores the link between trade liberalization, food importation and food security in West Africa. In Section 5, the nexus between trade liberalization, food dumping and food security was also explored. Section 6 concludes the chapter.

\section{Materials and methods}

The study relied on documentary evidence (secondary data). These were data sourced by extracting relevant information from other sources and previous studies. These documents were mainly annual publications of the WTO that contained information on trade liberalization; UNCTAD's documents that analysed key statistics and trends in international trade, trade performance and commodity dependence, export performance and trade liberalization, as well as other topics covered in its annual Economic Development in Africa series. Also used were The World Bank's publications on food security and FAO's The State of Food Insecurity in the World. Furthermore, ECOWAS publications such as ECOWAS Agricultural Policy were utilized. Other secondary sources such as text books, journal articles and other written works sourced from libraries were also utilized. Finally, the study also made extensive use of internet materials that contained information on trade liberalization and food security. These documents are already in the public domain. What the authors did was to refine, interpret, evaluate and analyse them.

To analyse our data, we used content analysis, rooted on systematic logical deductions. This meant that we organised and synthesised the large volumes of textual data we generated from all the documents mentioned above, with a view to searching for patterns and discerning what was relevant from the documents. In other words, we systematically reduced the documents to logical, meaningful and coherent interpretation, and on the basis that drew our inferences and conclusions. Figures were used where necessary to enhance clarity of thought and presentation.

\section{Overview of WTO's trade liberalization policy}

Trade liberalization means removing or reducing restrictions or impediments to the free movement or exchange of goods between and among countries. This 
includes removing or reducing tariff barriers such as surcharges and duties as well as non-tariff barriers which include quotas and licensing rules. The idea behind the policy is to minimize the role of government in making decisions on the allocation of resources and to change the incentive structure in favour of exports through the liberalization of imports to follow the path of export promotion instead of traditional import substitution [4]. The policy did not start with the WTO. It was part of a policy package of market-oriented reforms advocated by the International Financial Institutions (IFI), that is, the World Bank and the International Monetary Fund (IMF), in response to the economic crisis in Africa, brought about by the global economic crisis that followed the two oil crises of 1973 and 1979 [5, 6]. Then it was referred to as Structural Adjustment Programmes (SAP). It gained momentum with the establishment of the WTO in 1995, and became one of the major policies that guide international trade, especially in agriculture. The trade liberalization policy under the WTO regime has three fundamental components. They include:

1. Expansion of market access by requiring the conversion of all non-tariff barriers to tariffs (tariffication) and the binding and reduction of these tariffs.

2. Reduction of trade-distorting domestic subsidies or support.

3. Reduction of both the volume of and expenditures on subsidized exports $[7,8]$.

Accordingly, it has been noted that:

\begin{abstract}
Under the Agreement, countries agreed to substantially reduce agricultural support and protection by establishing disciplines in the areas of market access, domestic support, and export subsidies. Under market access, countries agreed to open markets by prohibiting non-tariff barriers (including quantitative import restrictions, variable import levies, discretionary import licensing, and voluntary export restraints), converting existing non-tariff barriers to tariffs, and reducing tariffs. ...countries also agreed to reduce expenditures on export subsidies and the quantity of agricultural products exported with subsidies, and prohibits the introduction of new export subsidies for agricultural products. Domestic support reductions were realized through commitments to reduce an aggregate measure of support (AMS), a numerical measure of the value of most trade distorting domestic policies [9].
\end{abstract}

Market access simply means the right which exporters have to access a foreign market. The WTO agreements allow WTO members to protect their markets, to the extent necessary to protect human, animal or plant life or health. In practice, 'market access' indicates the means in which this protection can be implemented. In the context of the WTO, it is a legal term that indicates the conditions imposed by a government for a product to enter a country and be released for free circulation in that country under normal circumstances [10]. Before the Uruguay Round, protection for agricultural products at the border did not always consist of tariffs only. In addition to tariffs, other non-tariff measures at the border have also been applied. One of the key elements of the Uruguay Round trade negotiations was the agreement by parties to convert these other types of border protection mechanisms into tariffs. The process of this conversion is known as 'tariffication'. With respect to export subsidies, they are governments' special incentives provided to promote more foreign sales. These subsidies, which depend on export performance, can take the following forms: divestment of government shares at lower market prices; cash payments; subsidies funded by producers or processors as a result of government measures such 
as assessments; marketing subsidies; transport and freight subsidies; and subsidies for commodities based on their incorporation into export products [10].

Some of the specific provisions of the Uruguay Round which were meant to enhance and accelerate the process of trade liberalization have been articulated as follows:

1. Tariffs: tariffs for industrial products were reduced on average from $4.7 \%$ to $3 \%$ and the share of zero-tariff products increased from $20 \%$ to $22 \%$ to $40-45 \%$. Tariffs were completely removed on construction equipment, pharmaceutical products, medical equipment, steel and paper products.

2. Quotas: countries replaced import quotas for agricultural products, textiles and clothing (under the multi-fiber agreement) with less restrictive tariffs over a 10 -year period. Tariffs for agricultural goods were reduced at the rate of $24 \%$ in developing countries and by $36 \%$ in industrialized countries. Tariffs for textiles were reduced by $25 \%$.

3. Subsidies: the quantity of agricultural exports to be subsidized was reduced by $21 \%$ over a six-year period.

4. Antidumping: antidumping procedures were made more rigorous, thereby ensuring that it became much more difficult to use them for protectionist purposes.

5. Safeguards: voluntary export restraints, orderly marketing arrangements and similar trade-restrictive measures were prohibited. Existing schemes were removed in 4 or 5 years [11].

Trade liberalization was forced on Africa in the form of Structural Adjustment Programmes (SAP) by the International Financial Institutions (IFIs) in the 1980s. The late 1970s and early 1980s witnessed a combination of factors that created a large-scale economic crisis in Africa. First, there was a global economic crisis occasioned by the two oil crises of 1973 and 1979 which strongly and negatively affected the demand for African exports and resulting in falling commodity prices. Secondly, interest rate hikes dramatically increased the cost of servicing foreign debt. The Gross Domestic Product (GDP) growth rate of the region plunged from $4.3 \%$ per annum in the period $1971-1975$ to $1.1 \%$ in $1981-1985$ [6]. In response to this economic crisis in Africa, the World Bank and IMF advocated and actually imposed a policy package of market-oriented reforms, otherwise known as SAP or economic liberalization. As a result of these structural adjustment programmes, agricultural policy in many developing countries (including West Africa) was characterized by a high level of market openness even before the Uruguay Round reforms [8].

Before this period, trade policies in most African countries were characterized by extensive state involvement in the economy, both in production and in marketing. In the decades following independence, most African countries adopted heavily interventionist policies [12]. Governments were involved in agricultural marketing and food processing through the creation of marketing boards, parastatal processing units, and government controlled cooperatives. The trade policies of many countries in Africa were informed by the doctrine of Import-Substitution Industrialization (ISI). This is from the 1960 s to the 1980 s. ISI was widely accepted then as a viable policy package to help developing countries achieve structural transformation and lessen their dependence on primary products. This strategy 
advocated the protection of the domestic market from foreign competition in order to promote domestic industrial production. Therefore, the domestic market in these countries was shielded from foreign competition through these policy measures. Non-tariff measures (NTMs) such as quantitative import restrictions and government licenses were used profusely to restrict imports. For example, some African countries such as Burundi, Ethiopia, Madagascar, Sudan, the United Republic of Tanzania, Zambia, and Nigeria, Ghana and Senegal in West Africa all adopted inward-oriented policies with significant trade restrictions [6]. However, with the introduction of SAP, African countries started the process of economic liberalization.

Thus, Africa has liberalized its economy even before the policy became a guiding principle of international trade under the WTO regime. However, it gained momentum with the establishment of the WTO in 1995 and the multilateral trade obligations enshrined in its agreements for African countries that are members. Import liberalization measures focused on three main policy areas: to reduce the overvaluation of currencies of African countries and removing exchange rate rationing; the decommissioning of non-tariff measures by reducing the list of products for which import licenses are required; and to reform the tariff system by reducing tariff dispersion and the general level of tariffs [13]. Liberalization of exports was also necessary to improve the balance of payments. There were four instruments that were considered to be the most distorting of exports and they were targeted with the following measures: withdrawal of export licenses; devaluation of the national currency; reducing or eliminating export taxes; and dismantling of agricultural marketing boards for export crops [6]. Thus, the process of liberalization in Africa involved the tariffication of non-tariff barriers, cuts in the number and value of tariffs, exchange rate liberalization and the removal of export barriers.

\section{Trade liberalization, food importation and food security in West Africa}

Extant literature has always glossed over the link between trade liberalization policy of the WTO and food security challenges prevalent in West Africa. In the first place, food insecurity in the region is a consequence of frequent weather- and market-related shocks, as well as by widespread conflicts and political instability in the region that often trigger the mass abandonment of arable land [14]. The marketrelated shocks in this case have to do with constant price spikes that make market prediction and projections difficult. Many authors tow this line, ignoring the effect of trade liberalization on food security in developing regions.

The effect of WTO's trade liberalization policy on food security in West Africa is evident. To start with, West Africa, during the food crisis of 2008, encountered the problems of rising food prices, high unemployment and population growth that has surpassed agricultural productivity. These developments, added to external factors which include trade restrictions by major international food exporters, have made West Africa prone to supply shocks and food insecurity. In the absence of increased agricultural productivity growth, the region's food needs are realized by depending on food aid and food imports. This reliance on food imports is facilitated by the system of free market exchange [15], otherwise known as trade liberalization. This dependence on imports has its drawback, as was underscored by the 2008 surge in world food prices in which export restrictions by major suppliers triggered widespread food riots in West Africa [16]. Export bans from some Asian countries such as India, for instance, threatened the availability of rice imports to West African countries at the peak of the food crisis [3]. 
World Trade Organization's Trade Liberalization Policy on Agriculture and Food Security... DOI: http://dx.doi.org/10.5772/intechopen.86558

Apart from export restrictions by major food suppliers, food importation encourages food self-reliance, as against food self-sufficiency strategy. Self-reliance in food occurs when a country pursues an outward-oriented trade regime in order to earn enough from its exports of goods and services to finance its food needs. Conversely, the food self-sufficiency approach (or what western literature, exemplified by Staatz et al. [3], described as an autarkic approach to food security) entails the country meeting its food requirements—or a substantial part of it—from domestic production [17]. However, food import dependency is viewed differently depending on each individual country's ability to pay its food import bill [18]. For some oil or mineral rich countries or for some of the relatively more industrialized countries (such countries are however few in West Africa, if at all), importing some types of food products seems more beneficial than producing these products at home, especially since they have enough foreign currency reserves to pay for the food import bills. But for cash-strapped countries (a category where many West African countries belong to), persistent food import becomes a problem when the high and rising food import bills take money away from other important development agenda without resolving food insecurity. Figure 1 shows the composition of West African food imports before and after WTO was established.

The figure shows that the composition of food imports has changed somewhat over time. Cereals have remained steadily at the top of the list (39\% between 1986 and 1990; 41\% between 2006 and 2010; and 43\% between 2011 and 2016), followed by fish, dairy products and sugar. Vegetable oils, however, have increased sharply, from seventh place in 1986-1990 (4\% of food imports) to second place in 2006-2010 (13\% of food imports). This is not surprising as during this time, West Africans were sharply increasing their consumption of fats and oil [19]. However, it decreased to $11 \%$ of food imports between 2011 and 2016. The figure also indicates that cereals are the major food staples consumed in West Africa. These staples not only constitute the highest type of food imported into West Africa but the region has also attained a certain level of self-sufficiency in them, as shown in the SelfSufficiency Ratios (SSR) in Figure 2.

As noted above, cereals are the main food staple in West Africa, and also the most imported food item in the region. They are very important to food security in West Africa, as they are the leading commodity group that are imported to address food requirements in normal years, but especially when the region faces shortfalls

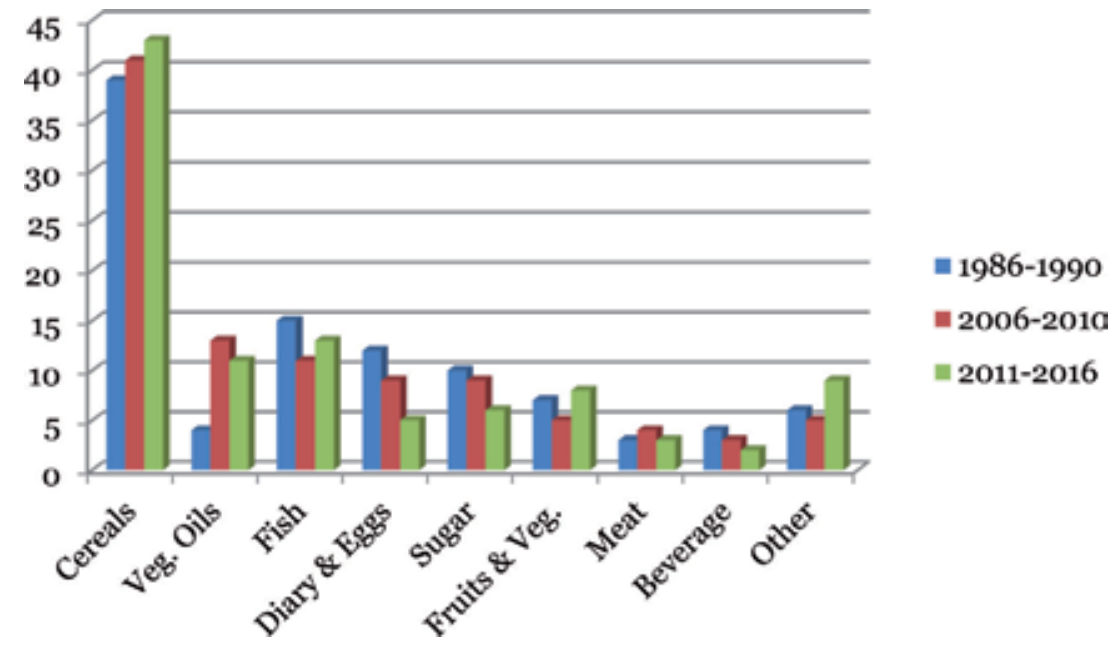

Figure 1.

Composition of food imports into West Africa pre-and post-WTO (\%). Source: Developed by authors from [19, 20$].$ 


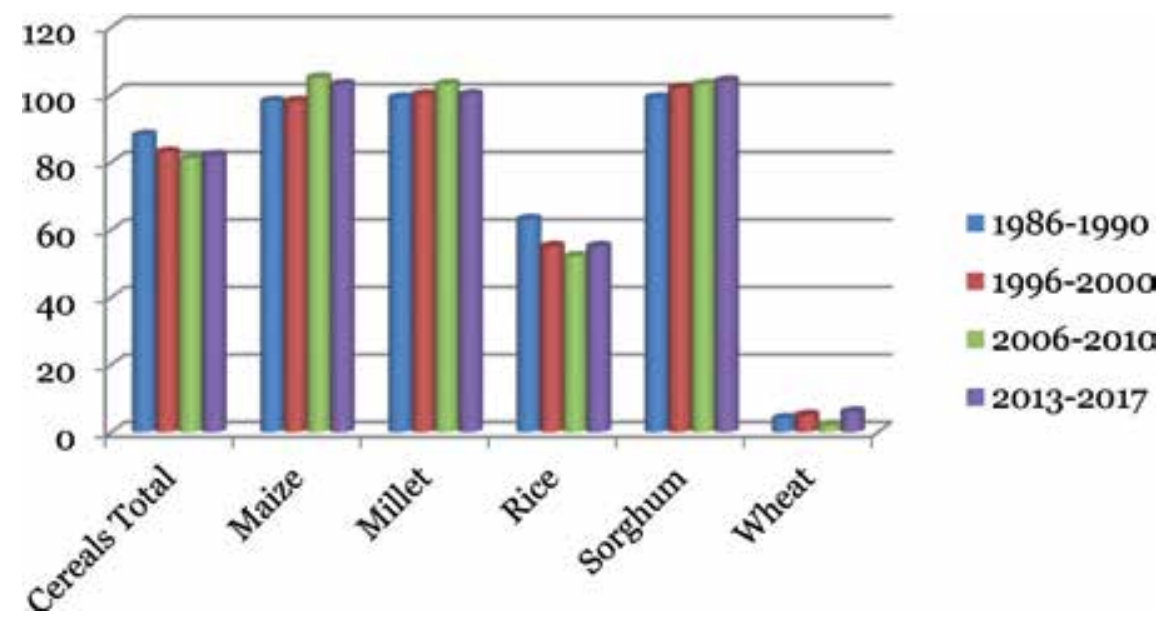

Figure 2.

Self-sufficiency ratios of individual cereals in West Africa (\%). Source: Developed by authors from [19, 20].

in production. The reliance of the region on the international market for cereals has been on the increase in recent years and as at 2010 was about $20 \%$. Five countries in West Africa that import cereals on large quantities to support their food deficit are Cape Verde, Liberia, Mauritania, Gambia and Côte d'Ivoire [21]. The region's overall self-sufficiency ratio (SSR) for cereals stood at 88\% between 1986 and 1990. This is prior to the coming into existence of the WTO and its liberalization policy in the agricultural sector. The SSR for cereals declined to 83\% between 1996 and 2000, few years after the establishment of the WTO, and declined further to an average of $81 \%$ in the 2006-2010 period. It increased slightly to 82\% between 2013 and 2017. For individual countries, SSRs for cereals vary widely, ranging from as low as $7 \%$ for Cape Verde to $100 \%$ for Mali in the 2006-2010 period.

Likewise, countries have major differences as regards changes in their SSRs over time. For instance, countries such as Burkina Faso, Guinea, Togo, Mali, The Gambia and Sierra Leone have improved their dependence on domestic cereal supplies. However, majority of the countries increased their reliance on imported supplies. Such countries include Nigeria, Senegal, Côte d'Ivoire, Liberia, Cape Verde and Mauritania [19]. Nigeria is by far the largest producer of cereals in West Africa. It accounted for $51 \%$ of the West African cereals supply over the period 2005-2010, followed by Mali (10\%), Niger (8\%) and Burkina Faso (7.5\%). As regards maize production in particular, Nigeria is also the West Africa's leading producer accounting for as much as $54 \%$ of total West Africa's maize production, followed by Ghana (10.6\%) and Cameroun (10.3\%) [22].

There are also significant differences in SSRs between commodities and countries. Given the limited potential for domestic production in the region, nearly all of the wheat consumed in West Africa (99\%) is imported. In addition, no country in the region fully meets its rice consumption requirements from domestic production alone, though some do so to a significant extent (the SSR of Mali is $96 \%$, that of Sierra Leone is $80 \%$ and that of Guinea is $80 \%$ ). Nigeria, the largest rice producer and consumer in the region, saw its SSR fall from $83 \%$ to $56 \%$ from the late 1980 s to 2006-2010 [19].

Apart from cereals, regional SSRs are also declining for some other basic food commodities, meaning that imports of such food commodities are on the increase. In particular, this is true for sugar, palm oil, milk, and poultry meat. From being a net exporter and almost having self-sufficiency in both poultry meat and palm oil in the 1980s, West Africa became a net importer of these products and its SSR has 




Figure 3.

Self-sufficiency ratios of selected non-cereal commodities in West Africa (\%). Source: Developed by the authors from $[19,20]$.

gone down to below $70 \%$ in the period between 2006 and 2010, and below $80 \%$ in the period between 2013 and 2017. For milk and sugar, the region has always depended on imports to meet a large share of its needs. In fact, in the case of sugar, the region now covers only some $12 \%$ of its needs, almost one-third of the level of the 1980s. These are illustrated in Figure 3.

As it is in the case of cereals, there are also large differences among the countries of the region regarding their dependence on imports in these other basic food commodities. None of the countries is self-sufficient in milk. Six counties (Cape Verde, Côte d'Ivoire, The Gambia, Ghana, Liberia and Nigeria) actually produced less than one-third of the milk they consumed within the study period, and their dependence on imports is increasing. For palm oil, all countries that are producers in the region, except Côte d'Ivoire and Benin, have decreased their SSR considerably, thereby increasing the importation of this staple. While palm trees are native to West Africa, the region has been unable to expand production and productivity to meet domestic and export demand. In fact, Figure 3 shows that the production capacity of West Africa for palm oil has been decreasing over the years. Other parts of the tropical world (in particular Malaysia and Indonesia) now produce and export more palm oil than other countries, including West African countries. These two countries alone account for $80 \%$ of world production and are the main exporters to West Africa and to other countries [23].

Another commodity where SSRs for almost all countries in West Africa have been declining fast is poultry meat. While the average SSR in the region is just under 70\%, some of the countries such as The Gambia and Cape Verde import more than $80 \%$ of their growing poultry meat consumption, whereas they have almost reached their lower consumption levels at the end of 1980s. Other countries have significantly increased their reliance on imports, and some have taken protective measures to limit this situation (for example, Nigeria's ban on chicken imports). Finally, as regards sugar, though many countries have never had a significant production, of those who have, only Niger seems to have managed to maintain its already low SSR. All the other countries have increased their reliance on imported sugar, as Figure 3 shows.

A study done in 1999 [8] found that trade liberalization intensified and sustained food trade deficit in Africa: an increase in food imports and an 


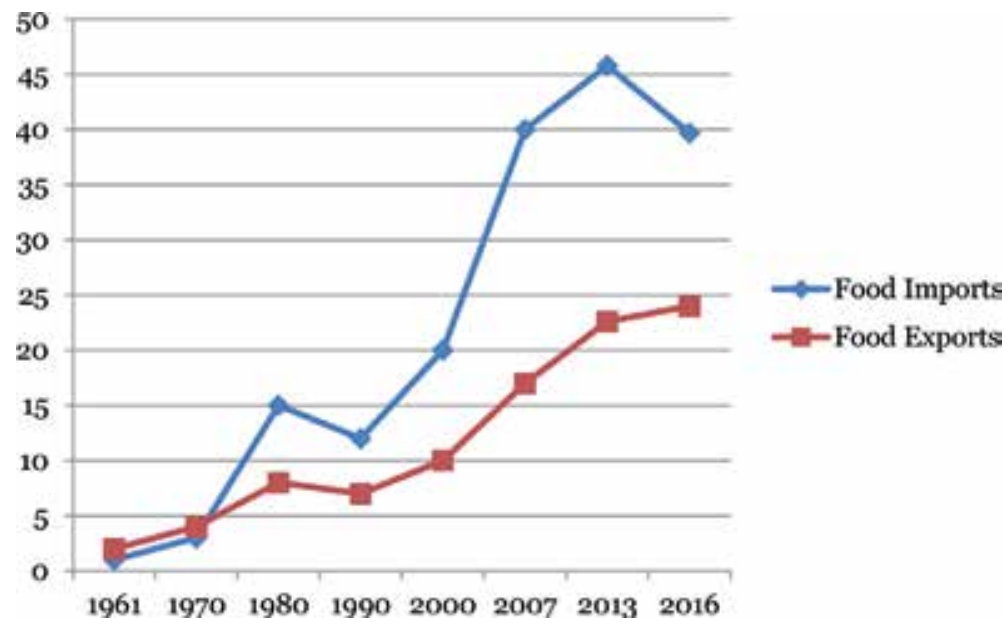

Figure 4.

Africa's food import and export trends, 1961-2016 (US\$ billion). Source: Developed by the authors from [18, 20].

accompanying decline in food production. Thirteen years after this study, another study [18] also found that this trend has continued as shown in Figure 4.

The figure shows that in the 1960s, when most African countries were gaining political independence, African countries were exporting more food to the rest of the world than they were importing. This trend continued till around 1970. Africa's food trade deficit started showing after 1970 and since then, the trend has continued at a much more alarming rate. In fact, between 2000 and 2009, nine African countries switched from being net agricultural exporters to being net agricultural importers. Three of these countries-Benin, Chad and Mali-are in West Africa [24]. By 2007, the food trade deficit amounted to about US\$ 22 billion, with total food imports by countries in the continent amounting to 40 billion US dollars. African food imports peaked at almost US $\$ 50$ billion in 2013 before coming down to US\$ 39.7 billion in 2016. This growth in African food imports also reflects in the growth of the various categories of food the region has been importing, which includes animal products, dairy products, fruit and vegetables, oils and staples. Figure 5 shows the value of imported food into West Africa from 1995 to 2017.

It could be deduced from the figure that the trade liberalization policy of the WTO has only opened the doors for more importation of food staples into West Africa, undermining food self-sufficiency and thereby threatening food security in the subregion.

As at 2010, staples constituted to a large extent the biggest share of all food imported into the region, and this has increased over the years. These staples (cereals, cassava, pulses, potatoes and other roots and tubers) represented more than $50 \%$ of all foods imported by West African countries in 2010 [14]. However, by 2016, it reduced to about 36\% as shown in Figure 6.

The figure shows that Nigeria, Ghana, Senegal and Cote d'Ivoire are some of the top countries that import staple food in West Africa, while Sierra Leone, Guinea Bissau and Cape Verde are some of the least importers within this period. Imports of all other food groups have also increased over the years, though averagely, animal products, dairy products, fruits and vegetables, and oils accounted for $1 \%, 4 \%, 5 \%$ and 3\%, respectively of total food imported as at 2010 [14].

Imports of poultry meat have also grown exponentially, increasing from virtually nothing to more than US\$ 600 million in 2012 [25]. Poultry meat is essentially sourced from the European Union, the United States and Brazil. However, some 
World Trade Organization's Trade Liberalization Policy on Agriculture and Food Security... DOI: http://dx.doi.org/10.5772/intechopen.86558

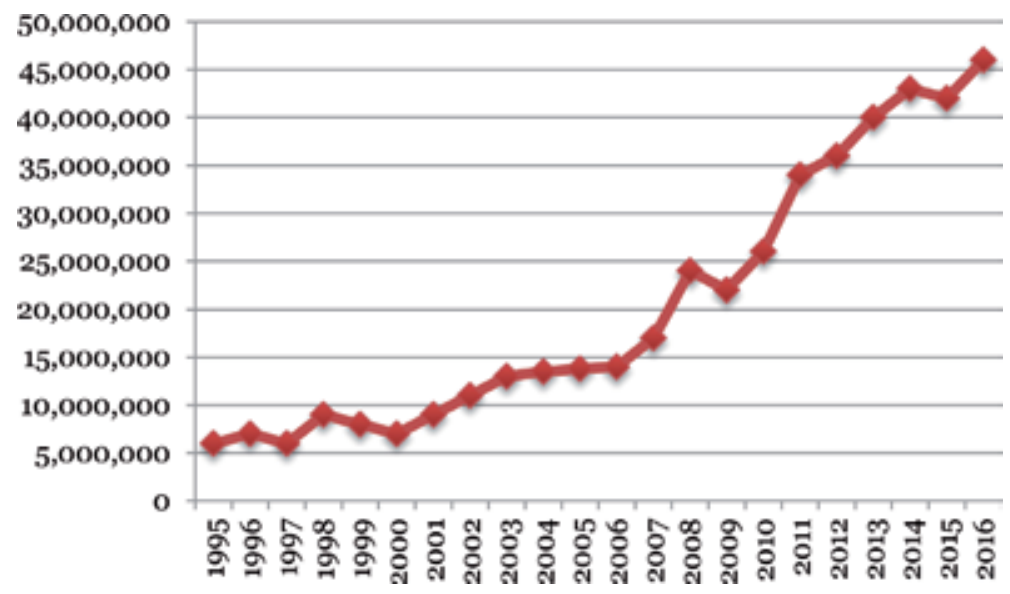

Figure 5

Import of foods, ECOWAS, 1995-2017 (US\$ million). Source: Developed by the authors from [20, 25].

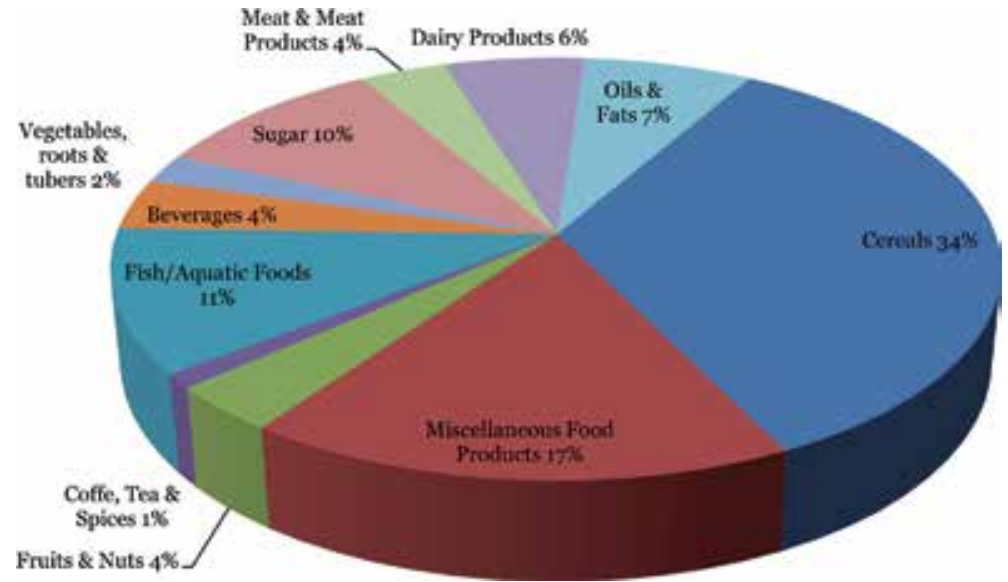

Figure 6.

Total West African imports in food products in percentage (2016). Source: Calculations from [20].

countries such as Nigeria and Senegal have banned the importation of frozen poultry meat into their countries since 2002, ostensibly to boost local production, after import surges of the 1990s occasioned by the liberalization of import barriers threatened the local industry. Presently, Nigeria alone accounts for about half of poultry meat produced within the ECOWAS territory. However, despite tremendous progress made in domestic production of poultry meat in West Africa, especially in Nigeria, Ghana and Senegal, the subregion is yet to attain self-sufficiency in poultry meat as about half of the poultry meat consumed in West Africa is still imported. Figure 7 shows the main origins of poultry meat imported into ECOWAS countries by 2017.

The increased dependency on international trade and importation by many countries in West Africa has a number of direct and indirect impacts on the realization of food security in the subregion. First, producers and consumers are exposed to greater vulnerability both to commodity price fluctuations and to deteriorating terms of trade. This kind of situation limits the ability of countries that tremendously rely on world trade and imports to absorb external shocks, such as overproduction or harvest failures in other countries [26]. Second, depending on imports for food needs of the population exposes the domestic food-producing industries to danger of extinction through steep competition. Obviously, imported food staples 


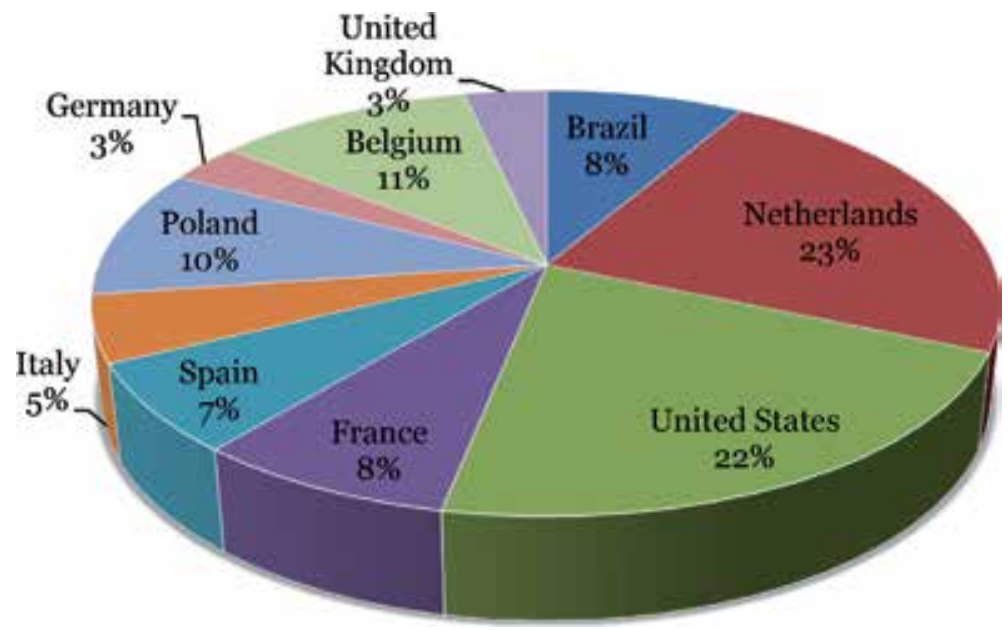

Figure 7.

Imports of poultry meat by major origin, ECOWAS, 2017. Source: Calculations from [20].

are cheaper in price due largely to export subsidy and domestic supports those products received from their home countries. When they are flooded in developing countries' markets, people tend to patronize these products more because they are not only cheaper, but also urban consumers mostly tend to have preference for these foreign products as they 'suit' their class and status. Domestic products should be left for 'local' people.

\section{Trade liberalization, food dumping and food security in West Africa}

Dumping occurs when manufacturers export a product to another country at a price below the normal price. It entails selling products in foreign markets at unfairly low prices (prices lower than domestic costs or production costs) for the purpose of gaining competitive advantage over other suppliers. Dumping occurs when trade companies export agricultural products from developed countries to developing countries' markets at prices below production costs in the country of origin, undercutting the prices of local agricultural products and consequently destroying small farmers' domestic markets [27]. An example of this could be ascertained in the different prices European Union (EU)'s producers sell their poultry meat in their home countries and in West African countries. For instance, in 2003, EU producers sold their chicken at an average of 1.48 Euro/kg. In France (the largest chicken producer in the EU), during the same year, consumers bought their chicken at $4.86 \mathrm{Euro} / \mathrm{kg}$. At the same time, EU frozen chicken was sold at $0.50 \mathrm{Euro} / \mathrm{kg}$ in the West African cities of Dakar, Cotonou, Douala, and Abidjan [28]. This is a classic example of dumping with serious implications for domestic production, food self-sufficiency and food security. Meanwhile, these frozen chicken parts exported to West Africa and other African countries have no value in the EU, because there is no demand and consequently no markets for them. The only alternative market is pet food, and because African traders offer higher prices than the price offered by the pet food industry in EU, the products are shipped to Africa and dumped in African markets.

Another example is the dumping of dairy products by the EU in West African markets. Every year, the EU, with nearly $40 \%$ of global trade volume, exports approximately 40,000 tons of milk powder and sweetened condensed milk to the Francophone countries of West Africa alone [29]. These products are subsequently 
sold at prices far below their market prices in the countries of origin, undermining domestic production. On the surface level, it looks good that these products are sold at lower prices. At least, consumers would not spend so much purchasing food. But as has been warned in [26], short-term interest in procuring food from international markets at lower prices should not lead countries to sacrifice their long-term interest in building their capacity to produce the food they need to meet their consumption needs. As noted in [29], in 1999, $1 \mathrm{~L}$ of milk from subsidized milk powder from the EU costs 160 African Francs in Senegal, while $1 \mathrm{~L}$ from domestic production costs about 350-400 African Francs. This summarizes the extent of dumping by the EU on West African markets. The focus on EU is because the Union is West Africa's biggest trading partner. The US trade with West Africa is mostly centred on exportation of machinery and importation of crude oil, except in few cases where it imports agricultural products such as cocoa from Cote d'Ivoire [30].

Both GATT and the WTO consider dumping as an unfair trade practice, yet some member countries (especially developed countries) of the world trading body still use it in their trade relations with developing countries. Countries that subsidize productions at home are mostly the ones that use dumping in their trade relations with trade partners. This is because subsidized products are usually exported at lower prices-prices that are lower than the cost of production and the prevailing price in international market. In international agricultural and food trade, the EU and the United States are the major users of dumping as a competitive strategy because of the high level of export subsidies and domestic support they grant to their farmers. Hence, as argued in [8], the rules governing the multilateral trading system are seen as providing opportunities for the United States and the European Union to continue subsidizing agricultural production and dumping the surpluses on the international market at artificially low prices while at the same time requiring developing countries to open up their markets to harmful and unjust competition from producers in industrialized countries. This brings about a situation where domestic food production in developing countries is displaced by cheap imported food. It has also stripped local farmers their ability to increase their incomes and for the local population to have access to food.

Apart from export subsidies and domestic support given by the US and EU to their farmers which encourage dumping, the Economic Partnership Agreements (EPAs) entered into between West African countries and the EU also encourages dumping of EU foods in West Africa. The agreement requires that West African countries should open up their markets for EU imports while EU gives them access to European markets as well. It has been argued that imports into West Africa from the EU would increase as a result of the agreement and that some African producers would be harmed as a result of the removal of tariffs on EU imports [31]. The implication is that West African food producers who cannot compete with the cheap imports are thrown out of production. This has very severe consequences for food security in the subregion. A study funded by the EU also shows that lower tariffs on potatoes, onions, poultry and prepared tomatoes could cause serious injury to domestic production and the well-being of producers, depress local industry and discourage the development of processing capacity [19]. In the same vein, the highly subsidized export of beef from the EU to West Africa has led to thousands of nomads in the Sahel to be driven to starvation by European beef dumping [32].

Also, trade liberalization has facilitated the dumping of frozen chicken cut parts (neck, back, legs, and wings) into West Africa by the EU. European Union consumers tend to eat breast rather than whole chicken, and there is no market in the EU for the other parts, except for pet food [28]. European poultry processing industry, therefore, has the choice between using the remaining parts as pet food 
and exporting to poor countries at low costs. These poultry products exported to developing countries are usually not hygienically produced, with high negative impact on food security [28]. Often, chickens are fed with antibiotics daily, not as medicines, but as growth hormones. This results in low quality of meat both in terms of taste and sanitary standards, with dire consequences on the food-quality aspect of food security. The costs of all these damages are carried by the importing country, and not by producers. This has been summarized thus:

The dumping of agricultural commodities on world markets increased food insecurity in developing countries by undercutting domestic production. The availability of cheap imported food depressed domestic food prices in developing countries, lowered the income of local farmers, and reduced incentives to invest in agriculture. Export dumping also reduced the export earnings of developing country producers by depressing world market prices for agricultural commodities [8].

A good example of the effect of dumping on food security is illustrated by the impact of trade liberalization in tomato concentrate on Senegal's domestic production capacity. Tomato processing industries in Senegal have been affected adversely by the influx of cheap food products that were previously produced domestically [33]. Those industries cannot compete with mass production from the developed countries especially the EU due to lacking economies of scale. So in Senegal, the promotion of a viable agro-industry has been exposed even further to subsidized competition. Before liberalization, Senegal was a noticeable exporter of processed tomatoes-especially into other West African countries, but increasing imports of EU subsidized tomato concentrate has undermined the domestic infant industry. Within a year of WTO's existence, exports of tomato concentrate from the EU into Senegal jumped from 64 tons to 5348 tons, following trade liberalization as dictated by the WTO. On poultry meat, by 1992, before WTO and its trade liberalization policy came into place, Ghana's domestic market supplied $95 \%$ of Ghana's poultry requirements [33]. However, a decade later, the domestic market supplied only $11 \%$ of the country's poultry requirements. The rest were supplied by foreign competitors which was made possible by trade liberalization. The issue was that local producers could not compete with the obviously subsidized imports from developed countries' markets. The resultant effect was that this undermined the domestic industry with its consequences on food security.

The irony of the situation is that the trade liberalization narrative ignores the historical precedent in most developed countries of how agricultural trade protections facilitated development of agricultural sectors and industrialization. Details of the extensive use of subsidies, policy supports, and market protections by nearly all industrialized countries as part of their own economic development have been provided in [34]. Liberalization of agricultural sectors was never the trajectory taken by developed countries in achieving agricultural development. Indeed, liberalization policies only arrived well after industrialization. Even then, trade liberalization is arguably more illusionary than existent because even in this era of WTO, industrialized countries still employ the use of subsidies, domestic support and other restrictive measures in their trade relations with the rest of the world. For instance, In OECD countries, support to the agricultural sector has been increasing rather than decreasing. While the total support amounted to US\$298 billion in 1986-1988 (before WTO), it amounted to US\$ 311 billion in 2001 (even with the WTO in place), with three quarters of this support going to farmers [27].

However, there is no gainsaying the fact that in some ways, trade liberalization influences food security positively. First, it expands markets. For consumers, it opens access to additional sources that can supplement domestic production to 
meet demand. Imports can be essential during drought, diseases, floods, or other disruptions to domestic production. Farmers can also benefit from access to larger markets, supporting their income by exporting excess quantities and providing access to a wider variety of low-priced inputs like fertilizer, seeds, pesticide, and machineries [35]. However, because the rules governing international trade is biased in favour of the interests of developed countries, reliance on it for food security as being championed in liberal literature will spell doom for developing countries in general and West Africa in particular. In line with the argument in [26], the role of international trade should be reduced to complement a quest for greater food self-sufficiency.

Closely related to food dumping is the issue of food aid. The effect of food aid on international trade, but especially on agricultural production in the countries receiving the aid had culminated in adopting the FAO Principles of Surplus Disposal as well as the founding of the Consultative Sub-Committee on Surplus Disposal (CSSD) as early as 1954. The Principles of Surplus Disposal is a kind of code of conduct that guides governments in providing food aid. Principally, they are meant to ensure that food and other agricultural commodities which are exported on concessional terms result in more consumption for the country receiving the food aid and do not displace normal commercial imports. Also, they seek to ensure that domestic production is not affected adversely or even discouraged. These principles were recognized in Article 10 of the Uruguay Round Agreement on Agriculture [36]. Article 10 demands that countries respect the FAO's Consultative Sub-Committee on Surplus Disposal and its principles and make food aid available 'to the extent possible.' However, neither the recommendation of the FAO-CSSD nor that of the WTO has had an impact on WTO members' food aid practices, as donors continue to use it as alternative to dumping after, in many cases, placing conditionality on them [36].

Thus, West African countries have been receiving large tons of food aid from developed countries. Among the highest recipients of food aid in a single year in West Africa were Liberia, which received 173,000 metric tons in 1997, and Ghana which received 123,000 metric tons in 1991. Both countries also received 55,338 metric tons and 81,000 metric tons of food aid in 1991 and 2000 respectively. Niger also amassed a total of 106,000 metric tons of food aid in 2010 alone. Sierra Leone, Cote d'Ivoire, Burkina Faso, and Cape Verde have also received food aids amounting to 75,000 metrics tons in 2002, 57,000 metric tons in 1990, 55,338 metric tons in 1991, and 53,227 metric tons in 1997 respectively [14]. It has been argued that this huge aid shipments of food, in particular wheat and rice, to West Africa have altered the consumption patterns in the region, shifting consumers' preferences from domestically produced 'inferior' cereals to 'superior' imported grains [37]. Therefore, in its own way, food aid has contributed to the food security crisis in West Africa by shifting consumers' preference for local food products to foreign food products, thereby undermining local production.

\section{Conclusion}

This paper demonstrated that WTO's trade liberalization policy on agriculture has not improved food security in West Africa. Rather, it has undermined food security in the subregion. This conclusion is based on the results of empirical evidence and data analysis which indicated that local food production has been on the decrease while food importation and dumping are on the increase. These are direct effects of trade liberalization. More so, the subregion's self-sufficiency ratios have been dwindling, which gives more impetus for food importation. This negative 
trend is made possible partly because of disincentive to continue production which is linked to the WTO's policy of discouraging government's supports and incentives to food producers in developing countries. The resultant effect is dumping of food products by the industrialized countries on West African markets which undermines local food industries and drives them out of production because of uncompetitive prices these foreign products offer. This has serious implications for food security in the subregion. On the basis of the foregoing, the paper concludes that the WTO's trade liberalization policy on agriculture has not improved food security in the West African subregion. In fact, the policy has actually undermined food security in West Africa.

Thus, the paper established that the WTO trade liberalization policy on agriculture encourages food self-reliance/food importation as against food selfsufficiency/domestic production. As a result of this, most West African countries that have acceded to the WTO agreement tend to pursue food self-reliance strategies as against food self-sufficiency strategies, thereby relying on food imports that expose them to the vagaries of international food price hikes. Finally, the paper also established that against WTO rules, developed countries, especially the United States and European Union, still give export subsidies and domestic supports to their farmers. These encourage dumping of the excess products on developing countries at relatively cheaper prices. It also harms domestic production and reduces the income of domestic farmers and other investors in the food production chain.

\section{Recommendations}

On the basis of the findings, the study puts forward the following recommendations:

i. West African countries should aim at food self-sufficiency instead of food self-reliance. A key advantage of a national food self-sufficiency strategy is that it ensures that the country depends less on the export policies of other countries, especially for important basic staples. The attention of this strategy is focused on the agricultural sector and it has the capacity to change the age-long underinvestment in agricultural production in most West African countries. Additionally, since agriculture provides employment for the majority of the active population in West Africa and is a major source of income for the majority of people, it follows that the strategy can promote overall development if they encourage increased productive investment in agriculture.

ii. As a corollary to the above, investments in the agricultural sector that will increase food availability and strengthen the food production system in West Africa should be given immediate priority by governments of West African countries, especially the innovation of family/smallholder farming. Reliance on international trade that is obviously biased against their food needs is not a strategy that can be sustained.

iii. West African countries, and indeed, all developing countries should move for the reform of the WTO agreements in general and the Agreement on Agriculture in particular, especially market access of West African commodities into developed countries' markets. Greater market access can be achieved through further reduction of developed country tariffs in order to 
address dirty tariffication. It can also be improved by applying tariff reductions on a product-by-product basis rather than industry-wide averages in place currently. A review of the Agreement should also be such that affords developing countries with a policy space that gives governments allowance to pursue independent policies such that food security objectives are given precedent over WTO trade obligations.

iv. West African and other developing countries should insist on the removal of export subsidies and domestic supports enjoyed by agricultural producers of developed countries from their governments. It is these subsidies and supports that bring down the prices of foreign goods which leads to dumping of the products in African markets, thereby, undermining domestic industries.

\section{Acknowledegments}

The authors wish to acknowledge the African Heritage Institution, Enugu, Nigeria, for allowing the use of its library and space by the authors during the course of this research.

\section{Conflict of interest}

The authors wish to declare that there is no conflict of interest.

\section{Author details}

Emeka C. Iloh ${ }^{1,2 *}$, Michael Nwokedi ${ }^{3}$, Chijioke Francis Onyebukwa ${ }^{1,2}$ and Queeneth Ekeocha ${ }^{2}$

1 Madonna University, Nigeria

2 African Heritage Institution, Enugu, Nigeria

3 University of Nigeria, Nsukka, Nigeria

*Address all correspondence to: iloh.emeka@gmail.com

\section{IntechOpen}

(C) 2020 The Author(s). Licensee IntechOpen. This chapter is distributed under the terms of the Creative Commons Attribution License (http://creativecommons.org/licenses/ by/3.0), which permits unrestricted use, distribution, and reproduction in any medium, provided the original work is properly cited. (cc) BY 


\section{References}

[1] USAID. West Africa Regional: Agriculture and Food Security [Internet]. 2019. Available from: https://www.usaid.gov/west-africaregional/agriculture-and-food-security [Accessed: 22 April 2019]

[2] USAID. Famine Early Warning Systems Network, West Africa. United States Agency for International Development; 2010

[3] Staatz JM, Dembélé NN, Kelly V, Adjao R. Agricultural globalization in reverse: The impact of the food crisis in West Africa. In: Background Paper Prepared for the Geneva Trade and Development Forum; 17-20 September 2008; Crans-Montana, Switzerland

[4] Shafaeddin SM. Trade liberalization and economic reform in developing countries: Structural change or de-industrialization? UNCTAD Discussion Papers. 2005; No. 179

[5] Clapp J. WTO agriculture negotiations: Implications for the global south. Third World Quarterly. 2006;27(4):563-577

[6] UNCTAD. Economic Development in Africa 2008: Export Performance Following Trade Liberalization-Some Patterns and Policy Perspectives. Geneva: UNCTAD; 2008. 114 p

[7] World Trade Organization. Doha WTO Ministerial 2001: Ministerial Declaration [Internet]. 2001. Available from: www.wto.org/english/thewto_e/ minist_e/min01_e/mindecl_e.htm [Accessed: 21 February 2019]

[8] Gonzalez CG. Institutionalizing inequality: The WTO agreement on agriculture, food security, and developing countries. Columbia Journal of Environmental Law. 2002;27(2):433-490
[9] Rena R. Impact of WTO policies on developing countries: Issues and perspectives. Transnational Corporations Review. 2012;4(3):77-88

[10] UNCTAD. Dispute Settlement: World Trade Organization. New York: United Nations; 2003. 84 p

[11] Salvatore D. International trade policies, industrialization and economic development. The International Trade Journal. 1996;10(1):21-47

[12] Engel J, Jouanjean M, Awal A. The History, Impact and Political Economy of Barriers to Food Trade in SubSaharan Africa: An Analytical Review. London: Overseas Development Institute; 2013. $54 \mathrm{p}$

[13] Abdillahi UA, Manini MM. Impact of trade openness on economic growth in Kenya. International Journal of Economics, Commerce and Management. 2017;V(6):109-137

[14] Kiawu JA, Jones KG. Implications of food aid and remittances for West African food import demand. African Journal of Agricultural and Resource Economics. 2013;8(1):30-44

[15] Bricas N, Tchamda C. Are the Cities of Sub-Saharan Africa So Dependent on Food Imports? [Internet]. 2017. Available from: https://www. chaireunesco-adm.com/IMG/pdf/01sowhat-0416-en_15mars_web.pdf [Accessed: 21 February 2019]

[16] Childs N, Kiawu J. Factors behind the Rise in Global Rice Prices in 2008. Washington DC: US Department of Agriculture; 2009. 25 p

[17] Gayi SK. Does the WTO Agreement on Agriculture Endanger Food Security in Sub-Saharan Africa? [Internet]. 2006. Available from: www.wider.unu. 
edu/publication/does-wto-agreementagriculture-endanger-food-securitysub-saharan-africa [Accessed: 21 February 2019]

[18] Food and Agriculture Organization (FAO). Why Has Africa Become a Net Food Importer? Explaining Africa Agricultural and Food Trade Deficits. FAO: Rome; 2012. 89 p

[19] African Development Bank (AfDB), Food and Agriculture Organization (FAO). Agricultural Growth in West Africa. Market and Policy Drivers. Rome, FAO: AfDB; 2015. 406 p

[20] International Trade Centre. Trade Map-International Trade Statistics [Internet]. 2018. Available from: https://www.trademap.org/tradestat/ Country_SelProductCountry_TS.asp $\mathrm{x}$ ?nvpm $=1|| 8|||0207||| 4|1| 2|1| 2|1| 4|1| 1$ [Accessed: 21 February 2019]

[21] Mensah E, Almas LK, Guerrero BL, Lust DG, Ibrahimov M. Agriculture and the state of food insecurity in Western Africa. In: Paper Prepared for Presentation at the Southern Agricultural Economics Association 48th Annual Meeting; 6-9 February 2016; San Antonio, Texas

[22] Food and Agriculture Organization. FAOSTAT [Internet]. 2013. Available from: http://faostat.fao.org [Accessed: 21 February 2019]

[23] Minal J, Bahari MM. Oil and fats scenario in Africa-Opportunities and challenges. Palm Oil Developments. 2011;55:1-9

[24] Valdés A, Foster W. Net FoodImporting Developing Countries: Who they Are, and Policy Options for Global Price Volatility [Internet]. 2012. Available from: https://www.ictsd.org/ sites/default/files/downloads/2012/08/ net-food-importing-developingcountries-who-they-are-and-policy- options-for-global-price-volatility.pdf [Accessed: 21 February 2019]

[25] World Bank. Connecting Food Staples and Input Markets in West Africa: A Regional Trade Agenda for ECOWAS Countries. Washington DC: World Bank; 2015. 248 p

[26] de Schutter O. The World Trade Organization and the post-global food crisis agenda: Putting food security first in the international trade system. In: United Nations Human Rights Council Briefing Note 04 [Internet]. 2011. Available from: https://wwwwwto.org/english/ news_e/news11_e/deschutter_2011_e.pdf [Accessed: 21 February 2019]

[27] Wiggerthale M. Dumping in the agricultural sector: An introduction. In: Schuster-Haus W, editor. Stop Dumping, Promote Food Security! Bonn: Germanwatch. 2004. pp. 6-12

[28] Hermelin B. Agricultural dumping in the chicken sector: The case of western and central Africa. In: Schuster-Haus W, editor. Stop Dumping, Promote Food Security! Bonn: Germanwatch. 2004. pp. 26-29

[29] Burmann A. Can't do without it! The EU is dumping dairy exports on a grand scale. In: Schuster-Haus W, editor. Stop Dumping, Promote Food Security! Bonn: Germanwatch. 2004. pp. 30-36

[30] United States Department of Commerce. U.S. Trade with SubSaharan Africa, January-December 2014 [Internet]. 2014. Available from https:// www.trade.gov/agoa/pdf/2014-us-ssatrade.pdf [Accessed: 21 February 2019]

[31] Busse M, Grossmann H. Assessing the Impact of ACP/EU Economic Partnership Agreement on West African Countries [Internet]. 2004. Available from: http://ageconsearch.umn.edu/ bitstream/26198/1/dp040294.pdf [Accessed: 21 February 2019] 
[32] Wolpold-Bosien M. Food dumping and the human right to food. In:

Schuster-Haus W, editor. Stop Dumping, Promote Food Security! Bonn: Germanwatch; 2004. pp. 22-25

[33] Pannhausen C. Economic Partnership Agreements and Food Security: What Is at Stake for West Africa? German Development Institute: Bonn; 2006. 73 p

[34] Chang H. Kicking Away the Ladder: Development Strategy in Historical Perspective. 1st ed. London: Anthem Press; 2006. 187 p

[35] Brooks DH, Ferrarini B, Go EC. Bilateral Trade and Food Security [Internet]. 2013. Available from: https:// www.adb.org/publications/bilateraltrade-and-food-security [Accessed: 21 February 2019]

[36] Murphy S. Food Aid: What Role for the WTO [Internet]. 2005. Available from: http://citeseerx.ist.psu.edu/ viewdoc/download?doi=10.1.1.190.60 72\&rep=rep1\&type=pdf [Accessed: 21 February 2019]

[37] Abdulai A, Barrett CB, Hazell P. Food Aid for Market Development in Sub Saharan Africa [Internet]. 2004. Available from: http:// barrett.dyson.cornell.edu/Papers/ FoodAidforMarketDevelopment.pdf [Accessed: 21 February 2019] 


\title{
Agricultural Production Amid Conflict: Implications for Africa's Regional Development
}

\author{
Jude Uwaoma Nwachukwu
}

\begin{abstract}
Agriculture is fundamental for the thriving and development of all societies. This is more the case in Africa where countless studies have demonstrated that agriculture plays major roles in the well-being of the predominantly agrarian African communities. Premised on the ideological posture that all human activities occur in situated social conditions, this study examines how conflict intersects with and impacts the agriculture economy of African communities and ultimately impedes African development. Using a Nigerian agrarian community as its site, the study appealed to political economy in carrying out this experiment. We employed interviews, direct and participant observation, photography, video and audio recordings, and strove to hew meaning from field data by using tables, graphs, descriptive analysis, and comparison with related studies. The study found that conflict imposes huge anti-development costs on Africa including high death tolls, reduced agricultural productivity, outmigration, displacement of populations, exposure to diseases, endangerment of women's and girls' lives, collapse of social order, discouragement of investors, looting, suspension of education, unemployment, food insecurity, high price of foodstuffs, and lack of effective social institutions for conflict resolution, among others. Limited for not using as many desired participants and leaving out some details, improvement is targeted as the study continues.
\end{abstract}

Keywords: Africa, development, agriculture, conflict, poverty

\section{Introduction}

This chapter makes just one case running on the wheels of one argument, namely, that agriculture is the pillar of life for African communities. The fact of the irreplaceable place of agriculture in Africans' lives and African development makes it imperative to strive for a better understanding of all the conditions and factors that define and shape its functioning. This ideological posture in approaching this crucially important subject takes its rise from the fact that, agriculture, like all other human activities, functions in situated social conditions which, individually yet collectively, affect it in many and varied ways. Our take is that it is by subjecting this complex, urgently important subject to extensive ethnographic study that we can come as close as possible to the core of the matter. As such, what is undertaken here is an anthropological inquiry aimed at interrogating how conflict, in all its forms and manifestations, intersects with and impacts agricultural production in Africa and, above all, how it impedes African development. Honing in on Nigeria 
as our case study site, the study aims at the generation of some body of scientific, evidence-based knowledge that contributes to the ongoing discourse on Africa's contemporary development. It is of importance to underscore at this point that this exercise is done not just for the purpose of understanding how conflict impacts agricultural production in general but specifically how this agriculture-conflict interface plays out in the region's socioeconomic and overall development.

In its expanded form, the argument sustaining this inquiry is anchored on the assumption that it can never become drab and trite and so cannot be overemphasized that agriculture is the life-wire of African communities. As such, this study is a proposal to the effect that every necessary step should and must be taken toward a much better understanding of how it functions in the context of the multistranded constellation of social, political, economic, cultural, institutional, natural, and/ or ecological conditions within which its activities are carried out. The pre- and post-independence economic history of Africa sides with, and evidently supports, the hypothetical assumption that African communities are predominantly agrarian, and that agriculture is something Africans co-evolved with for many millennia. Many scientific studies serve as ready-at-hand corroborating back-ups to support this public knowledge. Following Charles Darwin's firm belief that very important technological inventions and innovations rooted in the earliest histories of mankind owe their origins to Africa, archaeological historians have developed their theories around which they build the argument that modern day agriculture has its roots in Africa where it was originally invented. The foregoing is without prejudice to the fact that "At one time all the human beings in the world were hunters, gatherers and fishers, especially they were collectors of food not producers" [1]. Furthermore, "Until 10,000 years ago people everywhere were foragers" [2]. With the phase of nomadism gradually over in the evolution of Africa giving way to the development of settled communities, earliest Africans adapted to their environment to as far as developing the art of the domestication of some selected plants and animals, that is, cultivation and pastoralism. "This involved manipulating the reproduction of selected animals and plants, so that they were more suited to human requirements" [1]. Strikingly important about this is that it has also been argued that modern day African language has its foundations in these small and settled communities established thousands of years previously. In like manner, "The beginning of modern day history can be partly marked through the introduction and development of agricultural systems" [3].

The essence of factoring in these few points bordering on the archaeology of agriculture in Africa is to further underscore the importance of the region's agriculture economy as not only a means of survival in Africa but also as that which has continually played irreplaceable role in the life and development trajectory of Africa and its peoples on the one hand, and so constitutes a sector of life that must be protected from all incursions that are inhibitive of its progress and of African development, on the other. Even the buzzing nomenclatural wave of (African) civilization and all the contentious discourse around it is without merit outside the historical context of agriculture's role in that gradual development called civilization. This fact is especially with particular reference to the invention, improvement, and application of tools with which earliest Africans wrestled with and subdued their natural environment in the form of the domestication of certain plants and animals in their settled communities. This addition aims to make the case, again, that any and everything that stands in the way of agriculture and the role it plays in contemporary African development deserves close study attention as is intended and undertaken here.

Poised to make its case, this study appeals to available scientific data on the contribution of agriculture to the well-being of African nation-states soon after 
their independence in the late 1950s and early 1960s. We recall that, "In Africa 50 to 80 percent of the population lives in rural areas, and this rural population is predominantly peasant farmers. Agriculture accounts for about 40 percent of gross domestic product, 30 percent of exports, and 75 percent of employment" [4]. In addition to agriculture being the key provider of $90 \%$ of domestic food supply, which is thanks to the productive industry of smallholder rural farmers [5], other studies have documented that agriculture employs about 60\% (or more) of the workforce $[6,7]$. For the same reason of the primacy of place agriculture occupies in the life of African communities, it has been argued over time that any successful development plan in and for the region must target raising agricultural productivity in rural areas [8] which is considered a Green Revolution to raise food output [9]. For, in addition to minimizing hunger, poverty, and avoidable costly pecuniary value which the region wastes on food importation, we argue that emphasis on agriculture within and among African communities creates many jobs as it also discourages and reduces outmigration especially among young adults.

Some other compelling reasons explain the urgency of this kind of field study; they also shed light on the relevance and merit of this undertaking. First among them, we observe that Africa is a region very easily and quickly associated with poverty and it correlates; this stands in sharp contrast to the fact that agriculture not only portends to reducing poverty and hunger but also has the ability to redirect and sustain Africa's development trajectory in different ways. In other words, we argue that it is troubling that Africa is well-disposed to attaining enviable heights in development but is at the same time associated with the ravages of hunger, poverty, and food insecurity among other social plagues as though these were the region's exclusive earmarks. This is more so the case when discussions focus on the sub-Saharan African (SSA) sub-continent characteristically noted for population increase outpacing food production per capita, which often leads to the region's high rate of food importation [10]. There are some available scientific studies that are used to support the assertions about Africa's telling poverty indicators. Among some of such instances, it has been argued that post-independence African nationstates have performed far below their development potential, which is part of the reason Africa is easily described as one of the poorest parts of the world. For, as recent as 2016, the continent was still identified as taking the largest pie in hunger and poverty experiences:

There are large differences among continents in the prevalence of severe food insecurity. Approximately $27.4 \%$ of the population in Africa was classified as severely food insecure in 2016, which is almost four times as high as any other region. Alarmingly, food insecurity is on the rise, specifically in sub-Saharan Africa. From 2014 to 2016, food insecurity increased by about 3\% [11, 12].

The above underscores the daunting challenges before the region in light of attaining the Sustainable Development Goals 2 (SDGs) created in 2016 by the United Nations. It is evidently clear that the situation, rather than improving, has been getting worse over the years. This is starkly real from previous studies on the same global poverty measures in which Africa was described as the "the poorest part of the world" [13], indeed, the "ultra poor of the world" [14]. Some other social taxonomies such as less developed, underdeveloped, backward continent, and Third World are also used to refer to Africa's poverty indicators.

The foregoing points act as provocations to raise the question as to how agriculture could have lost its leading role in standing up to the assaults associated with poverty and underdevelopment in Africa. For, it is noteworthy that in the immediate post-colonial moments of African history, the region registered very impressive 
economic growth performance to which agriculture was a major contributor to the GDP for the period 1965-1987. This historical fact is in spite of the intervening episodes of fall in output mainly due to drought especially in the Sahel countries of SSA [15] followed by hikes in oil prices and an increasingly adverse effect of international debt during the decade under reference [15]. However, in spite of the aforementioned drop, the contribution of the agriculture sector to the GDP of parts of the region ticked up a little again to 1.3\% per annum for the period of 1980-1987, and rose even higher at the end of the decade resulting in an incremental growth rate of 2.1\% between 1987 and 1990. Lamentably, these initial trends in growth thanks to the contribution of the region's agriculture sector soon tilted and faded away for various policy and other reasons.

We argue that among those other reasons, wars and incessant conflicts rampant across Africa often account more than any other for the consistent decline in the contribution of the region's agriculture economy to its overall economic development. While many contemporary social inquirers simply lament the general socioeconomic backwardness of Africa [16], this study rather stands with poised optimism and hope for improvement anchored on investing more in agriculture but only by simultaneously and consistently pushing back on everything associated with conflict as an arch enemy of the former. Thus, whereas there is overwhelming evidence in recent decades that Africa has not enjoyed economic and social progress like other parts of the world are doing, we argue that "Improvements within the sector can unlock the door to social and economic improvement. Indeed, agriculture must be the engine for the economic and social progress" [14] of the African region. We opine that all the efforts African governments and international bodies mount in recent times aimed at increasing agricultural productivity and general development of the region will not fructify in any meaningful degree if they fail to simultaneously craft socioculturally and politically appropriate, sustainable, and responsive conflict management toolkit.

The hallmark of our argument for this study runs thus: whatever stands in the way or swims against the current of agriculture in Africa is the arch enemy of African development. We contend that typical of such social snag in the way of agriculture and of African development is the social phenomenon of incessant intra- and inter-ethnic conflict. Unfortunately, rather than being scanty across the face of the continent, there are many such waves blowing across the region and eroding the development potential of African communities. More telling is the fact that often such conflicts that impede the progress of African communities and sometimes decimate them hide and operate in the hardly noticeable hinterland niches characteristically known for agricultural activities. This lends even greater and more compelling cogency as to why conflict in Africa must be given closer and sustained attention first, by examining its causes and detailed human and socioeconomic costs and, secondly by installing institutional mechanics toward abating it where and when it cannot be completely eradicated. These constitute the core aims of this study, which at the same time stand as its merits, contributions, and relevance.

\section{Study methodology}

Since it is the case that the type of social phenomenon to be studied determines the study methodology applied, we adopted the analytic tool of political economy as our ideological inspiration and guide for the collection and interpretation of field data in this study. This choice is informed by the conviction that political economy opens a wide leeway for the exploration of factors impacting agricultural 
development in rural parts of Nigeria as with other parts of Africa. Central to this leaning to the political economy ideological framework is the insight that taking up a definitional stance should start with social practices, not fully formed concepts since meaning of ideas is forged in concrete social practices [17]. If the concept of political economy, among other things “... encompasses studies of production, circulation, accumulation and consumption of goods, services and value" [18], then, the social practices involved in these activities and other related factors intertwined with them, in space and time, need to be explored for much better understanding. This is why we chose to approach this study from the perspective of socially grounded etymology [17]. As such, certain specific Nigerian agrarian milieus that had experienced and or are currently going through the horrors and hazards of conflict were chosen for this project. The study pitched its main tent of data collection in Ukum Local Government Area (LGA) of Benue State in Central Nigeria to track how conflict impacts agricultural production but above all with the view to examine how this agriculture-conflict strange marriage in turn affects the community's development experience. We compared our field data from this principal study site with what obtains in other rural farming parts of Nigeria and, by extension, in other parts of Africa and by appealing to extant literature on the subject. For the scientific exercise of data collection and analysis, the study applied such techniques as individual and group interviews, direct and participant observation, photography, descriptive vignettes, video and audio recordings. To hew meaning from field data, the study used tables, charts, graphs, descriptive analysis, and comparison with extant literature on related studies. With this study toolkit answers were sought to such questions as: What is the meaning of conflict in the Nigerian and African social context? What is the relationship between agricultural production and conflict? In what ways does conflict impact agricultural production in Nigeria? What specific consequences does conflict have on community and general development in Nigeria? What are the causes of conflict especially in agrarian rural Nigeria? Who are the actors of intra- and inter-ethnic conflicts in Nigeria? What institutional instruments of conflict control and management are there in place in Nigeria? If there are such tools, how effective are they? These and related curiosities informed the questions with which our study participants were engaged in the process even as this ethnographic inquiry stretches on into the future for more extensive exploration.

\section{Situating the study}

To get to the core of the subject of this study—on how conflict impacts the agriculture economy and general development of Nigeria, and ultimately of Africathe ethnography crafted to experiment the ideological framework engineering it was carried out using the earlier stated methodological tools and experimented in Ukum community of Benue State, Nigeria. Figures 1 and 2 show the country and main site of the study respectively. Ukum is one of the 23 LGAs of Benue State in Central Nigeria. By virtue of its geographical location, it shares borders with Taraba and Nassarawa States in Northern Nigeria as is shown in Figure 1. Like other parts of Benue and sometimes much more, Ukum is heavily engaged in commercial agricultural production and is a major source of supply of both tuber crops, citrus, and a wide range of vegetables to other parts of Nigeria. Ukum is also replete with many markets that operate all week with Zaki-Biam being the largest.

Besides, and in addition to the foregoing, the Ukum community of Benue State was selected for this study for two major reasons: first, it purely represents the main features and heavily agrarian character of almost all the rural communities of Nigeria and Africa where incessant conflict looms amid the stages of agricultural 


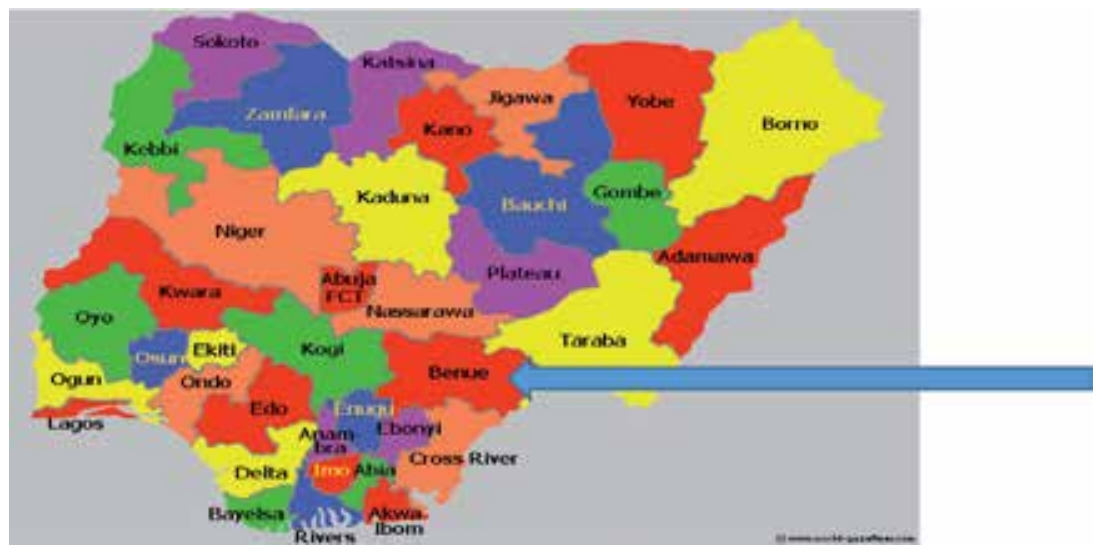

Figure 1.

Map of Nigeria with the 36 states of the country and showing the location of the study site (the map of Nigeria above was directly adapted from the Web).

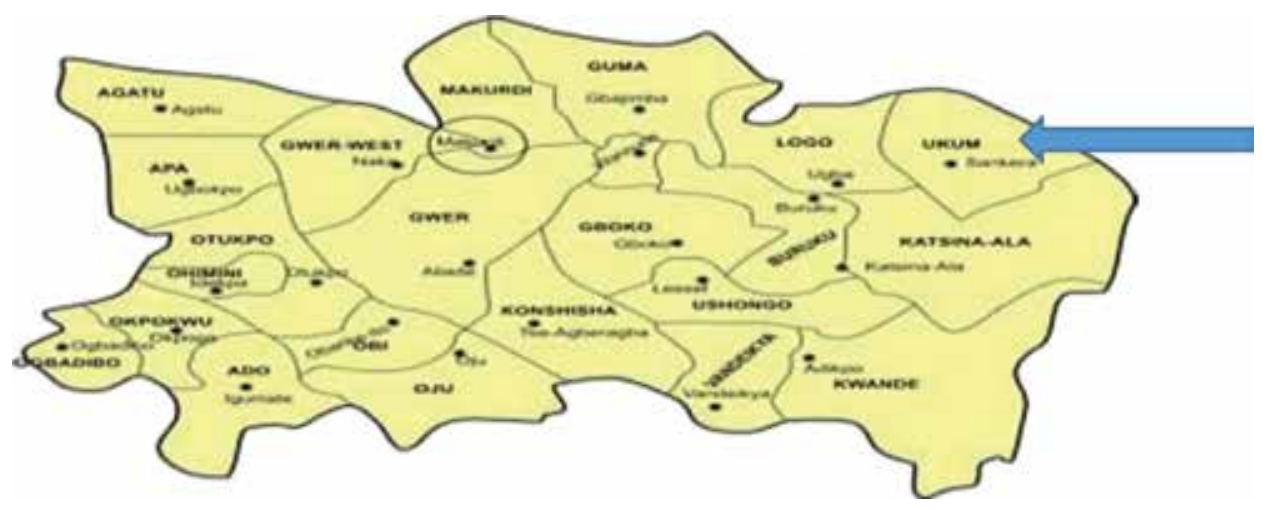

Figure 2.

Map of Benue state showing UKUM local government area (LGA) as the study site (the map of Ukum LGA above was directly adapted from the Web).

production. On the other hand, Ukum of the Tiv world characteristically typifies the tens of hinterland populations where conflicts are incubated and, in fact, frequently occur in Nigeria. Writing about the mainstream economic occupation of the people, an official statement of Ukum LGA states: "In fact, the Local Government is the pivot [...] of the Food Basket of the Nation ${ }^{1}$ for which Benue State is known" [19]. Writing more inclusively about the whole state in relation to the vast human and natural dispositions that conduce to the people's extensive, productive engagement in agriculture, our source continues:

Benue State is richly endowed with natural resources of different types. The State has vast and fertile land which is worked by an enterprising rural population. Agriculture forms the back-bone of the Benue Benue State economy, engaging more than 70 per cent of the working population. Bush fallowing using simple tools is the dominant system though mechanization and plantation agriculturelagroforestry

\footnotetext{
${ }^{1}$ See Appendix A as Figure A1 for "Food Basket of the Nation" symbol and pride of Benue State, Nigeria. We have and reserve our critical caveat over this symbol due to the political asymmetry and above all the core-periphery bipolarity we observed as this symbol represent though hardly spoken of by the indigenes.
} 
are gradually creeping in [...] Though the farms are generally small and fragmented, ranging from less than one hectare to more than six hectares, total output is generally impressive [19].

It is on the same basis of the notorious agrarian industry of the Tiv that some pioneering and outstanding anthropologist of the Tiv world once wrote: "The Tiv are farmers. They produce and trade what they eat and wear..." [20] ${ }^{2}$. Properly described, the ordinary and occupational life of the Ukums is the art of the production and marketing of agricultural goods, and vice versa. It is also the case, as we shall see later, that Ukum lives its agrarian life sometimes amid tremulous trepidations over possible conflict/war that may ensue usually from their Jukun neighbors. As earlier stated, it is on the basis of this dual features-of deeply agrarian character and of their experience of conflict - that the place was selected as the main and typical site for this study.

\section{Study findings: data representation and analysis}

This section is comprises the representation and analysis of data collected from the field of study and combines findings from the different study techniques applied in the process. First, we represent field data collected from farmers in Ukum, as are displayed in the accompanying tables and charts. This is followed by the representation and analysis of data from questionnaire responses, non-scalable interview responses from Ukum-based investors; and finally, we turn to and focus on data from direct and participant observation.

\subsection{Findings from questionnaires and interviews with farmers}

Informed by preliminary interactions with farmers from around the Zaki-Biam of Ukum main study site, the questions in Table 1 were formulated and used to

\begin{tabular}{l}
\hline A/1: Do conflicts bring about significant out-migration in your community? \\
\hline B/2: Do conflicts bring about high death toll in your community? \\
\hline C/3: Do farmers abandon their farms when conflict looms or occurs? \\
\hline D/4: Do conflicts make for reduction in areas of farmland covered? \\
\hline E/5: Do conflicts go with corresponding fall in output of food crops? \\
\hline F/6: As a farmer, does conflict discourage you from farming activities? \\
\hline G/7: Do conflicts enhance the spread of infectious diseases in your community? \\
\hline H/8: Do conflicts bring about increase in the price of food crops in your area? \\
\hline I/9: Do conflicts discourage prospective domestic and foreign agro-investors? \\
\hline J/10: Is there any direct connection between conflict and rate of poverty in your community?
\end{tabular}

Table 1.

Tracking the impact of conflict on agriculture and development in Ukum, Nigeria.

\footnotetext{
${ }^{2}$ It is of great importance to note here that the Ukum (and Tivland) of Bohannan's ethnographic experience and time has been very irreversibly transformed from subsistence to cash economy with so many causal linkages and implications this social transformation holds out for this population as our study observed it.
} 


\begin{tabular}{llll}
\hline Questions & Yes & No & Declined \\
\hline $\mathrm{A} / 1$ & 20 & 0 & 0 \\
\hline $\mathrm{B} / 2$ & 19 & 0 & 1 \\
\hline $\mathrm{C} / 3$ & 18 & 2 & 0 \\
\hline $\mathrm{D} / 4$ & 18 & 1 & 1 \\
\hline $\mathrm{E} / 5$ & 20 & 0 & 0 \\
\hline $\mathrm{F} / 6$ & 18 & 2 & 0 \\
\hline $\mathrm{G} / 7$ & 15 & 2 & 3 \\
\hline $\mathrm{H} / 8$ & 20 & 0 & 0 \\
\hline $\mathrm{H} / 9$ & 17 & 1 & 2 \\
\hline $\mathrm{J} / 10$ & 20 & 0 & 0 \\
\hline
\end{tabular}

Table 2.

Impact of conflict on agriculture and development in Ukum, Nigeria.

\section{Effects of Conflicts on Agriculture and Development in Nigeria}

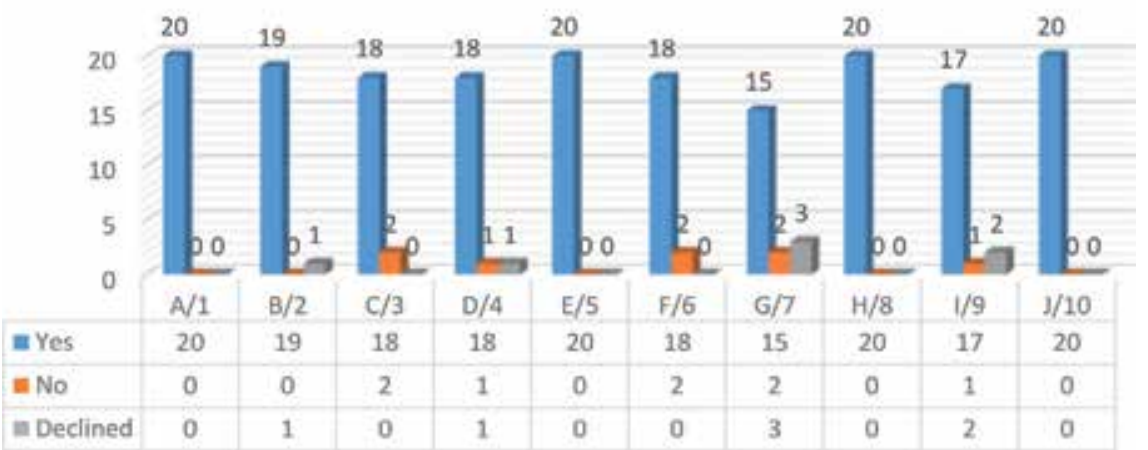

Figure 3.

Impact of conflict on Ukum-Nigerian farmers.

collect data working with randomly selected 20 participants who were also engaged in follow-up one-on-one interviews. The data thus gathered from respondents are laid out in Table 2 and Figure 3.

First, study data make it overwhelmingly clear that there is a direct correlation between the occurrence of conflict and outmigration among Ukum, Nigerian rural farmers; this is the stance of all respondents. With 19 out of 20 farmer-interviewees admitting that conflicts bring about high date tolls upon their communities, it is immediately and directly understandable why migration especially among young adults is usually very high in areas hard hit by conflict. Follow-up accounts of some informants indicate that some of these conflicts are socially engineered by their chiefs and elite whose prebendalist ${ }^{3}$ agenda is often hidden under the guise

\footnotetext{
${ }^{3}$ Prebendalism refers to political systems where elected officials and government workers feel they have a right to a share of government revenues, and use them to benefit their supporters, co-religionists and members of their ethnic group, and whom they, ipso facto, zombify and instrumentalize, but only to boost their purely utilitarian, materialist agenda. The term is commonly used to describe the patterns of corruption in Nigeria, and to point out why its democracy is not working. Though used in other or similar nomenclatural epithets all of which critique and caricature the flawed practice of democracy in Nigeria and other parts of Africa, it was Joseph's (2014) contribution that made it gain higher and projected currency in literature especially on corruption in Nigeria and its African likes.
} 
of community welfare and good. Yet they did not deny the need to stand up to and defend their lives, their land and property and, above all, their pride as a people against any and all attempts of their enemies to bully them out of their right to the land they have occupied from time immemorial.

According to our field data, 18 out of 20 farmers abandon their farmed plots when conflicts strike; similarly, a very high majority of Ukum farmers (18 out of 20) experiences very high drop in crop production, and this is partly accounted for by the telling levels of discouragement among farmers whose motivation to produce is highly reduced. A majority of respondents (15/20) affirmed that conflicts are often correlated with the spread especially of sexually transmitted diseases. Closer follow-up interviews revealed that the two farmers who answered in the negative and the three who declined the question made their responses as a result of the traumatizing, psychological shame and the harrowing embarrassment this question triggers suggesting also either they themselves, their relatives, and/or friends may have fallen victim to this.

On the other hand, it is strikingly noteworthy that all 20 participants stated that conflicts bring about sharp increase in the prices of foodstuffs and other commodities in the immediate conflict zones as in the wider areas of neighboring rural and urban communities. Whereas 17 out of 20 farmers see conflict as directly discouraging to prospective agro-based domestic and foreign investors in their communities, all 20 overwhelmingly concur that conflict inflicts wide-spread and multistranded poverty upon them. When further pressed in interviews in the direction of causality, all respondents agreed that land and related natural and or ecological resources are almost always the reason for conflict. This explanation was given for conflicts within and among communities of Ukum and those that occur between Ukum and other neighboring ethnic populations like the Jukun of Taraba (and Nassarawa) States bordering the Tiv.

\subsection{Findings from Ukum-based investors}

As follow-ups, questionnaires were floated among investors, traders, and other business people within and around Zaki-Biam market of Ukum LGA. The aim was to pool data to be compared with findings from Ukum indigenous farmers. The same respondents who participated in this section were also engaged in follow-up interviews. As with Section 4.1, the overall aim was to have a better understanding of how conflict affects agricultural production and general community development in Nigeria and Africa at large (Tables 3 and 4, Figure 4).

A/1: Have you ever experienced any cases of conflict in Ukumland?

$\mathrm{B} / 2$ : Do conflicts negatively affect investors' businesses in Ukumland?

C/3: Do you feel secure doing business around the Zaki-Biam market area?

D/4: Have you ever been hard hit by the outbreak of conflict in Ukumland?

E/5: Were your business assets looted during the crisis of conflict?

F/6: Did you witness any persons die during conflict here in Ukumland?

G/7: Have you ever felt discouraged by conflicts from expanding your investment here?

$\mathrm{H} / 8$ : Are other investors discouraged from investing their resources in Ukumland?

I/9: Do conflicts bring about increase in the prices of food crops and all commodities?

J/10: Do you feel there are effective institutional conflict management tools here?

Table 3.

Impact of conflict on agricultural investment in Ukum, Nigeria. 


\begin{tabular}{lccc}
\hline Questions & Yes & No & Declined \\
\hline $\mathrm{A} / 1$ & 16 & 3 & 1 \\
\hline $\mathrm{B} / 2$ & 20 & 0 & 0 \\
\hline $\mathrm{C} / 3$ & 3 & 16 & 1 \\
\hline $\mathrm{D} / 4$ & 15 & 3 & 2 \\
\hline $\mathrm{E} / 5$ & 16 & 2 & 2 \\
\hline $\mathrm{F} / 6$ & 18 & 2 & 0 \\
\hline $\mathrm{G} / 7$ & 17 & 2 & 1 \\
\hline $\mathrm{H} / 8$ & 15 & 4 & 1 \\
\hline $\mathrm{I} / 9$ & 20 & 0 & 0 \\
\hline $\mathrm{J} / 10$ & 20 & 0 & 0
\end{tabular}

Table 4.

Impact of conflict on agricultural investment incentives in Ukum, Nigeria.

Impact of Conflict on Agricultural Investment in Ukum, Nigeria

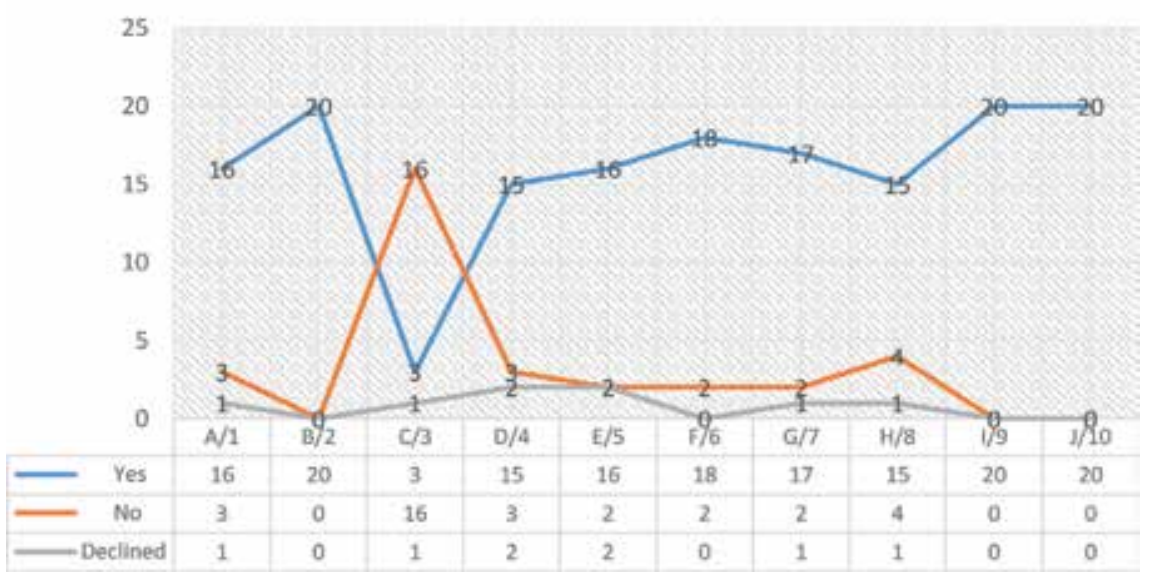

Figure 4.

Impact of conflict on agricultural investment incentives in Ukum, Nigeria.

First, our study found that majority of investors (16 out of 20) who operate businesses around conflict-prone areas of had at one point or the other in the past been directly negatively impacted by conflict. While all 20 respondents admitted that conflicts very negatively affect their investments, 16 out 20 investors expressed feeling insecure around the conflict-ridden areas of Zaki-Biam market in particular and Ukum LGA in general. On the other hand, whereas 15 out of 20 investors stated that they had experienced the occurrence of conflict in the area, which they said impacted their businesses and lives very negatively, 16 of them indicated that, in the heat of conflicts, their business assets were looted especially by indigenes; as a case in point, they referenced the $2001^{4}$ experience of near genocide in Ukum-Tivland.

\footnotetext{
${ }^{4}$ This reference is (frequently) made to the occurrence of the violence of October 22, 2001, when, in response to the ongoing, decade-long Tiv-Jukun conflict, “[...] the Nigerian army killed more than two hundred unarmed Tiv and destroyed their homes, shops, public buildings and other property in more than seven towns and villages in Benue State, Nigeria" (See Amnesty International, 2002; Ciboh, 2014; Vanguard Newspaper, November 19, 2001).
} 
In like manner, 18 out of 20 respondents admitted having seen people killed during seasons of conflict; on the other hand, 17 investor-respondents indicated being discouraged from investment while 15 admitted knowing that conflicts discourage other fellow investors as well. It is not surprising, therefore, that all 20 business investors stated that prices of food crops and all commodities skyrocket when conflicts strike. Finally, all 20 participants also indicated that, as of the time of this study, not much had been done by the government to install reliable and sustainable institutions of conflict management to guarantee security in the area.

\subsection{Findings from direct and participant observation}

The harrowing experience of conflict and its many-sided impact on agriculture and community development in Nigeria is incomplete and falls short of speaking personally and directly without a firsthand experience by a researcher who is onsite to track this delicate subject. This general lesson was the first among many we learnt in the field when we gained some close encounters with would-be study participants. Many farmers in the hinterland communities of Ukum were too reserved and withdrawn each time attempts were made to involve them in this social study. We think this is attributable to either of two related facts or both: first, they were too easily agitated to discuss it and recount their personal experiences especially when the study probes more deeply to provoke the ever-haunting traumatizing memories of the carnage many families suffered during the horrors of past conflicts. Many easily referenced the history of 2001 conflict earlier referenced on page 8 . On the other hand, some individuals were too afraid to discuss the topic as they mistook the researcher for government agent who had come to gather some sensitive pieces of information from them. These two points, we think, created feelings of palpable fear, suspicion, and heart-searing pain for those who had witnessed past intra- or inter-ethnic conflicts in the area. Those two social inhibitions unfortunately partly account for why we were unable to document some statistical nitty-gritty details on the human and social costs of conflict, which we target and hope will happen as this study progresses in the future.

While the above ambition looms, we personally observed some other facts worth representing here. First, moving around Zaki-Biam huge market and other smaller markets in Ukum LGA, we found that prices of locally produced agricultural (and non-agricultural) goods were high as of the time of this study. Our study found that this was due to fears of impending conflict and the political instability associated with it, which made farmers to cultivate less farmlands. A stringent warning from a

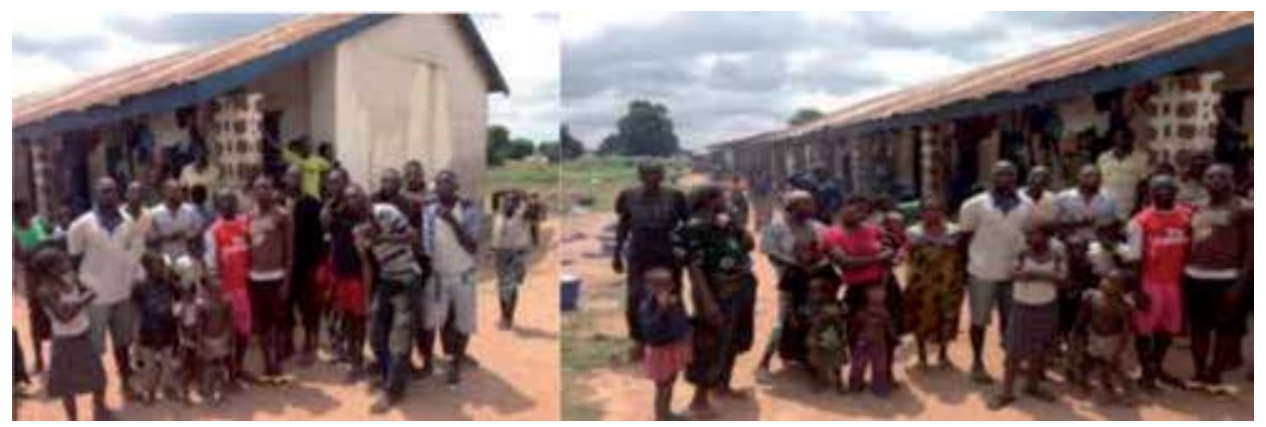

Figure 5.

A cross section of a displaced group of farmers taking refuge in an Ukum primary school (the twin pictures above are original to the researcher and were taken on September 4, 2014). 
Police Officer who lives in the area for the purpose of giving the people some sense of security and protection was breathtaking.

\begin{abstract}
In carrying out your research, tread with great caution watching the extent to which you go into the hinterlands in search of farmers as no one can guarantee when anything might happen especially during the period of bush clearing which marks the beginning of the farming season when age-long land or boundary related conflicts usually occur [Fieldnotes: 2014, August].
\end{abstract}

In furtherance with participating in, and personally observing, the goings-on in the life of the Ukum community, we encountered a large group of people inhabiting an elementary school along Ugba road within the Zaki-Biam market area as is displayed in Figure 5. Vignette 1 tells the story of the refugees.

Vignette 1. Refugees at home [Fieldnotes collected from Zaki-Biam, Ukum LGA, September 4, 2014]
Story narrated by an appointed "Caretaker" of the refugee group represented in Figure 5.
It was on a certain Sunday morning when the Pastor in-charge of St. Anthony's Catholic pariah woke up to the rude shock that a huge crowd of people had invaded and past the night inside the Church building. The 286 people of all ages and genders were found to have fled death from a crisis that arose in Ibi LGA in Taraba State between Fulani and Tiv communities in Ibi LGA. The group that took refuge in the Church compound are Tiv by origin but are in diaspora as farmers who had lived and settled in Ibi LGA for many decades. This was the first time ever this Tiv group in Ibi of Taraba State had any conflict with the Fulani. They were originally from Guma LGA of the Tiv extraction of Benue State. Fleeing the conflict, they were headed to their ancient Guma-Tiv community of origin but were caught up by night and so decided to sleep in the Church compound to continue with their home-bound journey the following morning. When they woke up and set out to do as they had planned they heard of another bigger crisis between the Fulani and the Tiv at home in Guma LGA and so got stuck at Zaki-Biam. The Pastor of the parish gave them refuge in the school premises, treated many of them who were ill at the parish hospital, galvanized and rallied his parishioners for other social services including clothing and constant raw food supply, appointed a parish member as Caretaker of the group as well as another parishioner who organized for water supply and cooking in the open field. The group took their bath in the field at night but slept on the hard crust of the cement floor at night. The Pastor notified the Bishop of the Diocese who instructed the Peace and Justice department of the Diocese to intervene with more and sustained help. The parish members and all their Church sodalities remained faithful in taking care of the refugee group and some of them had already housed them in their personal homes. The Bishop of the Anglican Communion of Zaki-Biam also stepped in and, with his flock provided the group with water containers and regular water supply. The Pastor of St. Anthony's Faith-Community wrote the Ukum LGA Chairman, the Inspector of Police, and the Traditional Ruler of Biam Ward; hardly any responses came from them as they all claimed there was no money to take care of them. Instead the Ukum LGA Chairman stated they should go back to their home to be taken care of. He also ordered they should vacate the school buildings, but thanks to the School Head Mistress who offered the group just one block to stay in while the school was in session. Meanwhile the people were consumed in fear as to what next might be their fate. Some of their teenage children were already hiring out themselves for menial jobs in the Zki-Biam market for little feeding money. The very many of the children who were in school before the conflict broke out a year earlier were now out of school indefinitely. The School Head Mistress expressed great concern over the danger women and girls among the group were exposed to including rape, unwanted pregnancy, and the contracting of sexually transmitted diseases (STDs). The oldest man in the group cried out over how they had lost many lives before they fled in addition to many of their family members whom they do not know where they fled to as other groups scattered out to other welcoming communities. He also lamented that their houses were burnt down together with all agricultural goods they stored in their granaries not to mention that many of them lost huge sums of money saved in their homes as proceeds from their farm produce sales as they were used to doing. He added that their aggressors were Fulani-Hausa cattle herdsmen whereas they themselves were crop farmers. The conflict arose because the herdsmen invaded their cultivated farmlands and let their livestock destroy all they had labored for and extended the destructive measures to them too claiming they were strangers who had no right to the land they had been cultivated for tens of decades unchallenged. The combatants also looted property in their homes including great values in their granaries and leaving them totally dispossessed of all they value and live for. 
Vignette 2. A few more cases of refugees at home due to land related conflicts in Nigeria

Across the length and breadth of Nigeria, there are multiple occurrences of intra-inter-ethnic conflicts sometimes happening simultaneously. Regardless of the niches of their occurrence, they have been found to share some features in common: they revolve around land and or land-related resources; they usually kick off during planting season and sometimes at any stage in the farming cycle; they claim thousands of lives with thousand others from the warring parties who flee the scenes and are usually displaced and sometimes become permanent refugees in their own country and in distant communities where they are often unwelcome; farmers abandon their unripe crops as they run away from the rampaging fury of their opposing combatants; agro produce stored at homes are either looted or burnt down together with the houses of the fighting groups; diseases of all kinds spread around; increased food scarcity and hunger ensue; suspension of educational, medical and other social services are halted, that is, where they exist at all; and, shocking yet not surprising, political leaders from both sides of the equation hardly go beyond making official statements condemning the act, among others. These are typified in the most and still ongoing violent feud between Utuma community in Biasa LGA of Cross River State and Isu community in Arochukwu LGA of Abia State both in Southeast, Nigeria. Striking are three notable dates of the incidence of conflict between the two ethnic groups as some Nigerian National Daily Newspapers [21-23] and other human rights-focused international observers reported and condemning the resurgence of this age-long conflict. There is a rich splinter of such conflicts hiding in rural farming communities across Nigeria in particular and Africa at large.

From the foregoing specific case drawn from direct observation, a few outstanding study findings emerge: inter-ethnic conflicts also come from clashes between Nigerian Fulani herdsmen (pastoralists) and their neighboring crop farmer-groups; conflict leads to displacement of farming populations; it causes loss of lives; it increases hunger and poverty as farmers are yanked off their source of livelihood; farm lands and agro products in storages are abandoned; looting also occurs; this in turn intensifies food scarcity; it also increases prices of agro-related and other commodities; women and girls are exposed to many dangers; worse still, there seems to be no hopes for a better future for Nigerian rural farmers with no appropriate, effective conflict resolution institutions in place. It is impossible not to see the how conflict among Nigerian, and all African farming communities is not directly inhibitive of development in the region.

\subsection{Seeking patterns from different areas of field data}

With the foregoing analyses drawn from a wide range of field data, a complex web of connections among closely related impacts of conflict on agricultural production and general development in Ukum community can be stretched out. In a wellsequenced and corroborated data representation, this study found that when Nigerian hinterland farming communities and their neighbors lurk in conflict, as they often do, many people flee those unsafe niches first in order to save their lives. Among those who escape conflict-ridden environments, young adults who constitute the heart of the requisite labor force assume the greater majority. Follow-up interviews on why youths are the age range who flee most, our study gathered that the political elite of their communities often play opportunism by fronting and sponsoring young men to go into war many of whom die therefrom. However, whether they die in the field of conflict or flee their communities, the study found that they invariably abandon their farms and aged, frail, and vulnerable family members behind. With this and subsequent drop in areas of farmland subjected to cultivation in the next farming season, the communities experience corresponding sharp fall in agricultural productivity. With these food shortage ensues; this is further aggravated by the fact that a good number of conflict-affected farmers are already down with debilitating diseases associated with hunger, malnutrition, exposure to malaria infection in the wild of refugee camps and forests, and STDs in the case of women and girls. 
In the face of the insecurity created by ethnic conflicts, investors find no compelling reasons to cast their treasure in the affected communities especially as many of them lose their business assets to looters most of whom are indigenes usually from the warring factions of the same locality or from opposable ethnic communities. Overall, therefore, Nigerian farming communities experience the horror of food insecurity, high prices of food stuffs and other commodities, backwardness in socioeconomic development and circular poverty due to constant conflicts.

Engaged in interviews on the issue of why Nigerian farming communities experience many and sometimes persistent conflicts among themselves and with their close and distant neighbors, some telling explanations bordering on causality were adduced. First, many held to the ideology that conflict is unavoidable among them because they and their neighbors are either farmers and so always in need of more land against the pressure mounted by increased food need and population growth. The second explanation appealed to the primordial conflict which led to the fission of the original Tiv group during the first stages of its migration and settlement where it is now. Incidentally, those who participated in the interviews would not see that the human and social cost of conflict, usually high and horrendous, is enough reason to stop or deter them from employing conflict in asserting their right over their land when it is contested by another group. Instead they cited the many conflicts within and around their area to argue that conflict is unavoidable and the other inevitable side of their lives as farmers. Particularly, they blame the official government for not making enough effort to institute effective conflict management mechanics in their communities. It was also found that when the government does step in during conflict, privileged officials politicize the moment as opportunities to further enrich themselves and gain more economically motivated social and political positions in society on the one hand and, on the other, that government intervention during conflicts between and among communities is often conducted in such ways that favor some communities to the detriment of others making it rather more difficult for the conflict to end peacefully.

\section{Discussion: conversation with related studies}

We did not kick off with this study on the assumption that it is the first and pioneering attempt to explore this subject; rather we began in the acknowledged awareness that ours is another attempt in the same direction of an ongoing social science inquiry that is however in need so much more to be done. As such we appealed to many earlier studies to seek meaning of and from what we gathered in the field as our contribution to the ongoing dialogue.

In keeping with the multilayer findings of our study, many other studies have also documented the agricultural production and above all African development costs of ethnic conflict in Africa. Some scholars have documented that massive loss of lives, destruction of property, and exposure to diseases on the one hand, and hindering of man power growth and labor strength, socioeconomic development, collapse of social cohesion and political stability on the other, are some of the costs of conflicts in many parts of Africa [24, 25]. Some other studies have underscored that conflicts in Africa threaten women and girls with reproductive health problems including STDs, unwanted pregnancy, and maternal mortality [26]. Not alone in that conclusion, others have also conducted studies corroborating that finding and push it further to include the dire consequences of conflicts on women and girls demonstrating that the confusion ensuing during and immediately after conflicts disrupts sources of livelihood and socioeconomic activities of women [27]. In like manner, some other studies have found that conflicts and civil wars, by forcing 
communities into refugee camps, greatly increase the risks of infectious diseases with the usual sexual violence they bring upon women and young girls [28]. This is in addition to the fact that the male folks in their lives-their husbands, brothers, and sons, who are the main combatants in conflicts-are often either seriously injured or killed, while the women themselves are subjected to the horrors of rape or even killed too. In addition to these findings, others studies [23] have linked conflicts with trauma which is in turn associated with poorer daily functioning, physical limitations, and chronic medical conditions.

Pushing the conversation further, a joint study of some scholars found that between 2011 and 2013, conflicts led to the loss of many lives. This is besides dozens of people who were rendered morbid, displaced, and thus became homeless and destitute [29]. It is also documented that in the long-drawn inter-communal conflict between Aguleri and Umuleri of Southeast Nigeria over land/boundary, in which automatic weapons and dynamite were used and thus described as the theater of fratricidal war, thousands of people fled for refuge in schools and public buildings, more than 300 people were killed, another 120 people were killed in the renewed episodes of the conflict. Still on the general implications of conflicts for economic development in Africa, it has also been documented that conflicts keep affected communities on a very low level of agricultural and general economic performance especially as they often decimate huge numbers of the warring populations [30]. On account of this situation it has been concluded by some scholars that "... conflict imposes costs beyond destruction" [31].

On the impact of conflict on agricultural production specifically-and by implication on African development in general—some studies [27] record that ethnic conflicts lead to diminished fortunes in agricultural productivity especially when they occur during farming seasons, which causes most farmers to abandon their farms and flee for fear of being attacked; this in turn results in low agricultural productivity in the following harvest season. They also found cases of the destruction of farmlands, farm crops, and the killing of cows all of which result in real and quantifiable material losses. A World Bank Development report [32] lays out a wide range of findings including that conflicts lead to high rate of youth unemployment, high incidence of circular poverty, low per capita income, overall economic decline, double loss caused by diverting valuable resources to destructive activities, more backward economic growth, forced migration, reduced access to education and health care, increased risk of predatory and contagious diseases in refugee camps, and increased mortality rate.

In groping specifically for causal explanations of conflicts in Africa, an army of scholars hone in on the fragile post-independence historical and political landscape directly precipitated by European colonial legacy which, from all intents and purposes, successfully but unsuccessfully imposed indirect rule on African communities aimed at hegemonizing populations that otherwise co-existed separately even in the face of their sociocultural differences [33-40]. By so doing, these students of contemporary Africa argue that colonial rule distorted by separating and amalgamating populations in such ways that made "... the struggle for political power, and control" [27] the epicenter of life in post-independence Africa. This is typified in the Nigerian case as is aptly captured in this historical backdrop:

The state of Nigeria was an artificial British imperial creation whose major groups-the Hausa-Fulani of the north, the Yoruba of the west, and the Igbo of the east-were each larger than most individual African states. Britain fostered strong regional governments and, moreover, encouraged a sense of regional rivalry, maintaining the balance between the three great regions from the center. There was no historical basis for the unity of these three and their different ethnic groups, 
except British imperial convenience. At independence, therefore, the new Nigeria inherited three powerful regions whose interests tended to draw them away from central authority and, once the British had departed, there was intense rivalry as to who should control the center [39].

In sum, this economically driven colonial balkanization and amalgamation of regions that ordinarily had nothing in common-except as they would later have oil in common to fall apart on in the Nigerian case, for example-would almost immediately be put to the test "... by inter and intra, regional and sectional disagreements..." [27]. It was this unhealthy political atmosphere that ruptured and culminated in the full-blown, total war of 1967-1970 in Nigeria with its multistranded fratricidal consequences, the rippling effects of which still linger across the nation till date.

Another crowded field of social scientists [24, 27, 41-45] argue that disputes over land and ecological resources, population explosion and the need for more land, boundary, territoriality, domination, oppression and exclusion, indigenesettler divide, chieftaincy and power relations and religious differences are specific causes of a particular character of conflicts classified as inter-intra-ethnic conflicts. Still more [46] use sing the 1992 Ugep-Idomi boundary conflict in Cross River State of Nigeria as a case in point to further the land resources-related causal account and arguing that boundary in relation to "... land, water, oil wells or other important natural resources..." is at the root of violent feuds between communities, and that these have continued to be on the increase in Nigeria. Other inquiries on the region's development experience further elongate the list of studies that fan the embers of the argument linking conflicts in Nigeria and Africa directly to land and natural resources found therein [24, 27, 28, 37, 41, 47, 48].

While not differing from the foregoing theoretical stance, other scholars [27, 49-51] talk rather specifically of "ecological resources" in their account of causes of conflicts in the region. As such, the case of natural resource conflicts in North-Central Nigeria has been used to exemplify this ideological interpretation contending that natural resource conflict is more dispersed than sociopolitical conflict. Natural resource conflicts usually occur, the study argues, in inaccessible hinterlands and often go unreported regardless of the fact that such conflicts are "...an important factor in the recurrent food crises characteristic of sub-Saharan Africa, since it deters those in rural areas from investing for increased production" [52].

Focusing on age-long conflict resolution mechanisms in Nigeria, and using the Mbaduku-Udam crisis bordering on territoriality to make a case, an extensive study [53] identifies "...land space and the resources available as one of the causes of...conflicts in Nigeria”. Not alone on that stance as other scholars $[54,55]$ also argue in the same light and conclude that territoriality in the sense of land area occupies centrality in inter-intra-ethnic conflicts adding that some of such conflicts date back to historical moments before the independence of Nigeria in 1960. One offers a deeper reason why conflicts rage around land: "The major occupation of most of ethnic groups who inhabit the North-Central Nigeria is farming. The need to acquire and use land for farming has, therefore, been at the root of several crises in this region" [51].

These ideologically differentiated accounts of conflict in Africa sometimes athwart each other seem to fall within the wider anatomic ambience captioned "Structural Causes of Conflict" by The Institute for Peace and Conflict Resolution of the Federal Republic of Nigeria [56]. According to the afore-cited institute, structural causes of conflict consists of four main manifestations including securityrelated manifestations of conflict further broken down into proliferation of small arms, corruption of law-enforcement agents, and vigilante groups; political manifestations of conflict including political conflicts, succession and dethronement 
conflicts, and territorial disputes; economic manifestations of conflict comprising general poverty and inequality, resource competition, unequal development, and market competition; and social manifestations of conflict including ethnic and communal conflict, youth unemployment, the situation of women, breakdown of social values, and psycho-cultural dispositions.

Varied and different as these contextually and ideologically driven accounts of conflicts in Nigeria and Africa seem, it is our argument that it would be an unsuccessful attempt at making any clear-cut differentiations at the level of causality in matters concerning conflicts in the region. Instead, from insights furnished by our study data and the findings they lead to, we argued that these shades of causes of conflict in Nigeria in particular and Africa at large are intricately interwoven so much that any attempts at understanding one must invariably make for understanding the rest. Even the IPCRFRN document earlier cited admits the intricate interconnectedness of causes of conflict across SSA.

\begin{abstract}
A particular conflict locale may exhibit the signs of more than one category (manifestation) of conflict The conflict in the Niger Delta, for instance, is an economic one (struggle for benefits derivable from an oil producing community), an ethnic/ communal one (the economic benefits...accrue to communities and the ownership of the land where the oil is located is therefore crucial to the enjoyment of benefits), a political one (political authorities must be those sympathetic to competing claims and all efforts to ensure that each party's candidate carries the day is put in), and one about traditional institution (the Urhobo and Ijaw contest of the claim of the Itshekiri to exclusive indigeneity of Warri and even the title of the paramount ruler of the Itshekiris as the Olu of Warri). Other conflicts in the country exhibit this multiple character trait. Actors in these multiple "battle fronts" are often the same [54].
\end{abstract}

It is easy to see the evidence-based persuasion behind the conclusion on the interconnectedness of causes of conflicts in Africa underscoring also that economic development is often accompanied by violent ethnic conflict. In light of the foregoing, therefore, this study refuses to be glued to only one explanatory mode in tracking the micro (agricultural development) and more so the macro (overall regional development) causes and impact of conflict in Nigeria and Africa at large. Not even the selective, persuasive argument that "Of all forms of group conflicts, it would seem that ethnic conflicts have remained the most entrenched and intractable in Nigeria" [24] seems ideologically compelling enough to sway the findings of our study in that direction. At least for now, we note that all forms of conflict in Nigeria and Africa as a whole as anywhere else in the world produce one common feature: conflicts halt human activities; they lead to stagnation of economic performance; and they bring about breakdown of social order and political stability necessary for any societies to function well. As these and many other studies have argued, this study infers that social disintegration and economic decline are the most probable outcomes of conflicts in Nigeria and Africa.

\title{
6. Conclusion
}

This study set out to make a case in favor of boosting agricultural productivity in Africa especially in conflict-prone agrarian environments in order to ultimately guarantee the contribution of the agriculture sector to the region's overall development. The main aim of the study was to inform and educate the general public but more so those who have positions of power in relation to peace and stability among African farming communities so that they could carry out their work without 
being disrupted by conflicts between and among themselves. The study sought evidence-based data to generate a body of scientific knowledge to achieve its set target. To carry out the experiment, we selected a Nigerian agrarian community we found as ideal and involved people from different sides of the dialogue on the agriculture-conflict interface to track how the impact of conflict ultimately affects Africa's development experience. To further enlighten ourselves on what we found from the field of ethnography, we consulted as many related studies we found relevant on the subject. Our project led to finding on how conflict amid agricultural production constitutes a most unfriendly environment ending in many very costly consequences for farmers and society at large.

This study found that intra-inter-ethnic conflicts in Nigeria as with other parts of Africa almost always revolve around land and resources related to land on the one hand, and that whereas conflict between communities and ethnic populations is unavoidable it has however become something so intricately entrenched in politicization by the elite from both sides of the warring camps, on the other. This, in itself, contributes to why no meaningful resolutions are achieved when communities lurk in conflict. This is besides the claim of many that the official government of the land does not seem to have any interest in installing and maintaining effective, responsive, sustainable conflict management apparatus. This makes people feel on edge especially in those areas that are characteristically conflict-prone. In line with the foregoing, it was found that the consequences associated with conflict amid agricultural production include loss of human lives and property; destruction of farmers' farms and granaries, looting of both farmers' and investors' assets; fall in agricultural productivity directly associated with fall in the area of land farmers cultivate; displacement of farming communities that usually end in unsafe refugee camps; hunger and malnutrition; high cost of agricultural and other goods; exposure to different diseases especially the endangering of women and young girls who are preyed upon and end up with sexually transmitted diseases (STDs) that further debilitate them; prolonged hold placed on education, medical and other social services; fear and horror in addition to protracted trauma and lasting psychological shock; increased outmigration especially by young adults who leave behind their vulnerable family members. The ultimate effect of all these impacts of conflict among conflicting farming populations is that they produce a constellation of drawbacks that militates against regional development in Africa. For, it takes healthy, able-bodied human beings operating in healthy, socially and politically stable environments to remain productive in what they do in order to develop themselves and develop their communities. It takes healthy human beings who stay on in production and in self-development to realize and sustain the ideals of development in Africa, all of which is in keeping with the defined ideals of the democracy of development in Africa and everywhere.

It is our conclusion, therefore, that where and when farming communities lurk in conflict over land and related resources, everything comes to a halt as their communities separately yet collectively stop growing especially in situations when government leaders take too long to take action and sometimes none at all, as our observations so far suggest. We suspend all policy-related recommendations at this time till more is done on this ongoing study. As such we project ourselves into other desired but yet unexplored aspects of this study including but not limited to engaging government officials in conversation beyond what is said in official publications; spending more time with farmers for more detailed data collection on statistical figures in light of the human and social cost of conflict in order to better inform policy recommendations. In pursuit of these goals, this self-sponsored study intends to involve more participants hoping to get to needed funds to break into these new grounds. 


\section{A.Appendix}

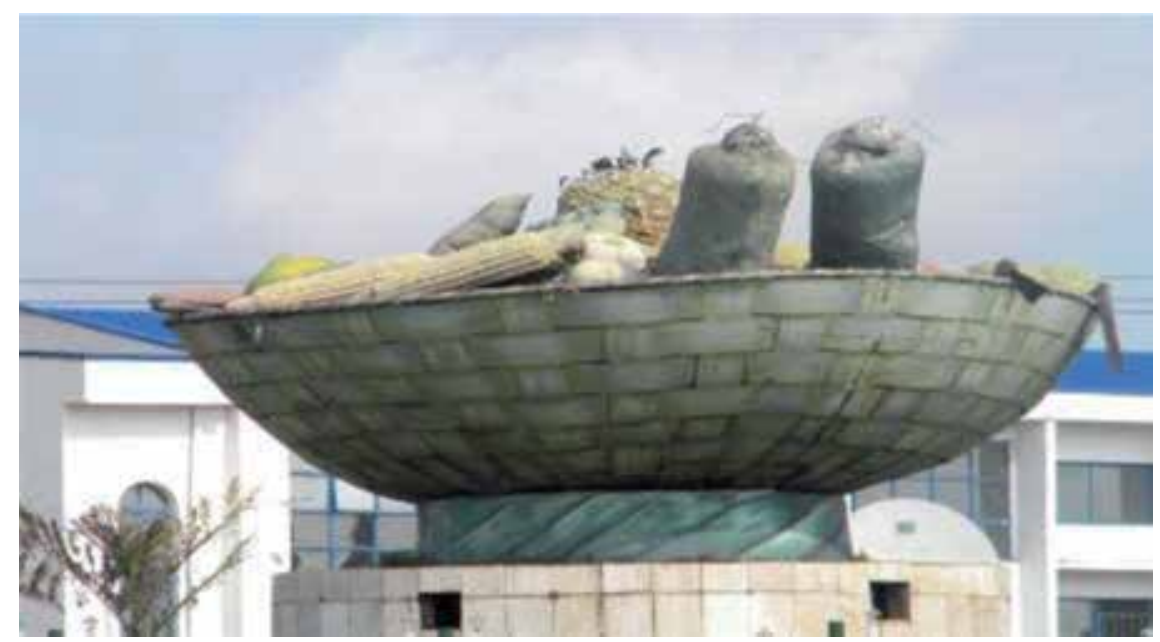

Figure A1.

Symbol of Benue State Pride_- "Food Basket of the Nation" (the picture above was captured at Makurdi, Benue state capital on July 20, 2013 by the researcher).

\section{Author details}

Jude Uwaoma Nwachukwu

Teachers College, Columbia University, New York, USA

*Address all correspondence to: jun2101@tc.columbia.edu

\section{IntechOpen}

(C) 2020 The Author(s). Licensee IntechOpen. This chapter is distributed under the terms of the Creative Commons Attribution License (http://creativecommons.org/licenses/ by/3.0), which permits unrestricted use, distribution, and reproduction in any medium, provided the original work is properly cited. (cc) $\mathbf{B Y}$ 


\section{References}

[1] Connah G. Forgotten Africa: An Introduction to its Archaeology. New York: Routledge; 2004. 39 p. ISBN: 0-415-30590-X (hbl)

[2] Kottak GP. Mirror for Humanity: A Concise Introduction to Cultural Anthropology. USA: McGrawHill; 2007. 108 p. ISBN-13: 978-0-07-353090-1

[3] Hopkins R. Agriculture in Africa. Available from: file://C:/Users/ fadau/AppData/Local/Microsoft/ Windows/INetCache/IE/JQ1QAUJ2/ Agriculture\%20i n\%20Africa\%20002.pdf

[4] Ake C. Democracy and Development in Africa. Washington, DC: The Brookings Institution; 1996.45 p. ISBN: 0-8157-0220-5

[5] Ake C. Democracy and Development in Africa. Washington, DC: The Brookings Institution; $1996.52 \mathrm{p}$. ISBN: 0-8157-0220-5

[6] Nwafor M, Eboh E, Chukwu J, Amuka J. Cost-effective agriculture growth options for poverty reduction in nigeria: evidence and policy implications. AIAE Research Paper 6. 2011;6:4-73. ISSN 079-4187

[7] Oyakhilomen O, Zibah R. Agricultural production and economic growth in Nigeria: Implication for rural poverty alleviation. Quarterly Journal of International Agriculture. 2014;53(3):207-223

[8] SESRTCIC. Statistical, Economic and Social Research and Training Center for Islamic Communities. 2007

[9] United Nations Millennium Development Project. Halving Hunger: It Can Be Done. Task Force on Hunger. London: Earthscan; 2005

[10] Delgado C, Mellor J. A structural view of policy issues in African development.
Agricultural and Applied Economics Association. 1984;66(5):665-670

[11] FAO. The State of Food Security and Nutrition in the World 2017: Building Resilience for Peace and Food Security. Rome: FAO; 2017. Available from: www. fao.org/3/a-I7695e.pdf

[12] UNICEF. The State of Food Security and Nutrition in the World 2017:

Building Resilience for Peace and Food Security. FAO: Rome; 2017. Available from: www.fao.org/3/a-I7695e.pdf

[13] Eicher C. Facing up to Africa's food crisis. Foreign Affairs. 1982;61(1):154-174

[14] United States Agency for International Development (USAID). Foreign Travel Data Sheet. 1997

[15] Morgan W, Jerzy S. Agricultural crisis in sub-Saharan Africa: Development constraints and policy problems. The Geographical Journal. 1994;160(1):57-73

[16] Easterly W, Levine R. Africa's growth tragedy: Policies and ethnic division. Quarterly Journal of Economics. 1997;112:1203-1250

[17] William R. What is Political Economy? Definitions and Characteristics. Available from: www. sagepub.com/sites/default/files/upmbinaries/26776_02_Mosco_Ch...22 p

[18] Preucel R, Hodder I, editors.

Contemporary Archaeology in Theory: A Reader. United Kingdom: Blackwell Publishing; 2004

[19] Ukum LGA. Profile of Ukum LGA of Benue State (A Handbook Manual of Ukum LGA). 2013

[20] Bohannan PL. Tiv Economy. Evanston: Northwestern University Press; 1968 
[21] Okoli A. VANGUARD Newspaper. Available from: https://www. vanguardngr.com/2018/04/10feared-dead-abia-cross-rivercommunal-clash-2/

\section{[22] Emeruwa C. DAILY POST}

Newspaper. Available from: http:// dailypost.ng/2018/04/28/boundarydispute-10-killed-abia-community/

\section{[23] Nwosu U. INDEPENDENT}

Newspaper. Available from: https: //www.independent.ng/tension-inarochukwu-over-alleged-murder-ofchief-by-utuma-people-of-cross-river/ 19 February 2019

[24] Rumun A. Implications of communal conflict on human health and corresponding indigenous conflict resolution styles in the contemporary Nigerian society. International Journal of Humanities and Social Science Invention. 2013;7(2):90-94

[25] Lincoln C. Health as a human security priority for the 21st century. Paper for Human Security Track 111. 2004

[26] United Nations Fund for Population Activities (UNFPA). 2001

[27] Onwuzuruigbo I. Causes and Management of Intra-Ethnic Conflict in Aguleri and Umuleri Communities, Southeastern Nigeria. Nigeria: University of Ibadan; 2009

[28] United Nations High Commissioner for Refugees (UNHCR). The State of the World's Refugees: Human Displacement in the New Millennium. 2006

[29] Okoli A, Atelhe G. Nomads against natives: A political ecology of herder/ farmer conflicts in Nasarawa State, Nigeria. American International Journal of Contemporary Research. 2014;2(4):72-88

[30] Aluaigba M. The Tiv-Jukun Ethnic Conflict and the Citizenship
Question in Nigeria. Bayero University, Kano-Nigeria: Amino Kano Centre for Democratic Research and Training; 2001

[31] Arias MA et al. Agricultural Production amidst Conflict: The Effects of Shocks, Uncertainty and Governance on Non-State Armed Actors. Working Paper

[32] World Bank. World Development Report 2008: Agriculture for Development. Washington, DC, World Bank; 2007

[33] Okere T, Njoku CA, editors. The Scramble for Africa: The Scramble Continues.

[34] Uwalaka J. The Struggle for an Inclusive Nigeria: Igbos to Be or Not to Be? Nigeria: Snaap Press; 2003

[35] Matlosa K. Democracy and conflict resolution in Africa: Challenges for postconflict reconstruction. Conflict Trends. 2006:9-15

[36] Achodo C. Conflict and post conflict patterns, issues, impact on economic development and poverty cycle in countries in Africa. African Forum on Poverty Reduction, Public Forum Paper. 2000. pp. 1-12

[37] Uchendu VC. The Igbo of

Southeast Nigeria. New York: Holt, Rinehart and Winston; 1965. ISBN-13: 978-0030524752

[38] Artadi E, Martin X. The economic tragedy of the XXth century: Growth in Africa. SNBER Working Paper. 2003

[39] Arnold G. Africa: A Modern History (1945-2015). Main: Atlantic Books.

ISBN-13: 9781786490360

[40] Alimba C. Probing the dynamic of communal conflict in Northern Nigeria. An Interdisciplinary Journal, Ethiopia. 2014;32(1):177-204 
[41] Rumun A. Implications of communal conflict on human health and corresponding indigenous conflict resolution styles in the contemporary Nigerian society. International Journal of Humanities and Social Science Invention. 2013;2(7):90-94

[42] Adesoji A, Alao A. Indigeneship and citizenship in Nigeria: Myths and the realities. The African Symposium. 2008;8(2):97-107

[43] Marietu TO, Olarewaju IO. Resource conflict among farmers and Fulani herdsmen: Implications for resource sustainability. African Journal of Political Science and International Relations. 2009;3(9):360-364

[44] Kimenyi M, Adibe J, Djire M, Jirgi AJ, Kergna A, Deressa TT, et al. The impact of conflict and political instability on agricultural investments in Mali and Nigeria. Africa Growth Initiative Working Paper. 2014;17:1-60

[45] Albert IO. Building Peace, Advancing Democracy: Experience with Third-Party Interventions in Nigeria's Conflict. Ibadan: John Achers (Publishers) Ltd; 2001

[46] Okoli AC. The political ecology of the Niger Delta Crisis and the prospects of lasting peace in the post-amnesty period. Global Journal of Human Social Sciences. 2013;13(3:1):37-46

[47] Ibeanu O. Aguleri/Umuleri conflict in Anambra State. In: Akinyele RT, editor. Boundary Disputes and Natonal Integration in Nigeria, Contemporary Issues in Boundaries and Governance in Nigeria. Lagos: Frankard Publishers; 2005. p. 2008

[48] United Nations Development Program (UNDP). Conflict in the Middlebelt Region of Nigeria: Engendering Peace in Agila Community. Abuja-Nigeria: Women Environmental Program (WEP); 2009
[49] Suhrke A. Environmental change, migration and conflict: A lethal feedback dynamic? In: Crocker C, Hampson F, Aall P, editors. Managing Global Chaos II. Washington, DC: United States Institute for Peace Press; 1996

[50] Baechler G. Why environmental transformation causes violence: A synthesis. Environmental Change and Security Projects ${ }^{1}$ of the Woodrow Wilson Centre. 1998;4

[51] Gleditsch NP. Environmental, change, security and conflict. In: Hampson CCF, Aall P, editors. Managing Global Chaos II. Washington, DC: United States Institute for Peace Press; 2001

[52] Blench R. Natural Resource Conflict in North-Central Nigeria: A Handbook and Case Studies. Cambridge: Mallam Dendo Ltd.; 2004

[53] Gbenda JS. Age-long land conflicts in Nigeria: A case for traditional peacemaking mechanisms in Ubuntu. Journal of Conflict Transformation. 2012;1.1(1\&2):156-176

[54] Alubo O. Nigerian Ethnic Conflicts and Citizenship Crises in the Central Region. Ibadan: PEFS; 2006

[55] Ayua IA. The historic and legal roots of conflicts in the benue valley. In: Gyuse TT, Ajene O, editors. Conflicts in the Benue Valley. Makurdi: Selfers Books; 2006

[56] The Institute for Peace and Conflict Resolution of the Federal Republic of Nigeria (IPCRFRN). 2003 


\title{
The Role of International Donors in Aquaculture Development in Africa
}

\author{
Olufemi Julius Olapade
}

\begin{abstract}
Aquaculture, one of the fastest food production sectors in the world, has received and continues to receive funding from international donors and funding agencies since its introduction in Africa. The sector plays a key role in many emerging economies because of its potential to contribute to increased food production and at the same time help reduce pressure on fish resources. In spite of huge natural resources and a high demand for fish and fishery products, aquaculture production in Africa has yet to catch up with major players globally. Increased aquaculture production is hoped will greatly complement current efforts aimed at achieving the United Nations Millennium Development Goals (MDGs), especially the eradication of extreme poverty and hunger, reduction in child mortality, improvement of maternal health, prevention of diseases, promotion of gender equity and women empowerment. Africa however is the only region of the world where the present level of per capita fish consumption has declined over the past decades as populations grow. Researchers have adduced reasons for the setback to the development of Africa aquaculture. The unanswered question however is "Has donors' support further the course of aquaculture development in Africa?"
\end{abstract}

Keywords: aquaculture, sub-Sahara Africa, farmers, international donors, constraints

\section{Introduction}

The aquaculture sector perceived as supplementary or alternative economic activity to the capture fishery is fast gaining ground globally [1]. It is the fastestgrowing food-producing sector in the world [1]. The sector has a potential of relieving the pressure on fish stocks, as well as filling the increasing supply-demand gap for marine fishes [2]. Aquaculture, the culture of aquatic animals and plants in fresh, brackish, and marine environments [3], plays major roles in providing food, employment, and foreign exchange earnings. Pillay [4] noted that aquaculture has potential to increase rural employment and improve the nutrition and income of rural population, especially in developing countries. Besides, the sector is expected to continue to strengthen its role in contributing to food security and poverty alleviation in many developing countries [5]. Development agencies world over have muted aquaculture integrated with agriculture (crop and animal farming) as the rational option for the development of poor economies, especially the third-world 
economy. The Code of Conduct for Responsible Fisheries (CCRF) muted aquaculture as a means to promoting the diversification of income and diet [6]. Other important factor that is drawing attention to aquatic farming is the need to achieve greater self-reliance in food production and greater balance of international trade. Declining catches from capture fisheries and the increasing demand for fish and fishery products lend clarion call for the urgent need to develop the aquaculture sector. The sector production potential is however huge and its capacity to contribute to increase in world's production of aquatic food is enormous and incontrovertible [5]. This production potential was evident in 2002 when fishfood production (fish, mollusks, and crustacean) yielded 36 million tonnes and production from aquatic plants gave 10 million tonnes [7] (Figure 1).

The top six major aquaculture producers are from Asia with China leading the pack in global aquaculture production. Production of fishfood including plants from low-income food deficient countries (LIFDCs) is greater than or equal to 38 million tonnes and production from these countries has been growing at an average compound rate of $9.2 \%$ since 1970 . This reported growth rate compares significantly with the $1.4 \%$ for capture fisheries and $2.8 \%$ for terrestrial farmed production systems [1].

On the global scale, especially between 1991 and 2000, according to FAO [7], fishfood production from aquaculture increased by a factor of $2.5 \%$. It is anticipated that the percentage increase will be furthered with the right environment and financing. Bolton [8] observed that only 550,000 tonnes of aquatic animals were grown in 2014 in sub-Saharan Africa. This production comprised of freshwater fish, mainly catfish, Tilapia and Nile Perch, which according to Bolton [8] is less than $1 \%$ of the world production. The leading freshwater fishfood producers in the region are Nigeria and Uganda [8].

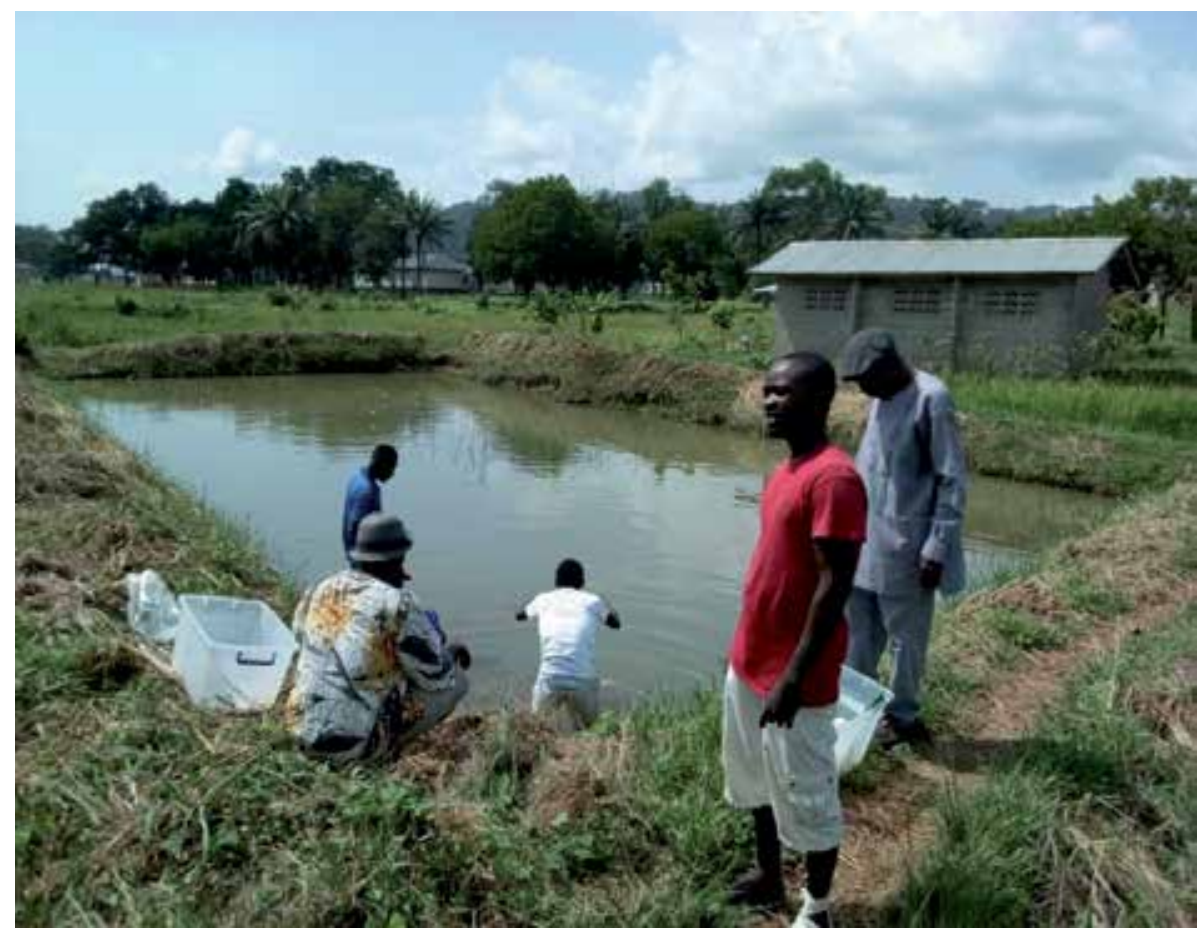

Figure 1.

A typical international donor-funded rural poor intervention in Sierra Leone. 
It is important to mention that in spite of Africa's natural endowment, her per capita fish consumption has dropped to almost half of the global average. Aquaculture provides only $2 \%$ of the region's supply and makes only a minor contribution to economic growth, employment, and foreign exchange. Realizing the role of aquaculture as an engine for improved food security and economic growth in Africa, FAO Committee on Fisheries (COFI) placed high priority on it as an investment area. Investment in aquaculture in sub-Saharan Africa has even become more attractive because of the development of domestic and export markets for fish, changing macroeconomic environments, and the stagnation of inland capture fisheries. As people become more aware of the benefits inherent in investing in aquaculture, private investment in commercial fish farming is on the increase in a number of African countries namely, Nigeria, South Africa, Kenya, Malawi, Namibia, Zimbabwe, and Egypt.

In a bid to further the development of aquaculture in Africa, FAO introduced an innovative program tagged-the Special Programme for Aquaculture Development in Africa (SPADA). The program among its many objectives aims to provide assistance to African countries to enhance aquaculture production, facilitate producers' access to financial services and markets, promote user-friendly regulatory frameworks, boost investment in aquaculture as well as exchange of knowledge. The program's agenda is in line with the priorities set by The New Partnership for Africa's Development (NEPAD) Action Plan for the Development of African Fisheries and Aquaculture. It is unarguable that investment in African fisheries and aquaculture has been remarkably low. Therefore, if fisheries and aquaculture are to meet expected economic and social benefits, meet the challenges of technological change, institutional reforms, and resource mobilization needed in support of the sector's development potential, there is the need for all concerned with the development of the sector to make the case for investment within the context of wider socioeconomic development. The objective of this chapter is to provide an overview of aquaculture production in the subregion and to evaluate the roles of international donors against the backdrop of aquaculture development in subSaharan Africa.

\subsection{Trend in global aquaculture production}

The global growth rate of aquaculture for more than 50 years has been dynamic and encouraging. Its average annual growth rate between 1970 and 2000 was $9.2 \%$, compared to only $2.8 \%$ for terrestrial farmed meat production systems [1]. Freshwater fish farming is on the increase globally for the production of fishfood [7]. The story is not different from what is obtained from the marine waters. Fishfood production from the marine waters has increased from $32 \%$ in 1991 to $36 \%$ in 2000. Production from the marine and brackishwater represents a higher proportion of the global total value of aquaculture than in freshwater (54\% in 1991 and 51\% in 2000). Of the total foodfish produced from marine and brackishwater in 2000, 81\% was from Asia, while $11 \%$ was produced in Europe. The value of 35.6 million tonnes of fishfood (fish, crustaceans, and mollusks) produced in 2000 was estimated to be US\$ 51 billion. Significant proportion of the production (89\%) valued at US\$ 40.8 billion was produced by Asian farmers. This was an indication that Asia appears to be dominating aquaculture production globally [7] (Table 1).

Global foodfish production from aquaculture in 2016 witnessed a meteoric increase from 25.7 to $46.8 \%$. Aquaculture production (aquatic plants included) in 2016 was 110.2 million tonnes, valued at estimated US\$243.5 billion. This production statistics comprise of 80.0 million tonnes of foodfish valued at 
Regional Development in Africa

\begin{tabular}{|c|c|c|c|c|c|c|}
\hline Region/selected countries & 1995 & 2000 & 2005 & 2010 & 2015 & 2016 \\
\hline \multirow[t]{2}{*}{ Africa } & 110 & 400 & 646 & 1286 & 1772 & 1982 \\
\hline & $0.5 \%$ & $1.2 \%$ & $1.5 \%$ & $2.2 \%$ & $2.3 \%$ & $2.5 \%$ \\
\hline \multirow[t]{2}{*}{ Egypt } & 72 & 340 & 540 & 920 & 1175 & 1371 \\
\hline & $0.3 \%$ & $1.1 \%$ & $1.2 \%$ & $1.6 \%$ & $1.5 \%$ & $1.7 \%$ \\
\hline \multirow{2}{*}{$\begin{array}{l}\text { Northern Africa, excluding } \\
\text { Egypt }\end{array}$} & 4 & 5 & 7 & 10 & 21 & 23 \\
\hline & $0 \%$ & $0 \%$ & $0 \%$ & $0 \%$ & $0 \%$ & $0 \%$ \\
\hline \multirow[t]{2}{*}{ Nigeria } & 17 & 26 & 56 & 201 & 317 & 307 \\
\hline & $0.1 \%$ & $0.1 \%$ & $0.1 \%$ & $0.3 \%$ & $0.4 \%$ & $0.4 \%$ \\
\hline \multirow{2}{*}{$\begin{array}{l}\text { Sub-Sahara Africa, Excluding } \\
\text { Nigeria }\end{array}$} & 17 & 29 & 43 & 156 & 259 & 281 \\
\hline & $0.1 \%$ & $0.1 \%$ & $0.1 \%$ & $0.3 \%$ & $0.3 \%$ & $0.4 \%$ \\
\hline \multirow[t]{2}{*}{ Americas } & 920 & 1423 & 2177 & 2514 & 3274 & 3348 \\
\hline & $3.8 \%$ & $4.4 \%$ & $4.9 \%$ & $4.3 \%$ & $4.3 \%$ & $4.2 \%$ \\
\hline \multirow[t]{2}{*}{ Chile } & 157 & 392 & 724 & 701 & 1046 & 1035 \\
\hline & $0.6 \%$ & $1.2 \%$ & $1.6 \%$ & $1.2 \%$ & $1.4 \%$ & $1.3 \%$ \\
\hline \multirow{2}{*}{$\begin{array}{l}\text { Rest of Latin America and the } \\
\text { Caribbean }\end{array}$} & 284 & 447 & 785 & 1154 & 1615 & 1667 \\
\hline & $1.2 \%$ & $1.4 \%$ & $1.8 \%$ & $2.0 \%$ & $2.1 \%$ & $2.1 \%$ \\
\hline \multirow[t]{2}{*}{ North America } & 479 & 585 & 669 & 659 & 613 & 645 \\
\hline & $2.0 \%$ & $1.8 \%$ & $1.5 \%$ & $1.1 \%$ & $0.8 \%$ & $0.8 \%$ \\
\hline \multirow[t]{2}{*}{ Asia } & 21,678 & 28,423 & 39,188 & 52,452 & 67,881 & 71,546 \\
\hline & $88.9 \%$ & $87.7 \%$ & $88.5 \%$ & $81.0 \%$ & $89.3 \%$ & $89.4 \%$ \\
\hline \multirow[t]{2}{*}{ China mainland } & 15,856 & 21,522 & 28,121 & 36,734 & 47,053 & 40,244 \\
\hline & $65.0 \%$ & $66.4 \%$ & $63.5 \%$ & $62.3 \%$ & $61.9 \%$ & $61.5 \%$ \\
\hline \multirow[t]{2}{*}{ India } & 1659 & 1943 & 2967 & 3786 & 5260 & 5700 \\
\hline & $6.8 \%$ & $6.0 \%$ & $6.7 \%$ & $6.4 \%$ & $6.9 \%$ & $7.1 \%$ \\
\hline \multirow[t]{2}{*}{ Indonesia } & 641 & 789 & 1197 & 2305 & 4343 & 4950 \\
\hline & $2.6 \%$ & $2.4 \%$ & $2.7 \%$ & $3.9 \%$ & $5.7 \%$ & $6.2 \%$ \\
\hline \multirow[t]{2}{*}{ Vietnam } & 381 & 499 & 1437 & 2683 & 3438 & 3625 \\
\hline & $1.6 \%$ & $1.5 \%$ & $3.2 \%$ & $4.6 \%$ & $4.5 \%$ & $4.5 \%$ \\
\hline \multirow[t]{2}{*}{ Bangladesh } & 317 & 657 & 882 & 1309 & 2060 & 2204 \\
\hline & $1.3 \%$ & $2.0 \%$ & $2.0 \%$ & $2.2 \%$ & $2.7 \%$ & $2.8 \%$ \\
\hline \multirow[t]{2}{*}{ Rest of Asia } & 2824 & 3014 & 4584 & 5636 & 5726 & 5824 \\
\hline & $11.6 \%$ & $9.3 \%$ & $10.4 \%$ & $9.6 \%$ & $7.5 \%$ & $7.3 \%$ \\
\hline \multirow[t]{2}{*}{ Europe } & 1581 & 2051 & 2135 & 2523 & 2941 & 2945 \\
\hline & $6.5 \%$ & $6.3 \%$ & $4.8 \%$ & $4.3 \%$ & $3.9 \%$ & $3.7 \%$ \\
\hline \multirow[t]{2}{*}{ Norway } & 278 & 491 & 662 & 1020 & 1381 & 1326 \\
\hline & $1.1 \%$ & $1.5 \%$ & $1.5 \%$ & $1.7 \%$ & $1.8 \%$ & $1.7 \%$ \\
\hline \multirow[t]{2}{*}{ EU-28 } & 1183 & 1403 & 1272 & 1263 & 1264 & 1292 \\
\hline & $4.9 \%$ & $4.3 \%$ & $2.9 \%$ & $2.1 \%$ & $1.7 \%$ & $1.6 \%$ \\
\hline
\end{tabular}


The Role of International Donors in Aquaculture Development in Africa DOI: http://dx.doi.org/10.5772/intechopen.86569

\begin{tabular}{lcccccc}
\hline Region/selected countries & $\mathbf{1 9 9 5}$ & $\mathbf{2 0 0 0}$ & $\mathbf{2 0 0 5}$ & $\mathbf{2 0 1 0}$ & $\mathbf{2 0 1 5}$ & $\mathbf{2 0 1 6}$ \\
\hline Rest of Europe & 121 & 157 & 201 & 240 & 297 & 327 \\
\hline \multirow{2}{*}{ Oceania } & $0.5 \%$ & $0.5 \%$ & $0.5 \%$ & $0.4 \%$ & $0.4 \%$ & $0.4 \%$ \\
\hline & 94 & 122 & 152 & 187 & 186 & 210 \\
\hline World & $0.4 \%$ & $0.4 \%$ & $0.3 \%$ & $0.3 \%$ & $0.2 \%$ & $0.3 \%$ \\
\hline
\end{tabular}

Table 1.

Aquaculture food fish production by region and selected major (1995-2016) producers (thousand tonnes; percentage of world total).

US\$231.6 billion and 30.1 million tonnes of aquatic plants valued at US\$ 11.7 billion, in addition was 37,900 tonnes of non-food products valued at US\$214.6 million. Production statistics from farmed food fish was 54.1 million tonnes of finfish (USD 138.5 billion), 17.1 million tonnes of mollusks (USD 29.2 billion), 7.9 million tonnes of crustaceans (USD 57.1 billion), and 938,500 tonnes of other aquatic animals (USD 6.8 billion) such as turtles, sea cucumbers, sea urchins, frogs, and edible jellyfish. The aquatic plants captured in the production data compose mainly seaweeds and some volume of microalgae while the non-food products were mainly ornamental shells and pearls. The production statistics presented in this review are incomplete, as about $35-40 \%$ of the producing countries did not report to FAO and this has made it impossible to present a more detailed information on the status and development trends of world aquaculture. Information presented in this review was based on the data FAO received from 120 nations in 2016. This data represent 84.3\% (67.5 million tonnes, aquatic plants excluded) of foodfish produced by volume globally; this includes production from China. According to FAO, production figure for the non-reporting countries was estimated at 15.1\% (12.1 million tonnes) of the total production in 2016.

Inland, marine, and coastal waters contribute significantly to global aquaculture production volumes. Inland fish farming, which is practiced in freshwater environment using different culture facilities, was the source of 51.4 million tonnes (64.2\%) of the world's farmed foodfish production-the 2016 production was higher than the $57.9 \%$ reported for 2000 . Finfish farming still dominates inland aquaculture, accounting for $92.5 \%$ (47.5 million tonnes) of total production from inland aquaculture. This production has however dropped when compared to $97.2 \%$ reported in 2000; this is believed to be caused by high interest in the farming of other species such as shrimps, crayfish, and crabs by farmers in Asia. Most of the data obtained from several major producing countries in East and Southeast Asia are for finfish farmed in marine cages and coastal ponds. Asia is the most productive continent in marine and brackishwater environment (12.2 million tonnes) and China was the highest producing country in the continent producing 9.4 million tonnes in total production. The annual average rate of growth in the production of food fish in marine waters between 1991 and 2000 was $12.6 \%$ and this was greater than what was obtained in other environments. The growth rate in the brackishwater was much less at $4.2 \%$. For mariculture and coastal aquaculture combined, FAO reported 28.7 million tonnes of fishfood valued at US\$ 67.4 billion in 2016.

In sharp contrast to the dominance of finfish in inland aquaculture, shelled mollusks (16.9 million tonnes) constitute $58.8 \%$ of the combined production of marine 
and coastal aquaculture. Finfish (6.6 million tonnes) and crustaceans (4.8 million tonnes) together were responsible for $39.9 \%$.

\section{Overview of aquaculture development in Africa}

Brummett et al. [9] enunciated briefly the history of aquaculture as a baby born in due time by the then colonial masters who conceived it as a viable means of food production. The history of the development of aquaculture in Africa dated back to the 1940s and 1950s when the colonial masters first introduced it, and since then it has come a long way [10]. Culture of indigenous species dominated the initial efforts of the colonial lords and appropriate culture technology was equally introduced through basic research as a way of entrenching aquaculture in Africa. The gains of the early investment especially with respect to the ponds and research stations established in many African countries during the initial investment periods were soon abandoned when African government's attention and interest shifted to the development of other sectoral priorities. These discouraging scenarios however did not alter the development of the perceived potential of aquaculture in Africa. This was evidenced by its adoption between the 1970s and 1990s by a number of international donor agencies as a tool in rural food security and economic development. The development of the sector was consequently according to Pillay [11] taking over from government by the donors. The actual culture attempt in Africa was the successful trial of Tilapia in the Democratic Republic of Congo in 1946 [12]. The success of the project stimulated high interest in aquaculture and this no doubt led to the establishment of about 300,000 production ponds in many African countries by the close of the 1950s [13]. In addition, a handful of aquaculture projects were also introduced in the 1970s and 1980s. The aim of the projects was to grow fish to close the supply gap with farm-raised fish and/or bolster sagging economies with high-value aquaculture products. The promotion of aquaculture in the early 1980s within the context of integrated aquaculture to address sociocultural and economic issues by some international development agencies and advanced research institutes has resulted in sustained aquaculture growth in handful of African countries, such as Côte d'Ivoire, Egypt, Ghana, Malawîi, Nigeria, and Zambia. Effort in this direction is contributing significantly to boost the growth of the sector. The dwindling catches from inland capture fisheries in sub-Saharan Africa and the development of domestic and export markets for fish has made investment in aquaculture attractive.

Countries like Côte d'Ivoire, Madagascar, Malawi, Nigeria, and Zambia now have well-established aquaculture programs for the promotion of investment in aquaculture. Investment in commercial aquaculture by individuals has been reported in Egypt, Kenya, Namibia, Nigeria, Malawii, South Africa, and Zimbabwe (Table 2). South Africa is unarguably the leading country in mariculture in Africa. It is important to note that although the growth of aquaculture in Africa is encouraging, when it is compared to the rest of the world, production from the region is still insignificant. According to FAO [14], the production from Africa is only about $0.9 \%$ (404,571 tonnes) of the global aquaculture production. Growth in the sector in terms of aquaculture expansion, increases in production, and income generation has been disappointing. The aquaculture in sub-Saharan Africa has been constrained by a number of problems ranging from reduced access to capital and markets, inadequacy of good feed and seeds, and reduced access to good-quality information or appropriate technologies. Consequently, for African aquaculture to meet its anticipated potential and compete well with production from countries like China, the bottlenecks constraining its development need to be removed as a matter of urgency. 
The Role of International Donors in Aquaculture Development in Africa DOI: http://dx.doi.org/10.5772/intechopen.86569

\begin{tabular}{lccccccc}
\hline Country & $\mathbf{2 0 0 8}$ & $\mathbf{2 0 0 9}$ & $\mathbf{2 0 1 0}$ & $\mathbf{2 0 1 1}$ & $\mathbf{2 0 1 2}$ & $\mathbf{2 0 1 3}$ & $\mathbf{2 0 1 4}$ \\
\hline Nigeria & $\mathbf{1 4 3 , 2 0 7}$ & $\mathbf{1 5 2 , 7 9 6}$ & $\mathbf{2 0 0 , 5 3 5}$ & 221,128 & 253,898 & 278,706 & 313,231 \\
\hline Uganda & 52,250 & $\mathbf{7 6 , 6 5 4}$ & 95,000 & 85,713 & 95,906 & 98,063 & 111,023 \\
\hline Ghana & 5594 & 7154 & 10,200 & 19,092 & 27,450 & 32,513 & 38,545 \\
\hline Kenya & 4452 & 4895 & 12,154 & 22,135 & 21,488 & 23,501 & 24,098 \\
\hline Zambia & 5640 & 8505 & 10,290 & 10,530 & 12,988 & 20,271 & 19,281 \\
\hline Madagascar & 10,836 & 6116 & 6886 & 8845 & 8585 & 8974 & 8470 \\
\hline South Africa & 3587 & 3433 & 3133 & 3572 & 3999 & 4010 & 4160 \\
\hline Other & 14,001 & 14,426 & 17,917 & 24,898 & 28,380 & 33,683 & 38,142 \\
\hline Total & 239,567 & 273,979 & 356,115 & 395,913 & 452,697 & 499,721 & 556,950 \\
\hline
\end{tabular}

Table 2.

Top seven aquaculture producers in sub-Saharan Africa from 2008 to 2014 by quantity (in tonnes) [15, 16].

\subsection{Constraints of aquaculture in Africa}

Aquaculture has a huge potential to grow in sub-Saharan Africa. The rural economy of most African countries hinges on subsistence cropping and extensive livestock grazing and this according to experts augurs well for the development of aquaculture in the region. Aquaculture as an agricultural activity must necessarily compete with other crops for basic inputs such as land, water, and nutrient and as such, its growth is dependent on its ability to compete and meet related challenges. These related challenges have made the sector to underperform over years despite the quantum of money invested by private operators and international donors. In addition, since most of the farmers operate small-scale aquaculture enterprises, there is the need to carry out an assessment of their needs, priority, and aspirations. The poor performance of the sector has also been linked to the lack of proper understanding of existing challenges in the sector, which are presumed to be location and agroecology specific. According to Brummett et al. [9], the food security and economic growth benefits of aquaculture can only be fully realized if the challenges confronting the sector are addressed and nipped. These challenges, Brummett et al. [9] noted, are not different from those facing other commercial enterprises. Satia [13], Coche [16], Costa-Pierce [17], and Coche and Pedini [18] elaborated on key constraints of the African aquaculture sector. Coche et al., [19], Williams [20], UNDP [21], and Lazard et al. [22] identified poor infrastructure, volatile prices of essential inputs, political instability, and lack of the necessary R\&D to backstop industrial growth as challenges respectively. Hetch [23] and Masser [24] jointly identified poor market development as one of the key constraints of the sector. Other key constraints identified by CIFA/ OP24 [26] as presented by Brummett et al. [9] include unavailability of good-quality fingerlings for stocking; unavailability of complete feeds; inadequate access to technical information; lack of marketing infrastructure, information, and organization; and inappropriate policies. These are however not quite different from what previous researchers in the field had elaborated, especially the ones compiled by the Africa Regional Aquaculture Review Meeting [28] (Table 3). Experiences gathered from different projects in some African countries clearly showed that improper alignment of internationally funded projects to local needs and ecology, government bureaucracies, and misapplication of grants by beneficiaries are issues that require serious attention if African aquaculture is to emerge from the woods. Other important issues to contend against are the rashness and hastiness of donors to achieve results not minding the sustainability factor and the expected long-term impact of the intervention. It is also important to mention here that significant portion of funds earmarked 


\begin{tabular}{|c|c|c|c|}
\hline \multirow[t]{2}{*}{ Issue } & \multicolumn{2}{|l|}{ Category } & \multirow[t]{2}{*}{ Researchers } \\
\hline & Small-scale system & Medium and large systems & \\
\hline Policy & Lack of clear policy & Lack of clear policy & [27] \\
\hline $\begin{array}{l}\text { Government } \\
\text { support }\end{array}$ & Poor & Poor & [27] \\
\hline $\begin{array}{l}\text { Research and } \\
\text { extension linkages }\end{array}$ & Weak & Weak or nonexistent & [27] \\
\hline $\begin{array}{l}\text { Research and } \\
\text { development } \\
\text { linkages }\end{array}$ & Weak & Weak or nonexistent & [23] \\
\hline Technical support & $\begin{array}{l}\text { Often inappropriate, lack of } \\
\text { flexibility }\end{array}$ & Inadequate & [27] \\
\hline Donor support & Donor dependence & Little provided to date & [27] \\
\hline Infrastructure & Poor or nonexistent & $\begin{array}{l}\text { Generally poor and often } \\
\text { inadequate }\end{array}$ & [20] \\
\hline $\begin{array}{l}\text { Prices of essential } \\
\text { inputs }\end{array}$ & Lacking, or volatile prices & Volatile & [2] \\
\hline Political instability & $\begin{array}{l}\text { Capable of disrupting } \\
\text { investment }\end{array}$ & $\begin{array}{l}\text { Capable of disrupting } \\
\text { investment }\end{array}$ & [22] \\
\hline Credit availability & $\begin{array}{l}\text { Generally not available and } \\
\text { needs questionable }\end{array}$ & $\begin{array}{l}\text { Necessary but often unavailable, } \\
\text { or difficult to access }\end{array}$ & [27] \\
\hline $\begin{array}{l}\text { Market } \\
\text { development }\end{array}$ & Poor or nonexistent & Poor or nonexistent & {$[24,25]$} \\
\hline Seed supply & $\begin{array}{l}\text { Insufficient and often } \\
\text { dependent on public sector, } \\
\text { little selection practiced }\end{array}$ & $\begin{array}{l}\text { Generally provided on farm, } \\
\text { monosex or hybridization } \\
\text { practiced by some farmers }\end{array}$ & [27] \\
\hline Feed supply & $\begin{array}{l}\text { Frequently inadequate (in } \\
\text { quality and or quantity) } \\
\text { supplemental feeds }\end{array}$ & $\begin{array}{l}\text { Generally provided on farm, } \\
\text { complete feed preferred }\end{array}$ & [27] \\
\hline Extension systems & $\begin{array}{l}\text { Lack of farmer participation, } \\
\text { inadequate support, few } \\
\text { technicians }\end{array}$ & Often neglect larger producers & [27] \\
\hline Data collection & $\begin{array}{l}\text { Poor and often unreliable, } \\
\text { farms dispersed, often } \\
\text { isolated }\end{array}$ & $\begin{array}{l}\text { On-farm data generally } \\
\text { collected but sometimes } \\
\text { inaccessible }\end{array}$ & [27] \\
\hline $\begin{array}{l}\text { Information } \\
\text { management }\end{array}$ & $\begin{array}{l}\text { Networking practically } \\
\text { nonexistent, group } \\
\text { formation desirable but often } \\
\text { inadequate }\end{array}$ & $\begin{array}{l}\text { Poor information exchange and } \\
\text { communications }\end{array}$ & [27] \\
\hline
\end{tabular}

Table 3.

Constraints of small-scale, medium, and large-scale aquaculture.

for project implementation in Africa are often spent to hire foreign experts who at times are not better than local experts who could be cheaply hired. These situations do not augur well for the development of aquaculture in sub-Sahara Africa.

\subsection{International donors' contribution to African aquaculture development}

The pace of the development of aquaculture in Africa is still slow despite the huge amount of money that has been invested by international donors and 
development agencies over the past 40 years. The sector has failed to realize its expected potential of enhanced food security and engender economic growth predicted by development agencies. Weak institutional arrangement and donordriven projects were presumed responsible for the slow growth rate of the sector. Brummett et al. ([9], p. 373) already asked the all-important question, "Who is in charge of supporting African aquaculture?;" and the next important question to ask is "Why the failure of the African aquaculture sector and what is or are the actual role(s) of international donors and funding agencies?"

Total external assistance to aquaculture development between 1978 and 1983 is estimated at $\$ 368$ million [27]. Josupeit [27] noted that $\$ 190$ million (52\%) of the fund originated from the three major international development banks including World Bank, ADB, and IADB. Development assistance to aquaculture in this period increased from 8.5 to $17.5 \%$ of the total allocated to the fisheries sector. Between 1978 and 1984, Hecht [23] reported that African aquaculture received some \$72.5 million while Asia and the Pacific received in the same period $\$ 171.3$ million, which was almost three times of what Africa received. Asian countries in the reporting period utilized the fund received to produce 1000 times more fish than Africa. The reason behind the disparity in volume produced was obvious. Between 1987 and 1997, global investment in aquaculture was estimated at $\$ 75$ billion, and between 1974 and 2006, the combined World Bank Group (which include the IFC) investment in aquaculture-related projects was about $\$ 1$ billion. One example of the funding for aquaculture made by IFC is presented in Table 4.

Moehl et al. [25] opined that money received by most of the African countries from international donors and funding agencies was invested in nonperforming infrastructure like the establishment of hatcheries and government stations; for instance, the establishment of the African Regional Aquaculture Centre (ARAC) in Port Harcourt, Nigeria and the Central Laboratory for Aquaculture Research (CLAR) in Abbassa, Egypt. Many other gargantuan aquaculture facilities' installation failed just as others previously mentioned. The failure of these facilities to produce positive or sustainable outcomes according to Moehl et al. [25] is an indication of how poorly aquaculture has been managed in Africa.

Government fish farms established in many African countries with international donors' support during the 1960s and 1970 and even after are in bad shapes and operating below capacity. Poor site selection probably motivated by political concerns, lackluster project design, and inability of government to maintain and continue with the farm operations after the exit of the external donors are some of the perceived problems of aquaculture in Africa. The roles of African government in aquaculture development have been discussed extensively by many researchers and organizations like FAO, but it appears government has rescinded its oversight function roles and limited itself to the vague role of creating a conducive environment for fish production as a means of achieving food security and poverty alleviation. This conducive environment has become so conducive for foreign donors and development agencies

\begin{tabular}{lccc}
\hline Region & IFC loans (US\$ millions) & Percent & Number of loans \\
\hline Africa & 6.4 & 9 & 1 \\
\hline Asia & 45.0 & 63 & 1 \\
\hline Latin America & 20.0 & 28 & 3 \\
\hline Total & 71.4 & 100 & All shrimp culture projects \\
\hline
\end{tabular}

Table 4.

Recent IFC aquaculture loans by region [28]. 
who so to say exploit it to intervene on government's behalf. The donors use the open window to advantage to establish criteria and objectives they deem fit for achieving anticipated rapid gains against rural poverty and hunger. The role of international donors and development agencies appears to hinge more on technology transfer and capacity building that are not compatible with local needs and traditional experiences of the beneficiaries. Instead of promoting in funded projects the development of value chains and sustainable support systems (extension and credit), emphasis is placed on the promotion of technologies that require inputs (labor, feed, and fertilizers) that are probably not locally available and that are often prohibitive where they are available and beyond the means of the beneficiaries. Delgado et al. [29] suggested the replacement of foreign donor priorities (e.g., poverty alleviation among the poorest of the poor; cheap food for low-income urban consumers) with those of local decision-makers and farmers. Delgado et al. [29] pointed out that a supply-side with emphasis on aquaculture as a commercial venture (at a variety of scales and intensities) will serve to generate income and create secondary business opportunities and generalized economic growth.

\section{Conclusion}

Aquaculture has a big future in Africa that could well surpass the achievement of the Asian countries provided the right investment options and technologies are made available. The expectation from the sector, as a growing food production enterprise is, great. Importantly, the sector is expected to bridge the gap between fish supply from capture fisheries and the demand for fish by the rising African population. Increase in population and acute competition for resources and the need for food security is making it imperative for aquaculture to fulfill its longforeseen role as an important contributor to increased nutritional and economic well-being. It is equally important to mention that Africa has substantial market to satisfy; this coupled with available abundant water and land resources that could enhance production is a tempting incentive. The expectation from the sector will however be a mere daydreaming if aquaculture development is not redirected and refocused. To achieve the role of aquaculture, African government has critical roles to play with respect to the formulation of policies that are pro-aquaculture and creation of good financial environment for would-be investor in the sector. The government is well aware of the challenges facing the sector and these challenges need to be addressed adequately if the sector is to go forward. Public sector is encouraged to complement the efforts of international donors and development agencies by devoting more resources to policy research for the facilitation and promotion of aquaculture. There is also the need for public sector agencies to improve on their investment in aquaculture research and education. International donors and development agencies' role should not be limited to that of hiring foreign consultants, technology transfer, and capacity building, but they should team up with host government to develop innovative financial models that favor sustainable aquaculture enterprises. Innovative financial models will help to fill the gap between traditional banking and grant-based donor finance.

\section{Acknowledgements}

The author acknowledges with thanks the various authors and books consulted in the course of drafting of this review work. 
The Role of International Donors in Aquaculture Development in Africa

DOI: http://dx.doi.org/10.5772/intechopen.86569

\section{Conflict of interest}

The author has no conflict of interest to declare. All citation used in the review have been duly referenced and author(s) of the work have been acknowledged for excerpting materials from their publications.

\section{Author details}

Olufemi Julius Olapade

Department of Aquaculture and Fisheries Management, School of Natural

Resources Management, Njala University, Sierra Leone

*Address all correspondence to: fem66@hotmail.com; ojulius@njala.edu.sl

\section{IntechOpen}

(C) 2020 The Author(s). Licensee IntechOpen. This chapter is distributed under the terms of the Creative Commons Attribution License (http://creativecommons.org/licenses/ by/3.0), which permits unrestricted use, distribution, and reproduction in any medium, provided the original work is properly cited. (cc) BY 


\section{References}

[1] FAO. Report of the first session of the Sub-Committee on Aquaculture, 18-22 April 2002, Beijing, People's Republic of China. In: FAO Fisheries Report No. 674. Rome, Italy: FAO; 2002. p. 66

[2] Williams MJ. The transition in the contribution of living aquatic resources to food security. In: Food, Agricultural Environment Discussion Paper. Washington, DC, USA: International Food Policy Research Institute; 1996

[3] Pillay TVR, Kutty MN. Aquaculture Principles and Practices. 2nd ed. Oxford, UK: Blackwell Publishing Ltd.; 2005. p. 640

[4] Pillay TVR. Aquaculture: Principles and Practices. Fishing News Books. USA: Blackwell Scientific Publication Ltd; 1993. pp. 92-155

[5] FAO. Aquaculture development. In: FAO Technical Guidelines for Responsible Fisheries No. 5. Rome, Italy: FAO; 1997

[6] FAO. Code of Conduct for Responsible Fisheries. Rome, Italy: FAO; 1995. p. 41

[7] FAO. Aquaculture development and management: Status, issues, and prospects. In: COFI:AQ/I/2002/2. Rome, Italy: FAO; 2002. p. 13

[8] Bolton J. Aquaculture in subSaharan Africa: Small successes, bigger prospects? 2017. Retrieved from: https:// theconversation.com/aquaculture-insub-saharan-africa-small-successesbigger-prospects-78861

[9] Brummett RE, Lazard J, Moehl J. African aquaculture: Realizing the potential. Food Policy. 2008;33:37-385. Available from: www.elsevier.com/ locate/foodpol

[10] Jamu DM, Ayinla OA. Potential for the development of aquaculture in Africa. NAGA, WorldFish Center Quarterly. 2003;26(3)

[11] Pillay TVR. Planning of Aquaculture Development-An Introductory Guide. Farnham, Surrey, UK: Fishing News Books, Ltd; 1997

[12] Vincke MMJ. The present state of development in continental aquaculture in Africa. In: Symoens J-J, Micha J-C, editors. The Management of Integrated Freshwater Agro-Piscicultural Ecosystems in Tropical Areas. Proceedings; The Netherlands, CTA; Rome, FAO; Belgium, Royal Academy of Overseas Sciences. 1995. pp. 27-62

[13] Satia B. A regional survey of the aquaculture sector in Africa south of the Sahara. In: ADCP/REP/89/36. FAO; 1989. p. 60

[14] FAO (Food and Agriculture Organization of the United Nations). Fisheries Statistics. 2003. Available from: http://www.fao.org FAO 2016a. Global aquaculture production dataset 1950-2014 (Fishstat). Available at: www. fao.org/fishery/statistics/software/ fishstat/en [Accessed: 2019]

[15] FAO. Global aquaculture production dataset 1950-2014 (Fishstat). 2016. Available from: www.fao.org/fishery/ statistics/software/fishstat/en [Accessed: 2019]

[16] Coche AG. Aquaculture development and research in SubSaharan Africa. National Reviews; CIFA Techn. Pap. No. 2; Suppl. FAO; 1994. p. 397

[17] Costa-Pierce BA. Research priorities in Sub-Saharan smallholder freshwater aquaculture. In: Koop K, editor. Aquaculture in Africa. A Workshop on Research in Aquaculture held in Harare, Zimbabwe, 23-27 January. Stockholm, IFS; 1991 
[18] Coche AD, Pedini M. Establishment of the aquatic farming systems network for Africa. FAO Aquaculture Newsletter. 1997;15:7-11

[19] Coche AG, Haight BA, Vincke MMJ. Aquaculture development and research in Sub-Saharan Africa, synthesis of national reviews and indicative action plan for research. In: CIFA Technical Paper Paper 23. Rome: ECA/EU/FAO; 1994. p. 151

[20] Williams MJ. Aquaculture and sustainable food security in the developing world. In: Bardach JE, editor. Sustainable Aquaculture. New York: John Wiley \& Sons; 1997. pp. 15-51

[21] UNDP. Overcoming human poverty. United Nations Development Programme. New York, USA; 1998

[22] Lazard JLY, Stomal B, Weigel J-Y. Pisciculture en Afrique subsaharienne: Situations et projets dans des pays francophones; propositions d'action. Paris: Ministère de la Coopération et du Développement; Aquaculture extension in sub-Saharan Africa; FAO Fisheries Department, Inland Water Resources and Aquaculture Service Series title: FAO Fisheries Circular-C1002 (2004); based on an original text proposed by Dr. Brummett RE (World Fish Center, West Africa Office) and Dr. V. Pouomogne (Institut de recherche agricole pour le développement) in Yaounde, Cameroon; 1991. p. 155

[23] Hecht T. A review of the development of clariid catfish culture in southern Africa. In: Report of the Technical Consultation on Species for Small Reservoir Fisheries and Aquaculture in Southern Africa, ALCOM Report 19. Harare, Zimbabwe: Food and Agriculture Organization of the United Nations; 1997

[24] Masser M. The status and future of inland aquaculture. World Aquaculture. 2000;31(3):34-62
[25] Moehl J, Halwart M, Brummett R. Report of the FAO-World Fish Center Workshop in small-scale aquaculture in Sub-Saharan Africa. In: Revisiting the Aquaculture Target Group Paradigm.

Limbé, Cameroon, 23-26 March 2004. CIFA Occasional paper, no. 25; Rome, FAO; 2005

[26] CIFA/OP24. Africa Regional Aquaculture Review. FAO Regional Office for Africa, Accra, Ghana; 2000, 50 pp. 29 November-05 December 1972, Rome; 1973. p. 34

[27] Josupeit H. A survey of external assistance to the fisheries sector in developing countries, 1978-1984. In: FAO Fisheries Circular 755. Rome: FAO; 1985

[28] IFC. International Finance Corporation website. 2006. Available from: http://www.ifc.org/ifcext/ agribusiness.nsf/Content/Aquaculture [Accessed: 2006]

[29] Delgado CL, Hopkins J, Kelly VA. Agricultural growth linkages in subSaharan Africa. In: Research Report 107. Washington, DC: International Food Policy Research Institute; 1998 

Section 4

\section{Environmental and Cultural Dimensions to Africa's Regional Development}





\title{
The Role of Culture in Achieving Sustainable Agriculture in South Africa: Examining Zulu Cultural Views and Management Practices of Livestock and Its Productivity
}

\author{
Adetoyese Ade. Adeyemo and Ekuyikeno Silas
}

\begin{abstract}
Africa continent has been said to lag behind in agricultural growth and development which has led to organizational and structural failures. Many factors have been investigated to this effect such as poor infrastructure, inadequate factors of production, poor energy, lack of modern agricultural facilities, etc. Cultural practices and the acceptability of advanced skills and knowledge have been less investigated as militating factors against agricultural growth and development. This chapter evaluates the Isi-Zulu cultural agricultural views and management practices of livestock on its productivity. A study was conducted at Umsinga municipality (Southeast of South Africa), dominated by Zulu culture. Small scaled farmers within the communities were engaged through a survey and focused group discussion. Prior research visits were made to the communities with chiefs and agricultural extension workers. A total of 90 small scaled farmers were selected across the municipality for this study. A survey was administered in the local language of the correspondence. Data showed that cultural purposes and management practices have been a limiting factor in livestock production. These have hindered agricultural growth and commercialization of livestock within municipality and province.
\end{abstract}

Keywords: cultural believes, management practices, Zulu, agriculture, livestock, gender ownership, goats and cattle

\section{Introduction}

Agriculture, among all other sectors, has proven to have a closer relationship with natural resources and her impacts have been significant to mankind over the centuries [1]. Livestock farming has contributed tremendously to the livelihood and social status of humans [2].

This sector has been lacking behind compared to others in developing countries. There are very few partnership and corporate organizations in the agricultural sector, because the factor of production is costly (such as the inability to acquire land, low land nutritional value, the high cost of mechanization, lack of capital and access to good roads, etc.) [3]. Therefore, many farmers prefer to operate individually. This gives rise to 
many smallholders than commercial farmers in developing countries [4]. Statistically, smallholder farmers have been found to contribute largely to the agricultural industry, especially in developing countries [1]. Also, it was reported that local production had contributed a larger quota (63\%) to the total livestock population in South Africa $[5,6]$. More research has been conducted to improve, increase production efficiency and solve some challenges facing small-scale farmers $[4,7]$.

As indicated by other researchers, there are other problematic factors facing small scale farmers and limiting livestock production in Africa [8]. According to Vink and Rooyen [9], there were 8 million households in South Africa located in rural areas in 2006, of these 17\% (1.3 million households) had access to land for farming purposes and $97 \%$ of those households engaged in some form of farming activity. Recent data shows that $43 \%$ of South Africans can be referred to as 'rural survivalists' [10]. Most households clustered in former homeland areas; the current households in KwaZulu-Natal were said to be located on relatively small plots of land [9]. They depended on multiple livelihood strategies with farming being an important but small contribution to livelihoods. At that time $78 \%$ of households engaging in agricultural production did so as an extra source of food for the household, $6 \%$ as an extra source of income, $3 \%$ as the main source of income and $8 \%$ as the main source of food. These smallholders, characterized by small plots of arable land and low output [11], are faced with a wide range of challenges including limited access to factors of production, credit, information and markets [12].

It is factual that the smallholder sector in South Africa is striving to provide employment and food security [13]. But the critical issue is how these farmers can improve their competitiveness by participating sustainably in agri-food supply chains [12]. Other factors that are recently identified and less investigated affecting agricultural development are gender ownership, inherited cultural management practices and cultural belief systems of certain livestock [14]. Rural farmers still hold the belief that livestock farming is not a source of income and it becomes a major barrier to commercialization of goats and cattle particularly in the agricultural industry [15-17].

Therefore, this study aimed at determining the effect of cultural views and management practices on livestock commercialization; secondly, evaluating livestock gender ownership and its productivity effect on socioeconomic development at Umsinga municipality.

\section{Materials and methods}

\subsection{Selection of study site}

The study was conducted at Umsinga Municipality, KwaZulu-Natal province, Southeastern part of South Africa. The study site is located on the geographical coordinates $28.7461^{\circ} \mathrm{S}, 30.4525^{\circ} \mathrm{E}$ [6]. Department of Agriculture and Environmental Affairs (2013) reported that $11 \%$ of the total surface area of South Africa was classified as arable, whereas $54 \%$ was classified as grazing land. KwaZulu-Natal province is listed as the second largest agricultural producing province in South Africa, in terms of agricultural households in livestock production [6]. Also, KwaZulu-Natal had $28.2 \%$ of its provincial population of households involved in agriculture while $41.9 \%$ out of this population are involved in livestock production [6]. Based on the agricultural involvement of the households in the province, this municipality was selected.

Umsinga Municipality is dominated by IsiZulu ethnic group, situated in central KwaZulu-Natal Province [18]. The Umsinga Municipality has a rainfall varying 
The Role of Culture in Achieving Sustainable Agriculture in South Africa: Examining Zulu... DOI: http://dx.doi.org/10.5772/intechopen.86759

between 550 and $2000 \mathrm{~mm}$ per annum over a landscape ranging up to altitude $3500 \mathrm{~m}$ above the sea level. Its temperature varies from the hot subtropical areas of north-eastern KwaZulu-Natal to the western parts where winter frost is a regular occurrence and snow is experienced from time to time [5]. It has a total landscape of $2501 \mathrm{~km}^{2}$ [18].

\subsection{Selection of households and livestock}

Prior visits to the communities during the feasibility study and supports by the extension and veterinary workers' meetings were organized with local authorities such as chiefs, smallholder farmers and livestock associations. A list of farmers keeping livestock (having goats or cattle or both) from each community was compiled for follow-up. In the process, the aim and purpose of the research project were disseminated to create interest and develop an interpersonal relationship with farmers. A total of ninety (90) smallholder farmers were selected based on their willingness to participate and across the municipality. These farmers engaged in a mixed system of farming. The crop production system is divided into two: Irrigation and garden farming system. Each household has allocated a portion of an irrigated plot which is part of the community irrigation scheme. The garden plot is the individual cultivated land around the settlement.

\subsection{Research procedure}

\subsubsection{Survey}

A survey was conducted to explore the existing chains and potential value for goats and cattle towards the gross socioeconomic value in Umsinga, and its opportunities for increasing the impact. Data were collected through personal engagement of selected livestock farmers using pre-tested questionnaires and by direct observation of livestock management practices, feeding systems and feed samples. The questionnaire was conducted from February to April 2017. The questionnaire was translated into the local language (IsiZulu) for a proper understanding of the concept.

\subsubsection{Data collection}

Data collection was divided into three categories: (1) Livestock production growth by the gender ownership. Number of livestock (goats and cattle) was recorded over a period of 12 months (May 2017-April 2018). During this time, production, mortality was recorded based by the gender ownership. (2) Livestock management routine by the gender ownership. This session recoded basic information of daily management routine of farmers such as feeding, farming system and animal health care. (3) Livestock usage by the gender ownership. This section investigates main reason for rearing livestock such as cultural prestige, income, milk and beef production and also identifying main tool for livestock increase (buying, production or gifts).

\subsubsection{Focused group discussion}

A total of 90 households were selected across the municipality. The aim of the discussion was to evaluate the cultural view, communal management practices, and identify available marketing opportunities of goats and cattle. Focus group discussion (FGD) was organized within each community using their local livestock 
association groups. These local groups were formed within the community and they hold weekly meetings for a year. The local groups were in charge of dippingtanks within the communities and ensure equal access to all livestock farmers. Data collected through FGD helped to verify data obtained through questionnaire interviews. It helped to identify the communal livestock management practices and community views about livestock. It also created an opportunity to discuss livestock health issues such as diseases in the area, malnutrition (feeding management), purpose for keeping livestock and usage of an irrigation scheme for livestock production.

\subsection{Statistical analysis}

Questionnaire and FGD data were analyzed by frequency procedure of Statistical Analytical Software. Livestock population was analyzed by the general linear model procedure. Frequency procedure and regression procedure were used to determine the annual livestock populations [19]. The statistical model was as follows:

$$
Y i j=\mu+G i+e i j
$$

where Yij = dependent variable (livestock numbers over 12 months); $\mu$ = overall mean; $\mathrm{Gi}$ = effect of gender owners and eij = residue error.

\section{Results}

\subsection{Descriptive statistic on livestock production by gender ownership}

Majority of homesteads (84\%) has goats compared to cattle (69\%). The population of goats in possession by homesteads was higher compared to other livestock (cattle, poultry, and sheep) (Table 1). The gender ratio (male to female) of owners was 2:5, while the ratio of the animal population owned by these genders was 4:6 (Table1).

\begin{tabular}{|c|c|c|c|c|c|}
\hline \multirow[t]{2}{*}{ Livestock } & \multirow[t]{2}{*}{ Communities } & \multicolumn{2}{|c|}{ Gender of owners } & \multicolumn{2}{|c|}{ Animal population owned by } \\
\hline & & Male & Female & Male & Female \\
\hline \multirow[t]{5}{*}{ Goats } & Madulaneni & 16 & 9 & 273 & 200 \\
\hline & Ntanyana & 21 & 3 & 411 & 12 \\
\hline & Nxamalala & 17 & 10 & 793 & 108 \\
\hline & Total & 54 & 22 & 1477 & 320 \\
\hline & Ratios (male:female) & \multicolumn{2}{|c|}{2.5} & \multicolumn{2}{|c|}{4.6} \\
\hline \multirow[t]{5}{*}{ Cattle } & Madulaneni & 8 & 10 & 73 & 46 \\
\hline & Ntanyana & 25 & 3 & 277 & 7 \\
\hline & Nxamalala & 7 & 8 & 173 & 89 \\
\hline & Total & 40 & 21 & 523 & 142 \\
\hline & Ratios (male:female) & \multicolumn{2}{|c|}{1.9} & \multicolumn{2}{|c|}{3.6} \\
\hline
\end{tabular}

Table 1.

Distribution of livestock ownership among the sampled population across the communities. 
The Role of Culture in Achieving Sustainable Agriculture in South Africa: Examining Zulu... DOI: http://dx.doi.org/10.5772/intechopen.86759

The ratio of gender ownership (male:female) for cattle is 2.9 households, but the ratio of the population of cattle owned is 3.6 respective (Table 1 ). The average populations of cattle per male owner and per female owner were 13 and 7, respectively. Females do not like keeping cattle because of the attention demanded in cattle management, such as herding [20]. There was an increase in cattle population among the male owners while it decreases among the female owners (Table 2). This was because the male receives cattle gifts as part of cultural and ceremonies.

\subsection{Socioeconomic impacts}

Most of the population sampled was rearing livestock for prestige (FGD). The cultural understanding and set up in the community give regards and honor livestock farmers based on the number of livestock, especially goats and cattle possessed by individual farmers. This agreed with the findings made by [6]. Census agricultural household (2013) reporting that $41.9 \%$ of agricultural household in KwaZulu-Natal are livestock farmers and $24.6 \%$ of agricultural households practice mixed farming.

\subsection{Ownership by the gender, cultural beliefs and management practices on livestock production}

The system of livestock husbandry at Umsinga is casual and cultural, and is not an organized activity because of the following reasons:

More male than female owners use modern medicine to cure goats $(P<0.0001$; Table 3). Among the population sampled, 4 and $10 \%$ of female and male owner respectively, uses traditional medicine and engages in dipping practices. The percentages of male and female owners using modern medicine were 57 and 19\%, respectively (Table 3). Vaccination program for livestock is poor and the cultural medicinal routine treatment is not better. It was discovered during the focus group discussion that a majority of farmers cannot identify or prevent in advance against infections that come with changes in season in these communities; thereby exposing livestock to seasonal diseases. Farmers only call for veterinary treatment when a disease outbreak has struck the kraal. As a result of delayed treatment, there is a high rate of mortality across seasons. Male owners have more financial funds for modern treatment than female owners.

About 32\% male and 9\% of female owners buy feed and feed crop residues (Table 3). There is a high proportion of male than female headed households use dryland crop production (Chi-square 4.7744, $\mathrm{P}<0.05$, Table 3). Questionnaire results indicated that farmers had little, or no supplementary feed offered to livestock. Animals only depend on feed found on communal grazing lands, which

\begin{tabular}{cccccc}
\hline \multirow{2}{*}{ Year $(\mathrm{N})$} & \multicolumn{2}{c}{ Gender } & RSME & Pvalue \\
\cline { 3 - 6 } & & Female & Male & & \\
\hline \multirow{2}{*}{ Goats } & $2012(\mathrm{n})$ & $11.7 \pm 11.85(23)$ & $20.6 \pm 58.25(43)$ & 47.7960 & 0.4044 \\
\cline { 2 - 6 } & $2013(\mathrm{~N})$ & $10.3 \pm 13.05(22)$ & $25.0 \pm 64.47(54)$ & 52.8919 & 0.2132 \\
\hline \multirow{2}{*}{ Cattle } & $2012(\mathrm{n})$ & $4.6 \pm 8.87(20)$ & $8.9 \pm 11.16(29)$ & 10.4351 & 0.0676 \\
\cline { 2 - 6 } & $2013(\mathrm{~N})$ & $6.0 \pm 12.57(21)$ & $7.5 \pm-13.73(41)$ & 13.3453 & 0.6037 \\
\hline
\end{tabular}

Table 2.

Mean of livestock numbers for different genders in Umsinga over the period of 2 years. 


\begin{tabular}{|c|c|c|c|c|c|c|}
\hline \multirow[t]{2}{*}{ Management routine } & \multicolumn{2}{|c|}{ Female (\%) } & \multicolumn{2}{|c|}{ Male (\%) } & \multirow[t]{2}{*}{ Chi-square } & \multirow[t]{2}{*}{ Pvalue } \\
\hline & No & Yes & No & Yes & & \\
\hline Dry land crop production & 32.22 & 2.22 & 48.89 & 16.67 & 4.7744 & * \\
\hline Homestead garden & 31.11 & 3.33 & 62.22 & 3.33 & 0.657 & NS \\
\hline Irrigation farming & 10.00 & 24.44 & 18.89 & 46.67 & 0.0005 & NS \\
\hline Goats (traditional medicine) & 30.00 & 4.44 & 55.56 & 10.00 & 0.0909 & NS \\
\hline Goats (modern medicine) & 15.56 & 18.89 & 8.89 & 56.67 & 10.989 & $* *$ \\
\hline Goats (dipping) & 30.00 & 4.44 & 46.67 & 18.89 & 2.8757 & NS \\
\hline Goats (buying fed) & 26.67 & 7.78 & 41.11 & 24.44 & 2.0128 & NS \\
\hline Goats (crop residues) & 32.22 & 2.22 & 58.89 & 6.67 & 0.3469 & NS \\
\hline
\end{tabular}

${ }^{*}$ Significant $(P<0.05) ;{ }^{* *}$ Significant $(P<0.005) ;{ }^{N S}$ Non-Significant $(P>0.05)$.

Table 3.

Variation in goats' management routine as affected by gender.

are totally dried and insufficient during winter grazing (sweet veld). Other standing forages are sour veld grasses (low nutrient grasses that can withstand dry season); therefore, animals struggled in search of food. For example, data showed that livestock is not allowed to graze on irrigated farming plots but are allowed on homestead gardens of individual farmers.

Almost $46.67 \%$ of male owners' and $24.44 \%$ of female owners practice irrigated farming, but only $8.89 \%$ (both genders) fed crop residues from the farm to livestock (Table 3). Nearly 23 and 7\% of male and female owners dip livestock and have homestead gardens (Table 3). Farmers do not allow livestock to graze on irrigating farming plots and very few release livestock to graze on homestead gardens (after harvesting). Therefore, livestock is only allowed access to maize-stover when it was planted in home gardens.

It's also revealed in Table 4 below, how the gender of owners across the communities affects interest in livestock and how it met specific purposes across communities. Goats are a major source of income among other goat purposes across these communities with fewer females than males benefiting (Chi-square 7.9537, $\mathrm{P}<0.001$, Table 4). The male owner (45.56\%) recognized goat production to this effect, compared to female ownership (13.33\%). Other uses of goats are as follows: goats' cultural purposes $(54.45 \%)$, goat's meat $(51.11 \%)$, goats' prestige $(36.67 \%)$, and goats' milk (4.44\%; Table 4). Umsinga farmers reared goats for social and cultural purposes than economic interest. Less than $4.44 \%$ of the population surveyed indicated that they milk goats, but not regularly. Whenever this milking is done, is for the head of the family only.

There are quite a few differences in the use of goat. For instance, female perspective goes for meat, prestige and cultural purposes (18.90, 16.67 and $15.56 \%$, respectively), while male perspectives go for income, meat and cultural (45.56, 32.22 and $33.78 \%$ ), respectively (Table 4). The cultural purpose is common and higher in male owners than female. It is a pointer to the fact that cultural purposes prevail above all other benefits to these owners. This agreed with the study made by [21-23] that African farmers have specific reasons or purposes for rearing livestock.

Only a small proportion of female (2.22\%) and a reasonable proportion of male (25.56\%) owners buy feed to supplement cattle feeding during the winter season (Chi-square 10.72, $\mathrm{P}<0.001$, Table 5), while 2.22 and $10.0 \%$ of female and male owners' gives crop residues. About 70 and $3.33 \%$ of owners treat their cattle with 
The Role of Culture in Achieving Sustainable Agriculture in South Africa: Examining Zulu... DOI: http://dx.doi.org/10.5772/intechopen.86759

\begin{tabular}{|c|c|c|c|c|c|c|c|}
\hline & & \multicolumn{2}{|c|}{ Female (\%) } & \multicolumn{2}{|c|}{ Male (\%) } & \multirow[t]{2}{*}{ Chi-square } & \multirow[t]{2}{*}{ Pvalue } \\
\hline & & No & Yes & No & Yes & & \\
\hline \multirow[t]{5}{*}{ Goat purposes } & Goats income & 21.11 & 13.33 & 20.00 & 45.56 & 7.9537 & ** \\
\hline & Goats meat & 15.56 & 18.89 & 33.33 & 32.22 & 0.263 & NS \\
\hline & Goats milk & 32.22 & 2.22 & 63.33 & 2.22 & 0.4486 & NS \\
\hline & Goats cultural purposes & 17.78 & 16.67 & 27.78 & 37.78 & 0.6996 & NS \\
\hline & Goats prestige & 18.89 & 15.56 & 44.44 & 21.11 & 1.4694 & NS \\
\hline \multirow[t]{3}{*}{ Goats increase } & Goats buying & 33.33 & 1.11 & 61.11 & 4.44 & 0.4892 & NS \\
\hline & Goats reproduction & 25.56 & 8.89 & 27.78 & 37.78 & 8.2677 & ** \\
\hline & Goats gifts & 32.22 & 2.22 & 58.89 & 6.67 & 0.3469 & NS \\
\hline
\end{tabular}

${ }^{*}$ Significant $(P<0.05) ;{ }^{* *}$ Significant $(P<0.005) ;{ }^{N S}$ Non-Significant $(P>0.05)$.

Table 4.

Uses of livestock (goats) as affected by the gender of owners.

\begin{tabular}{|c|c|c|c|c|c|c|c|}
\hline \multirow[t]{2}{*}{ Cattle } & & \multicolumn{2}{|c|}{ Female (\%) } & \multicolumn{2}{|c|}{ Male (\%) } & \multirow[t]{2}{*}{ Chi-square } & \multirow[t]{2}{*}{ Pvalue } \\
\hline & & No & Yes & No & Yes & & \\
\hline \multirow[t]{5}{*}{ Health routine } & Cattle (traditional medicine) & 33.33 & 1.11 & 63.33 & 2.22 & 0.0017 & NS \\
\hline & Cattle (modern medicine) & 11.11 & 23.33 & 18.89 & 46.67 & 0.1148 & NS \\
\hline & Cattle (dipping) & 11.11 & 23.33 & 18.89 & 46.67 & 0.1148 & NS \\
\hline & Cattle (buying fed) & 32.22 & 2.22 & 40.00 & 25.56 & 10.7200 & $* *$ \\
\hline & Cattle (crop residues) & 32.22 & 2.22 & 55.56 & 10.00 & 1.4678 & NS \\
\hline \multirow[t]{5}{*}{ Cattle purposes } & Cattle income & 21.11 & 13.33 & 33.33 & 32.22 & 0.8935 & NS \\
\hline & Cattle meat & 20.00 & 14.44 & 47.78 & 17.78 & 2.0429 & NS \\
\hline & Cattle milk & 32.22 & 2.22 & 63.33 & 2.22 & 0.4486 & NS \\
\hline & Cattle cultural purposes & 20.00 & 14.44 & 50.00 & 15.56 & 3.2078 & NS \\
\hline & Cattle prestige & 22.22 & 12.22 & 55.67 & 8.89 & 5.8655 & * \\
\hline \multirow[t]{3}{*}{ Cattle increases } & Cattle buying & 32.22 & 2.22 & 61.11 & 4.44 & 0.0035 & NS \\
\hline & Cattle reproduction & 27.78 & 6.67 & 41.11 & 24.44 & 3.0495 & NS \\
\hline & Cattle gifts & 32.22 & 2.22 & 56.67 & 8.89 & 1.0395 & NS \\
\hline
\end{tabular}

${ }^{*}$ Significant $(P<0.05) ;{ }^{* *}$ Significant $(P<0.005) ;{ }^{N S}$ Non-Significant $(P>0.05)$.

Table 5.

Management and uses of livestock as affected by the gender of owners.

the modern and traditional medicine respectively, while $70 \%$ take their cattle for dipping. FGD indicated that the farmers do not have management practices of buying grass (Lucerne hay) to support cattle nutritionally.

Only $25.56 \%$ of male owners buy feed perhaps because of their financial capability. Financial handicap owners were also a factor affecting modern medical treatment of cattle. Dipping treatment is free and the reagent use is provided by the Department of Agriculture and Environmental Affairs, many owners prefer dipping to traditional medicine. Similar proportions of male and female used cattle for meat (total 32.22\%), cultural purposes (total 30.0\%), rear cattle for income (total 45.55\%) and cultural prestige (total 21.11\%), and keep cattle for income (total 43.55\%). 


\section{Discussion}

\subsection{Livestock production as influenced by the gender of owners}

There was a decrease in goats' population among female owners over 12 months (1.4) while it increases among the male owners (5.6) (Table 2). The disparity in the population of goats owned is very wide compared to the gender of owners. This is due to some biased gender factors which had favored the men such as (a) cultural position of men. Men are regarded as heads of households and have a final decision on livestock. (b) Men are more traditionally inclined and are not easily deviated from cultural beliefs and practices. Men in these communities appreciate goat because it is widely accepted for cultural ceremonies like ancestral worship, a minor part of the lobola and special family community occasions (FGD). Goats are used to pay sexual harassment penalty and minor community fine [24]. These agreed with the findings of the focus group discussion. (c) The average population of goats per men ownership was 27 goats per ownership. It was discovered from the focus group discussion that men tend to keep goats as prestige in the municipality. The average population of goats per female owners is 22; this is because few goats owned by females was possessed at old age (i.e. eldest in the family) or when their husbands are late. Therefore, before female owners reach the disadvantage stage (either old age or widowhood) which gives them an edge and the right of ownership in the household. The government can encourage women livestock owners through projects/policies and programs. This cultural trait in IsiZulu is similar to Xhosa culture of South Africa, where livestock ownership (cattle) is concentrated entirely in the male hands [25].

Culture in South Africa is similar to that of Southern Tanzania as reported by [26], that woman cannot claim ownership of cattle and goats. In the case of a married woman who had an ownership contract of cattle and goats, the animals still belong to the man, even after divorce [26]. More opportunity was given to women in Zimbabwe, where women have control over milking, processing and marketing of milk but cannot influence other decisions such as breeding, feeding and slaughtering [27]. Women are only allowed to own poultry and small ruminants in Botswana [28]. This agreed with the reported by the Food and Agricultural Organization [29] that poultry keeping is largely the responsibility of women in Africa. Furthermore, projects to improve poultry productions were often seemed like a way to reach poor rural women [8]. This painted a picture that cultural behavior in Africa has shifted poultry farming to women.

This cultural practice agreed with $[29,30]$ findings in Niger, where the man takes control of all livestock used as part of dowry after the marriage. Nuer Society of Sudan does not permit women to own cattle and goats at all as part of their cultural practices, but they have the responsibility for grazing these animals [31]. However, this practice is contrary to the animal husbandry system in Pakis where women have the full ownership control over livestock brought as part of their dowry [32]. Also in Malawi, where women are head of households, they have a total influence on the livestock they process [33]. Studies showed that livestock ownership between genders is becoming an equity in Africa; Zimbabwe and Mozambique [27], Botswana [28], Namibia [34], Malawi [33], Nigeria [35], Kenya [36], Uganda [36].

In stipulations of the population of livestock across communities, goats had the highest population, followed by cattle while poultry and sheep were the smallest populations sampled. The highest population of goats is because goats are slaughtered for more cultural functions by Nguni people. So many households tend to rear more goats and cattle than other animals. Cattle were the second highest in the 
The Role of Culture in Achieving Sustainable Agriculture in South Africa: Examining Zulu... DOI: http://dx.doi.org/10.5772/intechopen.86759

livestock population because it's another livestock that is mostly used for cultural functions. Cattle are used for lobola package during "marriage negotiation" in preparation for the cultural wedding. Male owners have more goat and cattle than female owners because they are financially constrained to avoid cattle "thus goats are poor men's cow" (Table 1). Due to the environmental and nutritional stress of livestock during the dry season, small-holder farmers in the study site found it easier to manage goats than cattle. Goats are owned by many because (1) it is more affordable than cattle, (2) it can survive harsh environmental conditions, (3) it is a mixed feeder, especially during dry seasons when grasses lose nutrients, and it switches to browsing.

\subsection{Socioeconomic benefits}

Apart from the cultural benefit, there are also economic benefits. Many livestock farmers have an economic gain from livestock production. This is by individuals selling livestock to friends and butchers. Most times this is done when such an individual farmer is in financial need. Furthermore, Focus Group Discussion revealed that goats play an important role within the cultural activities; goat slaughtering is forbidden unless the head of the household gives contrary instructions. Livestock (cattle) is also used as cultural gifts (Lobola) to each other (FGD). Lobola is a cultural bride's gift from the groom's family parked together with bride price paid to the bride's family.

Livestock plays a major role in the bride's price ceremony is not complete without the cattle gift. The most important recognized socioeconomic benefit of goats is the usage in ancestral worship (FGD) which is an inherited cultural practice and belief among IsiZulu ethnic group of South Africa. This practice had been sustained alongside with this cultural practice; farmers keep or sell hide of goats and cattle. The hide is used as a pelt for sitting or designed as a cultural dress of IsiZulu people. This justified the impact of livestock to mankind apart from companionship, income, hide and skin, reported by [37]. It promotes inter-social relationship and serves as a means of legal local bills in communities. It also agreed with livestock impacts in Botswana reported by [38] that it is an important household asset in providing security, money, food, cultural and social identity, draught power, skin, hide and medium of exchange. World Bank [30] also reported that livestock production is a very important socioeconomic activity. Therefore, cattle and goats have not lost their socioeconomic benefits in the IsiZulu culture.

\subsection{Effect of gender ownership, cultural beliefs and management practices on livestock production.}

\subsubsection{Goat productivity}

The distribution of small ruminants in South Africa is not even and numbers tend to be higher in dry areas [5]. Flock sizes, especially are larger in dry than in humid areas [39]. Goats are reared among the IsiZulu tribe mainly for four major benefits, namely: meat, milk, skin and wool in this order of importance [40]. The majority of small ruminants are owned by individuals or families in community areas. Majority of farmers practice mixed farming which includes large variations of annual crops (maize, vegetables) and livestock (swine, poultry small and large ruminants) [8].

Annual crops like maize, vegetables (spinach, cucumber) and livestock like poultry, swine, small and large ruminant animals (FGD). All respondents (smallholder farmers) engaged in free-range systems of farming and graze on communal 
lands. Due to high rates of tick infestation, farmers through their groups and associations established dip-tanks within the community as a means of control.

No good flock management is practiced for a frivolous reason; farmers only rear for social purposes. FGD recorded that farmers practiced similar livestock farming system which has become a cultural norm in the area. It is a system whereby farmers have limited contribution (input and almost no feed) to the production. The only consistent management routine in goat rearing is the administration of modern medicine. Farmers find it easy to spray, drench, rub and inject goats.

It was observed that farmers have poor housing and tethering of livestock. A rural livestock farming system by both genders are the same but it affects livestock productivity because of inadequate facilities. This observation agreed with the study reported by [40] that small ruminant production in traditional systems throughout tropical Africa is fair. Small ruminants are generally recognized for their importance and contribution to mankind, especially in the tropics [28]. However, Africans who keep small ruminant stock rear it for irrational reasons for meeting particular needs and specific objectives of owners [29].

\subsubsection{Cattle productivity}

Improvement in cattle feeding through supplementation with additional feed source (such as silage and hay) will contribute greatly to cattle production. Observations during forage sampling at different seasons showed that cattle struggle to fed (graze) on communal pasture during the dry and early wet season because communal grazing lands are fully mature. It was noted during the focus group discussion, that Umsinga farmers treat cattle as livestock that do not need much attention and adequate management routine. Umsinga farmers believed that cattle have the ability to serve as draught animals and it is also a major factor in the opening up of arable areas, especially in places with heavy soils [41].

Large families during festive period do slaughter cattle for meat purposes as indicated from the focus group discussion and for cultural ceremonies. Apart from cattle being a source of income, the skin is culturally used for mat, decoration and clothing among the IsiZulu tribe. Another attribute of cattle farming in Umsinga communities is that the number of cattle herd is a form of prestige within the community. This has drawn the interest of many owners into the farming system. Cattle are rarely milked.

\section{Conclusion}

Livestock gender ownership has a great influence on goats and cattle productivity in Umsinga Municipality. Gender differences based on the cultural views, purposes and norms are affecting the commercialization of goats and cattle. The input of ownership by gender also made a difference in livestock productivity. Financial constraints and labor required for livestock management routines is also a barrier to production. By way of commendation, from all observations and surveys, a change of perspective will bring a positive change to livestock production in Umsinga community. Empowerment program towards the maximum profit of livestock production, especially as a source of income will change the socioeconomic and developments in the Municipality. This will encourage farmers to improve management practices, adequate health program and good breeding selection. Second, proper establishment and management of cultivated pastures specific for livestock 
The Role of Culture in Achieving Sustainable Agriculture in South Africa: Examining Zulu... DOI: http://dx.doi.org/10.5772/intechopen.86759

and water availability will greatly influence the production performance of livestock. Third, livestock farmers should be educated in forage conservation methods such as silage, hay and other management practices. Since most farmers are practicing mixed farming, it is easier to prepare and store hay from crop residue. Fourth, training to observe symptoms of common diseases and how to prevent should be created among farmers.

\subsection{Implications of this study}

This study shows that continuity in cultural believes and management practices poses no future for agriculture growth and commercialization of livestock in South Africa. As culturally belief, the impact of gender ownership on livestock is another factor limiting female ownership in livestock farming. Though cultural practices cannot totally eradicate or change but farmers mind set can be influence to towards agricultural growth and sustainability. Also, initiating livestock farming as a source of income will improve socioeconomic livelihood of rural farmers.

\section{Acknowledgements}

We want to acknowledge the Livestock association of Umsinga and every household that participated with their livestock farming. Also, we will like to appreciate the assistance of the Department of Agriculture, Rural Development, KwaZuluNatal province and Institute of Natural Resources in logistics and planning.

\section{Conflict of interest}

There was no conflict of interest among all authors.

\section{Author details}

Adetoyese Ade. Adeyemo ${ }^{1 *}$ and Ekuyikeno Silas ${ }^{2}$

1 Discipline of Animal and Poultry Science, School of Agriculture, Engineering and Earth Sciences, University of KwaZulu-Natal, Pietermaritzburg, South Africa

2 Discipline of Biological Sciences, School of Life Sciences, University of KwaZuluNatal, Pietermaritzburg, South Africa

*Address all correspondence to: toyeseade7@gmail.com

\section{IntechOpen}

(C) 2020 The Author(s). Licensee IntechOpen. This chapter is distributed under the terms of the Creative Commons Attribution License (http://creativecommons.org/licenses/ by/3.0), which permits unrestricted use, distribution, and reproduction in any medium, provided the original work is properly cited. (cc) BY 


\section{References}

[1] Yisehak K. Gender responsibility in small-holder mixed crop-livestock production systems of Jimma zone, South West Ethiopia. Livestock Research for Rural Development. 2008;20:11. Available from: http://www.lrrd.org/ $\operatorname{lrrd20/1/yise20011.htm~}$

[2] Valdivia C. Gender, livestock assets, resource management, and food security: Lessons from the SRCRSP. Agriculture and Human Values. 2001;18(1):27-39. DOI: 10.1023/A:1007613031102

[3] Donkin EF, Ramsay KA, van Marle-Köster E. Goat research and development in South Africa. Unpublished. 2006

[4] Sebei PJ, McCrindle CME, Webb EC. Factors influencing weaning percentages of indigenous goats on communal grazing. South African Journal of Animal Science. 2004;34(supplement 1). Peer-reviewed paper: 8th International Conference on Goats

[5] Donkin E, Ramsay K. A review of the current status of goat Research and Development in South Africa. In: Paper Presented at the Regional Workshop on Goat Development in Southern Africa; 31st July-4th August 2000; Mangochi, Malawi. Convened by Bunda college of agriculture, University of Malawi; 2006

[6] Census 2011 Agricultural Households. Statistics South Africa. Report no. 03-11-01. Pretoria: Statistics South Africa; 2013. p. 27

[7] Lo Bianco A. Agribusiness for Development: A Socioeconomic Analysis of the Milk Market Chain in the IFAD-Financed Western Sudan Resource Management Program Area. Rome: IFAD; 2007

[8] Rushton J, Ngongi SN. Poultry, women and development: Old ideas.
In: New Applications and the Need for More Research. Rome: Food and Agriculture Organization of the United Nations; 1998

[9] Vink N, van Rooyen J. The Economic Performance of Agriculture in South Africa Since 1994: Implications for Food Security. Pretoria: Development Bank of Southern Africa; 2009. (Development Planning Division Working Paper Series no. 17)

[10] Backeberg GR, Sanewe AJ. Systems approach to water use for food production and energy generation. In: Paper Presented at the First World Irrigation Forum of the International Commission on Irrigation and Drainage; 29 September-1 October; Mardin, Turkey. 2013

[11] Matungul PM, Lyne MC, Ortmann GF. Transaction costs and crop marketing in the communal areas of Impendle and Swayimana, KwaZulu-Natal. Development Southern Africa. 2001;18(3):347-363. DOI: 10.1080/03768350120070017

[12] Ortmann GF, King RP. Research on agri-food supply chains in southern Africa involving small-scale farmers: Current status and future possibilities. Agrekon. 2010;49(4):397-417. DOI: 10.1080/03031853.2010.526428

[13] Sinyolo S, Mudhara M, Wale E. The impact of smallholder irrigation on household welfare: The case of Tugela ferry irrigation scheme in KwaZulu-Natal, South Africa. Water SA. 2014;40:145-156. DOI: 10.4314/wsa. v40i1.18

[14] IFAD. International Fund for Agricultural Development. Innovation in Women's Small-Scale Poultry Activities. 2007. Available from: http:// www.ifad.org/gender/learning/sector/ agriculture/w_i.htm 
The Role of Culture in Achieving Sustainable Agriculture in South Africa: Examining Zulu... DOI: http://dx.doi.org/10.5772/intechopen.86759

[15] Adetoyese AA. Livestock Ownership by Gender and Seasonal Impact on Production: A Case Study in Umsinga Municipality. Pietermaritzburg: University of KwaZulu-Natal; 2015

[16] DAFF. Department of Agriculture, Forestry and Fishery. A Profile of the South African Beef Market Value Chain. 2012. Available from: http://www. nda.agric.za/docs/AMCP/Beef2012-13 [Accessed: 26 July 2014]

[17] NAMC. National Agricultural Marketing Council. Investigation by the Goat Working Group (a Committee of the NAMC) into the Marketing Potential for the South Africa Goat Industry. Report on the Investigation into the Potential for the South African Goat Industry. 2005. Available from: www. nda.agric.za/docs/AAPS?NAMC1.pdf

[18] Statistics South Africa. Census 2011 Statistical release-P0301.4

[19] SAS. SAS System for Windows, Release 9.1 (TS1M3). Cary, NC, USA: SAS Inst., Inc.; 2013

[20] DRDLR. Department of Rural Development and Land Reforms. Goat's Commercialization in KwaZulu-Natal: Interview. 2013. Available from: www. ruraldevelopment.gov.za

[21] Felix MK, Fair MD. Production Parameters for Boer Goats in South Africa. South Africa: Department of Animal Science, Wildlife and Grass Land Science. The University of Free State; 2009

[22] Wilson G. Market Access isn't Only Hurdle for Africa Small-Small Farmers. Marketplace. America, America Public Media's. Available from: http:// gretchenlwilson.com/stories/2012/09/ market-access-isnt-only-hurdle-forafrica $\%$ E2\%80\%99s-small-scale-farmers/

[23] Scoones I. Livelihood perspectives and rural development. Journal of
Peasant Studies. 2009;36(1):171-196.

DOI: $10.1080 / 03066150902820503$

[24] DAEA. Department of Agriculture and Environmental Affairs, KwaZuluNatal. 2013. Available from: www. kzndae.gov.za [Accessed: June, 2014]

[25] Hebinck P, Smith L. Livelihoods and rural transformation in the central Eastern Cape. In: Development Studies Association Annual Conference 'Different Poverties, Different Policies' Institute for Development Policy and Management; 10-12 September; University of Manchester. 2012

[26] Tesha N. Projects with Women in Agriculture, Ministry of Community Development, Intercoperation, Vera Mugittu, Lucy Maarse. Tanzania; 1998

[27] Chawatama S, Mutisi C, Mupawaenda AC. The socio-economic status of smallholder livestock production in Zimbabwe: A diagnostic study. Livestock Research for Rural Development. 2005:143. Available from: http://www.lrrd.org/lrrd17/12/ chaw17143.htm

[28] Oladele OI, Monkhei M. Gender ownership patterns of livestock in Botswana. 2008;20:156. Available from: http://www.irrd.org/irrd20/10/ ola20156.htm

[29] FAO. Foods and Agricultural Organization. Gender and Participation in Agricultural Development Planning. Rome: FAO; 1998

[30] World Bank. 2008. Gender in Agriculture. Available from: http:// www.worldbank.org/gender

[31] Dieckmann N. The Integration of Social and Gender Issues in Smallholder Dairy Production. World Animal Review No. 79. Rome: FAO; 1994. Available from: http://www.fao.org/3/ t3080T0d.htm 
[32] Dohmen C. The Role of Livestock in the Farming System and Involvement of Women. Pakistan: Social Forestry Project; 1992

[33] Fafchamps M, Gabre-Madhin E. Agricultural Markets in Benin and Malawi: Operation and Performance of Traders. World Bank Policy Research Working Paper No. 2734 (December 2001). Washington, DC: World Bank; 2001

[34] Duvel GH, Stephamus AL. A comparison of economic and cultural incentives in the marketing of livestock in some districts of the northern communal areas of Namibia. Agrekon. 2000;39(4):656-664. Available from: https://ageconsearch.umn.edu/ record/54225

[35] Olojede JC, Njoku ME. Involvement of women in livestock production: A means of reducing hunger and malnutrition in Ikwuano local government area of Abia State, Nigeria. Agricultural Journal. 2007;2:231-235. Available from: http://medwelljournals. com/abstract/?doi=aj.2007.231.235

[36] Okitoi LO, Ondwasy HO, Obali MP, Murekefu F. Gender issues in poultry production in rural households of Western Kenya. Livestock Research for Rural Development. 2007;19:17. Available from: http://www.lrrd.org/ lrrd19/2/okit19017.htm

[37] Nassif N, Amiri A. Goat production systems in a mountainous community of the Middle Atlas, Morocco. In: Bernues A, Boutonnet JP, Cassasus I, Chentouf M, Gabina D, Joy M, et al., editors. Economic, Social and Environmental Sustainability in Sheep and Goat Production Systems. Zaragoza: CIHEAM/ FAO/CITA_DGA; 2011.pp. 199-203. Available from: http://resources.ciheam. org/util/search/series.php?langue=fr

[38] Mrema MN. The economics of indigenous goat's production among small holder farmers in Botswana. In: Proceedings of the VI International Conference on Goats; 6-11 May Beijing, China. 1996. pp. 245-248

[39] Coetzee RJ. Socio-economic aspects of sustainable goat production. In: Webb EC, Cronje PB, editors. Proceedings of the Workshop on Research and Training Strategies for Goat Production Systems in South Africa; King's Lodge Hotel, Hogsback, Eastern Cape, South Africa; 1998. pp. 14-16

[40] IFAD. International Fund for Agricultural Development. Women and Milk Production. 2007. Available from: http://www.ifad.org/gender/learning/ sector/agriculture/w_m.htm

[41] Newman JA, Parsons AJ, Penning PD. A note on the behavioral strategies used by grazing animals to alter their intake rate. Grass and Forage Science. 1994;49:502-505. DOI: 10.1111/j.13652494.1994.tb02028.x 


\title{
A Gender Analysis of the Determinants of Youth Unemployment in Côte d'Ivoire
}

\author{
Ibrahima Sy and Akrassi Kouakou Evrard Kouame
}

\begin{abstract}
The purpose of this article is to improve knowledge and understanding of the determinants of unemployment duration by gender in Côte d'Ivoire. One of the central questions on this issue is to what extent the personal characteristics of jobseekers affect their exit from unemployment. In this sense, we apply a proportional risk model with heterogeneity correction of Weibull (2004), applied to data from the Household Employment Survey in Côte d'Ivoire (EEMCI) that was conducted in 2012 by AGEPE. The results of the study reveal that young men are much more likely to exit unemployment than young women. Even if the results show a negative relationship between high level of education and unemployment, the high representation of women on the unemployment rate remains attributable to their very low level of education and the weight of tradition relegating the role of the woman, as a matter of priority, to housework.
\end{abstract}

Keywords: long-term unemployment, young women, duration models, Côte d'Ivoire

\section{Introduction}

Cited as an example for its economic prosperity and its political stability at the beginning of independence until the end of the 1970s, Côte d'Ivoire experienced from 1980 a succession of events that will slow down its economic growth.

Political instability in the country since the late 1990s, which peaked with the post-election crisis of 2011, continues to leave a legacy, including youth unemployment. The latter has reached disconcerting proportions in a context of widespread poverty.

If the unemployment rate recorded in 2012, in Côte d'Ivoire, according to international criteria is $8.2 \%$, this figure is revised upwards by the Ivorian government that broadens the criteria taking into account the realities of the country. This rate would be close to $25 \%$. The unemployed would then be about 6.5 million people, a figure close to the 7 million announced in 2014 by the ILO (International Labor Office). Despite its predominantly young population and average economic growth of $9 \%$ per year since 2012, the labor market is characterized by increased long-term unemployment. Household Living Standards Surveys (ENVs) report an average duration of unemployment of 55 months, 53 months and 46.7 months respectively in 1998, 2002 and 2008. In addition, employment survey reports 
$[1,2]^{1}$ note that the unemployed, looking for a job, are respectively 67.8 months and 47.7 months on average, or about 4 years. Almost $76 \%$ of the unemployed are longterm unemployed.

Long-term unemployment, especially for first-time job seekers, mainly affects young people. In 2012, their unemployment duration was 58.9 months, just under 5 years. According to gender, young women leave unemployment after a period of 5.12 years against 4.16 years for young men. Among first-time claimants, they take 7 months more than young men to find a job. These figures show the lack of job opportunities for young people, on the one hand, and on the other hand, the difficulties young women face in entering the labor market.

Nevertheless, several measures in the fight against unemployment have been implemented. These measures began in 1985 with the implementation of the return to land policy. This failed because of its inconsistency with the theory of development as developed by Harris and Todaro [3]. The surplus of the rural labor force tends to migrate to the cities to feed the industrial labor force, hence the increased unemployment in urban areas.

In 1991, the Hiring Assistance Program was initiated to support young graduates, especially in urban areas, in order to inhibit the effect of previous initiatives. In the same period, the Absorption Program for Out-of-School Young People (PAJD) was launched to provide support to out-of-school youth. Other initiatives have been undertaken whose aim is to fight against unemployment, insecurity, poverty and exclusion by promoting the integration of young people. We can mention among others, the programs conducted by the Youth Employment Agency (AEJ) exAgency Study and Promotion of Employment (AGEPE) [2, 4]: the Employment

\begin{tabular}{|c|c|c|c|c|}
\hline & & Woman & Man & Ensemble \\
\hline \multirow[t]{3}{*}{ Age group } & 14-24 years old & 12.00 & 7.71 & 9.65 \\
\hline & 25-35 years old & 12.41 & 10.02 & 12.04 \\
\hline & 36 years old and + & 5.54 & 3.71 & 4.43 \\
\hline \multirow[t]{3}{*}{ Middle of residence } & Abidjan & 23.02 & 16.56 & 19.50 \\
\hline & Other urban & 13.83 & 8.22 & 10.70 \\
\hline & Rural & 4.95 & 2.73 & 3.72 \\
\hline \multirow[t]{4}{*}{ Level of education } & No & 5.97 & 2.72 & 4.39 \\
\hline & Primary & 12.82 & 5.36 & 8.60 \\
\hline & Secondary & 21.24 & 12.51 & 15.24 \\
\hline & Superior & 40.34 & 19.57 & 24.76 \\
\hline \multirow[t]{3}{*}{ Marital status } & Single & 16.07 & 11.27 & 13.10 \\
\hline & Married & 8.23 & 3.47 & 5.67 \\
\hline & Widower/divorced & 5.65 & 2.51 & 4.70 \\
\hline Global & & 10.34 & 6.5 & 8.2 \\
\hline
\end{tabular}

Source: Authors' calculations based on 2012 AGEPE data.

Table 1.

Youth unemployment rate by gender in Côte d'Ivoire (in\%).

${ }^{1}$ ENSETE: Enquête nationale sur la situation de l'emploi et du travail des enfants [2]. 
Assistance Program (EAP); project to support the economic treatment of unemployment (PATEC); Special Program for the Integration of Women (PSIF). In addition, the priority areas of youth employment in the National Development Plan (PND 12-15, 16-20) show the political will to provide sustainable solutions to youth unemployment.

However, these efforts have not been successful. The relatively high unemployment rate in 2012 hides disparities in terms of place of residence, age, sex and level of education. Unemployment is higher in urban areas and affects many more young people ( $85 \%$ of the unemployed) and especially graduates. In Abidjan, the economic capital, for example, the unemployment rate of the labor force was 19.5, while the unemployment rate of $14--24$-year-olds was $9.65 \%$ against $12.04 \%$ for $25-35$ years (see Table 1 in the appendix).

Therefore, it seems logical for Côte d'Ivoire that the implementation of appropriate policies in favor of the reduction of unemployment requires a better understanding of the factors likely to influence the occurrence of the phenomenon, particularly with regard to its duration. This work is part of this perspective. It tries to highlight the factors determining the duration of youth unemployment in Côte d'Ivoire by gender.

Section 2 describes the various works done in this direction. Section 3 presents the methodological approach used. The resulting econometric results and analyzes are presented in Section 4.

\section{The teachings of the literature review}

Long-term unemployment, or the persistence of unemployment, reflects what economists call the hysteresis effects of unemployment. The study of the length and frequency of unemployment is now central to the analysis of the functioning of the labor market. It is indeed a cross-cutting theme that can be found in different theories of nature. Foremost among these are job search approaches [5-8], matching models, efficiency wages and labor market segmentation approaches $[9,10]$. The relevance of this topic mobilizes several researchers to look at a microeconomic level. Many studies have tried to assess the explanatory factors of the phenomenon, for example, by studying the effects of individual characteristics (demographic, socio-economic and seniority unemployed), the economic situation, the rules of unemployment compensation (conditions of access, replacement rates and duration of compensation) and labor flows in the labor market [11], which are the key empirical facts that require a revision of the paradigm Walrassian [12]. This theoretical revision presupposes a rigorous description of the phenomenon and began with the work of Lancaster [13]. Their first estimates were made directly on the duration of unemployment or on the instantaneous rate of out of unemployment by postulating most often a particular specification. This type of study was gradually replaced by a structural approach explicitly modeling individual behaviors and based on "job search" models [14-20]. Most of these studies focused on the United States in view of the availability of data.

In France, work on this theme started a little later. A first group of works $[21,22]$ focused the analysis on the duration of youth unemployment by taking as a frame of reference the job search model. A second group of works [23] then studied, without direct reference to the microeconomic theory, unemployed seniority.

As a result of this work, several studies enriching the understanding of the duration of unemployment have developed in developed countries with various 
conclusions. Fougère [24] highlights the individual characteristics on which employers base their hiring selection strategies, particularly in periods of high unemployment in the case of France. His study is devoted to the influence of the economic situation on the individual durations of unemployment. The individual characteristics enumerated in his study are demographic (sex, age, nationality and family status) and socio-economic (initial training, qualification and previous career path). In the same vein, Bonnal and Fougère [25] reached the same conclusions with the integration of a new socio-economic variable (socioprofessional category of the individual). The work of Joutard and Werquin [26] enriches the understanding by including in the analysis of the individual determinants of duration the distinction between the exit of unemployment on a precarious job and that on a stable job. The results highlight the difference between individual factors and work experience according to the type of job found (stable or precarious). The work of Bourdet and Persson [27], based on a comparative analysis between France and Sweden, emphasizes the need to put in place appropriate policies to absorb youth unemployment fairly quickly. According to this study, the employment policy for young people became permanent in France while it was able to return to Sweden at its level of fifteen years ago (affecting about $4 \%$ of the young working population). According to him, this situation is due to the fact that in France the measures were taken late.

The growth and persistence of unemployment are worrying because of the change in its physiognomy, which highlights the duality between graduates and non-graduates [28] and the issue of the exit from unemployment with unemployed seniority [29]. The work of Lê et al. [30] leads to an increase in the long-term unemployment rate between 2008 and 2013 among the most fragile asset categories: workers, employees, young people, people without diplomas, single parents, inhabitants of sensitive urban areas and immigrants. In 2013, for example, people without a diploma have a long-term unemployment risk that is twice as high as those with a level of 2 years or more.

On the other hand, other studies have pointed out that the effect of time spent on unemployment on the risk of leaving unemployment is explained by the heterogeneous nature of the cohorts of entries into unemployment. According to Di Paola and Moullet [31], the non-taking into account of the heterogeneity existing between individuals leads to a negative temporal dependence of the risk of exit from unemployment. This phenomenon of negative time dependence of risk also underlined by Heckman and Singer [14] is better known under the name of "movers-stayers." It shows the importance of controlling individual heterogeneity in understanding the phenomenon.

Some studies on long-term unemployment have been observed in Africa. The first study is done by Lachaud [32]. According to this author, the mode of access to the labor market seems to be a major determinant of situations of social exclusion, and the influence of this factor goes far beyond what could be called the inherent "logical exclusion" of the destabilization of African economies. Guessan [33] indicates that Ivorian unemployed people in Côte d'Ivoire are less active in job search than non-Ivorian unemployed people and are more competitive. In addition, the study points out that the unemployment rate and the density of the municipality of residence of the unemployed influence the intensity of the job search and the choice of job search methods. Chort et al. [34] conclude for Senegal that apprenticeship is a decisive factor in entry into the labor market, based on the competing risk-entry duration models. By comparing the trajectories of former apprentices with those of non-apprentices, they conclude that the role of entry to apprenticeship is important for subsequent social and occupational integration. 
While in Côte d'Ivoire, the high rate of unemployment may be attributable, on the one hand, to the inadequacy of jobs in the modern sector ${ }^{2}$ and, on the other hand, to the fact that a large proportion of those wishing to work are not seeking a job, and the duration of unemployment can be explained by other additional parameters related to the personal characteristics of the individual. To our knowledge, no study has addressed the determinants of the duration of unemployment duration by integrating an econometric analysis for the case of Côte d'Ivoire. In view of the above, we will attempt to conduct this study based on the AGPEE literature and data in 2012.

\section{Methodology and data source}

Our econometric study of the links between the individual characteristics of young people and the duration of unemployment joins the paradigm of the demand for labor [35]. ${ }^{3}$ The heterogeneity of individual characteristics makes it possible to assess the correlation existing between jobseekers and the difficulty of getting out of unemployment. From a methodological point of view, our analysis is enriched by the integration of a certain number of explanatory variables.

\subsection{Econometric model of duration}

The objective being to estimate the probability of a young person finding a job according to the number of months spent unemployed, several econometric models could be useful: for example, a probit or a Tobit. The use of a duration model essentially resides in the fact that it allows to keep in the sample individuals still unemployed at the time of the survey. This type of model is necessary, especially to take into account the censored unemployment episodes. One of the difficulties encountered with the estimation by a duration model is to choose, from all the possible options, a particular description of the probability distribution of the duration variable, having implications on the form of the risk function. A common prediction of empirically observed unemployment durations is that they are characterized by a negative time dependence, ${ }^{4}$ leading to the rejection of constant random functions, such as that associated with the exponential model [36]. For this type of analysis, the Weibull model is the most appropriate. This parametric estimation method is widely used $[37,38]$ because of, on the one hand, the relatively simple form of its survival function and, on the other hand, it belongs both to the family of so-called accelerated life models and so-called proportional hazards models. In addition, the Weibull model can estimate a monotonous chance increasing, monotonous decreasing or constant. A first, primarily descriptive, approach to the durations of our sample using the non-parametric Kaplan-Meier estimator encourages

\footnotetext{
2 The distribution of jobs in Côte d'Ivoire is divided into three sectors: the modern sector characterized by modern production technology, a skilled and salaried workforce and compliance with labor regulations. The informal rural sector is identified by microenterprises often confused with the family unit, a rudimentary production technique and the non-respect of labor regulations.

${ }^{3}$ Mériaux [35] calls the "labor demand paradigm" as a guiding principle of an observational program. Rather than focusing on the exchange of facts that occur on the market, priority is given to the different characteristics of each individual that could be an asset or a constraint to the job search.

${ }^{4}$ Allowing to estimate the chances that an individual leaves unemployment, or any other state of the labor market, at a given moment, knowing that he was unemployed until the previous moment (function of risk).
} 


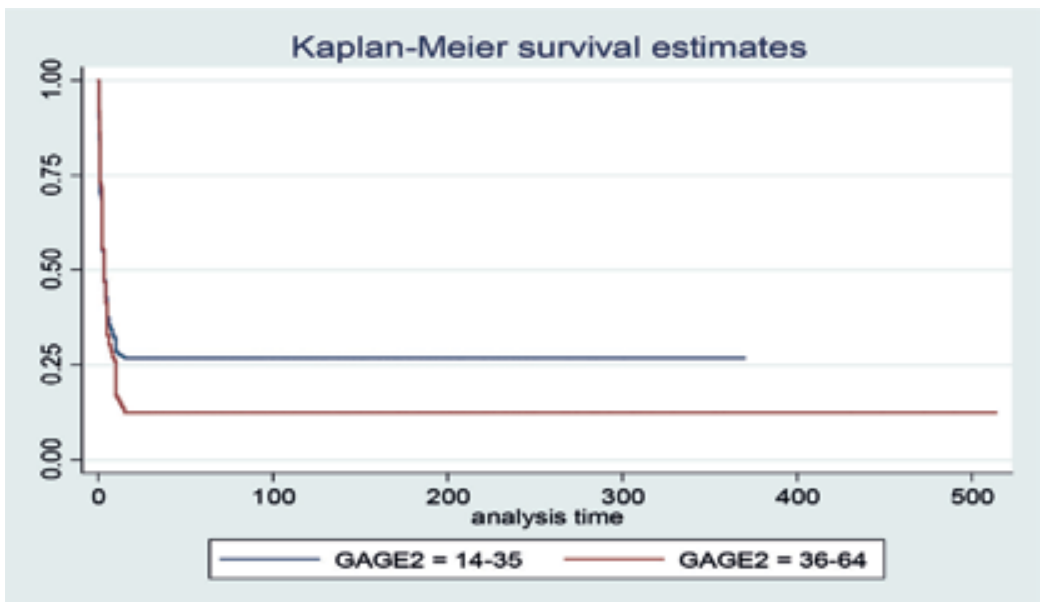

Figure 1.

Survival function by age group (labor force) obtained by non-parametric estimate of Kaplan-Meier. Source: Authors' calculations based on 2012 AGEPE data.

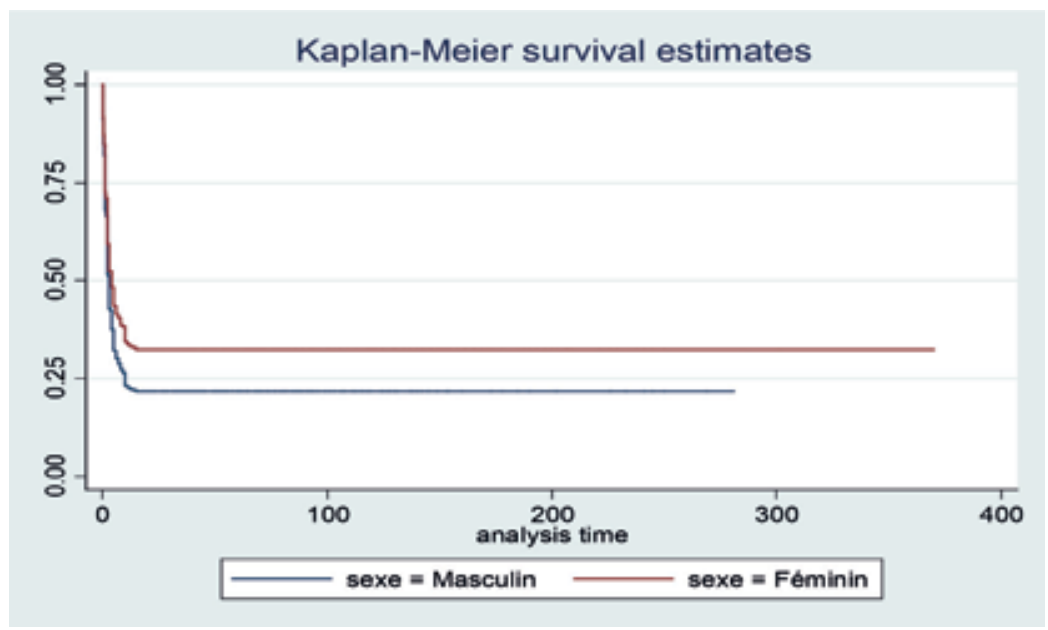

Figure 2.

Youth survival function by sex obtained from non-parametric Kaplan-Meier estimation. Source: Authors' calculations based on 2012 AGEPE data.

us to reject the exponential model (constant randomness) since it results in a decreasing monotonous distribution of durations, that is to say, a growing chance (see Figures 1 and 2). Anything that reinforces our choice of a Weibull model.

Let us note: $\mathrm{T}$ is the duration of unemployment; $\mathrm{T}^{*}$ is the random unemployment duration of an uncensored individual; $\mathrm{c}$ is the censored unemployment duration of an individual who has still not found a job at the time of the survey and censored, an indicator variable equal to 1 if the observation is censored and 0 otherwise.

$$
\left\{\begin{array}{l}
T=c, \text { if censored }=1 . \\
T=T^{*}, \text { otherwise. }
\end{array}\right.
$$

In addition, the model assumes that individuals whose unemployment durations are censored are representatives of all individuals whose unemployment durations 
are at least equal to $\mathrm{c}$. If we consider $\mathrm{c}$ as a random variable, then $\mathrm{c}$ must be independent of $\mathrm{T}^{*}$ after taking into account the other factors explaining the duration of unemployment. The distribution of probabilities of unemployment duration $\mathrm{T}$ can be specified by the following distribution function:

$$
F(t)=\operatorname{Prob}(T<t)
$$

$F(t)$ then represents the probability that an unemployment duration $\mathrm{T}$ lasts less than $t$ periods. The corresponding density function is:

$$
f(t)=\frac{d F(t)}{d t}
$$

By $f(t) d t$, we then have the probability that the unemployment duration $\mathrm{T}$ will end between $t$ and $(t+d t)$ periods. These functions (distribution and density) make it possible to determine the survival function $S(t)$ and the function $(t)$ with:

$$
\begin{aligned}
\lambda(t) & =\lim _{\Delta t \rightarrow 0} \frac{\operatorname{Prob}(t \leq T \leq t+\Delta t \mid T \geq t)}{\Delta t} \\
& =\lim _{\Delta t \rightarrow 0} \frac{F(t+\Delta t)-F(t)}{\Delta t S(t)}=\frac{f(t)}{S(t)}
\end{aligned}
$$

Or

$$
\lambda(\mathrm{t})=\frac{\mathrm{f}(\mathrm{t})}{\mathrm{S}(\mathrm{t})}=\frac{\mathrm{dF}(\mathrm{t}) / \mathrm{dt}}{\mathrm{S}(\mathrm{t})}=\frac{-\mathrm{dS}(\mathrm{t}) / \mathrm{dt}}{\mathrm{S}(\mathrm{t})}=-\frac{\mathrm{d} \ln \mathrm{S}(\mathrm{t})}{\mathrm{dt}}
$$

And so that:

$$
f(t)=S(t) \lambda(t)
$$

Generally, the identification of the factors that affect the probability of exit from unemployment to employment is analyzed using the risk functions. We subscribe to this logic. Moreover, Steiner [39] emphasizes that risk functions can be interpreted as reduced forms of the basic job search model as elaborated by McCall [40].

\subsection{Estimation method}

The duration models lend themselves to various types of estimation. The approach chosen for the estimates is the parametric method and, more specifically, proportional hazard models [41]. Suppose t follows a Weibull distribution, noted:

$$
f(t)=\lambda p(\lambda t)^{p-1}
$$

where $t$ is an embodiment of $\mathrm{T} ; \lambda$ is the risk function and $\mathrm{p}$ is a scale parameter. These parameters ( $\lambda$ and $p$ ) can be estimated by the maximum likelihood method.

The formulated likelihood function is the sum of the likelihood functions of uncensored and censored observations such that:

$$
\ln L(\beta, \alpha \mid \text { data })=\sum_{i=1}^{n}\left[\delta_{i}\left(\frac{\ln t_{i}-X_{i}^{\prime} \beta}{\sigma}-\ln \sigma\right)-\exp \left(\frac{\ln t_{i}-X_{i}^{\prime} \beta}{\sigma}\right)\right]
$$


where $\sigma=1 / p ; \delta_{i}=1$ for individuals having completed their period of unemployment; $\delta_{i}=0$ for those still unemployed and $X_{i}$ ' is the vector of the explanatory variables

As specified, the model may suffer from a heterogeneity problem. This problem can be considered in the duration models as the main result of an incomplete specification. It is usually due to the fact that the observed process may have started at different points in the calendar for the different individuals in the sample. To take into account this heterogeneity, a random element $v_{i}$ summarizing heterogeneity not taken into account in the model is introduced in the parametric model ${ }^{5}$ and the law of duration is rewritten conditionally to this term.

If there is apparently no general theorem in the choice of the distribution of this term, the most recurrent laws are the Gamma law and the inverse-Gaussian law (Inverse Gaussian). ${ }^{6}$ The Gamma distribution is frequently used in this type of analysis because the value of $\theta$ is higher with this specification. Thus, in the case where $v_{i}$ follows a Gamma distribution of mean 1 and variance $\theta$, the heterogeneity test is to check if the parameter $\theta$ is statistically different from zero.

Data from the study came from the Employment Survey of Households in Côte d'Ivoire (EEMCI) conducted in 2012 by the Agency for Studies and Promotion of Employment (AGEPE), a structure under the supervision of the Ministry of Employment. The purpose of the survey was to update the employment indicators, with a view to constitute a reference for the evaluation of current initiatives in the field of employment promotion.

\begin{tabular}{|c|c|c|c|c|}
\hline \multirow[t]{2}{*}{ Variables } & \multicolumn{2}{|c|}{ Young man } & \multicolumn{2}{|c|}{ Young woman } \\
\hline & Average & Standard deviation & Average & Standard deviation \\
\hline \multicolumn{5}{|l|}{ Marital status } \\
\hline Single & 0.519 & 0.492 & 0.387 & 0.487 \\
\hline Married & 0.403 & 0.491 & 0.598 & 0.490 \\
\hline Widower/divorced & 0.005 & 0.750 & 0.151 & 0.122 \\
\hline \multicolumn{5}{|l|}{ Middle of residence } \\
\hline Abidjan & 0.190 & 0.392 & 0.199 & 0.400 \\
\hline Other urban & 0.226 & 0.419 & 0.229 & 0.420 \\
\hline Rural & 0.583 & 0.493 & 0.571 & 0.494 \\
\hline \multicolumn{5}{|l|}{ Level of education } \\
\hline No & 0.440 & 0.496 & 0.574 & 0.494 \\
\hline Primary & 0.276 & 0.447 & 0.226 & 0.442 \\
\hline Secondary & 0.223 & 0.416 & 0.130 & 0.335 \\
\hline Superior & 0.061 & 0.240 & 0.300 & 0.170 \\
\hline \multicolumn{5}{|l|}{ Groupe d'âges } \\
\hline Young & 0.350 & 0.477 & 0.420 & 0.493 \\
\hline Young adult & 0.651 & 0.477 & 0.579 & 0.493 \\
\hline
\end{tabular}

Source: Authors' calculations based on 2012 AGEPE data.

Table 2.

Descriptive statistics of model varia.

\footnotetext{
5 The strictly non-parametric approach of the Kaplan-Meier estimator is robust to this problem.

${ }^{6}$ Finding done by Jenkins [42].
} 
EEMCI provides information on the socio-economic and demographic characteristics of 11,600 households, or 49,590 individuals. Among them, there are 28,875 individuals of working age or $58.23 \%$. The base sample comprises 19,115 individuals aged $14-35$ years. This young population represents $66.20 \%$ of people of working age and is composed as follows: $61.56 \%$ of employed persons (11,767 individuals); $7.30 \%$ (1394 young people) unemployed and $31.14 \%$ inactive (5954 young people).

\subsection{Model variables}

The dependent variable of the model is the duration of unemployment, continuous variable expressed in months. From the various works cited above and according to the variables available in the database, we retain these sociodemographic variables (age, sex, place of residence, marital status and level of education) as explanatory variables. Each of the variables has several modalities that are supposed to have different effects on the duration of unemployment (see Table 2 in the appendix).

It is expected that a married woman would tend to stay in unemployment longer than an unmarried woman by the presence of a spouse who is able to support the family. This situation is accentuated when there are dependent children. In addition, young women living in urban areas should experience longer unemployment durations. In addition, more educated individuals would be less likely to be in a state of prolonged unemployment.

\section{Econometric results}

At the level of the non-parametric approach, a first analysis is made by distinguishing according to the age group in order to capture the specificities that could exist between young people and adults. The parametric approach is discussed later.

\subsection{Non-parametric approach}

Kaplan-Meier estimators of the non-parametric approach for survival functions by age group show that adult unemployment durations are generally shorter than those of youth (see Figure 1). It also appears that the unemployment durations of young women are longer than those of young men (see Figure 2). Their survival function above that of young men confirms their difficulties in entering the labor market.

If we combine the age criterion with that of gender, we can, in relation to the level of the rates, constitute two groups of young people. The youngest (14-24 years old), and particularly young women, can be classified as the most group. Young men over the age of 24 are significantly less exposed to unemployment than those in the first group.

\subsection{Parametric approach}

Table 3 (annexed) presents the results of risk function estimates taking into account the heterogeneity between individuals. It traces the explanatory factors of the duration of unemployment among young people by sex.

Among the factors that expose workers to long-term unemployment, the analyses tend to highlight individual characteristics. Among these characteristics, it is common to distinguish "demographic" individual characteristics (sex, age and 


\begin{tabular}{|c|c|c|c|}
\hline Explanatory variables & Woman & Man & Ensemble \\
\hline \multicolumn{4}{|l|}{ Other characteristics } \\
\hline Man & - & - & $1.591(4.71)^{* * *}$ \\
\hline 14-24 years old & $1.266(1.41)$ & $1.190(1.22)$ & $1.240(1.99)^{* *}$ \\
\hline \multicolumn{4}{|l|}{ Level of education } \\
\hline No & $3.050(3.36)^{* * *}$ & $2.070(3.42)^{* * *}$ & $2.347(4.69)^{* * *}$ \\
\hline Primary & $1.673(1.57)$ & $1.314(1.29)$ & $1.438(0.04)^{* *}$ \\
\hline Secondary & $1.150(1.45)$ & $0.231(0.60)$ & $1.144(0.75)$ \\
\hline \multicolumn{4}{|l|}{ Middle of residence } \\
\hline Abidjan & $0.836(-0.93)^{*}$ & $1.020(0.14)$ & $0.950(-0.44)$ \\
\hline Other urban & $0.684(-1.34)$ & $0.908(-0.63)$ & $0.823(-1.61)$ \\
\hline Rural & Ref. & Ref. & Ref. \\
\hline \multicolumn{4}{|l|}{ Marital status } \\
\hline Single & $1.451(0.73)$ & $1.436(0.49)$ & $1.150(0.35)$ \\
\hline Married & $1.083(0.016)$ & $1.822(0.81)$ & $1.169(0.40)$ \\
\hline Widower/divorced & Ref. & Ref. & Ref. \\
\hline Constante & $0.280(-2.12)^{* *}$ & $0.270(-1.73)^{*}$ & $0.267(-3.09)^{* * *}$ \\
\hline $\operatorname{Ln}(p)$ & $0.482(10.52)^{* * *}$ & $0.454(0.454)^{* * *}$ & $0.461(15.95)^{* * *}$ \\
\hline $\operatorname{Ln}(\theta)$ & $1.320(12.48)^{* * *}$ & $1.360(23.28)^{* * *}$ & $1.579(36.32)^{* * *}$ \\
\hline$p$ & 2.3368 & 1.575 & 1.586 \\
\hline$\sigma=1 / p$ & 0.61746 & 0.635 & 0.630 \\
\hline$\theta$ & 6.169488 & 0.227 & 4.855 \\
\hline Number of observations & 2368 & 2530 & 4898 \\
\hline Wald $\operatorname{chi}^{2}(01)$ & 1023.86 & 1701.12 & 2100.95 \\
\hline Prob $>c h i^{2}$ & 0.000 & 0.000 & 0.000 \\
\hline Log likelihood & -4243.682 & -7246 & -8923 \\
\hline
\end{tabular}

Source: Authors' calculations based on 2012 AGEPE data.

${ }^{*}$ Significant at $10 \%$.

${ }^{* *}$ Significant at $5 \%$.

*** Significant at $1 \%$.

Table 3.

Determinants of the duration of youth unemployment by gender Weibull with correction of heterogeneity (Gamma).

family situation) and individual socio-economic characteristics (initial education and level of education) [43].

An examination of the results of the estimates for the entire young population reveals that young men are more likely to leave unemployment than young women. The positive significance of the coefficient of this variable confirms those obtained with the non-parametric approach. Unemployed young women aged 14-24 have the same characteristics as young men in the same age group, with the difference that young women enter the labor market earlier. Their greater difficulty in accessing the labor market may be due to their low level of education and the weight of tradition relegating the role of women to household chores.

If young people are unemployed longer compared to adults (see Figure 1), the results highlight particularities within the young population. It should also be noted 
that belonging to the group of individuals aged 14-24 rather than being a young adult (25-35 years old) increases the chances of getting out of unemployment.

This indicates that in Côte d'Ivoire, adults are leaving unemployment more quickly. They "survive" less time in the unemployment state. The age of the end of studies being around 24 years (short cycle of vocational training type), a possible explanation would be that at the exit of the education system, these young people have a strong employability.

Beyond age, it also seems that long-term unemployment would affect more young graduates. However, the results obtained with the level of education contrast this reasoning. It appears that it is young people with no education who are less likely to be unemployed.

This gives an idea of the type and quality of the job, regardless of the sex of the applicant. Thus, young women or young men with no education are those who have a high probability of getting out of unemployment relatively quickly. One possible explanation lies in the relocation or closure of many companies caused by the military-political crisis unleashed in 2002. What fuels the precarious job of workers without expertise or professional training? The informal sector, especially domestic ones, occupies the majority of young people. The formal private sector offers only a small proportion of jobs [44]. This situation is the result of a strong mismatch between training and employment. Policies in favor of the decline in unemployment would be more effective by favoring a revision of the Ivorian education system that would integrate the concerns of businesses and professions of the future (Table 4).

Other factors may play in favor of long-term unemployment, sometimes just as important: this is the fact of residing in the economic capital supposed to reduce the probability of leaving unemployment. However, among young women, residing in Abidjan increases the chances of staying longer unemployed. The economic capital is therefore an area with fewer job opportunities for them. Among young men,

\begin{tabular}{llccc}
\hline \multirow{2}{*}{ Age group } & & Woman & Man & Ensemble \\
\cline { 2 - 4 } & 14-24 years & 56.16 & 43.84 & 100.0 \\
\cline { 2 - 4 } & 25-35 years & 60.51 & 39.49 & 100.0 \\
\hline \multirow{2}{*}{ Place of residence } & Abidjan & 48.91 & 51.09 & 100.0 \\
\cline { 2 - 4 } & Other urban areas & 53.71 & 46.29 & 100.0 \\
\cline { 2 - 4 } & Rural areas & 57.17 & 42.83 & 100.0 \\
\cline { 2 - 4 } Educational level & None & 69.15 & 40.85 & 100.0 \\
\cline { 2 - 4 } & Elementary school & 64.71 & 30.42 & 100.0 \\
\cline { 2 - 4 } & High school & 43.64 & 56.36 & 100.0 \\
\cline { 2 - 4 } & Higher education & 40.69 & 59.31 & 100.0 \\
\hline \multirow{2}{*}{ Marital status } & Single & 46.63 & 53.37 & 100.0 \\
\cline { 2 - 4 } & Married & 66.99 & 33.01 & 100.0 \\
\cline { 2 - 4 } & Widowed/divorced & 83.64 & 16.36 & 100.0 \\
\hline \multirow{2}{*}{ Ensemble } & & 56.18 & 43.82 & 100.0 \\
\hline \multirow{2}{*}{ Sourc: } & & & 29 \\
\hline
\end{tabular}

Source: Authors' calculations based on 2012 AGEPE data.

Table 4.

Proportion of unemployed youth by gender (\%). 
there are no statistically significant differences in the chances of getting out of unemployment between those living in rural areas and those living in urban areas.

As we pointed out in Section 1, several initiatives have been undertaken to combat unemployment in Côte d'Ivoire. But to our knowledge, there are still no accompanying measures geared specifically to the long-term unemployed. This practice could significantly reduce the duration of long-term unemployment.

\section{Discussion}

The study highlights the importance of educational attainment in explaining the duration of youth unemployment. Indeed, the fact that young women are unemployed for long periods of time shows that they have low levels of education compared to young men. Several reasons can be given to explain this result. We can mention: the persistent reluctance in the schooling of the girl child in certain regions of the country; the early exits of the girl child from the educational system for household support, because of the weight of tradition relegating the role of the woman, primarily to household chores or to forced marriage and school pregnancies.

Policies for free schooling, especially for girls, should be evaluated and reoriented so that they can achieve their objectives. This new orientation could concern the complete care of the girl up to secondary school. In addition, the "zero school pregnancy" policy should be accentuated. In the short term, a policy to support women's entrepreneurship through a series of training courses and easy access to finance could be a real lever to reduce unemployment among young girls in Côte d'Ivoire. These policies should also integrate the needs of parents through incentives.

\section{Conclusion}

The purpose of this contribution was to analyze the determinants of the duration of youth unemployment in Côte d'Ivoire. Specifically, the author wanted to capture the particularities of long-term youth unemployment by gender. The proportional hazard model with heterogeneity correction applied to data from the Household Employment Survey in Côte d'Ivoire (EEMCI) results in the following results. Young men are more likely to leave unemployment than young women. The low level of education of these and the inadequacy of training in relation to the needs of the labor market largely justify this situation. In addition to educational level, the place of residence also determines the duration of unemployment among young women.

This work could be enriched by a spatial analysis that would highlight the most disadvantaged localities in terms of workforce absorption capacity.

However, this may be possible only if future surveys provide information at the disaggregated level (departments or communes). Also, to enumerate and characterize the long-term unemployed are certainly essential steps, but must be completed by examining the way out of long-term unemployment for an effective policy implementation in Côte d'Ivoire. 


\section{Author details}

Ibrahima ${ }^{1 *}$ and Akrassi Kouakou Evrard Kouame ${ }^{2}$

1 Laboratoire d'Économie Appliquée au Développement (LEAD), University in Toulon (UTLN), France

2 Université Félix Houphouët Boigny, Abidjan, Côte d'Ivoire

*Address all correspondence to: himrasy@yahoo.fr

\section{IntechOpen}

(C) 2020 The Author(s). Licensee IntechOpen. This chapter is distributed under the terms of the Creative Commons Attribution License (http://creativecommons.org/licenses/ by/3.0), which permits unrestricted use, distribution, and reproduction in any medium, provided the original work is properly cited. (c) BY 


\section{References}

[1] Agepe. Situation de l'emploi en Côte d'Ivoire en 2012. Rapport de synthèse. Abidjan: Agence d'études et de promotion de l'emploi (Agepe); 2013. Available from: http://directiongenerale mploi.ci/wp-content/uploads/2016/09/ Situation-de-lemploi-en-2012.pdf

[2] Ensete. Ministère du Plan et du Developpement. Enquete nationale sur la situation de l'emploi et du travail des enfants (Ensete 2013). Rapport descriptif sur le travail des enfants. Abidjan; 2013. Available from: http:// www.ins.ci/n/documents/travail_enfa nt/Enqute\%20nationale\%202013.pdf

[3] Harris JR, Todaro MP. Migration, unemployment and development: A two-sector analysis. The American Economic Review. 1970;60(1):126-142

[4] AGEPE. Enquête nationale sur la situation de l'emploi et du travail des enfants (ENSETE 2013): Rapport descriptif sur la situation de l'emploi, août. 2014

[5] Bull C, Jovanovic B. Demand-shift versus mismatch as causes of labour mobility. Review of Economic Studies. 1988;55:169-176

[6] Burdett K, Kiefer NM, Mortensen DT, Neumann GR. Earnings, unemployment, and the allocation of time over time. The Review of Economic Studies. 1984;51(4):559-578.7

[7] Deere DR. Labor turnover, jobspecific skills and efficiency in a search model. Quarterly Journal of Economics. 1987;81:5-833

[8] Stigler GJ. Information in the labor market. Journal of Political Economy. 1962;70 (5, Part 2):94-105. 24(1-2), pp. $63-132$

[9] Cain GG. The challenge of segmented labor market theories to orthodox theory: a survey. Journal of Economic Literature. 1976;14(4): 1215-1257

[10] Doeringer P, Piore MJ. Internal Labor Markets and Manpower Adjustment. New York: DC Heath and Company; 1971

[11] Fortin B, Fougère D, Lacroix G. The impact of government-sponsored training programs on labour market transition. In: Document de travail, CYRANO, 1999RP-03. 1999

[12] Diamond P. Consumer differences and prices in a search model. The Quarterly Journal of Economics. 1987; 102(2):429-436

[13] Lancaster T. Econometric methods for the duration of unemployment. Econometrica: Journal of the Econometric Society. 1979:47(4): 939-956

[14] Heckman J, Singer B. A method for minimizing the impact of distributional assumptions in econometric models for duration data. Econometrica. Journal of the Econometric Society. 1984;52(2): 271-320. DOI: 10.2307/1911491

[15] Kiefer NM. Economic duration data and hazard functions. Journal of Economic Literature. 1988;26(2): 646-679

[16] Lancaster K. The economics of product variety: A survey. Marketing Science. 1990;9(3):189-206

[17] Lancaster T. Generalised residuals and heterogeneous duration models: With applications to the Weilbull model. Journal of Econometrics. 1985; 28(1):155-169

[18] Lancaster T, Nickell S. The analysis of re-employment probabilities for the unemployed. Journal of the Royal 
Statistical Society. Series A (General). 1980:141-165

[19] Lancaster T, Chesher A. An econometric analysis of reservation wages. Econometrica: Journal of the Econometric Society. 1983:1661-1676

[20] Van den Berg GJ. Nonstationarity in job search theory. The Review of Economic Studies. 1990;57(2):255-277

[21] Fougère D. Recherche d'emploi en présence de contrats de travail de courte durée: modélisation et estimation sur données individuelles. Annales d'Economie et de Statistique. 1989: 225-257

[22] Moreau A, Visser M. Durée du chômage des jeunes en France. Annales d'Economie et de Statistique. 1990: 257-278

[23] Thélot C. La sortie du chômage. In: Mélanges économiques. Essais en l'honneur de: Edmond Malinvaud, Economica; 1988

[24] Fougère D. La durée du chômage en France. Réduction du chômage: les réussites en Europe. 2000:239-259

[25] Bonnal L, Fougère D. Les déterminants individuels de la durée du chômage. Économie \& Prévision. 1990; 96(1990-5):45-82

[26] Joutard X, Werquin P. Les déterminants individuels de la durée de chômage: de l'intérêt de distinguer les emplois stables des emplois précaires. Économie \& Prévision. 1992;102(1): 143-156

[27] Bourdet Y, Persson I. Chômage des jeunes et fonctionnement du marché du travail: Les cas français et suédois.

Économie et Statistique. 1991;249(1): 39-51

[28] Bougroum M, Ibourk A. Les effets des dispositifs d'aide à la création d'emploi dans un pays en développement: Cas du Maroc. Revue Internationale du Travail (BIT). 2003;142(3)

[29] Cases C, Lollivier S. Estimation d'un modèle de sortie du chômage à destinations multiples. Économie et Prévision. 1994;113-114:177-188

[30] Lê J, Le Minez S, Rey M. Chômage de longue durée: La crise a frappé plus durement ceux qui étaient déjà les plus exposés. In: Vue d'ensemble-Marché du travail, Insee. 2013

[31] Di Paola V, Moullet S. L'emploi public et les trajectoires d'insertion des jeunes. Economie et Statistique. 2003; 369-370:49-74

[32] Lachaud JP. Croissance économique, pauvreté et inégalité des revenus en Afrique subsaharienne: analyse comparative. Centre d'économie du développement, Université Montesquieu-Bordeaux IV; 1996

[33] N'Guessan CFJ. Analyse des déterminants de l'intensité de la recherche d'emploi en Côte d'Ivoire. L'Actualité Économique. 2015;91(3): 339-366

[34] Chort I, De Vreyer P, Marazyan K. L'apprentissage au Sénégal, déterminants et trajectoires. Autrepart. 2014;3:175-193

[35] Mériaux B. Point de vue sur les recherches françaises en économie du travail. Revue Économique. 1978: 120-140

[36] Delattre E, Salognon M. Entreprises, modes de gestion de la main-d'œuvre et allongement de la durée de chômage : une analyse économétrique. Recherches Économiques de Louvain. 2008;74(3): 299-325

[37] Allison PD. Survival Analysis Using the SAS System: A Practical Guide. USA: SAS Institute Inc.; 1995 
[38] Allison PD. Survival Analysis Using sas ${ }^{\circledR}$ : A Practical Guide (First ed.). SAS Publishing; 1995

[39] Steiner P. Le marché selon la sociologie économique. Revue européenne des sciences sociales. European Journal of Social Sciences. 2005;XLIII-132:31-64

[40] McCall JJ. Economics of information and job search. The Quarterly Journal of Economics. 1970: 113-126

[41] Cox DR. Regression models and lifetables. Journal of the Royal Statistical Society. Series B (Methodological). 1972;34(2):187-220. Available from: http://www.jstor.org/stable/2985181 [Accessed: 27 May 2020]

[42] Jenkins R. Social Identity. 2nd ed. Routledge; 2004

[43] Florens J-P, Fougère D, Werquin $P$. Durées de chômage et transitions sur le marché du travail. Sociologie du Travail. 1990;4:439-468

[44] Lautier B. Secteur informel et emploi: l'enseignement des pays sousdéveloppés. Revue Tiers Monde. 2013;2: 151-167 


\title{
The Factors Influencing SMEs Growth in Africa: A Case of SMEs in Zimbabwe
}

Kosmas Njanike

\begin{abstract}
Today Africa reports high levels of unemployment among other social issues causing governments' instability and low economic growth. Brain drain, low gross domestic product (GDP) per capita and growth reported across the continent requires an initiative on driving entrepreneurship development. The study seeks to investigate the determinants of small to medium enterprises (SMEs) growth in developing countries with a special focus on Zimbabwe. Informed by literature, the Zimbabwe Finscope Business Consumer Survey (2012) data was used to run a linear programming model regression analysis on the factors influencing SMEs profitability in that country. The study found that number of business units, education level, business type, family run businesses, expertise, licenced, advertising and bank account were significant in influencing SMEs profitability. The results will assist policymakers, development partners, entrepreneurs and other stakeholders. The insight can also be useful to venture capitalists, investment banks, investors and other financiers. There is need to support the millions of SMEs and future entrepreneurs in improving the regulatory and business environment, improving institutional support systems, promoting technology transfers, innovations and improving productivity.
\end{abstract}

Keywords: entrepreneurial development, Zimbabwe, business, employment

\section{Introduction}

Micro, small and medium enterprises have faced different challenges on the African continent. The challenges faced by small businesses has caused them not to grow, that is, low profitability and depressed growth. The definition of small to medium enterprises (SMEs) differs from country by country. In some countries the criteria for the classification is capital and in others is based on the number of employees. In other countries such as Japan a mixed criteria is used. For the purpose of the current study, small to medium enterprises have been defined as those business entities employing 75 or less people. With other enterprises not operating for long, the sector employs a large percentage of adults on the continent. Though the sector has managed to create many job opportunities the majority of the players operate under capacity. In comparison with other developed countries, enterprises on the continent have the capacity to contribute more to the gross domestic product (GDP) as well as creating more job opportunities. The policymakers and other 
players need to craft policies and strategies that enhance the growth of the sector. What then should be done? There is need to understand the factors influencing the performance of SMEs in Africa. Though factors may differ from one country to another the gap remains to be filled. Small to medium enterprises (SMEs) has been defined as a venture with less than 75 employees. The chapter investigates the determinants of small to medium enterprises in Africa using Zimbabwe as a case study.

\section{Background}

It is crucial for the economically active population segment to realise their aspirations in achieving economic independence as well as discovering their place in society. There is a global job crisis that has worsened the vulnerability of many in relation to lower job quality, high unemployment, higher job market inequalities, increased time to secure employment and high levels of uncertainty. Many African countries among other developing nations have been affected by this situation leading to many leaving their country of birth in search of greener pastures in neighbouring countries and other countries. There is urgent need to address the employment crisis using a multi-faceted approach towards business growth and job creation. One way is to improve or support the SMEs sector that employs a huge population and has potential to employ more. The SMEs sector faces a myriad of challenges across the continent and fails to live up to expectations. Zimbabwe has not been spared in this crisis as there are high business failures and unemployment levels. Several studies have been done on SMEs in different countries including Zimbabwe but the sector remains depressed or incapacitated. There are a number of areas that need attention for creation of value through the SME sectors that have not been addressed in the extant literature. This study contributes to literature by investigating the determinants of SMEs profitability in Zimbabwe.

In spite of the fact that $99 \%$ of business enterprises in developing countries are SMEs the sector is yet to exploit its potential in terms of growth and contribution to the economy. Despite of so much having been written on the importance of SMEs in developing economies the sector is still entangled in a myriad of challenges. SMEs are found in all sectors of the economy and represent a wide variety of information and communication technology (ICT) use, formality and firm sizes. SMEs contribute in different ways to economies in Africa. The SMEs differ from one country to another on the continent in terms of number (World Bank, 2016) and factors affecting growth or operations. It is also important to note that there are many things in common in the same sector and a policy implemented in one country or region may possibly work in others. However as variation between countries across the continent may be huge data uncertainty is high.

The number of SMEs in a country is not essentially correlated with the level of economic development. On the African continent activity is dispersed across the large number of more or less formal SMEs. For example in more developed economies economic activity is a large extent structured in larger entities, in the agriculture, manufacturing and services sector. Therefore the number of SMEs in developing economies is mainly determined by supply side (institutional) factors. The number of SMEs does not necessarily reflect their contribution to the overall economy. In a study on SMEs, Beck and Demirgüç-Kunt [1] state that the sectors impact on GDP and employment shows a strong positive relationship with GDP per capita. As a result the more developed a country is the greater is its importance to the entire economy. The study also revealed that there exists a significant negative correlation between employment and GDP contributed by the informal economy and GDP per capita. A large informal sector in Sub-Saharan Africa results in a 
big number of SMEs but with low levels of GDP per capita. This may help explain the situation in many countries in Africa with people leaving for greener pastures though the number of SMEs recorded is high.

With a systematic development approach, SMEs play a role in driving the economy from an underdeveloped stage towards high growth and industrialisation. Studies have shown that SMEs start to play a crucial role at an early growth stage. The informal sector in African economies is still great, comprised of the majority of SMEs. The services sector is developed in two different ways [2]. Economic growth gives rise to both business and household sector demand for services such as utilities, transportation, trade, business and personal services. On the other hand, the growing economy also gives rise to incentives for business entities to graduate from the informal sector as local market growth potential improves. When the service sector grows substantially in proportion to overall production in society it is an indication of economies becoming more formalised and developed (Lake et al. 2010). This finding supports the view that SMEs play a pivotal role in service sector growth. Therefore industrial development can be attributed to improved investment, business environment and favourable raw material prices. Agriculture producers and other raw material providers have to hunt for improved production for increased competitiveness. Assisting African SMEs to develop is important for Africa for the global economy, following the creation of a growing middle class with disposable income, in line with market opportunities for new investors. The SMEs have created about $80 \%$ of the continent's employment, forming a new middle class that fuels demand for more goods and services.

SMEs have become a force to reckon in the development Zimbabwe's economy. For the past two decades the Zimbabwe's economy has struggled to perform in comparison to other economies [3]. The period has continued to be characterised with firm closures and many people losing jobs through retrenchments (Nyathi et al. 2018). As more workers lost their jobs the number of SMEs was on the rise with many becoming entrepreneurs by default. The majority of the economically active citizens have survived through operation of small businesses (Nyathi et al. 2018). The high levels of unemployment in the country have ushered many in the area of business as the economic conditions of continue to deteriorate [4]. Though many enterprises are started, few have survived and grown phenomenally due to selfemployment desire and a myriad of challenges. In a study of SMEs survival Abduli (2013) argues that starting an enterprise is one thing and survival or sustainability is another. Profitability and sustainability have to be enhanced if more job opportunities are to be created and business growth experienced.

The country of Zimbabwe has been hit by massive brain drain as many migrate to other countries for greener pastures. It is estimated that 3-4 million Zimbabweans live in the diaspora [5]. Running a profitable venture is critical and also considering the risks in business and understanding what influences the stability and health of the economy is crucial $[6,7]$. Developing country governments, private sector and other development institutions, must ponder on SMEs and create opportunities for Africa's young people for economic growth and stability. All regional blocks, governments, banks and other development partners have to develop all-inclusive programmes and policies to consolidate SMEs if the region is to realise economic growth. This has motivated this study to investigate the determinants of SMEs growth in Africa with a special focus on Zimbabwe. The government of Zimbabwe has to take an aggressive approach to drive an inclusive and balanced growth through the SMEs because of the huge potential for industrialisation if entrepreneurial mode is fostered. There is need to research on factors influencing SMEs business operations for insight to policymakers and other development players. 
The rest of the chapter is arranged as follows: Section 3 presents Literature Review; Section 4 describes the data used; Section 5 outlines the research methods used; Section 6 reports, analyses and discusses the results; and Section 7 concludes.

\section{Literature review}

There are many studies that have been done on entrepreneurship and SMEs on various issues concerning this sector. The following are some of the topics addressed in literature: security, technology use, employees, productivity, expertise, strategies and funding among others. Review of literature provides the foundation of knowledge on entrepreneurship and growth of business. There is also need for Identification of gaps in research in understanding the area better.

In a study focusing on the growth challenges and opportunities of SMEs in South Africa's food processing sector Mather [8] argues that the challenges faced must be viewed from a viewpoint of restructuring South Africa's agrifood system. Using a sample of 30 companies Mather [8] found that procurement practices are the most significant obstacles to the operations of these small firms. However this finding contradicts with Hanks et al. (2008), as supply chain management (SCM) used in the country operates within a regulatory framework set by the national government may be appropriate for bigger companies. However, the study did not address other factors affecting small to medium business operations.

Focusing on Small, Micro and Medium Enterprises (SMMEs) Ngcobo and Sukdeo [9] identified this sector as appropriate for job creation opportunities in SA. The study stresses the point that not many of these businesses succeed. The findings showed that challenges faced included the following: funding, regulations, inaccessible markets lack of confidence and labour costs.

Oyelana and Smith [10] focused on SMEs in South Africa to have a greater insight on their operations. The study used data collected through questionnaires. The study identified lack of finance, lack of managerial skills and training as important areas to consider in SMEs operation. Oyelana and Smith argue that these concerns must be addressed properly if the SMEs sector is to succeed in South Africa.

Yoshino and Taghizadeh-Hesary [11] revealed that SMEs made up more than $98 \%$ of Asian businesses providing two out of three private sector jobs. The authors also emphasised that functional support is vital for the sector. The study showed that SMEs face challenges such as insufficient use of information technology, limited access to finance, low research and development expenditures, lack of databases, low levels of financial inclusion and undeveloped sales channels. These were blamed for slow growth of SME businesses. However there are many other factors affecting SMEs that could have been included in the study.

Nkua et al. [12] focused on the effect of accessibility to credit on SMEs growth and operations. Nkua et al. [12] argue that credit availability is important for the survival and growth of SMEs. It is also argued that policy makers should pursue financial sector policies to boost financial intermediaries to design appropriate products and services for SMEs. In Ghana lack of adequate access to credit is a major limitation of small businesses growth. The argument is based on the premise that funds are required for investment in innovation and restructuring among other needs. This results of the study showed that a significant positive relationship between access to credit and certain attributes of a firm. Results also revealed that the following factors also affect SMEs access to bank credit: recording, business registration, asset ownership, documentation and business planning. 
Abeh [13] focused on the evaluation of different paradigms, prospects, challenges and policies towards SMEs in Delta State, Nigeria. A survey was used to collect data. The results of the study showed that the following affected the growth of SMEs; government efforts and prospects of SMEs. It was found that age and gender were not significant.

Ocioo et al. [14] analysed the extent to which the SMEs were affected by competition and globalisation in Ghana. The study found that gloabalisation ushered in technological changes and greater competition levels. The study conducted a Kendall's Co-efficient of Concordance to assess the extent various challenges influenced businesses in competitiveness and globalisation. Ocioo recommended that SMEs must properly strategize to embrace the changes in the market place and culture around the globe. The study did not analyse other many other factors that have the potential to affect small business operations and growth in Ghana.

Gombarume and Mavhundutse [15] assessed the challenges affecting SMEs in Chitungwiza, Zimbabwe. They also looked at SMEs accessibility to loans from formal financial institutions and the impact of government policy on their growth and operations. The study found that SMEs were getting inadequate financial support from financial institutions. However an unstable macroeconomic environment was also found to be limiting the sector's growth. Gombarume and Mavhundutse advocated loan guarantee schemes and formalisation of SMEs.

Khalique et al. [16] considered the competitiveness of SMEs in a knowledgebased economy and explored the challenges that they face in Malaysia. The study also focused on intellectual capital and argued that it has become a lubricant of modern organisations in becoming competitive in knowledge-based economies.

Decker et al. [17] acknowledged that currently the operation and development of a service that uses wireless and mobile terminals is yet to be accepted by many SMEs in developing countries. This is mainly due to market structure and technical reasons that have become obstacles mobile business. This makes it imperative to also investigate the influence of mobile phones on SMEs operations and growth.

Kazimoto [18] found that SMEs often experience challenges on meeting the standards of their products for the international market and in securing microloans at initial stages of their life. This mainly applied to unemployed starting the business. The study assessed challenges that SMEs face in meeting international marketing standards. The results showed that SMEs experience the following on the international market: ignorance of standards and regulations; inadequate financial support; lack of government support; lack of consumer knowledge; lack of vital entrepreneurial and poor networking structures. Kazimoto recommended the need for more information availability to SME owners and the government to avail funds at concessionary rates. The study also use of more adverts, latest technology, attending networking events, seminars and trainings by entrepreneurs.

Turyahikayo [19] researched on challenges experienced by SMEs in raising funds in Uganda. The study used the social capital theory to show that SMEs in Uganda experience challenges in raising finance. Other challenges investigated include inadequate collateral, information opaqueness, low technical skills, poor managerial knowledge, competition, lack of professionalism and unavailability of suitable credit schemes.

Tinarwo [20] studied the challenges faced by the SMEs influencing their business operations, performance and growth in Gazaland industrial area in Harare, Zimbabwe. The findings showed that lack of government support, local authority unfair treatment, stiff competition, lack of markets, lack of finance, unfair treatment from the local authority, stiff competition, lack of training and low levels of technology use. Suppliers mistrust and poor infrastructure were also highlighted as hampering SMEs from formalising their business. 
On a study focusing on business start-ups in Zimbabwe, Nyoni and Bonga [3] found that majority of SMEs in Zimbabwe were prompted by unprecedented a shrinking job market as many workers were laid off. Nyoni and Bonga argue that SMEs have a great potential to play a crucial position in addressing socio economic challenges such as poverty and unemployment in Zimbabwe. It is also argued that many developed economies trace their development from SMEs growth and development. The results of the study show that enterprises in Zimbabwe are mainly influenced by the following factors technology, start-up funding, marketing, management skills, education level, social networks, age of owner, government, gender and financial support.

In sum extant literature reveals that factors influencing SMEs operation and growth include: technology, start-up funding, marketing, management skills, education level, social networks, age of owner, government, gender, financial support, lack of government support, local authority unfair treatment, stiff competition and research and development. There is no study that has considered or analysed the effect of these factors in a single study, The current study seeks to consider 26 variables in investigating the determinants of SMEs profitability with special reference to Zimbabwe.

\section{Methodology}

The current study used Finscope MSME Survey Zimbabwe (2012) that used random selection of eligible small to medium enterprises. It was a comprehensive survey focusing on individual entrepreneurs and owners of micro, small and medium enterprises (MSMEs) and their general needs. This survey carried out 3222 face to face interviews with business owners across all provinces in Zimbabwe. Those interviewed were above 18 years, business owners or generating income through business activities and employing 75 people or less. The survey provided critical information allowing one to analyse determinants of SMEs operation and growth focusing on a number of characteristics. The survey generated information about the characteristics and statistics of informal and formal SMEs operations. The survey gives valuable information permitting different elements of business that have not been studied before, owing to lack of appropriate information at the national level.

To address the research objective that seeks to investigate the determinants of SMEs business growth and operations in Zimbabwe an econometric model was created. The study estimated linear probability model (LPM) to investigate the determinants of SMEs growth, operations and profitability. The dependent variable is profitability, the level of profit obtained in the last 12 months.

In this analysis the LPM take as the dependent variable, profitability, the level of profits obtained in the past year. The 25 independent variables are as below.

profitability $=\mathrm{f}$ (number of business units, travelling distance, education level, age, ownerun, business type, family business, ownership, use ICT, motivation of starting business, financial problem, business regulation problem, business planning problem, employee motivation, advertising, licenced, bank account, business insurance, business records, business advisory, education, corruption, tax, marital)

\subsection{Descriptive statistics}

Twenty six variables considered have their frequency, percentage, mean and standard deviation displayed in Table 1 below. 
The Factors Influencing SMEs Growth in Africa: A Case of SMEs in Zimbabwe DOI: $h$ ttp://dx.doi.org/10.5772/intechopen.87192

\begin{tabular}{|c|c|c|c|c|}
\hline Characteristics of SMEs & Frequency & $\%$ & Mean & Std. Dev. \\
\hline Total number of respondents & 3222 & & & \\
\hline Businessnum & & & 1.262259 & 0.5354235 \\
\hline 1 & 2508 & 77.84 & & \\
\hline 2 & 598 & 18.56 & & \\
\hline 3 & 104 & 3.23 & & \\
\hline 4 & 10 & 0.31 & & \\
\hline 5 & 1 & 0.03 & & \\
\hline 6 & 1 & 0.03 & & \\
\hline Travel time & & & 7.053974 & 19.75407 \\
\hline Less than 10 mins & 494 & 29.30 & & \\
\hline $11-20$ & 366 & 21.71 & & \\
\hline $21-30$ & 278 & 16.49 & & \\
\hline $31-60$ & 214 & 12.69 & & \\
\hline $60-120$ & 116 & 6.88 & & \\
\hline $120-180$ & 59 & 3.50 & & \\
\hline$>180$ & 159 & 9.43 & & \\
\hline Education level & & & 4.22874 & 1.512077 \\
\hline No schooling & 134 & 4.16 & & \\
\hline Some primary education & 347 & 10.77 & & \\
\hline Grade 7 complete & 442 & 13.72 & & \\
\hline Some secondary incomplete & 715 & 22.19 & & \\
\hline Secondary school compete & 1246 & 38.67 & & \\
\hline A level & 52 & 1.61 & & \\
\hline College & 219 & 6.80 & & \\
\hline University degree & 67 & 2.08 & & \\
\hline Age & & & 3.336127 & 1.389518 \\
\hline $18-24$ years & 279 & 8.66 & & \\
\hline $25-30$ years & 647 & 20.08 & & \\
\hline $31-40$ years & 990 & 30.73 & & \\
\hline $41-50$ years & 608 & 18.87 & & \\
\hline $51-60$ years & 414 & 12.85 & & \\
\hline 60 years and above & 284 & 8.81 & & \\
\hline Ownerun & & & 0.996586 & 0.0583389 \\
\hline Yes & 3211 & 99.66 & & \\
\hline No & 11 & 0.34 & & \\
\hline Bustype & & & 0.0145872 & 0.119912 \\
\hline Formal & 3175 & 98.54 & & \\
\hline Informal & 47 & 1.46 & & \\
\hline fambus & & & 0.4484792 & 0.4974157 \\
\hline Yes & 1445 & 44.85 & & \\
\hline No & 1777 & 55.15 & & \\
\hline
\end{tabular}


Regional Development in Africa

\begin{tabular}{|c|c|c|c|c|}
\hline Characteristics of SMEs & Frequency & $\%$ & Mean & Std. Dev. \\
\hline Ownership & & & 0.7846058 & 0.4111593 \\
\hline Yes & 2528 & 78.46 & & \\
\hline No & 694 & 21.54 & & \\
\hline Use ICT & & & 0.0391061 & 0.1938776 \\
\hline Yes & 126 & 3.91 & & \\
\hline No & 3096 & 96.09 & & \\
\hline Motivations & & & 0.3311608 & 0.4707038 \\
\hline Self-motivated & 1067 & 33.12 & & \\
\hline Default & 2155 & 66.88 & & \\
\hline Financial problem & & & 0.3792675 & 0.4852801 \\
\hline Yes & 1222 & 37.93 & & \\
\hline No & 2000 & 62.07 & & \\
\hline Business regulation problem & & & 0.0260708 & 0.1593705 \\
\hline Yes & 84 & 2.61 & & \\
\hline No & 3138 & 97.39 & & \\
\hline Business planning problem & & & 0.0021726 & 0.0465673 \\
\hline Yes & 7 & 0.22 & & \\
\hline No & 3215 & 99.78 & & \\
\hline Employee motivation & & & 0.1610801 & 0.3676619 \\
\hline Yes & 519 & 16.11 & & \\
\hline No & 2703 & 83.89 & & \\
\hline Advertising & & & 0.1387337 & 0.3457221 \\
\hline Yes & 447 & 13.87 & & \\
\hline No & 2775 & 86.13 & & \\
\hline Licenced & & & 0.1511484 & 0.358249 \\
\hline Yes & 487 & 15.11 & & \\
\hline No & 2735 & 84.89 & & \\
\hline Bank account & & & 0.1021105 & 0.3028406 \\
\hline Yes & 329 & 10.21 & & \\
\hline No & 2893 & 89.79 & & \\
\hline Business insurance & & & 0.016139 & 0.1260298 \\
\hline Yes & 52 & 1.61 & & \\
\hline No & 3170 & 98.39 & & \\
\hline Business record & & & 0.0121043 & 0.1093686 \\
\hline Yes & 39 & 1.21 & & \\
\hline No & 3183 & 98.79 & & \\
\hline Business advisory & & & 0.0912477 & 0.2880057 \\
\hline Yes & 294 & 9.12 & & \\
\hline No & 2928 & 90.88 & & \\
\hline Expertise & & & 0.2597765 & 0.43858 \\
\hline Yes & 837 & 25.98 & & \\
\hline
\end{tabular}


The Factors Influencing SMEs Growth in Africa: A Case of SMEs in Zimbabwe DOI: $h$ ttp://dx.doi.org/10.5772/intechopen.87192

\begin{tabular}{|c|c|c|c|c|}
\hline Characteristics of SMEs & Frequency & $\%$ & Mean & Std. Dev. \\
\hline No & 2385 & 74.02 & & \\
\hline Corruption & & & 0.005897 & 0.0765768 \\
\hline Yes & 19 & 0.59 & & \\
\hline No & 3203 & 99.41 & & \\
\hline Tax & & & 0.0204842 & 0.1416714 \\
\hline Yes & 66 & 2.05 & & \\
\hline No & 3156 & 97.95 & & \\
\hline Marital status & & & 0.7579143 & 0.4284124 \\
\hline Yes & 2442 & 75.79 & & \\
\hline No & 780 & 24.21 & & \\
\hline Profitability & & & 41.84699 & 44.96179 \\
\hline Refused & 55 & 1.71 & & \\
\hline Less than USD $\$ 100$ & 334 & 10.37 & & \\
\hline USD \$100-USD\$199 & 181 & 5.62 & & \\
\hline USD \$200-USD\$299 & 201 & 6.24 & & \\
\hline USD \$300-USD \$399 & 197 & 6.11 & & \\
\hline USD \$400-USD\$699 & 297 & 9.22 & & \\
\hline USD \$700-USD\$999 & 207 & 6.42 & & \\
\hline USD $\$ 1000-U S D \$ 1399$ & 237 & 7.36 & & \\
\hline USD \$1400-USD \$2499 & 1230 & 38.17 & & \\
\hline USD \$2500-USD \$4999 & 152 & 4.72 & & \\
\hline USD\$5000-USD\$7999 & 53 & 1.64 & & \\
\hline USD $\$ 8000-U S D \$ 10999$ & 28 & 0.87 & & \\
\hline USD \$11000-USD \$15999 & 22 & 0.68 & & \\
\hline USD \$16000-USD\$29999 & 12 & 0.37 & & \\
\hline USD $\$ 30000-U S D \$ 39999$ & 5 & 0.16 & & \\
\hline USD $\$ 40000-U S D \$ 49999$ & 2 & 0.06 & & \\
\hline USD $\$ 50000-U S D \$ 59999$ & 5 & 0.16 & & \\
\hline USD\$70000-USD\$99999 & 3 & 0.09 & & \\
\hline USD $\$ 100000_{+}$ & 1 & 0.03 & & \\
\hline urce: Finscope MSME Surve & & & & \\
\hline
\end{tabular}

Table 1.

Descriptive statistics.

\subsection{Variables included in the model}

Variables considered in this study are those in accordance with the literature and availability of Finscope MSME Survey data may influence profitability of small to medium enterprise. Below is a brief description of the variables included in the Linear Probability Models (LPM) and the reasons for using them.

\subsubsection{Number of businesses}

One with two or more businesses is likely to report better profits than relying on one. Two business units are likely to produce more profits. There are higher chances 
for one to become better of (a billionaire) with multiple streams of income. There has to be a strategy to diversify the income streams to boost the bottom line and if one project goes down, the other one(s) could succeed.

\subsubsection{Owner run}

The owner of the business running an enterprise may not have expertise of the business. The owner may not be having the zeal for entrepreneurship and it may be difficult for such a business to grow or report outstanding profits. On the other hand with expertise and professionalism, some owners run business that succeeds and ends up employing more with different qualifications. The success may differ from one company to another but vision, professionalism and entrepreneurship skills will separate them. Thousands of ambitious entrepreneurs start businesses and many of them fail. There is need to find how this factor determine profitability of businesses in Zimbabwe.

\subsubsection{Business type}

Formal businesses often perform better than informally run enterprises. The absence of entrepreneurial skills in small informal businesses explains the nongrowth and failure of businesses across the African continent. The informal sector has not been viewed as a springboard of prosperous and prolific business development, profitability and growth. Banerjee and Duflo [21] argue that majority of the enterprises of the poor do not exhibit the entrepreneurial spirit and are often revealing disappointments in the economies they operate. Naude [22] also argues that constructive policies work better in the formal economy than the informal. However, the informal sector acts as a buffer from slipping into deeper poverty. There is need to investigate how informal or formal business type influences profitability.

\subsubsection{Family business}

Family businesses are run according to the vision, culture, expertise and ability of the members thereof. In such businesses profit can be much more if business is run professionally. Because it is a family business, expertise from outside may be blocked for fear of diluting power. There are some examples of businesses that were started by families that have grown into large corporations or household names in different sectors. However many others have failed along the way as disagreements ensue. In a family business, profits or success may be viewed as dynamic combination of business performance, family business culture and stakeholder personality.

\subsubsection{Business premises}

Operating premises may be a determining factor of profitability made by small businesses. Fixed costs such as rentals may hinder SMEs from reporting high levels of profit. The premises one is operating from give the businesses value and image. If one owns the premise s/he is likely to build attractive permanent structures that may attract more and better business as the market views it as organised and professional.

\subsubsection{Distance travelled}

Some entrepreneurs have to travel to their business premises and the times taken vary with distance and mode of transport. Distance may influence time spent 
on business, opening of business and costs of travelling. In such cases operations, professionalism or reliability and profit levels are affected by these factors. There is need to investigate the effect of distance or time taken to work on profitability.

\subsubsection{Ownership}

In SMEs the most crucial or important stakeholders are the owners, customers and staff. The owners of the business take important decisions in everyday activity and determine the success or profitability of business [12]. Their vision, expertise, philosophy and other resources influence greatly the success of the venture. How does ownership structure affect profitability levels of SMEs in Zimbabwe?

\subsubsection{Use ICT}

Information and communications technology (ICT) has developed rapidly and changed how business is done across the globe. There are reports of businesses that have succeeded by use of mobile phones, smartphones, tablets, computers in doing business. In addition to that business is also being done online through internet and other social media platforms [23]. Today's consumer has become more inclined to online searching, internet sales and purchasing of goods and services. Many SMEs are unable to exploit opportunities arising in this form preferring to use the traditional methods of doing business [11].

\subsubsection{Motivation}

The lack of entrepreneurial skills, zeal and capacity hinder business success. Njanike [24] argues that before one starts a business the following important question must be answered: Am I an entrepreneur? If one gets into business by default the probability of failure is high and if self-driven such enterprises will sustain adversaries. Many enterprises on the African continent today are a product joblessness, retrenchment, economic malaise and shrinking job markets.

\subsubsection{Financial problem}

Many SMEs highlight lack of financial resources as the hindrance from success or high profit levels. Formal financial institutions prefer large enterprises to SMEs sighting high financial costs. Large enterprises have lower risk of default, clear financial statements. SMEs have limitation of finance, low research and development investment and low levels of financial inclusion [11]. Those SMEs with capital or access to financial resources have more chances of survival and better profit levels.

\subsubsection{Business regulation problem}

Government regulations have an effect on the performance of SMEs or any other business. The regulations enforced by the government can promote or hinder business growth. Some businesses are required to sell their products through some outlined procedures and their adherence assures them of continuity in business. For example some gold miners are required to sell minerals through the government agencies and are not allowed to export them on their own. In Kenya a study found that a positive relationship existed between profitability and other government requirements in some sectors [25]. 


\subsubsection{Employee motivation skills}

Financial and non-financial benefits contribute to profitability of an enterprise as employees are motivated to achieve organisational goals. Improving motivation combined with good culture may increase net profits [14]. These benefits may include the 13th cheque, medical aid, lunch packs and transport allowances among others.

\subsubsection{Advertising}

An advertised business grows more or enjoys more profits than the one that does not. Large corporations have marketing departments or personnel to drive sales and interact with the consumer. Consumers become aware of your product to gain or sustain market share through advertising [26]. To what extent does advertising influence profitability of SMEs in Zimbabwe?

\subsubsection{Licenced}

The licenced businesses are able to access orders or jobs from large corporations or government departments as it is a requirement. The licenced SMEs are likely to enjoy business, benefits and loans that the unlicensed entities are not able to access. They are also likely to be making more profits with clear records and systems in place. In many cases depending on the sector they are expected to adhere to certain rules monitored by a regulator [19].

\subsubsection{Bank account}

A firm with a bank account is more likely to be having a licence and to some extent operating with clear records. Having an account with a formal financial institution makes a firm have access to loans and other financial services. Customers are also able to pay for goods or services using debit cards, credit cards and other electronic transfers rather than paying cash. More business may be experienced with more convenient payment methods on board.

\subsubsection{Business records}

A business operated with proper records has a higher chance of survival as determination of profitability is easy. Those that operate without records are not able to assess the extent of profits or losses obtained. With clear records a business is able to attract outside funding and access loans. It is also possible for projections of cashflows, profits and business demand. Analysis of events, assessment of business activities and planning is easier with records [27]. How can one ascertain profits if no proper records are in place?

\subsubsection{Business advisory}

It is difficult to operate without independent view of others or experts in the business field. In more developed countries business advisory is taken seriously rather than depend on one's intellect and belief in business. The skills that a small business owner or other employees have are complemented by consulting business advisors on some important issues to maximise profits [25]. 


\subsubsection{Expertise}

Requisite skills or expertise in business is a necessity and there is need to have them. One may have worked for a company in the same line of business, trained or attended college for the skill(s). Because small businesses may not have the capacity to pay a qualified individual the owner, of the business has to have an appreciation or knowledge on it [25]. This is the only way outstanding profits can be obtained.

\subsubsection{Corruption}

Depending on the line of business or sector red tape may hinder an establishment or growth of business. In Africa there are corrupt tendencies on licencing or permission to operate or in winning tenders. These are hindrances that may cause SMEs not to succeed and enjoy high profit levels [10]. To what extent has corruption affected business profitability in Zimbabwe?

\subsubsection{Tax}

Every legitimate (licenced) business is expected to pay tax to the government. Many informal businesses evade tax and continue reporting high profits [13]. On the other hand paying tax may have indirect benefits as the money paid to the government is used for public goods. Increasing corporation tax has an effect on business profits as costs are increased.

\subsubsection{Age}

Many studies have found varying results on effect of age on SMEs profitability. The young may not be able to perform as expected in business unless they are well trained. Those with experience are likely to produce better results as they may have worked elsewhere or have been operating for some time as one learns from mistakes. However the effects on profitability of SMEs in Zimbabwe remain to be investigated.

\subsubsection{Gender}

Women and men operate businesses in the same sector and profitability of their businesses varies. Does gender have an effect on SMEs business profitability in Zimbabwe?

\subsubsection{Marital status}

There are cases were marital status determines success and profitability of business. The one married has an advantage of sharing ideas for business prosperity with his/her spouse. In some cases married women are limited by their husband's approval and not able to make progressive business decisions [13]. To what extent has marital status influenced success, growth and profitability of business?

\subsubsection{Education level}

Education level is a basic requirement of business and the higher the level the better results are expected in business. Depending on the business complexity or market dynamics one is not able to handle some pressures with lower levels of 
education. The higher the level of education obtained the greater the results or profits are expected. With education one is expected to be more organised with better appreciation of business concepts.

\subsubsection{Level of Business R\&DD}

Many developed countries today are what they are because of investment in research. A business that takes research and development (R\&D) seriously is always outstanding and is expected to report high profits. B\&D drives innovation, business growth, profitability and ultimately economic growth. Research shows that R\&D contributed significantly to the growth of businesses and economies of Republic of Korea, India and China [28]. In some countries R\&D did not increase profitability and growth significantly. R\&D is an important factor to consider on business profitability but for this study the data was not available.

In sum, the following factors were considered in this study: profitability, businessnum, travel distance, education level, age, ownerun, business type, family business, ownership, use ICT, self- motivation, financial problem, business regulation problem, business planning problem, employee motivation, advertising, licenced, bank account, business insurance, business record, business advisory, expertise, corruption, tax and marital status. R\&D is an important determinant of profitability but was not considered because of lack of data.

\section{Empirical results}

This section gives the results of the LPM regression (see Table 2) and discusses the results.

A total of 3222 observations were considered in the analysis. The LPM regression results were reported.

Number of business entities or units (businessnum) was found statistically significant at $10 \%$ level. The more business entities one has the greater the profits obtained. The findings were in line with Ayyagari et al. [29] who argued that the concept of diversification helps explain business dynamics in this case. If one unit is doing well and the other one is not the owner is cushioned and enjoys some income. In terms of income two is better as they can provide you with twice the income. With two or more businesses there may be synergy in marketing and other aspects of business [30].

The variable of travel was not significant with a negative correlation. It may not have been significant but the negative sign shows that to some extent as the distance from the work place increases the less profit is reported. With owner managed businesses the problem may be absence when crucial decisions are to be made and lack of supervision. However, the findings contradicted Kapteyn and Wah [31] who found distance travelled significant to profitability.

Education level was found significant at $1 \%$ level. This shows that the more one is educated the better the management and profitability of business in Zimbabwe. Someone educated is expected to have a better appreciation of business concepts hence better profits. A number of studies have shown that education level contributes positively to profitability of a business [18].

Age was found not to be significant. This showed that age had no significant effect on profitability levels of business. However, the results contradicted Abeh [13] who found that age had an effect on business profitability of small businesses.

The ownerun variable was found not to be significant implying that whether the business is run by the owner or not there is no effect on profitability of business. 
The Factors Influencing SMEs Growth in Africa: A Case of SMEs in Zimbabwe DOI: $h$ ttp://dx.doi.org/10.5772/intechopen.87192

\begin{tabular}{|c|c|}
\hline & LPM \\
\hline Variables & Profitability \\
\hline \multirow[t]{2}{*}{ Businessnum } & $-4.156^{*}$ \\
\hline & $(2.172)$ \\
\hline \multirow[t]{2}{*}{ Travel } & -0.0324 \\
\hline & $(0.0556)$ \\
\hline \multirow[t]{2}{*}{ Education level } & $2.511^{* * *}$ \\
\hline & $(0.875)$ \\
\hline \multirow[t]{2}{*}{ Age } & 1.375 \\
\hline & $(0.872)$ \\
\hline \multirow{2}{*}{ Ownerun } & 5.366 \\
\hline & $(22.86)$ \\
\hline \multirow{2}{*}{ Bustype } & $19.82^{* *}$ \\
\hline & $(9.884)$ \\
\hline \multirow{2}{*}{ Fambus } & $-7.660^{* * *}$ \\
\hline & $(2.223)$ \\
\hline \multirow[t]{2}{*}{ Ownership } & -0.245 \\
\hline & $(2.577)$ \\
\hline \multirow[t]{2}{*}{ Useit } & 5.072 \\
\hline & $(6.902)$ \\
\hline \multirow[t]{2}{*}{ Motivations } & 2.312 \\
\hline & $(2.317)$ \\
\hline \multirow[t]{2}{*}{ Finprob } & -3.575 \\
\hline & $(2.239)$ \\
\hline \multirow[t]{2}{*}{ Busregprob } & 0.448 \\
\hline & $(6.055)$ \\
\hline \multirow[t]{2}{*}{ Busplanprob } & -37.28 \\
\hline & $(25.89)$ \\
\hline \multirow[t]{2}{*}{ Empmot } & -3.266 \\
\hline & (3.041) \\
\hline \multirow[t]{2}{*}{ Advertising } & $6.067^{* *}$ \\
\hline & $(2.916)$ \\
\hline \multirow{2}{*}{ Licenced } & $-5.504^{*}$ \\
\hline & (3.058) \\
\hline \multirow[t]{2}{*}{ Bankacc } & $-8.432^{*}$ \\
\hline & $(4.335)$ \\
\hline \multirow[t]{2}{*}{ Businsurance } & -1.694 \\
\hline & (8.899) \\
\hline \multirow[t]{2}{*}{ Busrec } & 2.055 \\
\hline & $(9.941)$ \\
\hline \multirow[t]{2}{*}{ Busadvisory } & -2.711 \\
\hline & (3.988) \\
\hline
\end{tabular}




\begin{tabular}{ll}
\hline & LPM \\
\hline Expertise & $-5.456^{* *}$ \\
\hline & $(2.648)$ \\
\hline Corruption & 8.426 \\
\hline Tax & $(13.56)$ \\
\hline & -6.087 \\
\hline Marital & $(9.387)$ \\
\hline & -0.0188 \\
\hline Constant & $(2.571)$ \\
\hline & $54.20^{* *}$ \\
\hline & $(23.93)$ \\
\hline Observations & \\
\hline R-squared & 3222 \\
\hline $\begin{array}{l}\text { Standard errors in parentheses. }{ }^{*} p<0.1 \\
{ }^{* *} p<0.05 \\
{ }^{* * *} p<0.01 \\
\text { Source: Stata } 2014 .\end{array}$ & 0.043 \\
\hline
\end{tabular}

Table 2.

Empirical results.

The results contradicted that of Soni [32] who argues that the one running the enterprise determines SMEs profitability.

The type of business (bustype) was found significant at $5 \%$ level implying that the formal business was more likely to report better profits than an informal enterprise. Formal businesses have an advantage of being taken seriously by customers and stand better chances of getting big contracts. The finding was in line with Kazimoto [18] who found that formal business had more opportunities hence better profits.

Family business (fambus) was found significant at $1 \%$ significance level showing that a business owned by a family was likely to have more profits than the one owned by different people. This may be due to less conflicts in running the business as a family. This is in tandem with Soni [32] who found that family businesses are likely to report better profits but results may vary as the enterprises get bigger with time.

Ownership variable was found not to be significant. This shows that the ownership structure had no effect on the profitability of SMEs in Zimbabwe. However, this differs with other studies that found that ownership influences profitability levels of businesses [12].

The use of ICT (useit) in business was not significant. This implied that the application of technology in business operations had no impact on profitability of SMEs in Zimbabwe. The level of technological development of the country and/or consumers may have an impact on the effectiveness of ICT use. The study contradicted a number of studies that found ICT applications having a huge impact on profitability of business $[11,14]$. The argument is that the use of ICT use drives costs of operations down.

The reasons for starting a business (motivations) were found not significant. The reasons behind the start of an enterprise had no effect on the profitability of small 
businesses in Zimbabwe. The results contradicted with other studies that argue that motivation had an effect on profitability and sustainability of SMEs [32, 33].

Financial problems (finprob) were found not significant. The issues to do with the business having financial problems at some stage of the business had no significant impact on the profitability of business. This contradicted with other studies that found that financial problems contributed to SMEs business failure and suppressed growth $[12,34,35]$.

Business regulation problems (busregprob) was found not significant implying that the challenges encountered due to some regulations in place had no effect on the profitability of SMEs in Zimbabwe. Some studies have shown that some regulations indeed have had a negative effect of business profitability [14, 32].

The business planning problem (busplanprob) had no significant impact on profitability. The problems associated with business planning had no significant impact on SMEs operating in Zimbabwe. However this differed with other studies that found that lack of planning was the major hindrance of SMEs growth and sustainability $[10,12])$.

Employee motivation (empmot) had no significant effect on profitability of SMEs in Zimbabwe. This implies that any form of scheme to motivate staff had no impact on profitability levels. The reason may be that as many are owner/family run incentives may not mean much to them as they will be building on value of business. However many studies found different results from the current one because motivation of employee is believed to be having a huge impact on profitability of business [36, 37].

Advertising of business was significant at 5\% significance level. This implied that adverts are an important component of a growing business. The more expenditure on advertising the better the profits achieved in business. The results were in line with some studies that reported that a business that does not advertise may not produce outstanding results $[26,38]$.

The licenced variable is significant at $10 \%$ level. This implies that a business operating legally is more likely to report more profits than one operating illegally. The legal status makes such businesses operate more profitable and sustainable [31, 36].

Bank account variable was found to be significant at $10 \%$ level. If a company is financially included higher profits are expected. If a company has a bank account it is likely to access funds at cheaper costs and more profits are reported as a result [39]. The results are in tandem with findings of Nkuah et al. [12] who reported that those firms with bank accounts are likely to report better profits than the financially excluded. Financial services are important in an economy and particularly for SMEs entrepreneurs. Financial institutions play a pivotal role in the resource allocation process and entrepreneurs need finance to grow their businesses.

Business insurance (businsurance) was found not significant. This implies that business insurance has no influence on profitability of business. However the results differed with some other studies that reported that an insured business was likely to report more profits [40].

Business records (busrec) was found not significant. This implied that whether the business records are in place or books done by a professional had no effect on the profitability of SMEs in Zimbabwe. The finding contradicted other studies that reported that those firms with business records are likely to have better profits [12].

Business advisory was found not significant. This means that whether the business owners receive business advice or not there is no effect on profitability of SMEs in Zimbabwe. Though business advisory is important some sectors may not require special business advisory let alone for a small firm. The findings disagree with some studies that advocate for business advisory at any stage of growth and in decision making $[11,33,41]$. 
Expertise was found significant at $5 \%$ level. This implies that if the business operator is skilled the higher the probability of better profits. The findings are in line with other studies $[19,32]$. To operate a business it is best for one to be knowledgeable for better results to be realised. For the SMEs to contribute more to the GDP and create more job opportunities, there is need to train the operators in every sector.

Corruption was found not to be significant. Any corrupt activity in the system does not have any effect on profitability of business in Zimbabwe. This contradicts with some studies that have found that corruption has become a hindrance to business growth and profitability $[16,36]$. In some cases corrupt activities in the system may hinder licences, permits to operate or sell in some markets influencing profitability of business. Some countries have been affected by corruption making it difficult to operate business.

Tax variable was not significant. Any form of tax or tax status of a company has no influence on the profitability of an enterprise in Zimbabwe. A business that avoids tax usually reports more profits as tax is an expenditure that reduces profits $[13,15,33]$.

Marital status was not significant. Whether one is married or not has no significant effect on profitability levels. Some single women are operating in Zimbabwe with varying results and equally competing with married individuals. Business is no longer determined by marital status as individuals can take independent decisions or make decisions aimed at promoting business [13].

\section{Conclusion}

The findings call for enhanced coherence of strategies and policy formulation on employment creation across the multilateral system. The following factors were found significant: number of business, education level, business type, family business ownership, expertise, licencing, advertising and bank account. The policymakers should craft policies that enhance their contribution to profitability, growth and creation of employment. There is need for policy makers and other social partners to design and implement strategies that enhance employment opportunities in their countries. It is necessary for authorities at local, national and regional levels to embark on evidence-based analysis feeding the social dialogue and policy making processes for building a knowledge base for employment creation in SMEs. The discovery that all variables considered in this study have a form of relationship to SMEs' profitability is a good starting point. This serves to assist in intervening in SMEs sector on better designs and stimulations of productive business activities and strategies for job creation. The factors investigated in this study have to be considered and ensure the environment is improved for SMEs growth and profitability. The governments can provide the effective assistance required for young women and men in business to make a good start in the world of business. This will positively influence young people's personal and professional success in all stages of life.

Looking ahead to improve standard of living, create more job opportunities and economic growth the combination of growth factors that Africa presents create unparalleled opportunities for SMEs in the long term. The continent's natural resources as well as fast growing economies will sustain high levels of business growth making Africa's rise unavoidable. This will take political will and selfless decisions by the countries' leaders. The basis of a sustainable undertaking in Africa is dependent on the empowerment and support of regional SMEs and young entrepreneurs to reduce brain drain and poverty. The governments, international investors and other developmental institutions should be central to the stability 
The Factors Influencing SMEs Growth in Africa: A Case of SMEs in Zimbabwe DOI: $h$ ttp://dx.doi.org/10.5772/intechopen.87192

of the world's economy. There is need to support the millions of SMEs and future entrepreneurs in improving the regulatory and business environment, improving institutional support systems, promoting technology transfers, innovations and improving productivity.

\section{Acknowledgements}

The authors are grateful to FinMark Trust for the permission to use their Finscope MSME Survey Zimbabwe (2012) data.

\section{Author details}

Kosmas Njanike

Bindura University of Science Education, Bindura, Zimbabwe

*Address all correspondence to: kosmasnjanike@gmail.com

\section{IntechOpen}

(C) 2019 The Author(s). Licensee IntechOpen. This chapter is distributed under the terms of the Creative Commons Attribution License (http://creativecommons.org/licenses/ by/3.0), which permits unrestricted use, distribution, and reproduction in any medium, provided the original work is properly cited. (cc) BY 


\section{References}

[1] Beck A, Demirgüç-Kunt A. Small and Medium Enterprises Across the Globe: A New Database. World Bank Policy Research Working Paper 3127. 2003

[2] Fjose S, Grünfeld LA, Green C. SMEs and Growth in Sub-Saharan Africa. Identifying SME Roles and Obstacles to SME Growth. MENONPublication No. 14/2010. 2010. pp. 1-25. Available from: https://www.norfund. no/getfile.php/1339831484571386/ Bilder/Publications/SME\%20and\%20 growth\%20MENON\%20.pdf

[3] Nyoni T, Bonga WG. Anatomy of the small \& medium enterprises (SMEs) critical success factors (CSFs) in Zimbabwe: Introducing the $3 \mathrm{E}$ model. Journal of Business and Management (DRJ-JBM). 2018;1(2):1-18

[4] Mugozhi F, Hlabiso G. Determinants of small to medium enterprises' success or failure: An ex-post appraisal of startup business by young entrepreneurs in Zimbabwe. The International Journal of Humanities and Social Studies. 2017;5(3):39-46

[5] UNDP. The Potential Contribution of the Zimbabwe Diaspora to Economic Recovery. United Nations Development Programme Comprehensive Economic Recovery in Zimbabwe Working Paper Series. Working Paper 11. 2010. pp. 1-64. Available from: https://www. zimbabwesituation.com/old/WP11.pdf [Accessed: 20 April 2018]

[6] Pompe PPM, Bilderbeek J. The prediction of bankruptcy of smalland medium-sized industrial firms. Journal of Business Venturing. 2005;20(6):847-868. DOI: 10.1016/j. jbusvent.2004.07.003

[7] Dennis WJ, Fernald LW. The chances of financial success (and loss) from small business ownership. Entrepreneurship Theory and Practice. 2001;26(1):75-83
[8] Mather C. The growth challenges of small and medium enterprises (SMEs) in South Africa's food processing complex. Development Southern Africa. 2007:607-622. DOI: $10.1080 / 03768350500364208$

[9] Ngcobo S, Sukdeo R. Challenges facing SMMEs during their first two years of operation in South Africa. Corporate Ownership and Control. 2015;12(3):505-512

[10] Oyelana AA, Smith W. An investigation into challenges as well as means to overcome challenges facing small and medium enterprises (SMEs) in South Africa. Journal of Economics. 2015;6(2):177-188

[11] Yoshino N, Taghizadeh-Hesary F. Major Challenges Facing Small and Medium sized Enterprises in Asia and Solutions for Mitigating Them. ADBI Working Paper 564. Tokyo: Asian Development Bank Institute; 2016. Available from: http://www.adb.org/ publications/majorchallenges-facingsmall-and-medium-sized-enterprisesasia-and-solutions/

[12] Nkua JK, Tanyeh JP, Gaeten K. Financing small and medium enterprises (SMEs) in Ghana: Challenges and determinants in accessing bank credit. International Journal of Research in Social Sciences. 2013;2(3):12-25

[13] Abeh O. The problems and prospects of small and medium scale enterprises (SMEs) growth and development in Nigeria: A study of selected SMEs in delta state. International Journal of Scientific Research in Education. 2017;10(3):278 294. Retrieved from: http://www.ijsre. com

[14] Ocioo CE, Akaba S, Worwal-Brown D. Globalization and competitiveness: 
Challenges of small and medium enterprises (SMEs) in Accra, Ghana. International Journal of Business and Social Science. 2014;5(4):287-296

[15] Gombarume FB, Mavhundutse S. Challenges faced by small to medium scale enterprises: A case study of Chitungwiza, Zimbabwe. Greener Journal of Business and Management Studies. 2014;4(4):103-107

[16] Khalique M, Isa AH, Shaari JAN, Ageel A. Challenges faced by the small and medium enterprises (SMEs) in Malaysia: An intellectual capital perspective. International Journal of Current Research. 2011;33(6):398-401

[17] Decker M, Schiefer G, Bulander R. Specific challenges for small and medium-sized enterprises (SME) in $\mathrm{m}$-business. In: Proceedings of the International Conference on E-Business (ICE-B 2006); August 2006; Setúbal, Portugal. INSTICC Press; 2006. pp. 169174. Available from: http://www.ice-b.org

[18] Kazimoto P. Assessment of challenges facing small and medium enterprises towards international marketing standards: A case study of Arusha Region Tanzania. International Journal of Academic Research in Accounting, Finance and Management Sciences. 2014;4(2):303-311

[19] Turyahikayo E. Challenges faced by small and medium enterprises in raising finance in Uganda. International Journal of Public Administration and Management Research (IJPAMR). 2015;3(2):21-33

[20] Tinarwo R. An investigation into the challenges faced by small to medium enterprises in Zimbabwe: A case of Gazaland Market. IOSR Journal of Business and Management. 2016;18(9):148-153

[21] Banerjee A, Duflo E. Poor Economics: A radical rethinking of the way to fight global poverty. New York:

Public Affairs; 2011

[22] Naude W. Entrepreneurship in Economic Development. Research Paper No. 2008/20. 2008. pp. 1-47

[23] Harvie C, Charoenrat T. SMEs and the rise of global value chains. In: Integrating SMEs into Global Value Chains: Challenges and Policy Actions in Asia. Japan: Asian Development Bank, Asian Development Bank Institute; 2015. pp. 1-26

[24] Njanike K. Small to Medium Enterprises Handbook: Ideas and Secrets of Starting a Business. India: Sarah Books Pvt Ltd; 2016

[25] Osano KL. Effect of government regulations on profitability of commercial banks in Kenya. Strategic Journal of Business and Change Management. 2018;5(18):67-72

[26] Riaz S, Furqan M, Siddique SS. The impact of advertising on the profitability of public and private sector commercial banks. European Journal of Business and Management. 2015;7(28):117-124

[27] Ligthelm AA. Small Business Success and Failure in Soweto, 20072011, Research Report No. 412. Pretoria: UNISA, Bureau of Market Research; 2011. pp. 51-75

[28] Organisation for Economic Co-operation and Development (OECD). OECD Science, Technology and Industry Scoreboard 2013. Paris: OECD Publishing; 2013

[29] Ayyagari M, Demirgüç-Kunt A, Maksimovic V. Small vs. Young Firms Across the World: Contribution to Employment, Job Creation, and Growth. Policy Research Working Paper 5631. Washington, DC: World Bank; 2011

[30] Grant R, Jammine A, Thomas

$H$. Diversity, diversification and 
profitability among British. The Academy of Management Journal. 1988;31(4):771-801

[31] Kapteyn A, Wah SH. Challenges to Small and Medium-size Businesses in Myanmar: What are They and How Do We Know? Paper No: 2015-030. CESRSchaeffer Working Paper Series. 2015. pp. 1-35

[32] Soni S. The Challenges Facing Small Businesses: A Global Perspective. South Africa: The Dorrian Consulting Group; 2005. pp. 1-5. Available from: www. dorriangroup.com/docs/NewsNov2005. pdf [Accessed: 23 March 2019]

[33] Petkovic S, Jager C, Sasi B. Challenges of small and medium sized companies at early stage of development: Insights from Bosnia and Herzegovina. Management. 2016;21(2):45-76

[34] Uesugi I, Sakai K, Yamashiro GM. Effectiveness of Credit Guarantees in the Japanese Loan Market. RIETI Discussion Paper Series 06-E-004. Tokyo: Research Institute of Economy, Trade and Industry; 2006

[35] Riding AL, Haines G. Loan guarantees: Costs of default and benefits to small firms. Journal of Business Venturing. 2001;16(6):595-612

[36] Christina B, Neelufe A, Al Amri $S$. Challenges and barriers encountered by the SMEs owners in Muscat. International Journal of Small Business and Entrepreneurship Research. 2014;2(3):1-13

[37] McGrath S. Challenges facing skills development for micro and small enterprise development in South Africa. Small Business Monitor. 2003;1(1):57-63

[38] Stankovska I, Josimovski S, Edwards C. Digital channels diminish SME barriers: The case of the UK. Economic
Research - Ekonomska Istraživanja. 2016;29(1):217-232

[39] International Finance Corporation. The SME Banking Knowledge Guide. Washington, D.C.: IFC; 2009. Available from: http://www.ifc.org/ ifcext/gfm.nsf/AttachmentsByTitle/ SMEBankingGuidebook/\$F ILE/ SMEBankingGuide2009.pdf

[40] Chatterjee A, Wehrhahn R. Insurance for micro, small, and medium-sized enterprises. ADB. 2016. Available from: https://www.adb.org/ sites/default/files/publication/298101/ insurance-msmes.pdf [Accessed: 13 March 2019]

[41] Wu W. Beyond business failure prediction. Expert Systems with Applications. 2010;37(3):2371-2376 


\title{
Solid Waste Management in Africa: Governance Failure or Development Opportunity?
}

\author{
Linda Godfrey, Mohamed Tawfic Ahmed, \\ Kidane Giday Gebremedhin, Jamidu H.Y. Katima, \\ Suzan Oelofse, Oladele Osibanjo, Ulf Henning Richter \\ and Arsène H. Yonli
}

\begin{abstract}
Waste management is a social, economic, and environmental problem facing all African countries. If the 2030 Agenda for sustainable development is to be achieved, sustainable waste management approaches must be an environmental and public health imperative deserving political priority. Current reasons for the poor management of waste in Africa, include, amongst others, weak organizational structures; lack of appropriate skills; inadequate budgets; weak legislation; lack of enforcement; low public awareness; corruption, conflict; political instability; and lack of political will. At the heart of the problem, is a failure in governance. However, through these gaps, many social and technological innovations have emerged. Innovations that recognize the opportunity that waste provides as a secondary resource. Diverting waste away from dumpsites and landfills towards reuse, recycling and recovery can improve the livelihoods of thousands of informal waste reclaimers, while also creating new jobs and business opportunities for the continent. Reintroducing secondary resources such as polymer, fiber, metals and nutrients back into local value chains has the potential to strengthen manufacturing economies and reduce the economic burden on product imports. Bringing waste under control in Africa and unlocking the opportunities that "waste" provides as "resource" will require immediate intervention by government, business and civil society.
\end{abstract}

Keywords: solid waste, infrastructure services, green jobs, recycling

\section{Introduction}

Africa is facing a growing waste management crisis. While the volumes of waste generated in Africa are relatively small, compared to developed regions, the mismanagement of waste in Africa is already impacting human and environmental health. However, Africa is set to undergo a major social and economic transformation over the coming century as its population explodes, cities urbanize and consumer purchasing habits change. This is expected to lead to exponential growth in waste generation (Figure 1), which will put considerable strain on already 


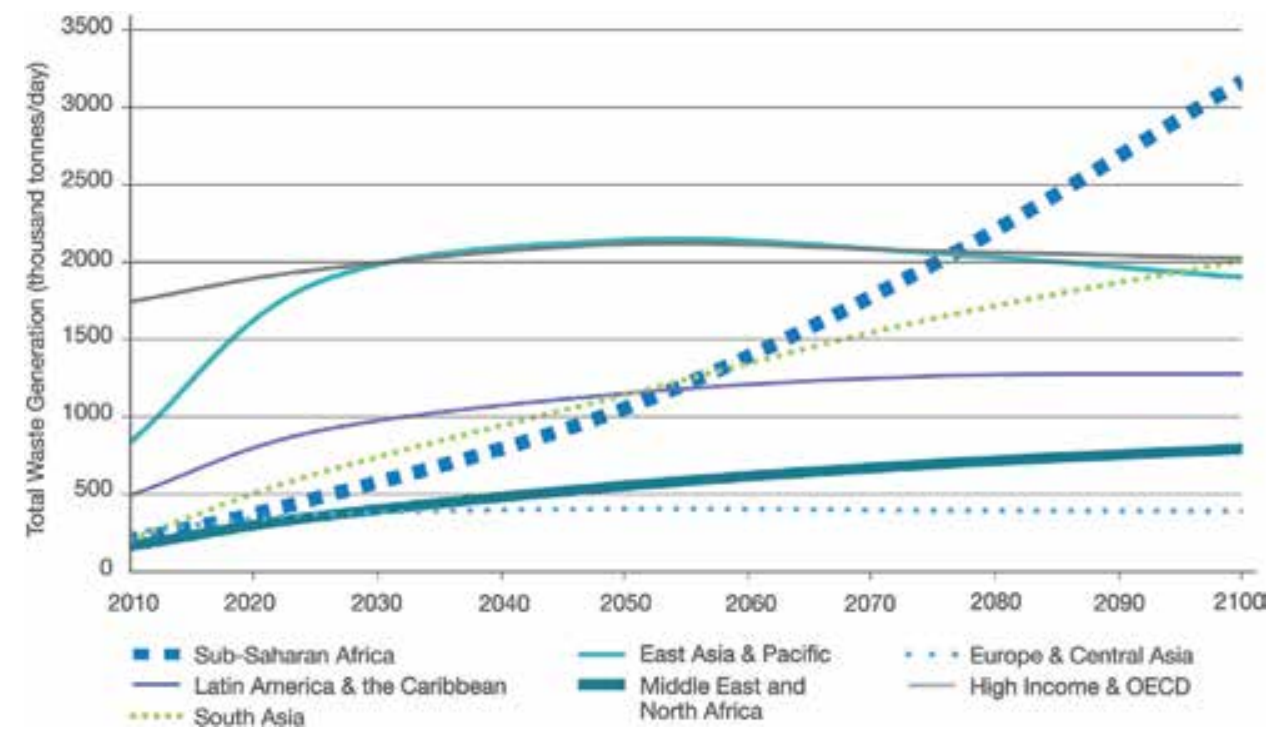

Figure 1.

Total municipal solid waste generation by region (adapted from [1]).

constrained public and private sector waste services and infrastructure, and further exacerbate the current state of waste management. In fact, the rate of growth in waste generation in Africa is expected to be so significant that any decrease in waste generation expected in other regions globally will be overshadowed by Africa, particularly Sub-Saharan Africa.

\section{Background}

The first Global Waste Management Outlook, published by the United Nations Environment Programme (UNEP) and the International Solid Waste Association (ISWA) in 2015 [2], highlighted the need for greater detail on the generation and management of waste at the regional level. The first Africa Waste Management Outlook published by the UNEP in June 2018 was in response to this global call [3]. The Africa Waste Management Outlook sets out the current state of solid waste management in Africa, including the state of waste governance; the associated environmental, social and economic impacts of waste; and the opportunities that waste provides through appropriate solutions and financing mechanisms. This chapter summarizes the key findings of the Africa Waste Management Outlook and places them within the context of development in Africa.

\section{State of waste in Africa}

Available data shows that 125 million tonnes per annum of municipal solid waste (MSW) was generated in Africa in 2012, of which 81 million tonnes (65\%) was from sub-Saharan Africa [4]. This is expected to grow to 244 million tonnes per year by 2025 . However, with an average waste collection rate of only $55 \%$ (68 million tonnes) [4], nearly half of all MSW generated in Africa, remains within our cities and towns, dumped onto sidewalks, open fields, stormwater drains and rivers. The average MSW collection rate in sub-Saharan Africa is lower at only 44\%, although 
the coverage varies considerably between cities, from less than $20 \%$ to well above $90 \%$ (Figure 2). The average MSW collection rate for the continent is expected to increase to only $69 \%$ by 2025 [4].

Good waste collection services are often only found in the city centres, while municipal waste services in suburbs and peri-urban areas are usually poor. The situation is much worse in rural areas where often no formal waste collection services exist. Current MSW collection services in most African countries are therefore completely inadequate resulting in the leakage of waste into the environment, including the freshwater and marine environment.

Considering that an estimated $80-90 \%$ of the MSW generated in Africa is recyclable, it makes little sense that more than $90 \%$ of the waste generated in Africa is still disposed of to land, typically to uncontrolled and controlled dumpsites. With so little regard for the opportunity that waste presents as secondary resource, only $4 \%$ of the waste generated in Africa is currently recycled, often by very active, but typically marginalized, informal reclaimers.

On average, $57 \%$ of MSW in Africa is wet, biodegradable, organic waste

(Figure 3). This high organic waste content, relative to paper and packaging, is typical of MSW in developing countries. Biodegradable organic waste, such as food and garden waste, can be easily processed into valuable products such as compost or biogas, yet it remains largely an untapped resource for the continent. As a result, there is a growing move internationally, including in Africa, towards the decentralized management of organic waste through small-scale composting and anaerobic digestion due to the failures in municipal waste collection services [8].

A waste stream of growing concern for Africa is waste plastic, with an estimated $13 \%$ of the MSW generated in Africa being plastic (Figure 3), the bulk of which is also dumped to land [9].

Waste streams in Africa are also changing as consumer behavior changes and as new markets in a growing middle class emerge, with increasing volumes of packaging and waste electrical and electronic equipment (WEEE) being generated, often with inadequate end-of-life solutions for these products [10,11]. Cheap and substandard products are increasingly being imported into African countries leading to new and emerging waste streams. The amount and types of hazardous waste are also increasing, with little awareness of its nature or management.

Food losses and waste in Africa are significant, occurring primarily at the early stages of the food supply chain [12]. In sub-Saharan Africa, roughly $37 \%$ of all the

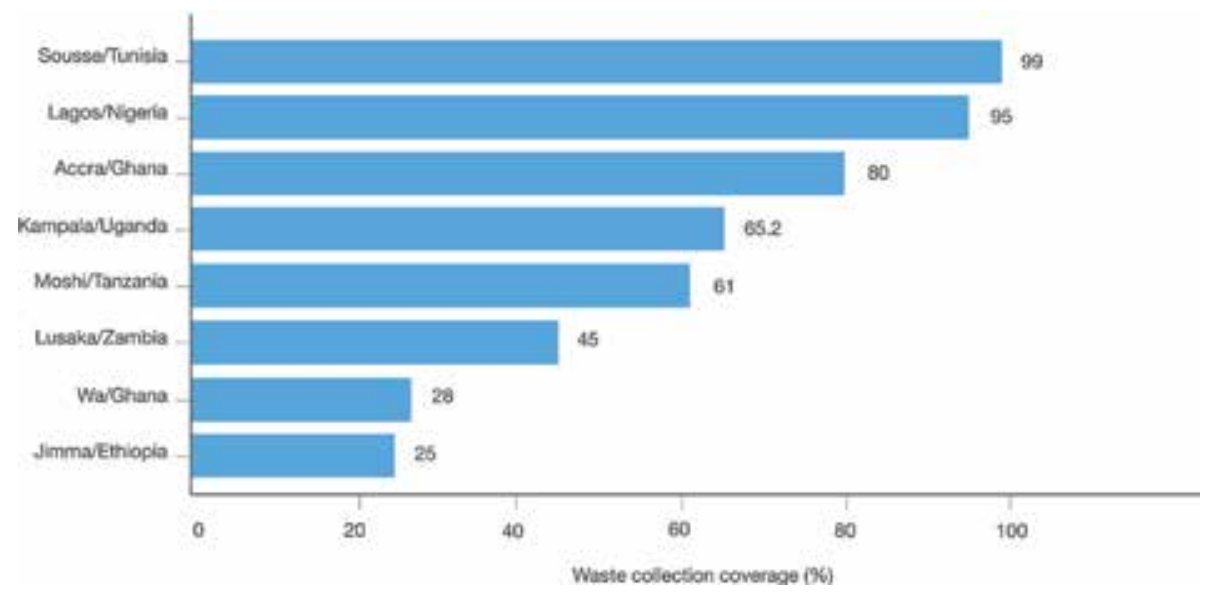

Figure 2.

MSW collection coverage for cities in Africa (adapted from [5-7]). 


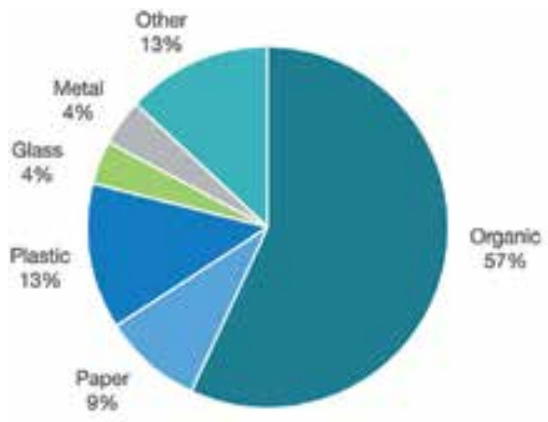

A Sub-Saharan Africa

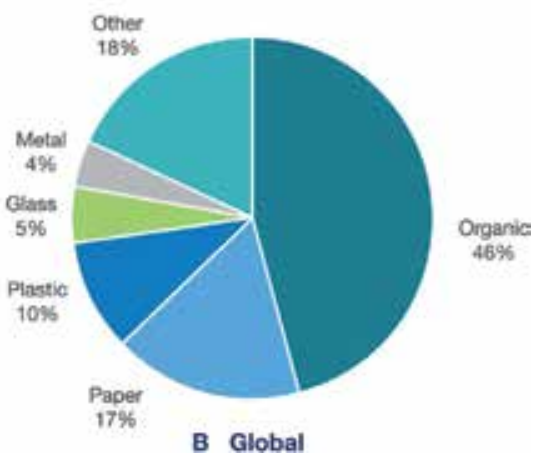

Figure 3.

MSW composition in sub-Saharan Africa and global [9].

food produced is lost or wasted [12]. For a continent with high levels of poverty, hunger and malnutrition, the loss and wastage of more than a third of all food produced, is unacceptable.

\section{Waste governance in Africa}

A number of policies (international, continental and regional) are already in place to address pollution and waste in Africa. However, it remains unclear as to how these policies have been translated into action and what progress, if any, has been made towards achieving their objectives and commitments. The inability of governments to enforce waste and environmental legislation in many African countries has given rise to a culture of impunity and has weakened the effectiveness of waste management in general [13]. What is clear, is the inability of governments and private industry to keep pace with growing waste streams and the timely development of policies and strategies to effectively deal with it [14].

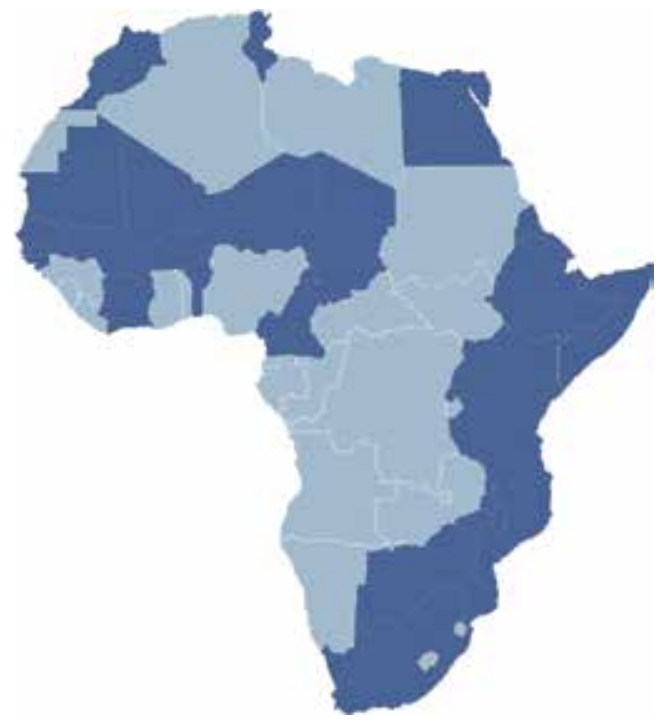

Figure 4.

African countries that have implemented local or national bans against waste plastics (dark blue shaded) (adapted from [15]). 
As a result, the response from many African countries has been to implement product bans on "problematic" products, particularly on single-use plastics. According to UNEP [15], 29 countries in Africa have already implemented some sort of regulation against plastics either at local or national level (Figure 4). These regulations vary from a ban on single-use (thin) plastic bags (and associated requirements for bag thickness) to complete bans on all plastic bags. The growing public outcry against plastic is now sparking action by governments on possible further bans on other single-use plastic products, such as PET beverage bottles and food services industry products such as plastic straws, cups, containers and utensils.

The slow adoption, limited use and poor design of economic instruments in solid waste in Africa, including alternative policy instruments such as extended producer responsibility (EPR) represents a "lost opportunity" [16].

In addition, the non-domestication of international agreements is making Africa an easy target for illegal dumping of hazardous waste from outside of the continent $[17,18]$.

\section{Environmental and social impacts of mismanaged waste}

Weak waste collection systems in Africa combined with uncontrolled and controlled dumping of waste, often associated with open burning, are causing significant economic, social and environmental impacts. Current waste management practices in Africa are resulting in the leakage of waste into the environment. Furthermore, the indiscriminate dumping of waste in urban areas creates risks of disease, flooding and environmental pollution. Research has shown a correlation between proximity to open dumpsites and incidence of disease, including increased risk of cholera, malaria, typhoid fever, dengue fever and Zika [19-22].

Open burning of waste causes significant air pollution which impacts human health and contributes to changing climates. These impacts are not always local, but can be far reaching. Methane and black carbon released through open burning of waste are short-lived climate pollutants with strong effects on regional and global climate change [2].

Africa has become a dumping ground for waste, particularly hazardous waste, often from developed countries, with many African countries, particularly in west and north Africa, becoming a global destination for end-of-life EEE and vehicles exported from developed countries in North America, Europe and Asia $[10,16,23,24]$. Current electronic waste recycling practices, often informal, pose potential risks to people and the environment $[25,26]$. Children and women are heavily involved in WEEE recycling in Africa, constituting the most vulnerable group for this waste. Recycling of used lead-acid batteries in informal workshops in Africa is a major source of lead pollution, exposing considerable numbers of people and the environment to adverse effects [27, 28].

Plastic as a percentage of MSW for sub-Saharan Africa is higher than the global average, at 13\% [9] and is a waste stream of growing concern for the continent. With weak waste collection systems and disposal of waste to uncontrolled and controlled dumpsites, the leakage of plastic into the environment poses a significant threat to the environment and economies $[29,30]$. This is compounded by the lack of recycling in Africa.

Improper waste management has serious health and environmental consequences. If it persists, it will undermine Africa's efforts to achieve the sustainable development goals (SDGs). 


\section{The opportunities in waste as resource}

With only a 4\% recycling rate, opportunities to develop a "secondary resources economy" are still largely unexplored in Africa. Current waste management practices have resulted in waste being overlooked for the value that it can provide to local economies. As a result, viable polymer (from plastic), fiber (from paper), metals and nutrients (from organic waste), amongst others, are being lost to Africa's economy through disposal of waste to dumpsites and landfills. Resources which could have been reintroduced back into local and regional economies to support manufacturing and reduce the economic burden on product imports.

Preliminary calculations suggest that diverting waste away from dumpsites towards reuse, recycling and recovery could, conservatively, inject an additional US $\$ 8$ billion every year into the African economy [31]. Creating significant socioeconomic opportunities for the continent. And if done responsibly, at the same time address the environmental and human health impacts associated with the current mismanagement of waste. Waste therefore provides considerable opportunity for the continent if only it could be safely collected and directed towards reuse, recycling and recovery.

The informal sector has played a very active role to date in the collection and diversion of reusable and recyclable waste away from landfill in Africa. As such, integrating informal reclaimers into future waste management activities is key to unlocking these opportunities, while also ensuring their improved livelihoods. Labour-intensive collection, sorting and processing of secondary resources could also create many direct jobs and even more indirect and induced employment opportunities at higher levels of pay. Developing local end-use markets that support the local beneficiation of these secondary resources would also ensure that fewer jobs migrate with these secondary resources to other countries.

Because of the gaps that exist in current waste collection and disposal systems, and in waste reuse, recycling and recovery, many social and technological innovations have emerged on the African continent over the past decade. These include innovative waste collection models, such as Wecyclers in Nigeria or Packag-ching in South Africa. Wecyclers uses low-cost, environmentally friendly cargo bicycles called "wecycles" to provide households and businesses in Lagos with convenient collection services for recyclable waste [32]. The Wecyclers and Packag-ching collection programmes reward residents for their recyclables through convenient collection systems, often in areas with no or poor municipal waste collection systems. Innovative end-uses for waste have also emerged on the continent. The Rethaka Foundation's Repurpose Schoolbag initiative addresses not only waste, but also aims to bring light to families and keep children safe while walking to school. The initiative collects and repurposes plastic waste such as PVC billboards into low-cost, highly visible schoolbags for local disadvantaged students, equipped with a small solar panel [32]. The PET recycling company (PETCO) model of voluntary Extended Producer Responsibility (EPR) for end-of-life PET plastic bottles, has resulted in a $65 \%$ post-consumer recycling rate in South Africa [33]. Utilizing both formal and informal actors in the value chain, the PETCO model is now being replicated in other countries in Africa, including Kenya, Ethiopia and Uganda [34].

Africa has however, recently seen investment in large-scale, traditional waste treatment technologies, such as the first waste PET plastic food-grade bottle-tobottle recycling plant, established by Extrupet in South Africa in 2015. Extrupet has the capacity to recycle over 2.5 million PET bottles per day, converting the waste PET bottles into fiber, thermoforming, food-grade and strapping-grade material, thereby producing high-quality, reliable end-products for use in packaging and other applications [35]. The Reppie $50 \mathrm{MW}$ waste-to-energy plant at the Koshe 
dump in Addis Ababa, Ethiopia marks a significant transition in Africa's management of waste, with the establishment of a large-scale, MSW thermal treatment plant [35].

But uptake of alternative waste treatment technologies in Africa has generally been slow, with dumping and open burning of waste remaining the dominant "technology" choice for the management of waste on the continent. While many alternative waste treatment technologies are available worldwide, only some of them are appropriate, or economically viable, for Africa, at least in the short- to medium-term.

Given the current state of waste management in most African cities, conventional waste treatment technologies are often difficult to implement. A combination of small-scale, low-cost, decentralized, community-driven initiatives and larger-scale, higher-cost, centralized initiatives will therefore be required for Africa. Low-technology (and low-cost) solutions such as cargo bicycles, motor tricycles or donkeycarts are often good alternatives for waste collection in African cities, particularly where access is constrained. Recycling technologies are already being implemented for wastes such as plastic, paper, glass, metal, oil, e-waste and organic waste, but need to be significantly scaled up through the development and strengthening of local and regional end-use markets.

Although almost all African countries have some policies that dictate how waste should be managed, there are many factors that constrain the waste management system in Africa. These factors include weak legislation, lack of enforcement, low public awareness, negative attitudes, the poor state of services, corruption, political instability and conflicts [36].

Poor financing is a major constraint to the development of the waste sector in Africa. This is largely due to the fact that the waste sector is still perceived as a high-risk investment in Africa [37]. There are tremendous challenges and constraints to waste management finance and to setting up sustainable revenue models in Africa. Existing waste management financing models currently used in Africa are limited, aggravated by weak institutional frameworks and poor governance of public resources. Strengthening institutions and regulatory frameworks is therefore paramount in reducing the perceived sector risk. There is a huge need for investment finance in the waste sector. However, raising investor confidence is a challenge, particularly in low income countries. Project costing and cost recovery is often poorly understood by government agencies in charge of waste logistics and management.

Estimated investment needs for the sector range from US\$6-42 billion (in 2015), depending on the alternative waste treatment technologies implemented. These figures are expected to triple to US\$17-125 billion by 2040, given current population growth and urbanization patterns and assuming investment in large-scale waste technologies [37]. Public-private partnerships will therefore be key to unlocking the opportunities that waste provides as secondary resource for the African continent.

\section{Conclusions}

Africa faces many challenges with respect to solid waste management. Factors such as lack of awareness; weak environmental legislation and enforcement; and limited resources, including financial resources, result in inefficient waste management in most African countries, which directly impacts upon human and environmental health. Available evidence suggests that the current poor state of solid waste management is largely due to failures in governance and organizational weaknesses resulting in poor service delivery and a perceived high risk for private 
sector investors. The economic, social and environmental costs of inaction-of doing nothing-far outweigh the cost of implementing waste management solutions on the continent, and if the 2030 Agenda for sustainable development is to be achieved, action has to be taken.

While the costs of implementing alternative waste treatment technologies is suggested to be in the range of US\$6-42 billion, diverting waste away from dumpsites and landfills towards reuse, recycling and recovery could inject a potential US $\$ 8$ billion per annum of resource value into the African economy. This will result in improved livelihoods for informal reclaimers and the creation of new job and business opportunities for the continent.

But African countries cannot harness the development opportunity that waste provides, if waste remains scattered, uncollected across our environment, and our towns and cities, and if there is no incentive (political, legislative or economic) to divert waste away from dumpsites and landfills into economically productive value chains.

The African Union has set an aspiration that "African cities will be recycling at least $50 \%$ of the waste they generate by 2023" $[38,39]$. The authors of the Africa Waste Management Outlook fully support the goal of the African Union and believe that even higher rates can be achieved, by developing appropriate collection systems and end-use markets for the following opportunity waste streams

i. Composting, bioenergy recovery (e.g. anaerobic digestion) or higher value product recovery (biorefinery) of organic waste

ii. Reuse and recycling of paper and packaging e.g. plastic, paper, metal, glass

iii. Refurbishment, repair, reuse, recycling of electronic waste

The Africa Waste Management Outlook has set out a vision for Africa to "Extend regular and reliable waste collection services to all, with safe disposal of residual waste to engineered landfills, while maximizing the recovery of secondary resources from these waste streams through social and technological innovations appropriate for Africa."

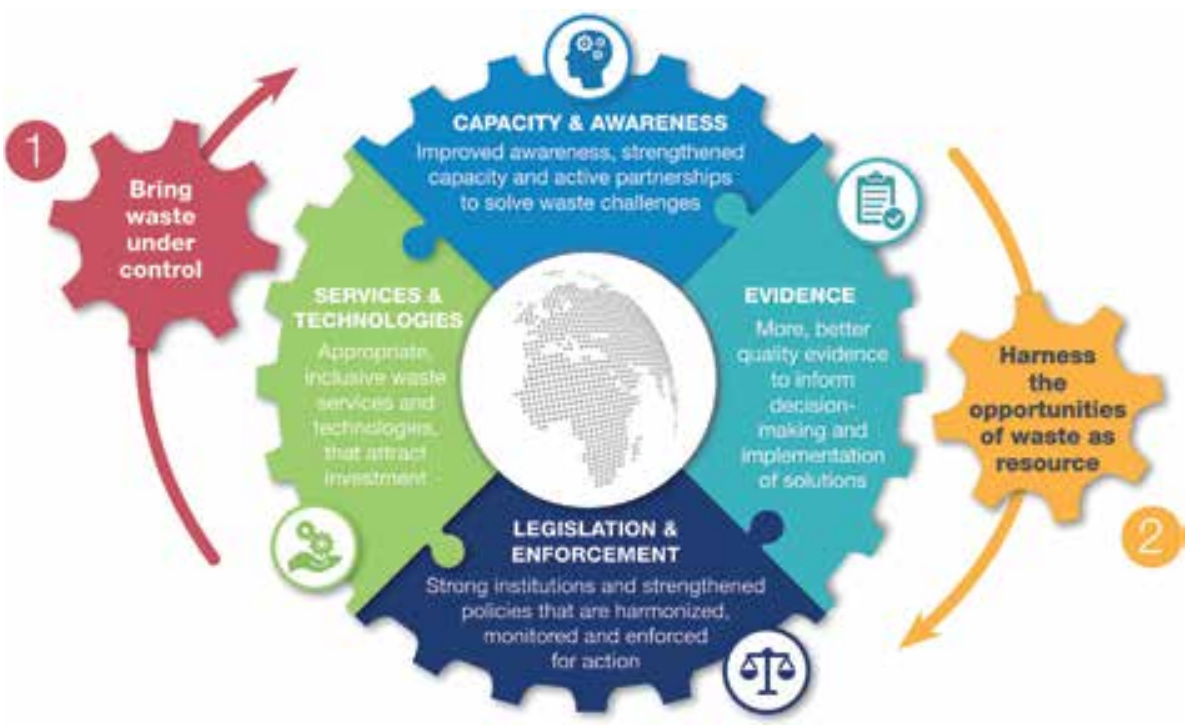

Figure 5.

Proposed approach to addressing solid waste in Africa [3]. 
This requires that government, business and civil society "bring waste under control" (i.e. collection services for all and safe disposal of waste to engineered landfills), while simultaneously "harnessing the opportunities of waste as resource" through reuse, recycling and recovery. This will require a clear strategy for (i) capacity development and awareness raising, (ii) evidence generation and use in support of decision-making and policy development, (iii) strengthening institutions, policies and enforcing legislation, and (iv) adopting appropriate, inclusive waste services and technologies (Figure 5).

Good governance is crucial for creating an enabling environment for sustainable materials management (including waste management) [40]. As such, there is a need to strengthen capacity (financial, institutional, technological and infrastructural) to drive environmentally sound waste management [41]. Since solid waste management is a sustainable development issue that cuts across socio-economic activities, it must be considered a political priority for Africa.

Finally, regional and sub-regional approaches to solving solid waste issues in Africa, with sharing of information and experiences, must be explored as capacity and resources vary greatly between countries.

\section{Acknowledgements}

The authors acknowledge the role of the UNEP (through its Africa Office and its International Environmental Technology Centre-IETC), without whose leadership, the development of the Africa Waste Management Outlook would not have been possible. The financial contribution of the Governments of Japan and South Africa in the development of the Outlook are also acknowledged. 


\section{Author details}

Linda Godfrey ${ }^{1,2 *}$, Mohamed Tawfic Ahmed ${ }^{3}$, Kidane Giday Gebremedhin ${ }^{4}$, Jamidu H.Y. Katima ${ }^{5}$, Suzan Oelofse ${ }^{1,2}$, Oladele Osibanjo ${ }^{6}$, Ulf Henning Richter ${ }^{7}$ and Arsène $\mathrm{H}$. Yonli ${ }^{8}$

1 CSIR, Pretoria, South Africa

2 North-West University, Potchefstroom, South Africa

3 Suez Canal University, Egypt

4 Mekelle University, Ethiopia

5 University of Dar es Salaam, Tanzania

6 Waste Management Society of Nigeria, Nigeria

7 Tongji University, China

8 Université Ouaga 1 Pr Joseph Ki-Zerbo, Burkina Faso

*Address all correspondence to: lgodfrey@csir.co.za

\section{IntechOpen}

(C) 2019 The Author(s). Licensee IntechOpen. This chapter is distributed under the terms of the Creative Commons Attribution License (http://creativecommons.org/licenses/ by/3.0), which permits unrestricted use, distribution, and reproduction in any medium, provided the original work is properly cited. (cc) BY 
Solid Waste Management in Africa: Governance Failure or Development Opportunity? DOI: $h$ ttp://dx.doi.org/10.5772/intechopen.86974

\section{References}

[1] Hoornweg D, Bhada-Tata P, Kennedy

C. Peak waste: When is it likely to occur? Journal of Industrial Ecology. 2015;19(1):117-128. DOI: 10.1111/ jiec.12165

[2] United Nations Environment Programme (UNEP). Global Waste Management Outlook. 2015. Available from: http://web.unep.org/ourplanet/ september-2015/unep-publications/ global-waste-management-outlook

[3] United Nations Environment Programme (UNEP). Africa Waste Management Outlook. Nairobi, Kenya: United Nations Environment Programme; 2018

[4] Scarlat N, Motola V, Dallemand JF, Monforti-Ferrario F, Mofor L. Evaluation of energy potential of municipal solid waste from African urban areas. Renewable and Sustainable Energy Reviews. 2015;50(October):1269-1286. DOI: 10.1016/j.rser.2015.05.067

[5] UN-Habitat. Solid Waste Management in the World's Cities: Water and Sanitation in the World's Cities. Malta: Gutenberg Press; 2010. Available from: https://unhabitat.org/ books/solid-wastemanagement-in-theworlds-cities-water-and-sanitationinthe-worlds-cities-2010-2/

[6] Getahun T, Mengistie E, Haddis A, Wasie F, Alemayehu E, Dadi D, et al. Municipal solid waste generation in growing urban areas in Africa: Current practices and relation to socioeconomic factors in Jimma, Ethiopia. Environmental Monitoring and Assessment. 2012;184(10):6337-6345

[7] Madinah N, Boerhannoeddin A, Rriffin RNBR. Performance assessment of public service organizations in shared solid waste services: A case for Kampala Capital City Authority in Uganda.
World Journal of Social Science. 2014;1(2):86-106. DOI: 10.5430/wjss. v1n2p86

[8] Van Wyk L. Towards distributed grids: A paradigm shift for waste infrastructure in Africa. In: Godfrey L, editor. Africa Waste Management Outlook. Nairobi, Kenya: UNEP; 2018. pp. 158-161. Available from: https://t.co/ BYjYbHpwwz

[9] Hoornweg D, Bhada-Tata P. What a Waste: A Global Review of Solid Waste Management. Urban Development Series Knowledge Papers No. 15. Washington, DC: World Bank; 2012. Available from: http://siteresources.worldbank. org/INTURBANDEVELOPMENT/ Resources/336387-1334852610766/ What_a_Waste2012_Final.pdf

[10] Baldé CP, Forti V, Gray V, Kuehr $\mathrm{R}$, Stegmann P. The Global E-Waste Monitor. Bonn/Geneva/Vienna: United Nations University (UNU), International Telecommunication Union (ITU) and International Solid Waste Association (ISWA); 2017. Available from: https://www.itu.int/en/ITU-D/ Climate-Change/Documents/GEM\%20 2017/Global-Ewaste\%20Monitor\%20 2017\%20.pdf

[11] Schluep M, Terekhova T, Manhart A, Müller E, Rochat D, Osibanjo O. Where are WEEE in Africa? In: Electronics Goes Green. Stuttgart: Fraunhofer Verlag; 2012. pp. 1-6

[12] Food \& Agriculture Organization (FAO). Global Food Losses and Food Waste-Extent, Causes and Prevention. 2011. Available from: http://www.fao. org/docrep/014/mb060e/mb060e.pdf

[13] United Nations Environment Programme (UNEP). Enforcement of Environmental Law: Good Practices from Africa, Central Asia, ASEAN 
Countries and China. 2014. Available from: http://wedocs.unep.org/ bitstream/handle/20.500.11822/9968/ enforcement-environmentallaws. pdf? sequence $=1 \&$ is Allowed $=y$

[14] Onibokun AG, Kumuyi AJ. Governance and waste management in Africa. In: Onibokun AG, editor. Managing the Monster: Urban Waste Governance in Africa. Ottawa, Canada: International Development Research Centre; 1999. ISBN 0-88936-880-5

[15] United Nations Environment Programme (UNEP). Banning SingleUse Plastics: Lessons and Experiences from Countries. 2018. Available online: https://wedocs.unep.org/ bitstream/handle/20.500.11822/25496/ singleUsePlastic_sustainability.pdf

[16] UNEP (United Nations

Environment Programme). Solid Waste Management. Vol. II: Regional Overviews and Information Sources. Osaka, Japan: UNEP International Environmental Technology Centre (IETC); 2005. Available from: http:// www.unep.or.jp/Ietc/Publications/spc/ Solid_Waste_Management/SWM_Vol-II. pdf

[17] Osibanjo O. Hazardous wastes. In: Invited Seminar Lecture Presented to the Parliamentary Committee on Environment and Poverty Alleviation, Tanzania Parliament, Dodoma, Tanzania. 2002

[18] Ahmed-Hameed A. The challenges of implementing international treaties in third world countries: The case of maritime and environmental treaties implementation in Nigeria. Journal of Law, Policy and Globalization. 2016;50:22-30. Available from: http:// www.iiste.org/Journals/index.php/ JLPG/article/viewFile/31287/32126

[19] Okot-Okumu J. Solid waste management in African Cities-East Africa. In: Rebellonm LFM, editor.
Waste Management-An Integrated Vision. Rijeka: InTech; 2012. Available from: http://cdn.intechopen.com/ pdfs/40527/InTech-Solid_waste_ management_in_african_cities_east_ africa.pdf

[20] Suleman Y, Darko ET, AgyemangDuah W. Solid waste disposal and community health implications in Ghana: Evidence from Sawaba, Asokore Mampong municipal assembly. Journal of Civil and Environmental Engineering. 2015;5-6(202):1-6. DOI: 10.4172/2165-784X.1000202

[21] Ziraba AK, Haregu TN, Mberu B. A review and framework for understanding the potential impact of poor solid waste management on health in developing countries. Archives of Public Health. 2016;74(55):1-11.

Available from: https:// archpublichealth.biomedcentral.com/ track/pdf/10.1186/s13690-016-0166-4

[22] Moss E, Eidson A, Jambeck J. Sea of Opportunity: Supply Chain Investment Opportunities to Address Marine Plastic Pollution. New York: Encourage Capital on behalf of Vulcan, Inc; 2017. Available from: http://encouragecapital. com/wp-content/uploads/2017/03/ Sea-of-Opportunity-Plastics-Reportfull-report.pdf

[23] Osibanjo O, Nnorom IC. The challenge of electronic waste (e-waste) management in developing countries. Waste Management and Research. 2007;25(6):489-501. DOI: 10.1177/0734242X07082028

[24] Osibanjo O. Draft ECOWAS E-Waste Regional Strategy. 2012. Available from: https://www.basel.org. ng/index.php/conference-abstracts/ doc_download/76-prof-osibanjo-draftecowas-e-wastestrategy

[25] Igharo GO, Anetor JI, Osibanjo OO, Osadolor HB, Dike KC. Toxic metal levels in Nigerian electronic 
waste workers indicate occupational metal toxicity associated with crude electronic waste management practices. Biokemistri. 2014;26(4):107-113

[26] Grant K, Goldizen FC, Sly PD, Brune MN, Neira M, van den Berg $\mathrm{M}$, et al. Health consequences of exposure to e-waste: A systematic review. The Lancet Global Health. 2013;1(6):e350-e361

[27] Africa Institute. Regional Policy Guidelines: Economic Instruments for the Environmentally Sound Management of Used Lead Acid Batteries. 2013

[28] Blacksmith Institute. Initiative for Responsible Battery Recycling: Ending Lead Poisoning in Thiaroye Sur Mer, Senegal. Senegal: Blacksmith Institute; 2009. Available from: http:// www.blacksmithinstitute.org/files/ FileUpload/files/PCRs/Blacksmith\%20 Institute_\%20Senegal\%20Lead\%20 Project\%20Update.pdf

[29] Jambeck J, Hardesty BD, Brooks AL, Friend T, Teleki K, Fabres J, et al. Challenges and emerging solutions to the landbased plastic waste issue in Africa. Marine Policy. October 2018;96:256-263. DOI: 10.1016/j. marpol.2017.10.041

[30] Jambeck J, Brooks AL, Wilcox C, Fabres J, Beaudoin Y, Lane W, et al. Marine litter in Africa: Identifying sources and seeking solutions. In: A Discussion Document for the African Marine Waste Conference; 9-13 July 2017. 2017

[31] Oelofse S, Nahman A, Godfrey L. Waste as a resource: Unlocking opportunities for Africa. In: Godfrey L, editor. Africa Waste Management Outlook. Nairobi, Kenya: UNEP; 2018. pp. 101-118. Available from: https://t.co/ BYjYbHpwwz

[32] Iwuoha JP. Business Ideas, Environment and Green,
Get Inspired! 2015. Available from: http://www.smallstarter. com/category/browse-ideas/ environmental-businesses/

[33] PETCO. A New Way of Thinking: Review of PETCO Activities. 2017. Available from: http://petco.co.za/ wp-content/uploads/2018/06/ PETCO-2017-Annual-Review_FINAL_ webview.pdf

[34] Coca-Cola. Coca-Cola Fast-Tracks Collection and Recycling of PET Plastic Bottles Across Africa. 2019. Available from: https://www.coca-colaafrica. com/stories/coca-cola-fast-trackscollection-and-recycling-of-pet-plasticbottles

[35] Yonli AH, Godfrey L. Appropriate solutions for Africa. In: Godfrey L, editor. Africa Waste Management Outlook. Nairobi, Kenya: UNEP; 2018. pp. 119-150. Available from: https://t.co/BYjYbHpwwz

[36] Katima JHY, Godfrey L. Waste management as a priority in Africa. In: Godfrey L, editor. Africa Waste Management Outlook. Nairobi, Kenya: UNEP; 2018. pp. 3-12. Available from: https://t.co/BYjYbHpwwz

[37] Richter UH. Financing waste management. In: Godfrey L, editor. Africa Waste Management Outlook. Nairobi, Kenya: UNEP; 2018. pp. 151174. Available from: https://t.co/ BYjYbHpwwz

[38] African Union Commission (AUC). Agenda 2063: The Africa We Want. 2015. Available from: https://au.int/ sites/default/files/pages/3657-fileagenda2063_popular_version_en.pdf

[39] African Union Commission (AUC). Agenda 2063. First Ten-Year Implementation Plan 2014-2023. 2015. Available from: http://www.un.org/ en/africa/osaa/pdf/au/agenda2063first10yearimplementation.pdf 
[40] Wingqvist ŐG, Slunge S.

Governance Bottlenecks and Policy Options for Sustainable Materials Management-A Discussion Paper. Stockholm, Sweden: United Nations Development Progamme and the Swedish Environmental Protection Agency; 2013. Available from: http:// www.naturvardsverket.se/Documents/ publikationer6400/978-91-620-

8688-6.pdf

[41] Bello IA, bin Ismail MN, Kabbashi

NA. Solid waste management in Africa:

A review. International Journal of Waste Resources. 2016;6(2):1-4. DOI: 10.4172/2252-5211.1000216 



\title{
Edited by Norbert Edomah
}

\begin{abstract}
"Regional development is a broad term but can be seen as a general effort to reduce regional disparities by supporting (employment and wealth-generating) economic activities in regions. In the past, regional development policy tended to try to achieve these objectives by means of large-scale infrastructure development and by attracting
\end{abstract} inward investment" (OECD, 2014).

A territorial and regional approach to development is crucial in addressing regional challenges, regional economic competitiveness, and reducing socio-economic discrepancies. This book provides a forum to articulate and discuss Africa's regional development issues in view of the rising opportunities within the African region.

This volume contains 14 chapters and is organized in four sections: Introduction; Industry, Trade and Investment in Africa; Agricultural Services and the Waterenergy-food Nexus in Africa; and Environmental and Cultural Dimensions to Africa's Regional Development.

Published in London, UK

\section{IntechOpen}

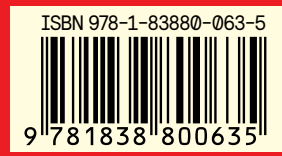

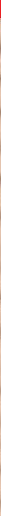

